Reverse electrodialysis (RED) is a nonpolluting, sustainable technology that converts the free energy of mixing of two solutions with different salinity directly into electrical energy. In RED, a concentrated salt solution and a less concentrated salt solution are brought into contact through an alternating series of anion exchange membranes (AEM) and cation exchange membranes (CEM). Anions migrate through the AEM towards the anode and cations move through the CEM towards the cathode. The difference in chemical potential between both solutions is the driving force for this process. The chemical potential difference generates a voltage over each membrane and the overall potential of the system is the sum of the potential differences over the all membranes. At the electrodes a redox couple is used to convert the chemical energy into electrical energy. The electrons produced migrate from the anode to the cathode through an external electrical circuit in order to maintain electro-neutrality in the cathode and anode compartment. This electron migration can be used to generate electrical power

ISBN: 978-90-365-2928-0
Mass Transport in Reverse Electrodialysis for Sustainable Energy Generation

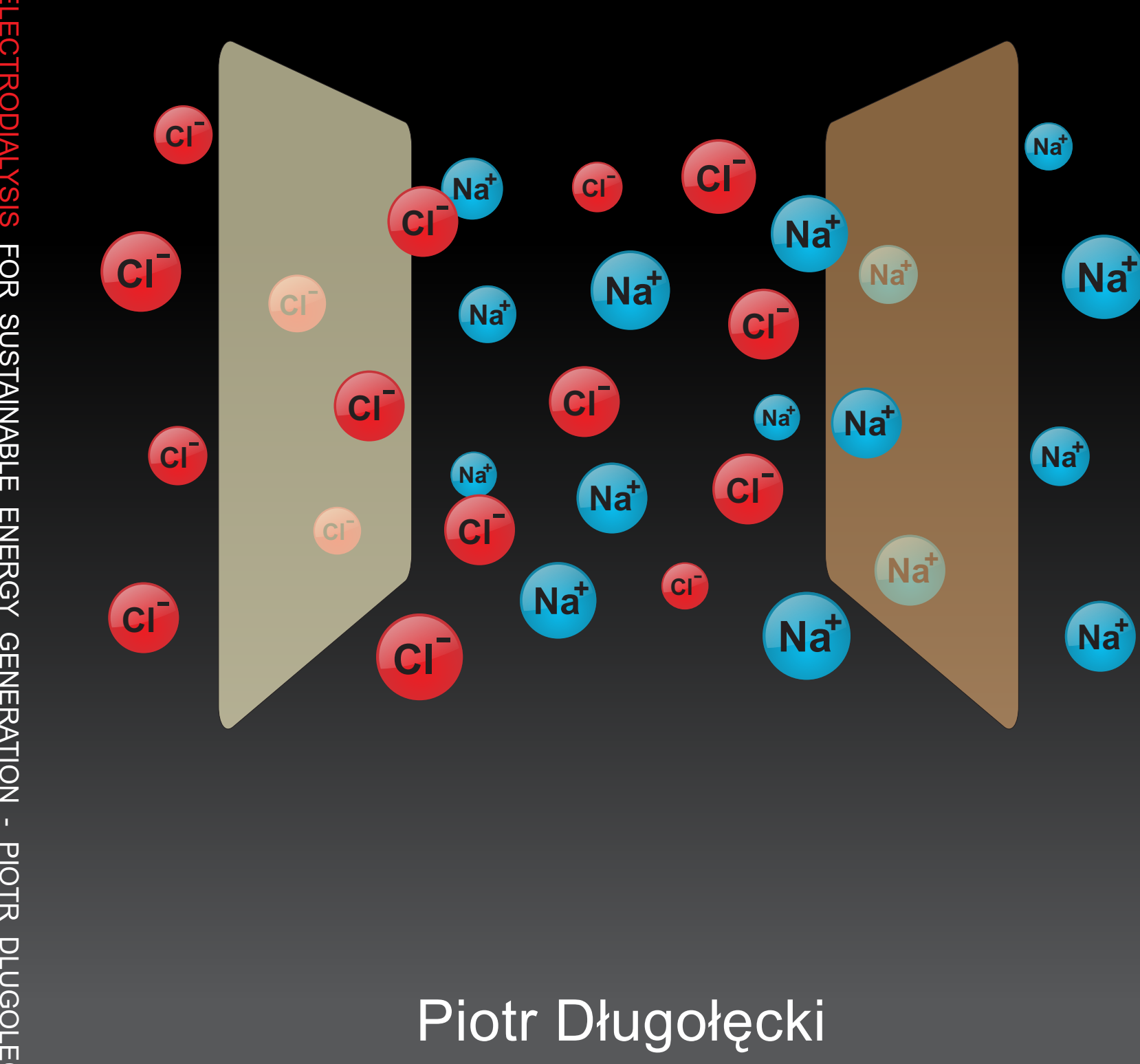

\section{INVITATION}

I am very pleased to invite you to the public defense of my dissertation on

Wednesday

$18^{\text {th }}$ of November at 14:00 hrs.

in the Fries Museum (Turfmarkt 11) in Leeuwarden

Introduction to the dissertation will start at 13:45 hrs. in the Fries Museum

You are cordially invited to the reception after the defense

Piotr Długołęcki tel. 0618571713 piotr.dlugolecki@wetsus.nl

Paranymphs

Adriaan Jeremiasse adriaan.jeremiasse@wetsus.nl

Petra Ondráčková petra.ondrackova@wetsus.nl 


\section{MASS TRANSPORT IN \\ REVERSE ELECTRODIALYSIS FOR SUSTAINABLE ENERGY GENERATION}

Piotr Edward Długołęcki 
Graduation committee

Chairman

Prof. Dr. G. van der Steenhoven University of Twente

Promotor

Prof. Dr. -Ing. M. Wessling University of Twente

Assistant promotor

Dr. Ir. D.C. Nijmeijer

University of Twente

Committee members

Prof. Dr. -Ing. H. Strathmann University of Stuttgart

Prof. Dr. -Ing. Th. Melin RWTH Aachen

Prof. Dr. Ir. C.J.N. Buisman Wageningen University

Prof. Dr. Ir. W.G.J. van der Meer University of Twente

Dr. B.A. Boukamp University of Twente

Mass transport in reverse electrodialysis for sustainable energy generation

P.E. Długołęcki, PhD Thesis, University of Twente, The Netherlands

ISBN: 978-90-365-2928-0

Cover design by P.E. Długołęcki

Copyright (O P.E. Długołęcki, Enschede, 2009

All rights reserved.

Printed by PrintPartners Ipskamp, Enschede 


\title{
MASS TRANSPORT IN \\ REVERSE ELECTRODIALYSIS FOR \\ SUSTAINABLE ENERGY GENERATION
}

\author{
DISSERTATION
}

\author{
to obtain \\ the degree of doctor at the University of Twente, \\ on the authority of the rector magnificus, \\ prof. dr. H. Brinksma, \\ on account of the decision of the graduation committee, \\ to be publicly defended \\ on Wednesday $18^{\text {th }}$ of November 2009 at 14.00
}

by

\section{Piotr Edward Długołęcki}

born on the $24^{\text {th }}$ of September 1980

in Warsaw, Poland 
This dissertation has been approved by the promotor

Prof. Dr. -Ing. M. Wessling and the assistant promotor Dr. Ir. D.C. Nijmeijer. 
"The future belongs to those who believe in the beauty of their dreams"

Eleanor Roosevelt

For my parents

Halina Długołęcka and Edward Długołęcki ${ }^{\dagger}$ (23/10/1948-19/12/2006) 



\section{Table of Contents}

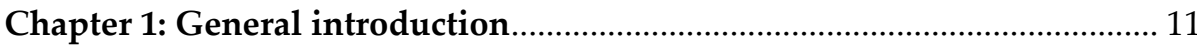

1. Energy and climate change outlook ........................................................ 12

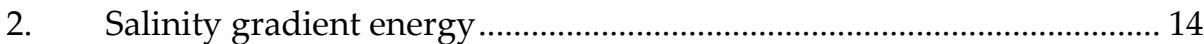

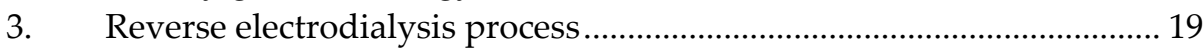

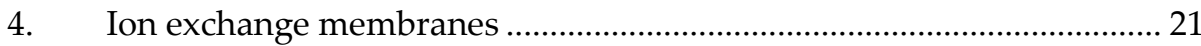

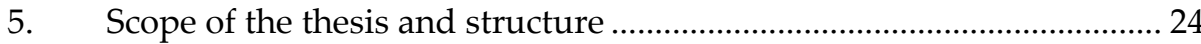

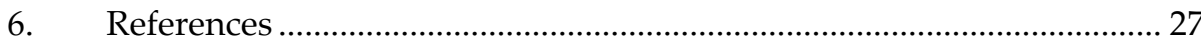

Chapter 2: Current status of ion exchange membranes for power generation from salinity gradients............................................................................ 31

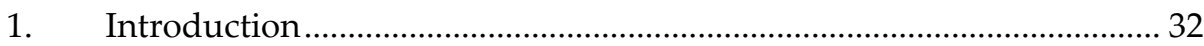

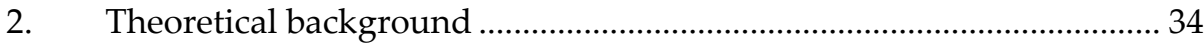

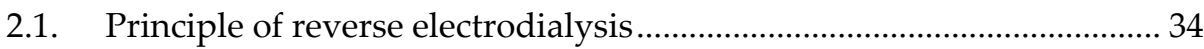

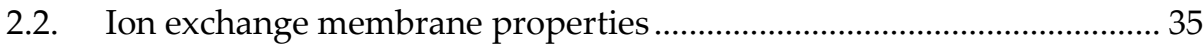

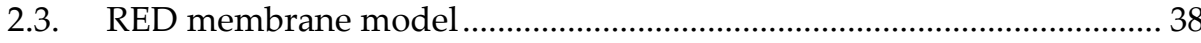

3. Experimental part ................................................................................. 41

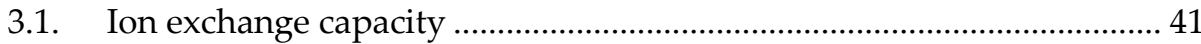

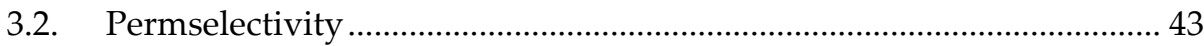

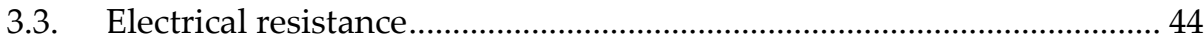

3.4. Swelling degree and membrane thickness ............................................... 46

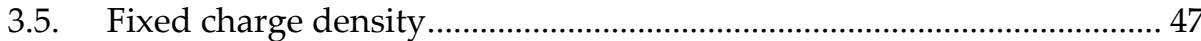

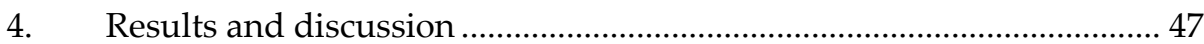

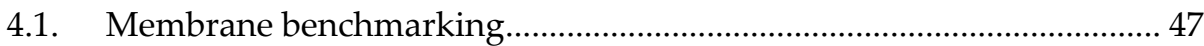

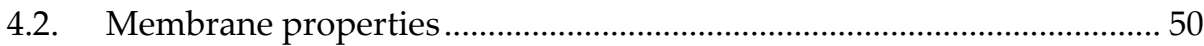

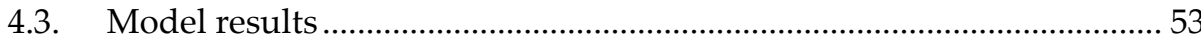

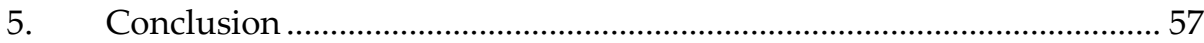

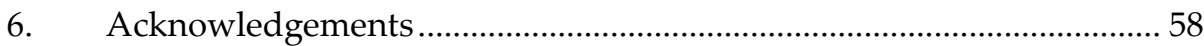

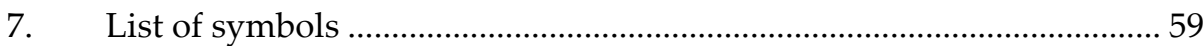

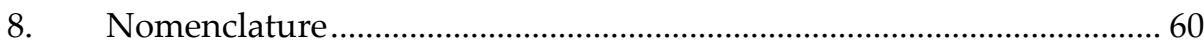

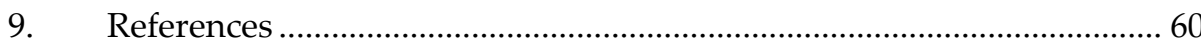

\section{Chapter 3: Transport limitations in ion exchange membranes at low}

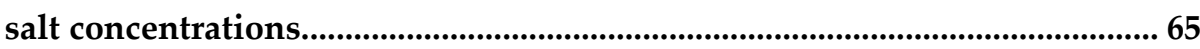

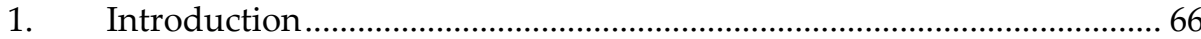

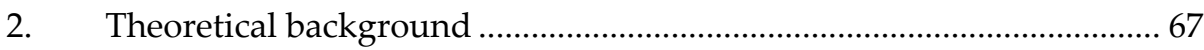


2.1. Current-voltage curves ……………………......................................67

2.2. Chronopotentiometry .....................................................................69

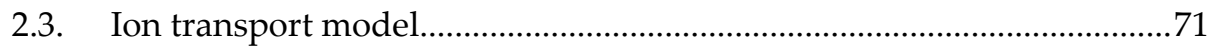

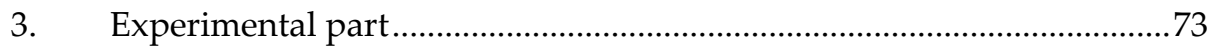

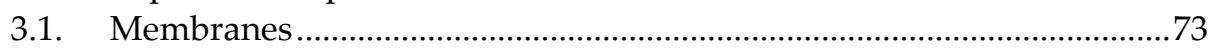

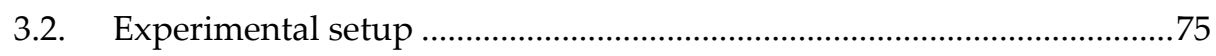

3.3. Determination of ion transport numbers …………..................................

3.4. Determination of resistance and limiting current density ….....................76

3.5. Swelling degree....................................................................................7

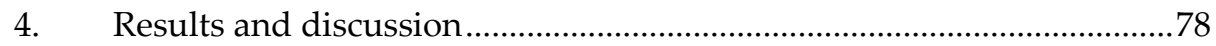

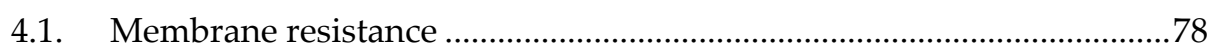

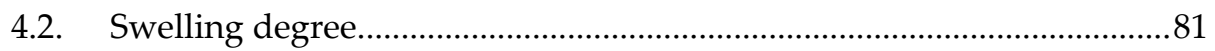

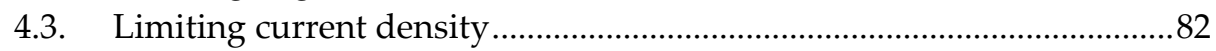

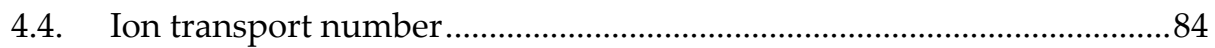

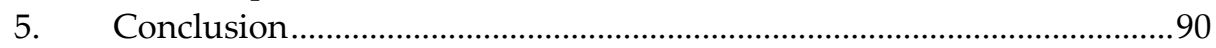

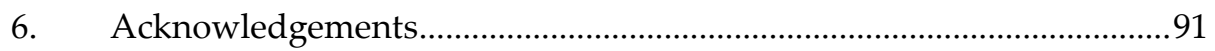

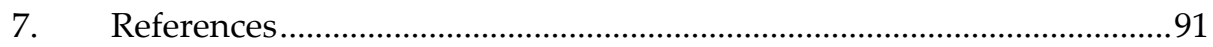

Chapter 4: On the resistances of membrane, diffusion boundary layer and double layer in ion exchange membrane transport ......................................97

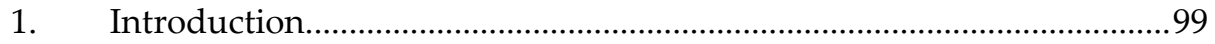

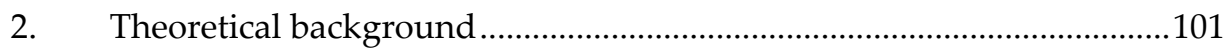

2.1. Electrochemical impedance spectroscopy ……………………................101

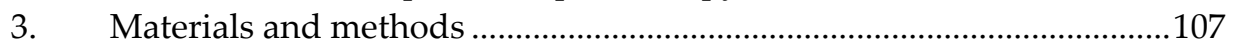

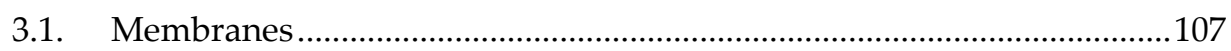

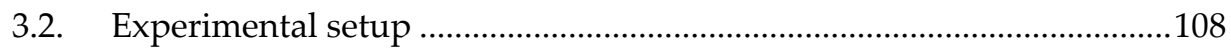

3.3. Direct current measurements................................................................110

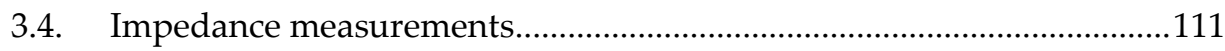

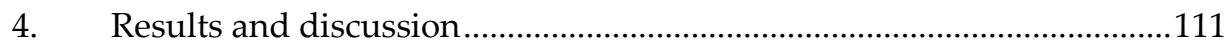

4.1. Resistance determined from direct current measurements ......................111

4.2. Electrochemical impedance spectrometry (EIS) .........................................115

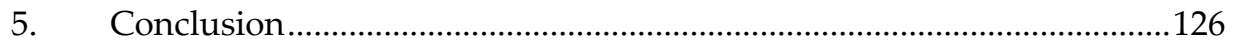

6. Acknowledgements...........................................................................127

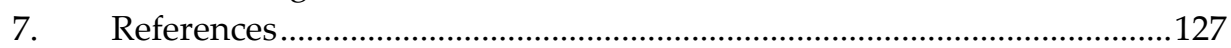

Chapter 5: The practical potential of reverse electrodialysis as process for sustainable energy generation ....................................................................133

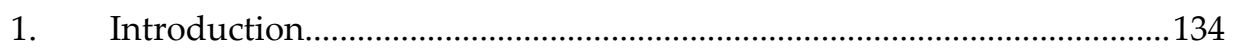

2. Experimental section ..........................................................................137 


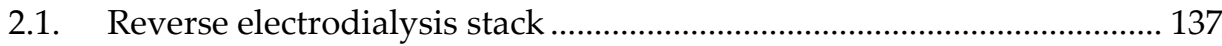

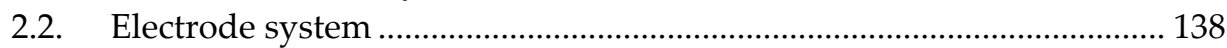

2.3. Measuring cells with Haber-Luggin capillaries....................................... 138

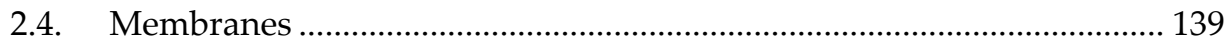

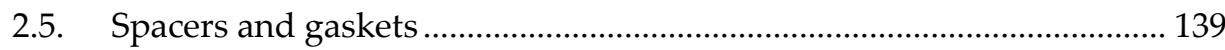

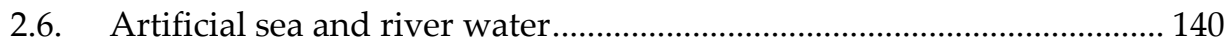

2.7. Electrochemical characterization measurements .................................... 140

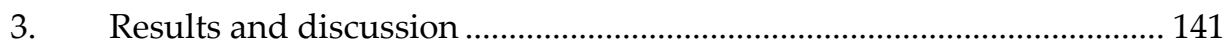

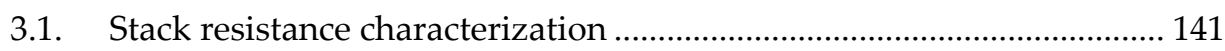

3.2. Stack open circuit voltage (OCV)............................................................ 143

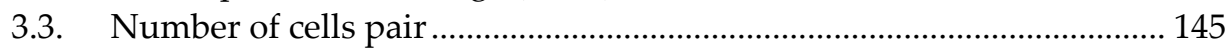

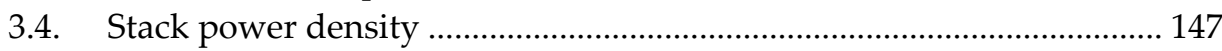

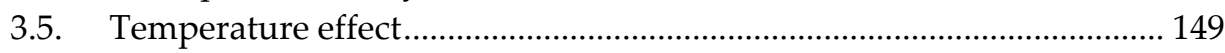

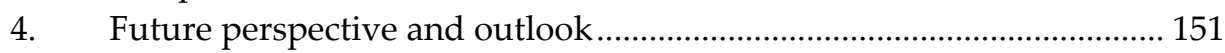

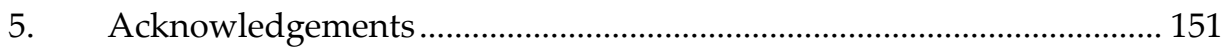

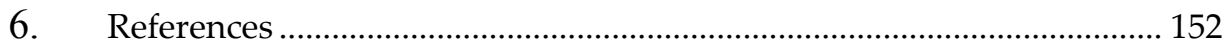

Chapter 6: Ion conductive spacers for increased power generation in reverse electrodialysis process.................................................................................... 155

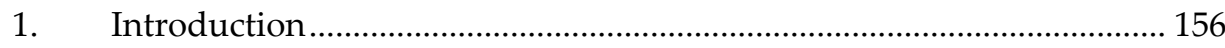

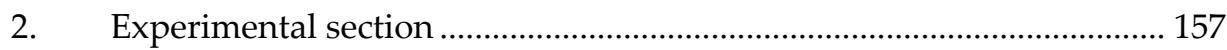

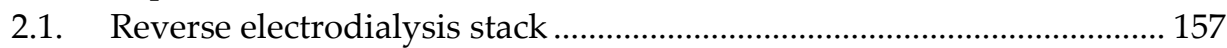

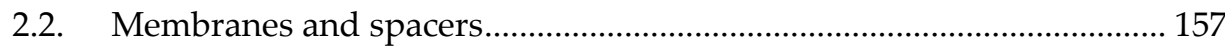

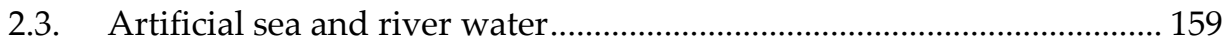

2.4. Electrochemical characterization measurements .................................... 160

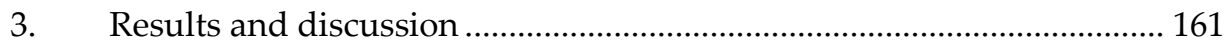

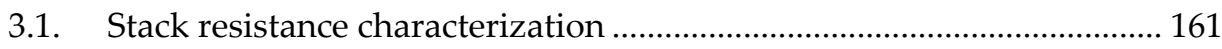

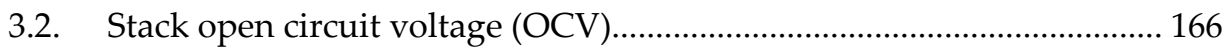

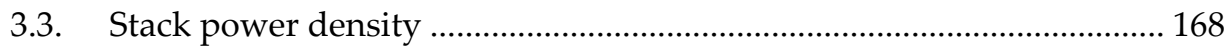

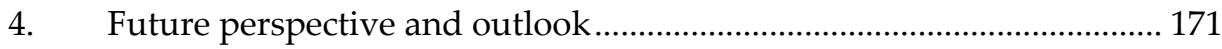

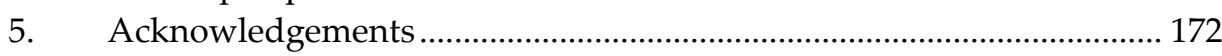

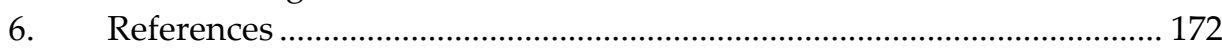

Chapter 7: General conclusions and future outlook............................................ 175

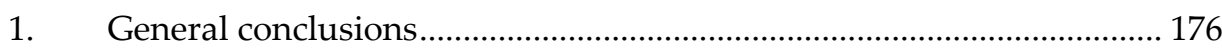

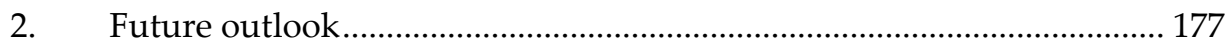

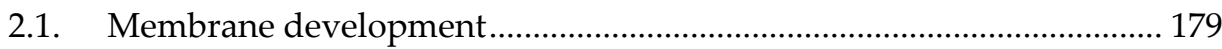

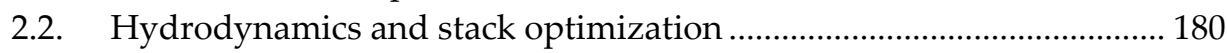

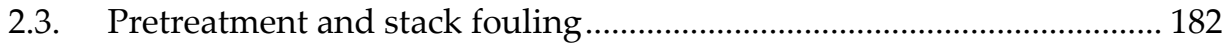

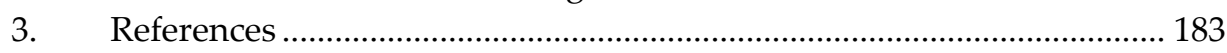




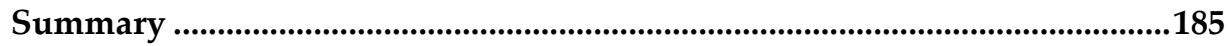

Samenvatting..........................................................................................................189

Acknowledgements ...................................................................................................195

About the author ......................................................................................................198

List of publications and patents...............................................................................199 


\title{
Chapter 1
}

\section{General introduction}

\begin{abstract}
This PhD thesis investigates the design and optimization of the reverse electrodialysis process, with a strong focus on membranes and ion transport, concentration polarization phenomena and spacer properties in relation to the RED process performance. This Chapter discusses the global need for sustainable and renewable energy sources and introduces the concept and basic principles of salinity gradient energy. It ends with a description of the scope and structure of this PhD thesis.
\end{abstract}




\section{Energy and climate change outlook}

In 2007 the United Nation's Intergovernmental Panel on Climate Change (IPCC) presented its fourth assessment report and with a confidence level of $>90 \%$ it concludes that the global warming effect is caused by human activities [1]. Human induced a tremendous increase in atmospheric concentrations of greenhouse gases, such as carbon dioxide, methane, nitrous oxide and halocarbons. Between 1970 and 2004, the largest grow in green house gas emissions came from the supply of energy (e.g. power plants), and the transport and industry sectors, while residential and commercial buildings, forestry and agriculture sectors have been growing at a lower rate [1].

Moreover, the IPCC report predicts a worldwide temperature increase at the end of $21^{\text {st }}$ century of 1.1 to $6.4{ }^{\circ} \mathrm{C}$ and sea level rises of $18-59 \mathrm{~cm}$ compared to the years 1980-1999 (specific numbers depend on the specific location). With a high confidence it can be assumed that these significant changes led and will lead to extreme weather events (e.g. floods), dramatic changes in the ecosystem, change of global agricultural patterns and a negative impact on fresh water systems [1].

To achieve stabilization and reduction of greenhouse gas concentrations in the atmosphere to a level that prevents dangerous anthropogenic interference with the climate system, the Kyoto Protocol was introduced in 1997. This protocol was signed by more than 160 countries and covered over $55 \%$ of the global greenhouse gas emissions. In the period of 2008-2012 the participating countries agreed to reduce their greenhouse gas emissions by 5\% with respect to 1990 [2]. Unfortunately, this protocol was not ratified by the world's biggest emitter of greenhouse gasses, the United States. In addition, the European Union agreed to reduce the emission of greenhouse gasses by at least $20 \%$ in 2020 compared to the 1990 levels [3].

To achieve this aim, the introduction of renewable and sustainable energy sources, new green technologies and improvement of existing 
technologies based on fossil fuels are needed. Therefore, in 2007, the European Union (EU) committed itself to a $20 \%$ share of renewable energy sources in the overall energy consumption and a 10\% share for biofuels at EU level by 2020 [3]. Until now, especially the implementation of renewable energy sources remains limited and covers only $7 \%$ of the primary energy consumption. There still exists a huge open field for sustainable power generation technologies (Figure 1) [3].

\section{EU27, GROSS INLAND CONSUM PTION \\ (ENERGY MIX in M toe, \%) (2006)}

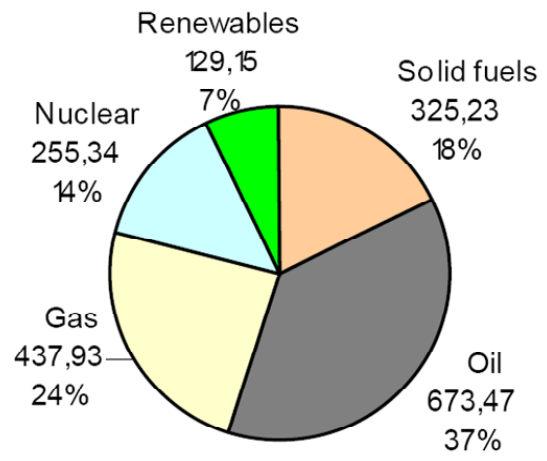

Figure 1: Energy mix and consumption in the European Union (2006) [3].

Nevertheless, in 2020 still approximately $80 \%$ of the total energy will be produced from crude oil, gas, solid fuels and nuclear energy, which will lead to growing oil scarcity and restrictions in security of supply [3]. Security of energy supply is a very important issue, especially in the European Union. Crude oil reserves are mainly located in the Middle East region and a large amount of crude oil is imported to Europe. Moreover, newly industrialized countries such as China and India rapidly increase their fossil fuel consumption and simultaneously this increased fossil fuel consumption leads to a depletion of the easily extractable oil reserves. The uneven distribution of fossil fuels and limited crude oil reserves makes the fossil fuels market unpredictable and as a 
result of that the crude oil prices in the last decade highly fluctuated [4]. Strong fluctuations and increased oil prices were especially observed after the war in Iraq, hurricane Katrina, strikes in Venezuela and global economy crises. The world economy is straightforward linked to the prices of fossil fuels. These circumstances make the European Union vulnerable to the severe and dangerous consequences of decreasing supplies and increasing fossil fuel prices. This, combined with the desire of the European Union to significantly reduce its emission of green house gasses, urges the developments in the direction of renewable and sustainable energy sources.

\section{Salinity gradient energy}

Salinity gradient energy is a sustainable energy source with a large world wide potential of $2.6 \mathrm{TW}$ and it is available where ever two solutions of different salinity mix, e.g. where river water flows into the sea [5]. Each second thousands of cubic meters of river (fresh) water freely flow into the sea or ocean and this natural river discharge can be used to generate sustainable energy (Figure 2).

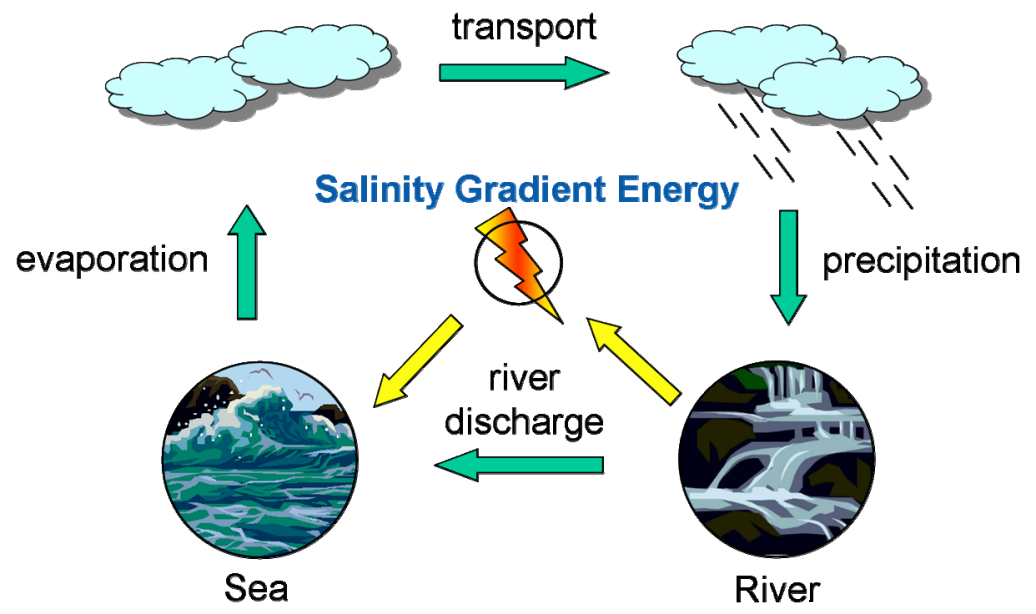

Figure 2: Schematic representation of the natural water cycle and the position of salinity gradient energy in this cycle. 
Water from the sea or ocean (concentrated salt solution) evaporates, is transported via clouds and subsequently precipitates again as fresh water. This fresh water (diluted salt solution) is transported through rivers towards the sea, oceans or lakes (high salinity lake) to close the natural cycle. Salinity gradient energy interferes with this last step in the natural cycle as it uses the discharge of river water into the sea to generate power.

Potentially interesting areas for salinity gradient power are therefore in the neighborhood of river deltas where river water flows into the sea. Moreover, also the Dead Sea and the Great Salt Lake should be taken into consideration as source for salinity gradient energy due to their high salinity. Other large sources for salinity gradient energy can be found in subterranean and industrial brines, which due to their high salinity, can be mixed not only with river (fresh) water, but also with sea water.

The theoretically available amount of energy obtainable from the controlled mixing of a relatively concentrated salt solution (e.g. sea water) and a diluted salt solution (e.g. river water) can be calculated from the Gibbs free energy, where the total amount of energy available from mixing $1 \mathrm{~m}^{3}$ of a concentrated and $1 \mathrm{~m}^{3}$ of a diluted salt solution can be determined from the Gibbs energy of the system after mixing, subtracted by the Gibbs energy before mixing (Figure 3, Equation 1) [6-8].

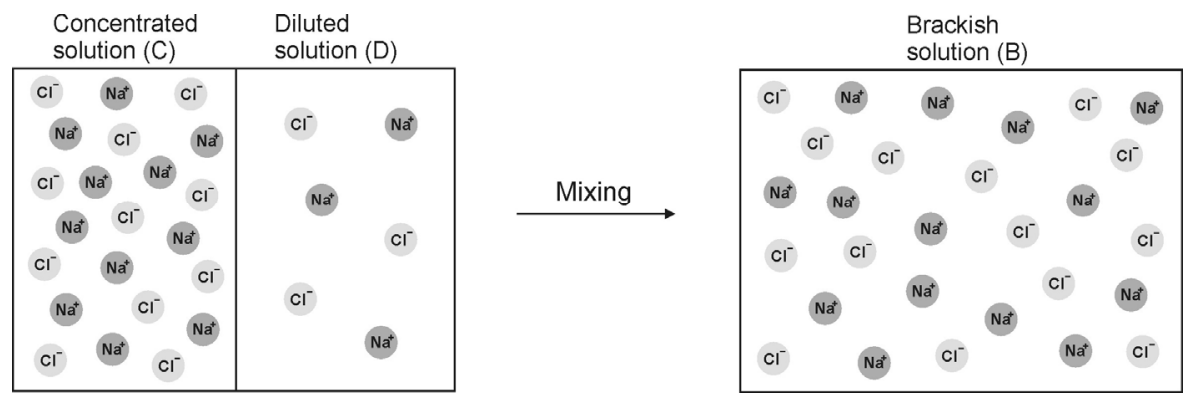

Figure 3: The mixing of a concentrated and a diluted solution to a brackish solution. 


$$
\Delta G_{m i x} \equiv G_{b}-\left(G_{c}-G_{d}\right)
$$

Where $\Delta \mathrm{G}_{\text {mix }}$ is the free energy of mixing $(\mathrm{J} / \mathrm{mol}), \mathrm{Gb}$ is the Gibbs energy of the mixture, the brackish water $(\mathrm{J} / \mathrm{mol}), \mathrm{Gc}_{\mathrm{c}}$ is the Gibbs energy of the concentrated salt solution (e.g. sea water) $(\mathrm{J} / \mathrm{mol})$ and $\mathrm{G}_{\mathrm{d}}$ is the Gibbs energy of the diluted salt solution (e.g. fresh water) $(\mathrm{J} / \mathrm{mol})$.

The Gibbs energy of an ideal solution is equal to:

$$
G=\sum \mu_{i} \cdot n_{i}
$$

Where $\mathrm{G}$ is the Gibbs energy of the system $(\mathrm{J} / \mathrm{mol}), \mu_{\mathrm{i}}$ is the chemical potential of component $i$ in the solution $(\mathrm{J} / \mathrm{mol})$ and $n_{i}$ is the number of moles of component $\mathrm{i}$ in the solution.

The chemical potential of a component $\mathrm{i}\left(\mu_{\mathrm{i}}\right)$ in an ideal solution can be written as (e.g. [9]):

$$
\mu_{i}=\mu_{i}^{0}+\bar{V}_{i} \Delta p+R T \ln x_{i}+\left|z_{i}\right| F \Delta \varphi
$$

where $\mu_{\mathrm{i}}{ }^{0}$ is the chemical potential of component $\mathrm{i}$ under standard conditions $(\mathrm{J} / \mathrm{mol}), \Delta \mathrm{p}$ is the pressure change compared to atmospheric conditions (Pa), $\bar{V}$ is the molar or specific volume of component $\mathrm{i}\left(\mathrm{m}^{3} / \mathrm{mol}\right), \mathrm{R}$ is the universal gas constant $(8.314 \mathrm{~J} /(\mathrm{mol} \cdot \mathrm{K})), \mathrm{T}$ is the absolute temperature $(\mathrm{K})$, $\mathrm{x}_{\mathrm{i}}$ is the mol fraction of component $\mathrm{i}, \mathrm{z}$ is the valence of an ion (-), F is the Faraday constant (96485 C/mol), and $\Delta \varphi$ is the electrical potential difference $(\mathrm{V})$. Since there is no pressure change or charge transport when the concentrated and the diluted solution are mixed, Equation 3 reduces to:

$\mu_{i}=\mu_{i}^{0}+R T \ln x_{i}$

When Equation 4 is substituted in Equation 2 and 1, the standard chemical potential $\left(\mu_{i}{ }^{0}\right)$ is eliminated and the final Equation describes the Gibbs energy of mixing of a concentrated and a diluted salt solution: 


$$
\begin{aligned}
& \Delta G_{m i x}=\sum_{i}\left(G_{i, B}-\left(G_{i, C}+G_{i, D}\right)\right) \\
& \left.=\sum_{i}\left(\left(n_{i, C}+n_{i, D}\right) R T \ln x_{i, B}\right)-\left(n_{i, C} R T \ln x_{i, C}+n_{i, D} R T \ln x_{i, D}\right)\right)
\end{aligned}
$$

And when $\mathrm{n}$ is replaced by $\mathrm{c} \cdot \mathrm{V}$, this changes into:

$$
\Delta G_{m i x}=\sum_{i}\left(c_{i, C} V_{C} R T \ln \left(x_{i, C}\right)+c_{i, D} V_{D} R T \ln \left(x_{i, D}\right)-c_{i, B} V_{B} R T \ln \left(x_{i, B}\right)\right)
$$

Because the mixing of two solutions is a spontaneous process, the Gibbs energy of mixing is negative: energy is released when two solutions are mixed. With Equation 6, the theoretical available amount of energy available from the mixing of two salt solutions can be calculated and thus the theoretical potential of salinity gradient energy can be evaluated. The work or energy theoretically obtainable from the mixing of $1 \mathrm{~m}^{3}$ of sea water with $1 \mathrm{~m}^{3}$ of river water as calculated from Equation 6 equals 1.4 MJ, but if we assume that this cubic meter of river water is mixed with an "infinite" amount of cubic meters of sea water, 2.3 MJ can be extracted [6, 8, 10,11]. Table 1 shows the theoretical potential of salinity gradient energy at several locations worldwide [5-8, 10-14]. 
Table 1: Possible sources and theoretical potential of salinity gradient energy [5].

\begin{tabular}{lcc}
\hline Source & Flow rate $\left(\mathrm{m}^{3} / \mathbf{s}\right)$ & Power (Watts) \\
\hline Amazon River (Brazil) & $2 \cdot 10^{5}$ & $4.7 \cdot 10^{11}$ \\
\hline La Plata-Parana River (Argentina) & $8 \cdot 10^{4}$ & $1.9 \cdot 10^{11}$ \\
\hline Congo River (Congo, Angola) & $5.7 \cdot 10^{4}$ & $1.3 \cdot 10^{11}$ \\
\hline Yangtze (China) & $2.2 \cdot 10^{4}$ & $5.2 \cdot 10^{10}$ \\
\hline Ganges River (Bangladesh) & $2 \cdot 10^{4}$ & $4.7 \cdot 10^{10}$ \\
\hline Mississippi River (USA) & $1.8 \cdot 10^{4}$ & $4.2 \cdot 10^{10}$ \\
\hline Rhine (The Netherlands) & $2.2 \cdot 10^{3}$ & $5.2 \cdot 10^{9}$ \\
\hline Great Salt Lake (USA) & 125 & $4.2 \cdot 10^{9}$ \\
\hline Dead Sea (Jordan, Israel) & 38 & $1.8 \cdot 10^{9}$ \\
\hline
\end{tabular}

In general, two major technologies exist that are able to convert salinity gradient energy into electrical power: pressure-retarded osmosis (PRO) and reverse electrodialysis (RED) $[12,15,16]$. PRO and RED are the most frequently studied processes to extract the potential energy available from the mixing of fresh and salt water, although some other membrane-based processes are proposed as well. Both technologies make use of membrane technology, are sustainable and pollution free (no emission of e.g. $\mathrm{CO}_{2}$ and $\mathrm{NO}_{x}$ ). In PRO, two solutions of different salinity are brought into contact by a semi-permeable membrane that only allows the transport of the solvent (water) and retains the solute (dissolved salts). In PRO an external turbine is used to generate the energy $[17,18]$. In RED, a number of anion and cation exchange membranes are stacked together in an alternating pattern between an anode and a cathode and allow the selective transport of salt ions only. The charge transport through the membranes is directly converted into electrical energy. 
Each technology has its own field of application: Pressure retarded osmosis seems to be more attractive for power generation using concentrated saline brines, whereas reverse electrodialysis is assumed to be more beneficial for power generation using seawater and river water [15]. Although both are still in a stage of development, RED has a few advantages over PRO. PRO requires high pressure equipment and an external turbine that converts the osmotic pressure difference between the two solutions into electricity. In addition, in PRO large amounts of water are transported through the membrane, thus making the process more sensitive towards fouling.

\section{Reverse electrodialysis process}

Reverse electrodialysis (RED) is a non-polluting, sustainable technology to generate power from the mixing of solutions with different salinity $[6-8,10$, 12-15, 19]. In RED a concentrated salt solution (e.g. sea water) and a diluted salt solution (e.g. fresh water) are brought into contact through an alternating series of anion exchange membranes (AEM) and cation exchange membranes (CEM) (Figure 4) [6-8, 10, 12-15, 19].

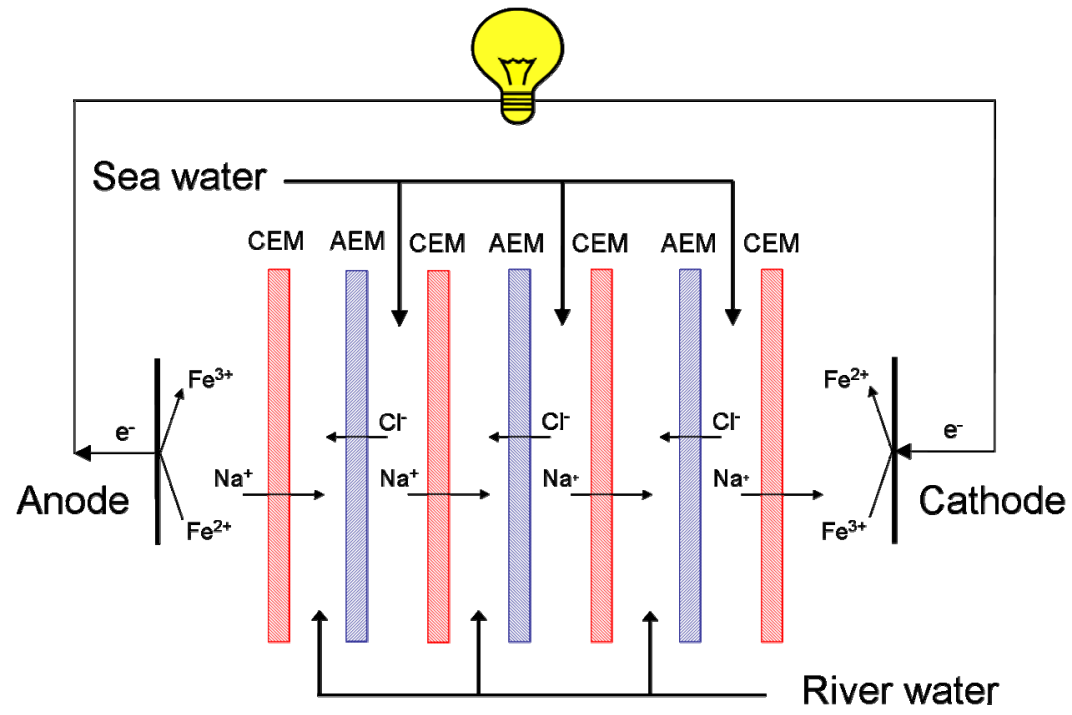

Figure 4: Schematic representation of the principle of reverse electrodialysis. AEM is an anion exchange membrane, CEM a cation exchange membrane. 
In RED, anions migrate through the AEM towards the anode and cations move through the CEM towards the cathode. The difference in chemical potential between both solutions is the driving force for this process. The theoretical value of the potential over an ion exchange membrane for an aqueous monovalent electrolyte (e.g. $\mathrm{NaCl}$ ) can be calculated using the Nerst equation (Equation 7) [10, 14]:

$$
\Delta \mathrm{V}^{\circ}=\mathrm{N} \frac{\alpha \mathrm{RT}}{\mathrm{zF}} \ln \left(\frac{\mathrm{a}_{\mathrm{c}}}{\mathrm{a}_{\mathrm{d}}}\right)
$$

Where $\Delta \mathrm{V}^{\circ}$ is the theoretical stack potential $(\mathrm{V}), \mathrm{N}$ is the number of membranes $(-), \alpha$ is the membrane selectivity $(-), \mathrm{R}$ is the universal gas constant (8.314 $\mathrm{J} /(\mathrm{mol} \cdot \mathrm{K})), \mathrm{T}$ is the absolute temperature $(\mathrm{K}), \mathrm{z}$ is the electrochemical valence (-), $\mathrm{F}$ is the Faraday constant $(96485 \mathrm{C} / \mathrm{mol})$, ac is the activity of the concentrated solution (mol/l) and ad is the activity of the diluted solution (mol/l).

For fresh water $\left(0.017 \mathrm{M} \mathrm{NaCl}, \gamma_{ \pm}=0.878\right)$ and sea water $\left(0.5 \mathrm{M} \mathrm{NaCl}, \gamma_{ \pm}=0.686\right)$ the theoretical voltage difference over each membrane is $80.3 \mathrm{mV}$. The overall potential of the system is the sum of the potential differences over each membrane. At the electrodes red-ox reactions occur to convert this electrochemical potential directly into electricity. To maintain electroneutrality, electrons migrate from the anode to the cathode through an external electrical circuit and power an external load.

The stack power output can be calculated using Kirchhoff's law, which is defined as [11, 19]:

$$
\mathrm{W}=\mathrm{I}^{2} \mathrm{R}_{\text {load }}=\frac{\left(\mathrm{V}^{\mathrm{o}}\right)^{2} \mathrm{R}_{\text {load }}}{\left(\mathrm{R}_{\text {stack }}+\mathrm{R}_{\text {load }}\right)^{2}}
$$

Here I is the current (A), Rload is the resistance of the load $(\Omega)$, Rstack is the stack resistance $(\Omega)$ and $\mathrm{V}^{0}$ is the stack open circuit potential $(\mathrm{V})$.

The overall stack resistance is the sum of the individual resistances in the stack: the resistance of the concentrated salt solution (sea water), the resistance of the diluted salt solution (fresh water), the resistance of the cation and anion 
exchange membranes, the resistance of the electrodes and the resistance of the electrolyte. The maximum power output of the system $\left(\mathrm{W}_{\max }\right)$ is obtained when the resistance of the external load (Rload) equals the resistance of the stack ( $R_{\text {stack }}$ ) $[11,20,21]$. In that case, Equation 8 changes into Equation 9, which shows the relationship between the open circuit potential $\left(\mathrm{V}^{0}\right)$, the maximum power output and the stack resistance $[7,19]$.

$$
\mathrm{W}_{\text {max }}=\frac{\left(\mathrm{V}^{0}\right)^{2}}{4 \mathrm{R}_{\text {stack }}}
$$

The open circuit voltage depends on the membrane selectivity and the concentration difference between the two salt solutions, while the stack resistance is mainly determined by the resistance of the fresh water solution and the membrane resistance $[10,11,19]$.

\section{Ion exchange membranes}

In general, a membrane is defined as a permselective barrier between two phases. Under the influence of a driving force, some components of a feed mixture can permeate through the membrane while others are retained. Membranes thus allow the selective transport of certain species from a feed mixture, while others are rejected.

The membranes are one of the key elements in RED and the membranes used in this process are ion exchange membranes that carry negative or positive charged groups fixed to the polymer matrix of the membrane. Ion exchange membranes are widely used in many processes such as electrodialysis, diffusion dialysis, membrane capacitive deionization and Donnan dialysis. Recently, also the application of ion exchange membranes for energy generation from e.g. the mixing of fresh and salt water, from wastewater in microbial fuel cells or in other types of fuel cells such as PEM fuel cells or direct methanol fuel cells gained more attention [15, 20-32]. 
Ion exchange membranes used in RED can be divided into two types: cation exchange membranes (CEM) and anion exchange membranes (AEM). Cation exchange membranes have negatively charged groups attached to their polymer matrix while anion exchange membranes contain positively charged groups attached to their polymer matrix (Figure 5).

a) Anion exchange membrane

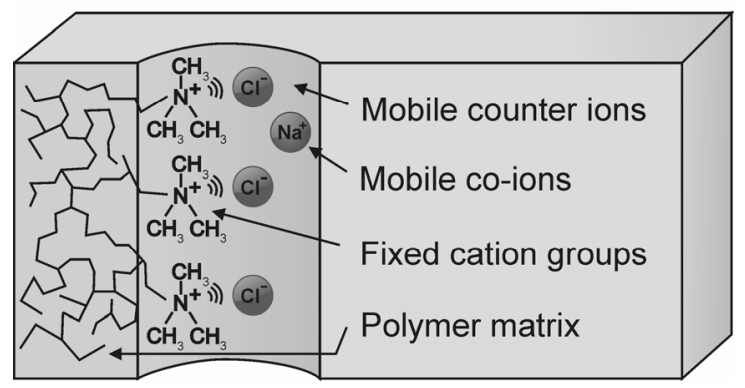

b) Cation exchange membrane

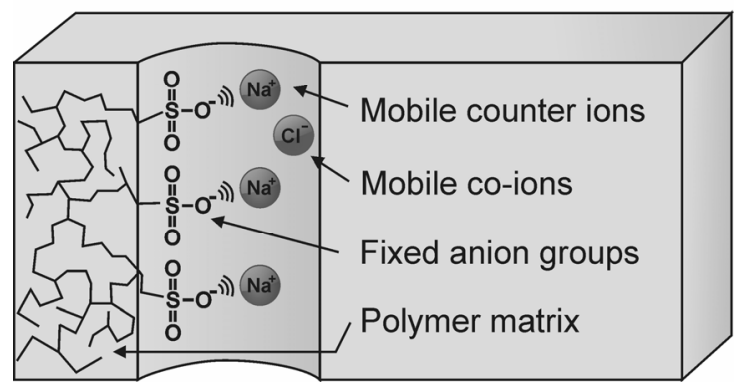

Figure 5: Schematic representation of a) an anion exchange membrane and b) a cation exchange membrane.

Ions with the same charge as the charged fixed groups in the membrane are called co-ions, while ions with a charge opposite to the fixed charges of the membrane are denoted as counter ions. In principle, only counter ions are able to permeate through the membrane, while co-ions are excluded by the membrane due to Donnan exclusion [33]. A permselectivity value of a membrane of $100 \%$ in this respect means that all co-ions are rejected, while 
lower values indicate that part of the charge is carried by the counter ions, but also the transport of co-ions contributes to the charge transport. As the membranes are one of the key elements in the RED process, the performance of the membranes has a large effect on the overall performance of the RED stack as well [19]. Especially, the permselectivity and the membrane resistance are important characteristics of the membrane.

When a cation exchange membrane is in contact with a diluted electrolyte solution, the cation (counter ion) concentration in the membrane will be much higher than the cation concentration in the solution due to the presence of the fixed charges in the cation exchange membrane. The concentration of anions (co-ions) in the membrane on the other hand, will be much lower than in the solution. Due to these concentration differences ions start to migrate from one side to another to maintain electro neutrality in the membrane and the bulk solution. This thus creates an electric field in the direction opposite to the direction of the diffusional flow. The Donnan equilibrium (an electrochemical equilibrium) and steady state will be reached when the electric field balances the diffusional driving force of all ionic species.

Due to the fixed charges in the membrane and the ionic transport through the membrane, an electrical double layer and a diffusion boundary layer will be formed at the membrane-solution interface [33]. The electrical double layer stems from the fact that the fixed ionic charges attached to polymer matrix attract oppositely charged ions from the solution [33, 34]. The electrical double layer is very thin; the thickness is typically in the order of nanometers (Debye length) $[33,35,36]$. When a current passes through an ion exchange membrane, the majority of the charge through the membrane is transported by counter ions, as a result of the Donnan exclusion. In the bulk solution, current (or charge) is carried by both positive and negative ions. The difference in ion transport number between the bulk solution and the membrane results in the building up of diffusion boundary layers at the membrane surface [37-41]. As a consequence, the concentration decreases at one 
side of the membrane and increases at the other side of the membrane and this phenomenon is called concentration polarization [37]. These diffusion boundary layers typically have thicknesses in the micrometer range [37-41]. Figure 6 shows schematically the different layers existing at the membranesolution interface of an ion exchange membrane due to the transport of charge.

a)

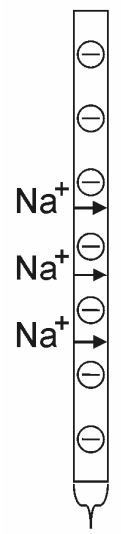

Cation exchange membrane b)

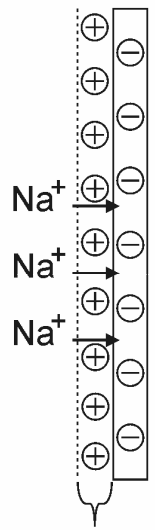

$\mathrm{nm}$ scale double layer c)

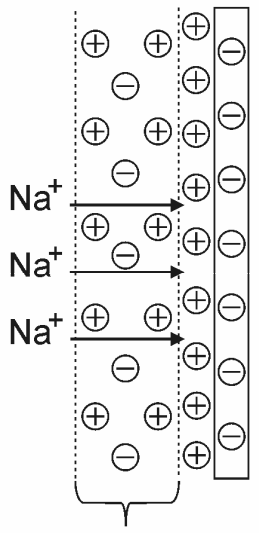

$\mu \mathrm{m}$ scale diffusion boundary layer

Figure 6: Representation of the electrochemical layers existing at the ion exchange membrane surface; a) ion exchange membrane, b) electrochemical double layer and c) diffusion boundary layer.

The presence of these layers in ion exchange membrane processes such as RED affects the performance of ion exchange membranes, and as a consequence it also influences the overall RED process power output, making it an important issue to address.

\section{Scope of the thesis and structure}

The scope of this $\mathrm{PhD}$ thesis is the design and optimization of the reverse electrodialysis process, with a strong focus on membranes and ion transport, concentration polarization phenomena and spacer properties in relation to the process performance. 
This thesis can be divided into two major parts. The first part (Chapter 2 to 4 ) focuses on membranes for RED, membrane properties and membrane characterization methods. The second part (Chapter 4-6) deals with one of the biggest problems in membranes processes and in reverse electrodialysis in particular: concentration polarization phenomena and the influence and design of spacers as a tool for RED process optimization.

Chapter 2 describes the current status of commercially available ion exchange membranes and investigates their properties. It discusses the RED process, the characterization of ion exchange membranes for RED, and the desired membrane properties and bottlenecks of currently existing membranes for power generation in RED.

Usually, characteristics of ion exchange membranes are determined at standard conditions i.e. in $0.5 \mathrm{M} \mathrm{NaCl}$ solution. For many applications this is sufficient, but for reverse electrodialysis, which typically operates in the low concentration range $(<0.5 \mathrm{M})$, this does not represent the practical situation [19]. Therefore, Chapter 3 discusses the influence of the solution concentration on ion transport phenomena in ion exchange membranes. In this Chapter the relationship between the membrane resistance, the limiting current density and the counter ion transport number of commercially available membranes in the concentration range of $0.017 \mathrm{M}-0.5 \mathrm{M} \mathrm{NaCl}$ and at various hydrodynamic conditions is investigated. It shows the strong need for a more detailed characterization technique to investigate and to be able to discriminate between the membrane resistance and the different phenomena occurring at the membrane-solution interface, which are typically associated with ion exchange membrane processes.

Chapter 4 shows the application of Electrochemical Impedance Spectroscopy (EIS) as a strong method to characterize ion exchange membrane resistances at various electrolyte concentrations. EIS is able to distinguish between the pure membrane resistance and the resistances to ionic charge transport of the layers adjacent to the membrane surface. The importance of 
these layers with respect to increasing overall resistance in the ion exchange membrane system is discussed and the results of EIS measurements are compared with the standard characterization technique (direct current method). In addition, this Chapter shows the importance of liquid flow rate and temperature on the different resistances.

Chapter 5 deals with the characterization of the full RED stack and the practical potential of reverse electrodialysis as sustainable energy source is discussed. Moreover, this Chapter quantifies the individual contributions of concentration polarization phenomena, spacer shadow effects and single stack resistance in RED under different hydrodynamic conditions in a certain temperature range. It provides valuable knowledge for optimal reverse electrodialysis process design, optimization and performance increase and allows us to reflect on the potential and operating window of RED.

Chapter 6 is dedicated to concentration polarization phenomena and spacer performance and design. It explores the potential of ion conductive spacers in RED as a tool to eliminate the so-called spacer shadow effect, which is observed when non-conductive spacer materials are applied. This effect significantly reduces the power output in RED. Theoretical calculations are combined with direct current and alternating current experimental stack characterization methods and the results clearly show the strong beneficial effect of the use of ion-conductive spacers as an instrument to increase the power output in RED.

Chapter 7 discusses the current status and the future potential of reverse electrodialysis as a sustainable energy source. It summarizes the main insights that were gained in this PhD thesis, evaluates the practical potential of this technology and assesses important research directions for further development and scale-up of the RED process that need to be addressed before reverse electrodialysis can be referred to as a full scale and mature technology for sustainable energy generation from salinity gradients. 


\section{References}

1. IPCC, Climate Change 2007: The Physical Science Basis, Summary for Policymakers. In 2007.

2. United Nations Framework Convention on Climate Change, Kyoto Protocol (1998).

3. European Commission's Second Strategic Energy Review. In 2008.

4. http://www.bloomberg.com/energy/.

5. G. L. Wick, Power from salinity gradients, Energy 3 (1978) 95-100.

6. J. W. Post, H. V. M. Hamelers, C. J. N. Buisman, Energy recovery from controlled mixing salt and fresh water with a reverse electrodialysis system, Environmental Science and Technology 42 (2008) 5785-5790.

7. J. Veerman, J. W. Post, M. Saakes, S. J. Metz, G. J. Harmsen, Reducing power losses caused by ionic shortcut currents in reverse electrodialysis stacks by a validated model, Journal of Membrane Science 310 (2008) 418-430.

8. J. Veerman, M. Saakes, S. J. Metz, G. J. Harmsen, Reverse electrodialysis: Performance of a stack with 50 cells on the mixing of sea and river water, Journal of Membrane Science 327 (2009) 136-144.

9. H. Strathmann, Ion-Exchange Membrane Separation Processes, 1st Edition, Elsevier, 2004.

10. R. E. Lacey, Energy by reverse electrodialysis, Ocean Engineering 7 (1980) 1-47.

11. J. N. Weinstein, F. B. J. W. Leitz, Electric power from differences in salinity: the dialytic battery, Science 191 (1976) 557-559.

12. E. Brauns, Towards a worldwide sustainable and simultaneous largescale production of renewable energy and potable water through salinity gradient power by combining reversed electrodialysis and solar power?, Desalination 219 (2008) 312-323.

13. E. Brauns, Salinity gradient power by reverse electrodialysis: effect of model parameters on electrical power output, Desalination 237 (2009) 378-391.

14. J. Jagur-Grodzinski, R. Kramer, Novel process for direct conversion of free energy of mixing into electric power, Industrial \& Engineering Chemistry Process Design and Development 25 (1986) 443-449. 
15. J. W. Post, J. Veerman, H. V. M. Hamelers, G. J. W. Euverink, S. J. Metz, K. Nymeijer, C. J. N. Buisman, Salinity-gradient power: Evaluation of pressure-retarded osmosis and reverse electrodialysis, Journal of Membrane Science 288 (2007) 218-230.

16. K. L. Lee, R. W. Baker, H. K. Lonsdale, Membranes for power generation by pressure-retarded osmosis, Journal of Membrane Science 8 (1981) 141-171.

17. S. Loeb, Production of energy from concentrated brines by pressure retarded osmosis. I. Preliminary technical and economic correlations, Journal of Membrane Science 1 (1976) 49-63.

18. K. Gerstandt, K. V. Peinemann, S. E. Skilhagen, T. Thorsen, T. Holt, Membrane processes in energy supply for an osmotic power plant, Desalination 224 (2008) 64-70.

19. P. Dlugolecki, K. Nymeijer, S. Metz, M. Wessling, Current status of ion exchange membranes for power generation from salinity gradients, Journal of Membrane Science 319 (2008) 214-222.

20. R.E. Lacey, Energy by Reverse Electrodialysis, Ocean Engng. 7 (1980) 147.

21. F. Suda, T. Matsuo, D. Ushioda, Transient changes in the power output from the concentration difference cell (dialytic battery) between seawater and river water, Energy 32 (2007) 165-173.

22. R. K. J. Jagur-Grodzinski, Novel Process for Direct Conversion of Free Energy of Mixing into Electric Power Ind. Eng. Chem. Process Des. Dev. (1986) 443-449.

23. R. Audinos, Electric power produced from two solutions of unequal salinity by reverse electrodialysis, Indian Journal of Chemistry 31A (1992) 348-354.

24. R. E. Pattle, Production of Electric Power by mixing Fresh and Salt Water in the Hydroelectric Pile, Nature 174 (1954) 660.

25. R. A. Rozendal, H. V. M. Hamelers, C. J. N. Buisman, Effects of Membrane Cation Transport on $\mathrm{pH}$ and Microbial Fuel Cell Performance, Environmental Science and Technology 40 (2006) 52065211. 
26. B. E. Logan, B. Hamelers, R. Rozendal, U. Schroder, J. Keller, S. Freguia, P. Aelterman, W. Verstraete, K. Rabaey, Microbial Fuel Cells: Methodology and Technology, Environmental Science and Technology 40 (2006) 5181-5192.

27. M. H. Yildirim, A. Schwarz, D. F. Stamatialis, M. Wessling, Impregnated membranes for direct methanol fuel cells at high methanol concentrations, Journal of Membrane Science 328 (2009) 127133.

28. M. H. Yildirim, D. Stamatialis, M. Wessling, Dimensionally stable Nafion-polyethylene composite membranes for direct methanol fuel cell applications, Journal of Membrane Science 321 (2008) 364-372.

29. C. Sollogoub, A. Guinault, C. Bonnebat, M. Bennjima, L. Akrour, J. F. Fauvarque, L. Ogier, Formation and characterization of crosslinked membranes for alkaline fuel cells, Journal of Membrane Science 335 (2009) 37-42.

30. S. Feng, Y. Shang, X. Xie, Y. Wang, J. Xu, Synthesis and characterization of crosslinked sulfonated poly(arylene ether sulfone) membranes for DMFC applications, Journal of Membrane Science 335 (2009) 13-20.

31. S. K. Das, A. S. Bansode, Heat and mass transport in proton exchange membrane fuel cells - A review, Heat Transfer Engineering 30 (2009) 691-719.

32. Q. Li, J. O. Jensen, R. F. Savinell, N. J. Bjerrum, High temperature proton exchange membranes based on polybenzimidazoles for fuel cells, Progress in Polymer Science (Oxford) 34 (2009) 449-477.

33. H. Strathmann, Membrane Science and Technology Ion-Exchange Membrane Separation Processes, 9, 1 1st Edition, Elsevier, 2004.

34. H. G. L. Coster, T. C. Chilcott, A. C. F. Coster, Impedance spectroscopy of interfaces, membranes and ultrastructures, Bioelectrochemistry and Bioenergetics 40 (1996) 79-98.

35. I. Rubinstein, SIAM, Electro-Diffusion of Ions, Edition, Philadelphia, 1990.

36. A. J. Bard, L. R. Faulkner, Electrochemical Methods, Edition, Wiley, New York, 1980. 
37. J.-H. Choi, J.-S. Park, S.-H. Moon, Direct Measurement of Concentration Distribution within the Boundary Layer of an Ion-Exchange Membrane, Journal of Colloid and Interface Science 251 (2002) 311-317.

38. J. J. Krol, M. Wessling, H. Strathmann, Concentration polarization with monopolar ion exchange membranes: current-voltage curves and water dissociation, Journal of Membrane Science 162 (1999) 145-154.

39. J. S. Park, T. C. Chilcott, H. G. L. Coster, S. H. Moon, Characterization of BSA-fouling of ion-exchange membrane systems using a subtraction technique for lumped data, Journal of Membrane Science 246 (2005) 137.

40. J.-S. Park, J.-H. Choi, J.-J. Woo, S.-H. Moon, An electrical impedance spectroscopic (EIS) study on transport characteristics of ion-exchange membrane systems, Journal of Colloid and Interface Science 300 (2006) 655-662.

41. P. Sistat, A. Kozmai, N. Pismenskaya, C. Larchet, G. Pourcelly, V. Nikonenko, Low-frequency impedance of an ion-exchange membrane system, Electrochimica Acta 53 (2008) 6380-6390. 


\title{
Chapter 2
}

\section{Current status of ion exchange membranes for power generation from salinity gradients}

\begin{abstract}
Reverse electrodialysis (RED) is a non-polluting, sustainable technology used to generate energy by mixing water streams with different salinity. The key components in a RED system are the ion-exchange membranes. This paper evaluates the potential of commercially available anion and cation exchange membranes for application in RED. Different membrane properties and characterization methods are discussed and a theoretical membrane model for RED was used to allow fair comparison of the characterization results for application in RED. The results of this study suggest that the membrane resistance should be as low as possible, while the membrane selectivity is of minor importance. Based on the results, the best benchmarked commercially available anion exchange membranes reach a power density of more than 5 $\mathrm{W} / \mathrm{m}^{2}$ whereas the best cation exchange membranes show a theoretical power density of more than $4 \mathrm{~W} / \mathrm{m}^{2}$. According to the membrane model calculations power densities higher than $6 \mathrm{~W} / \mathrm{m}^{2}$ could be obtained by using thin spacers and tailor made membranes with low membrane resistance and high permselectivity especially designed for reverse electrodialysis. This makes RED a potentially attractive alternative for energy production.
\end{abstract}

\section{Scientific publication:}

P. Dlugolecki, K. Nymeijer, S. Metz, M. Wessling, Current status of ion exchange membranes for power generation from salinity gradients, Journal of Membrane Science 319 (2008) 214-222. 
Current status of ion exchange membranes for reverse electrodialysis

\section{Introduction}

Renewable and sustainable energy sources are playing an important role in the $21^{\text {st }}$ century and are becoming increasingly important due to environmental problems, such as global pollution phenomena and global warming [1]. Membrane technology provides an opportunity to gain renewable and sustainable energy from salinity gradients via, e.g. pressure retarded osmosis [2,3] and reverse electrodialysis [4]. The latter method seems more attractive for power generation using sea and river water [5]. Reverse electrodialysis (RED) is a non-polluting, sustainable method for energy generation by mixing fresh and salt water. RED converts the free energy generated by mixing the two aqueous solutions into electrical power and the system can be applied wherever two solutions of different salinity are mixed, e.g. where river water flows into the sea $[6,7]$. The principle of RED was first proven by Pattle, who with his pioneering work in this field was the first one that generated power using RED [4]. In the 70s, Weinstein and Leitz investigated the effect of solution composition on power output and the main conclusion of this work was that large-scale energy conversion by RED may become practical, but only with major advances in the manufacturing of ion exchange membranes and with careful optimization of the operating conditions [7, 8]. In the early 80s, Lacey conducted a comprehensive investigation on RED [9]. Conclusion of his work was that to make RED commercially available it is necessary to minimize the internal stack resistance of the RED cells and to maximize the net power output from the cell [9]. Lacey concluded that membranes for RED should have a low electrical resistance and a high selectivity combined with a long service life time, acceptable strength, dimensional stability and low-cost [9]. In the mid 80s, Jagur-Grodzinski investigated membrane spacer modifications and different salt solution streams in order to generate more energy [10]. In 2007, Turek studied the effect of solution velocity on cell power output and process economy [11]. Turek 
mentioned that the main bottleneck for a successful RED system seems to be the membrane price. Despite that remark, the focus of most of the earlier work on RED was on stack design, solution flow and solution composition, but not on membrane characterization and membrane performance [7, 10-12]. Most scientists used electrodialysis membranes to study the RED process $[7,10,12$, 13]. The ion exchange membranes are the key elements in the RED system [9, 11]. The most important membrane properties for RED are: electrical resistance, selectivity, ion exchange capacity, swelling degree, and of course the membrane resistance and its selectivity (the ability of the membrane to distinguish between cations and anions), because of their direct effect on the overall RED performance. Up to now, it is still not known which membrane parameter is the dominant factor with respect to power generation in RED. It is essential to identify the key membrane parameters for RED in order to further improve the power output of RED. The data available in the existing literature do not offer sufficient information on membrane properties relevant to RED to enable proper mutual comparison of the different commercially available membranes. Currently, no complete overview is available with respect to the application of ion exchange membranes in RED which covers the full range of membrane types.

This paper presents an extensive overview of membrane benchmarking. It investigates a range of membrane properties of commercially available membranes that are important with respect to application in RED. The objective of this study is to determine the membrane properties under equivalent conditions to enable a fair comparison of the results and a proper evaluation for application in RED. The measured membrane properties are used for model calculations that predict the theoretical power density of these membranes under RED conditions. This approach is necessary to identify the key membrane characteristics for an optimal RED process. 


\section{Theoretical background}

\subsection{Principle of reverse electrodialysis}

In RED, a concentrated salt solution and a less concentrated salt solution are brought into contact through an alternating series of anion exchange membranes (AEM) and cation exchange membranes (CEM) (Figure $1)$.

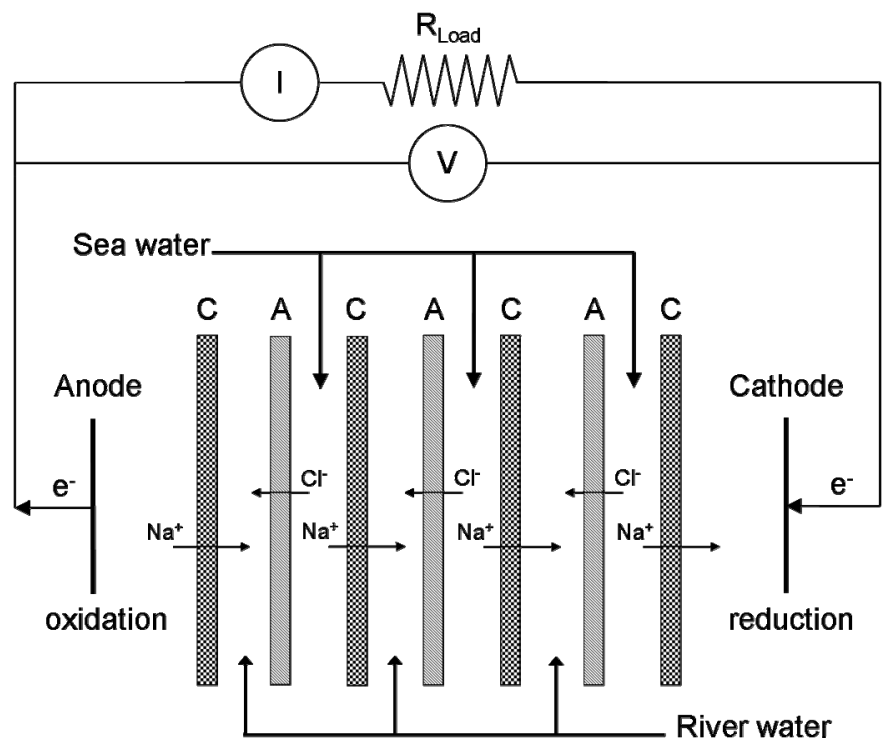

Figure 1: Schematic representation of reverse electrodialysis; $\mathrm{A}$ is an anion exchange membrane, $\mathrm{C}$ a cation exchange membrane, $\mathrm{V}$ is the potential difference over the applied external load (V), I is the electrical current (A) and RLoad is the resistance of the external load $(\Omega)$. A redox couple is used at the electrodes to mitigate the transfer of electrons.

The membranes separate the concentrated solution from the diluted solution and only ions can pass through the ion selective membranes. Anion exchange membranes contain fixed positive charges which allow anions to permeate through the AEM towards the anode and cation exchange membranes contain fixed negative charges which allow cations to be transported through the CEM 
towards the cathode. The difference in chemical potential between both solutions is the driving force for this process. At the electrodes a redox couple is used to mitigate the transfer of electrons. The chemical potential difference generates a voltage difference over each membrane.

The theoretical value of the potential over the membrane for an aqueous monovalent electrolyte (e.g. $\mathrm{NaCl}$ ) can be calculated using the Nerst equation (Equation 1):

$$
\Delta \mathrm{V}_{\text {theo }}=\frac{\mathrm{RT}}{\mathrm{zF}} \ln \left(\frac{\mathrm{a}_{\mathrm{c}}}{\mathrm{a}_{\mathrm{d}}}\right)
$$

Where $\Delta \mathrm{V}_{\text {theo }}$ is the theoretical membrane potential for $100 \%$ selective membrane $(\mathrm{V}), \mathrm{R}$ is the gas constant $\left(8.314 \mathrm{~J} \cdot \mathrm{mol}^{-1} \cdot \mathrm{K}^{-1}\right), \mathrm{T}$ is the absolute temperature $(\mathrm{K}), \mathrm{z}$ is the electrochemical valence, $\mathrm{F}$ is the Faraday constant (96485 C. $\left.\mathrm{mol}^{-1}\right)$, ac is the activity of the concentrated solution (mol-1-1) and ad is the activity of the diluted solution $\left(\mathrm{mol} \cdot \mathrm{l}^{-1}\right)$. For fresh $\left(0.017 \mathrm{M} \mathrm{NaCl}, \gamma_{ \pm}=0.878\right)$ and sea water $\left(0.5 \mathrm{M} \mathrm{NaCl}, \gamma_{ \pm}=0.686\right)$ the theoretical voltage difference per membrane is $80.3 \mathrm{mV}$. The overall potential of the system is the sum of the potential differences over each pair of membranes.

\subsection{Ion exchange membrane properties}

Ion exchange membranes are membranes with fixed anionic or cationic exchange groups that are able to transport cations or anions. The specific properties of ion exchange membranes are all related to the presence of these charged groups. Amount, type and distribution of ion exchange groups determine the most important membrane properties. Based on the type of fixed charge group, ion exchange membranes can be classified as strong acid and strong base, or weak acid and weak base membranes. Strong acid cation exchange membranes contain sulfon groups as charged group. In weak acid 
membranes, carboxylic acid is the fixed charged group. Quaternary and tertiary amines are the fixed positive charged groups in strong and weak base anion exchange membranes, respectively.

\subsubsection{Ion exchange capacity}

The ion exchange capacity (IEC) is the number of fixed charges inside the ion exchange membrane per unit weight of dry polymer. The ion exchange capacity is a crucial parameter which affects almost all other membrane properties. The IEC is expressed in milli equivalent of fixed groups per gram of dry membrane (meq/g membrane).

\subsubsection{Fixed charge density}

Ion exchange membranes contain fixed charged groups attached to the polymer backbone. In cation exchange membranes, the fixed negative charges are in electrical equilibrium with the mobile cations (counter-ions). The opposite relation exists in anion exchange membranes. The fixed charge density, expressed in milli equivalent of fixed groups per volume of water in the membrane (meq/l) strongly depends on the IEC and the swelling degree of the membrane: in the swollen state, the distance between the ion exchange groups increases thus reducing the fixed charge density. The transport of counter ions through the membrane is determined by the fixed charge density in the membrane and the difference between the concentration of the electrolyte solution in contact with that membrane. The concentration and type of the fixed ionic charges determine the permselectivity and the electrical resistance of the membrane.

\subsubsection{Permselectivity}

When an ion exchange membrane is in a contact with an electrolyte (salt solution), ions with the same charge (co-ions) as the fixed ions are 
excluded and cannot pass through the membrane, while the oppositely charged ions (counter-ions) can pass freely through the membrane. This effect is known as Donnan exclusion [14]. The permselectivity of a membrane describes the charge selectivity of the ion exchange membrane. It reflects the ability of the membrane to discriminate between ions of opposite charge.

\subsubsection{Electrical resistance}

The electrical resistance of the membrane is an important property of ion-exchange membranes, because it is directly related to the maximum power output in reverse electrodialysis and the energy consumption in electrodialysis processes $[9,15]$. The membrane resistance is determined by the ion exchange capacity and the mobility of the ions within the membrane matrix. The electrical resistance is dependent on temperature and decreases with increasing temperature. The specific membrane resistance is in principle reported in $\Omega \cdot \mathrm{cm}$. However, more useful and most often reported in literature is the membrane resistance in $\Omega \cdot \mathrm{cm} 2$.

\subsubsection{Heterogeneous and homogenous ion exchange membrane}

Ion exchange membranes can be divided with respect to their structure and preparation procedure into two categories: homogeneous and heterogeneous membranes. In homogenous ion-exchange membranes the fixed charge groups are evenly distributed over the entire membrane matrix. Homogenous membranes can be manufactured via polymerization and polycondensation of functional monomers (e.g fenylosulfonic acid with formaldehyde) or via functionalization of a polymer by for example dissolving the polymer in a suitable sovent and subsequent functionalization by e.g. postsulfonation [16-20]. Heterogeneous membranes have distinct macroscopic uncharged polymer domains of ion exchange resins in the membrane matrix. This type of membranes can be produced by melting and pressing of a dry ion- 
exchange resin with a granulated polymer (e.g. polyvinylochloride) [21]. Another method to prepare heterogeneous membranes is dispersion of the ion exchange resin in a polymer solution [22]. The distinct difference between homogenous and heterogeneous ion exchange membranes also influences the properties of the specific membrane.

\subsection{RED membrane model}

To predict the relative contribution of the different components in a RED stack, a theoretical model was used [8]. The relationship between the salt concentration (activity) in the two compartments (diluted and concentrated), the process temperature and the selectivity of the membrane is shown in Equation 2:

$$
\mathrm{V}^{\mathrm{o}}=\mathrm{N} \frac{2 \alpha_{\mathrm{av}} \mathrm{RT}}{\mathrm{zF}} \ln \left(\frac{\mathrm{a}_{\mathrm{c}}}{\mathrm{a}_{\mathrm{d}}}\right)
$$

Where $\mathrm{V}^{0}$ is the open circuit potential of the membrane stack $(\mathrm{V}), \alpha_{\mathrm{av}}$ is the average membrane permselectivity of an anion and a cation exchange membrane pair (-), $\mathrm{N}$ is the number of membrane pairs (-), $\mathrm{R}$ is the gas constant $\left(8.314 \mathrm{~J} \cdot \mathrm{mol}^{-1} \cdot \mathrm{K}^{-1}\right), \mathrm{T}$ is the absolute temperature $(\mathrm{K}), \mathrm{z}$ is the electrochemical valence, $\mathrm{F}$ is the Faraday constant $\left(96485 \mathrm{C} \cdot \mathrm{mol}^{-1}\right)$, ac is the activity of the concentrated salt solution $\left(\mathrm{mol} \cdot \mathrm{l}^{-1}\right)$ and ad is the activity of the diluted salt solution $\left(\mathrm{mol} \cdot \mathrm{l}^{-1}\right)$.

The stack resistance can be defined as the sum of the resistances of the individual stack components as shown in Equation 3 [9]:

$$
\mathrm{R}_{\text {stack }}=\frac{\mathrm{N}}{\mathrm{A}} \cdot\left(\mathrm{R}_{\mathrm{aem}}+\mathrm{R}_{\mathrm{cem}}+\frac{\mathrm{d}_{\mathrm{c}}}{\kappa_{\mathrm{c}}}+\frac{\mathrm{d}_{\mathrm{d}}}{\kappa_{\mathrm{d}}}\right)+\mathrm{R}_{\mathrm{el}}
$$


Where $\mathrm{N}$ is the number of membrane pairs, $\mathrm{A}$ is the effective membrane area $\left(\mathrm{m}^{2}\right)$, Raem is the anion exchange membrane resistance $\left(\Omega \cdot \mathrm{m}^{2}\right), R_{\mathrm{cem}}$ is the cation exchange membrane resistance $\left(\Omega \cdot \mathrm{m}^{2}\right), \mathrm{d}_{\mathrm{c}}$ is the thickness of concentrated compartment $(m), d_{d}$ is the thickness of $(m), \kappa_{c}$ is the concentrated compartment conductivity $\left(\mathrm{S} \cdot \mathrm{m}^{-1}\right), \kappa_{\mathrm{d}}$ is the diluted compartment conductivity $\left(\mathrm{S} \cdot \mathrm{m}^{-1}\right)$ and $\mathrm{Rel}$ is the electrode resistance $(\Omega)$.

The final stack power output of the RED stack can be found from Kirchhoff's law and is defined as:

$$
\mathrm{W}=\mathrm{I}^{2} \mathrm{R}_{\text {load }}=\frac{\left(\mathrm{V}^{\mathrm{o}}\right)^{2} \mathrm{R}_{\text {load }}}{\left(\mathrm{R}_{\text {stack }}+\mathrm{R}_{\text {load }}\right)^{2}}
$$

Here I is the current (A), Rload is the load resistance $(\Omega)$, Rstack is the stack resistance $(\Omega)$ and $\mathrm{V}^{0}$ is the stack open circuit potential $(\mathrm{V})$.

To generate a maximum power output $\left(\mathrm{W}_{\max }\right), \mathrm{R}_{\text {load }}$ needs to be equal to $\mathrm{R}_{\text {stack }}[8$, $9,12]$.

In that case, Equation 4 changes into Equation 5 which shows the relationship between the open circuit potential, the maximum power output and the stack resistance.

$$
\mathrm{W}_{\text {max }}=\frac{\left(\mathrm{V}^{0}\right)^{2}}{4 \mathrm{R}_{\text {stack }}}
$$

Combination of Equation 5 with Equations 2 and 3 finally yields Equation 6 which relates the maximum power output of the RED stack to the individual contributions of each component. More specifically, it relates the maximum power output of the system $\left(W_{\max }\right)$ to the average membrane selectivity $\left(\alpha_{\text {av }}\right)$ and the membrane resistance ( $R_{a e m}$ and $\left.R_{c e m}\right)$. 


$$
\mathrm{W}_{\max }=\mathrm{N} \cdot \mathrm{A} \frac{\left[\alpha_{\mathrm{av}} \cdot \mathrm{RT} / \mathrm{F} \cdot \ln \left(\mathrm{a}_{\mathrm{c}} / \mathrm{a}_{\mathrm{d}}\right)\right]^{2}}{\left(\mathrm{R}_{\mathrm{aem}}+\mathrm{R}_{\mathrm{cem}}+\frac{\mathrm{d}_{\mathrm{c}}}{\kappa_{\mathrm{c}}}+\frac{\mathrm{d}_{\mathrm{d}}}{\kappa_{\mathrm{d}}}\right)}
$$

Where $\mathrm{N}$ is the number of membrane pairs (-), $\alpha_{\mathrm{av}}$ is the average membrane pair permselectivity $(-), \mathrm{R}$ is the gas constant $\left(8.314 \mathrm{~J} \cdot \mathrm{mol}^{-1} \cdot \mathrm{K}^{-1}\right), \mathrm{T}$ is the absolute temperature $(\mathrm{K}), \mathrm{F}$ is the Faraday constant $\left(96485 \mathrm{C} \cdot \mathrm{mol}^{-1}\right)$, ac is the concentrated solution activity $\left(\mathrm{mol} \cdot \mathrm{l}^{-1}\right)$, ad is the diluted solution activity $\left(\mathrm{mol} \cdot \mathrm{l}^{-1}\right)$, Raem is the anion exchange membrane resistance $\left(\Omega \cdot \mathrm{m}^{2}\right)$, Rcem is the cation exchange membrane resistance $\left(\Omega \cdot \mathrm{m}^{2}\right), \quad$ A is the effective membrane area $\left(\mathrm{m}^{2}\right), \mathrm{d}_{\mathrm{c}}$ is the thickness of the concentrated compartment $(\mathrm{m})$, $\mathrm{d}_{\mathrm{d}}$ is the thickness of the diluted compartment $(\mathrm{m}), \kappa_{\mathrm{c}}$ is the concentrated $(0.5 \mathrm{M} \mathrm{NaCl})$ compartment conductivity $\left(4.648 \mathrm{~S} \cdot \mathrm{m}^{-1}\right)$ and $\kappa_{\mathrm{d}}$ is the diluted $(0.05 \mathrm{M} \mathrm{NaCl})$ compartment conductivity $\left(0.551 \mathrm{~S} \cdot \mathrm{m}^{-1}\right)$.

Equation 6 predicts theoretical membrane stack power output and relates the maximum power output of the system to the individual membrane characteristics, it can be used as a tool to compare different anion and cation exchange membranes with respect to their performance in a RED stack. If equation 6 is used for power output prediction with only cation exchange membranes, then the average membrane pair permselectivity $\left(\alpha_{\mathrm{av}}\right)$ will be replaced by individual membrane selectivity $(\alpha)$, the resistance of anion exchange membrane term will be removed and concentrated and diluted thickness (d) will be divided by 2 because it is related to half a cell. The obtained power output per for one type of the membrane is used to compare membranes with each other.

In the model a few assumptions were made: (i) concentration polarization phenomena near the membrane surface are negligible due to the small current densities obtained through the membranes. This phenomenon can be minimized with well design fluid dynamics between the membranes, (ii) the resistance of the electrodes is assumed to be negligible compared to the 
membrane resistance. This assumption is allowed when a large number of membrane cell pairs is used, (iii) the feed solution does not change in concentration along the channels. This assumption has a strong relationship with the feed channel design and in a well designed system this effect can be neglected.

In order to compare commercially available membranes with each other it is more desirable to convert the power output into power density normalized for the membrane area $\left(\mathrm{W} / \mathrm{m}^{2}\right)$. Power density per square meter of membrane can be easily calculated from the maximum power output:

$$
\mathrm{w}_{\text {max }}=\frac{\mathrm{W}_{\text {max }}}{\mathrm{A} \cdot \mathrm{N}_{\mathrm{m}}}
$$

Where $\mathrm{W}_{\max }$ is the maximum power density $\left(\mathrm{W} / \mathrm{m}^{2}\right), \mathrm{W}_{\max }$ is maximum power output $(\mathrm{W}), \mathrm{A}$ is the effective membrane area $\left(\mathrm{m}^{2}\right)$ and $\mathrm{N}_{\mathrm{m}}$ is the number of membranes (-).

Obtained power output per one type of the membrane (anion or cation exchange membrane) is used only to benchmark membranes with each other.

\section{Experimental part}

The properties of several commercially available ion exchange membranes are investigated in order to evaluate their potential performance for RED. This paragraph describes the different experimental characterization methods applied.

\subsection{Ion exchange capacity}

The IEC was measured by titration [14, 23]. In the case of cation exchange membranes (CEM), the functional groups were brought into the $\mathrm{H}^{+}$ form by immersing the membrane in $1 \mathrm{M} \mathrm{HCl}$ for at least $24 \mathrm{~h}$ (the solution was 
changed three times to complete ion exchange). The membrane was rinsed with demineralized water in order to remove sorbed acid, until the rinse water was free of $\mathrm{Cl}^{-}$(tested with $\mathrm{AgNO}_{3}$ for $\mathrm{AgCl}$ precipitation). After that the membrane was brought into $\mathrm{Na}^{+}$form by immersing it in a $2 \mathrm{M} \mathrm{NaCl}$ solution. The solution was replaced three times to ensure complete exchange. The different $\mathrm{NaCl}$ solutions were collected and titrated with $0.1 \mathrm{M} \mathrm{NaOH}$ to determine its proton content. The number of protons in the solution could be directly related to the total charge in the membrane sample.

In the case of anion exchange membranes (AEM), the functional groups were brought into the $\mathrm{Cl}$-form by immersing the membrane in $3 \mathrm{M} \mathrm{NaCl}$ for a period of at least 24 hours (the solution was changed three times to complete ion exchange). The membrane sample in $\mathrm{Cl}^{-}$form and in equilibrium with demineralized water (tested with $\mathrm{AgNO}_{3}$ for $\mathrm{AgCl}$ precipitate) was brought into the $\mathrm{NO}_{3}$ - form by leaching it with a $0.2 \mathrm{M} \mathrm{NaNO}_{3}$ (analytical grade, Boom B.V., The Netherlands) solution [24]. To ensure complete exchange the solution was replaced several times and stirred for at least one hour between each replacement. The different solutions were collected and the chloride ion concentration was determined using ion exchange chromatography.

The IEC of the membrane was calculated as the ratio of the total charge and the dry weight of the measured membrane:

$$
\mathrm{IEC}=\frac{\mathrm{c}_{\text {total }}}{\mathrm{m}_{\mathrm{dry}}}
$$

Where IEC is the ion exchange capacity of the membrane (meq./g), Ctotal is the total charge (meq.) and mdry is the dry weight of the ion exchange membrane under investigation $(\mathrm{g})$. 


\subsection{Permselectivity}

The permselectivity was determined using a static membrane potential measurement. A schematic representation of the permselectivity set-up used for this measurement is shown in Figure 2 [25].

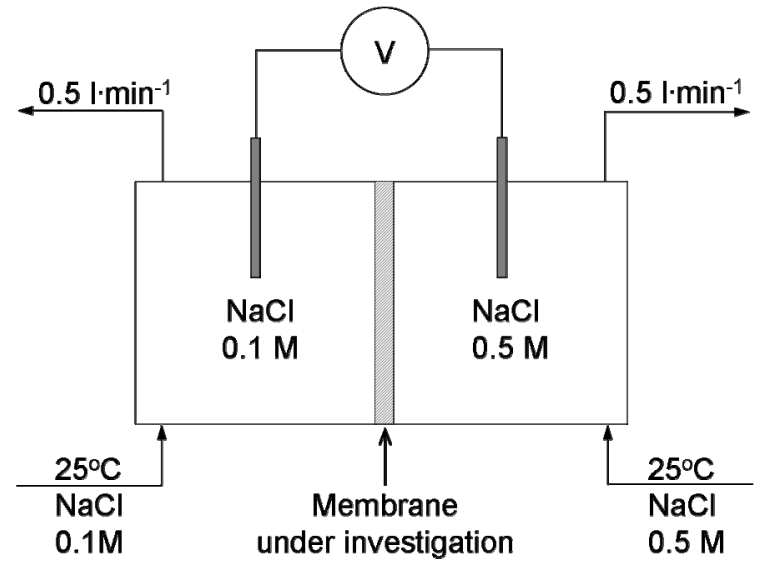

Figure 2: Schematic representation of the set-up to determine the permselectivity of a membrane.

The experimental set-up consisted of two cells separated by the membrane under investigation. On one side of the membrane a $0.1 \mathrm{M} \mathrm{NaCl}\left(\gamma_{ \pm}=0.778\right)$ solution (Analytical grade, Boom B.V., The Netherlands) flowed through the cell and on the other side a $0.5 \mathrm{M} \mathrm{NaCl}\left(\gamma_{ \pm}=0.686\right)$ solution was used. Two double junction $\mathrm{Ag} / \mathrm{AgCl}$ reference electrodes (Metrohm AG, Switzerland) were placed into the solution on either side of the membrane and were used to measure the potential difference over the membrane. The effective area of the membrane under investigation was $23.8 \mathrm{~cm}^{2}$. The temperature was $25 \pm 0.2^{\circ} \mathrm{C}$. Prior to an experiment the membrane was equilibrated in a $0.1 \mathrm{M} \mathrm{NaCl}$ solution for 24 hours. The membrane potential was measured after 20-30 minutes when steady state was reached. Finally the membrane permselectivity could be calculated as the ratio between the measured membrane potential $\left(\Delta \mathrm{V}_{\text {meas }}\right)$ and the theoretical membrane potential $\left(\Delta \mathrm{V}_{\text {theo }}\right)$ : 


$$
\alpha=\frac{\Delta \mathrm{V}_{\text {meas }}}{\Delta \mathrm{V}_{\text {theo }}} \times 100 \%
$$

Where $\alpha$ is the membrane permselectivity (\%), $\Delta \mathrm{V}_{\text {meas }}$ is measured membrane potential and $\Delta \mathrm{V}_{\text {theo }}$ is the theoretical membrane potential $(\mathrm{V})$. The theoretical membrane potential is the membrane potential for a $100 \%$ permselective membrane as calculated from the Nerst equation.

\subsection{Electrical resistance}

To measure the electrical resistance of ion exchange membranes, a six compartment cell with a four electrode arrangement was used (Figure3).

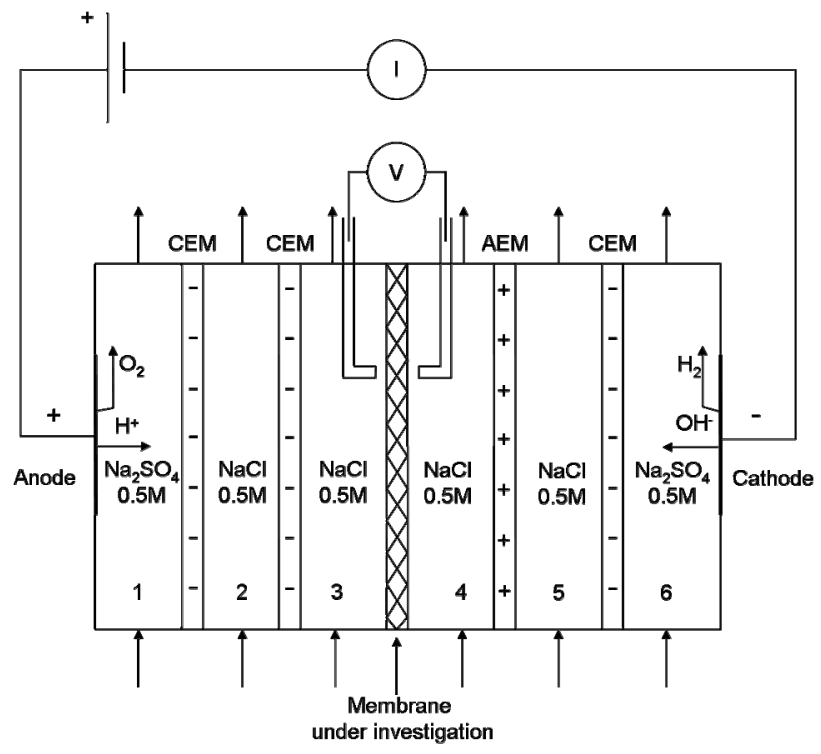

Figure 3: Six compartment cell used to determine the membrane resistance; CEM is a cation exchange membrane, AEM is an anion exchange membrane, $\mathrm{V}$ is the potential difference over the Haber-Luggin capillaries (V) and I is the electrical current (A) [26, 27].

The measuring set-up was made from plexiglass and consisted of 6 separate compartments with a solution volume of $2 \mathrm{dm}^{3}$ [28]. The central membrane, 
which was the membrane under investigation, was either a cation or an anion exchange membrane. The investigated membrane was equilibrated in the measuring solution for at least 24 hours. The other four membranes were auxiliary ion exchange membranes produced by Mega (Czech Republic). The area of each membrane in the cell was $23.8 \mathrm{~cm}^{2}$. In both compartments adjacent to the membrane under investigation a $0.5 \mathrm{M} \mathrm{NaCl}$ (analytical grade, Boom B.V., The Netherlands) was pumped. The second and fifth compartment contained the same solution to avoid influences of the electrode reactions at the working electrodes. The electrode compartments (compartment 1 and 6) contain a $0.5 \mathrm{M}$ $\mathrm{Na}_{2} \mathrm{SO}_{4}$ solution (Analytical grade, Boom B.V., The Netherlands). The anode compartment contained an anode which was made of titanium covered by platinum. The cathode compartment contained a cathode which was made from stainless steel. The electrode reactions are:

Anode: $2 \mathrm{H}_{2} \mathrm{O} \rightarrow \mathrm{O}_{2} \uparrow+4 \mathrm{H}^{+}+4 \mathrm{e}^{-}$

Cathode: $2 \mathrm{H}_{2} \mathrm{O}+2 \mathrm{e}^{-} \rightarrow \mathrm{H}_{2} \uparrow+2 \mathrm{OH}^{-}$

All solutions were pumped by gear pumps (Cole-Parmer Instrument Co., Digital Gear Pump, USA) and the flow rate of each stream was adjusted to 500 $\mathrm{ml} / \mathrm{min}$. The conductivity (Metrohm AG, 712 Conductometer, Switzerland) and $\mathrm{pH}$ (Metrohm AG, $827 \mathrm{pH}$ lab, Switzerland) of the solution close to the membrane under investigation were continuously monitored to ensure a constant composition during a set of experiments. All experiments were performed at a temperature of $25 \pm 0.2{ }^{\circ} \mathrm{C}$. A power supply (Delta Electronica B.V., ES030-5, The Netherlands) was connected to the anode and the cathode to apply the current over the six compartment cell. Haber-Luggin capillaries were used as electrodes. These capillaries were filled with a $2 \mathrm{M} \mathrm{KCl}$ solution and they were connected to a small reservoir which contains calomel reference electrodes (QiS, QM 712X, ProSense B.V., The Netherlands). The calomel 
reference electrodes were connected to a multimeter (Fluke Co. 87V True RMS Multimeter, USA) and measured the potential difference over the membrane under investigation.

The voltage drop over the membrane under investigation at different current densities was measured using Haber-Luggin capillaries. The final resistance was given by the slope of the current density versus voltage drop curve. This resistance represents the combined solution and membrane resistance (Equation 12):

$$
\mathrm{R}_{\mathrm{m}+\mathrm{s}}=\frac{\mathrm{U}}{\mathrm{i}}
$$

Here $\mathrm{U}$ is the voltage drop measured between the Haber- Luggin capillaries (V), $\mathrm{i}$ is the current density $\left(\mathrm{A} / \mathrm{m}^{2}\right)$ and $\mathrm{R}_{\mathrm{m}+\mathrm{s}}$ is the combined membrane and solution resistance $\left(\Omega \cdot \mathrm{m}^{2}\right)$.

To obtain the pure membrane resistance, this combined resistance had to be corrected for the resistance of the solution, which could be determined from a blank experiment without a membrane.

\subsection{Swelling degree and membrane thickness}

The swelling degree and corresponding water content of the cation and anion exchange membranes was measured by immersing the membrane in demineralized water and in various $\mathrm{NaCl}$ solutions at room temperature for at least 24 hours (to reach equilibration of the membrane). The samples were removed from the solution, the surface water was removed with blotting paper and weight and wet thickness of the membrane sample was determined. Subsequently the membrane was dried in an oven at $50{ }^{\circ} \mathrm{C}$ for a period of 48 hours and after that its dry weight was determined. The swelling degree is 
given by the ratio of the amount of absorbed water ( $\left.m_{w e t}-m_{d r y}\right)$ and the dry weight of the membrane (Equation 13) [17]:

$$
\mathrm{SD}=\frac{\mathrm{m}_{\mathrm{wet}}-\mathrm{m}_{\mathrm{dry}}}{\mathrm{m}_{\mathrm{dry}}} \cdot 100 \%
$$

\subsection{Fixed charge density}

The fixed charge density, cfix, of the membrane could be calculated from the concentration of ion exchange groups attached to polymer matrix (IEC) and the swelling degree:

$$
\mathrm{c}_{\mathrm{fix}}=\frac{\mathrm{IEC}}{\mathrm{SD}}
$$

Where cfix is the fixed charge density (mol/l), IEC is the ion exchange capacity of the membrane (meq./gdry) and SD is the swelling degree of the membrane (gH2O/gdry).

\section{Results and discussion}

\subsection{Membrane benchmarking}

In this work, different properties of commercially available ion exchange membranes are investigated in order to evaluate their potential performance under RED conditions. The membranes are selected based on their low resistance and high selectivity. Both homogeneous and heterogeneous membranes are considered. Membranes are characterized based on their ion exchange capacity, permselectivity, electrical resistance, charge density, swelling degree and thickness. The main characteristic of the membranes is also 
mentioned. Table 1 shows the experimentally determined values of these properties.

Table 1: Comparison between experimental data (bold) and commercial data [29-32]

\begin{tabular}{|c|c|c|c|c|c|c|c|c|c|c|}
\hline Membrane & \multicolumn{2}{|c|}{$\begin{array}{c}\text { IEC } \\
\text { (meq./g dry) }\end{array}$} & \multicolumn{2}{|c|}{$\begin{array}{c}\text { Permselectivity } \\
(\%)\end{array}$} & \multicolumn{2}{|c|}{$\begin{array}{c}\text { Resistance }^{b} \\
\left(\Omega \cdot \mathrm{cm}^{2}\right)\end{array}$} & \multicolumn{2}{|c|}{$\begin{array}{l}\text { SD } \\
(\%)\end{array}$} & \multicolumn{2}{|c|}{$\begin{array}{l}\text { Thickness } \\
(\mu \mathrm{m})\end{array}$} \\
\hline \multicolumn{11}{|c|}{ Cation Exchange Membranes } \\
\hline \multicolumn{11}{|l|}{ Fumasep $^{\circledR}$} \\
\hline FKE & 1.36 & $>1.0$ & 98.6 & $>98$ & 2.46 & $<3.0$ & 12 & 15 & 34 & $50-70$ \\
\hline FKD & 1.14 & $>1.0$ & 89.5 & $>95$ & 2.14 & $<3.0$ & 29 & $25-30$ & 113 & $90-100$ \\
\hline \multicolumn{11}{|l|}{ Neosepta ${ }^{\circledR}$} \\
\hline $\mathrm{CM}-1$ & 2.30 & $2.0-2.5$ & 97.2 & $>96^{c}$ & 1.67 & $1.2-2.0$ & 20 & $35-40$ & 133 & $120-170$ \\
\hline CMX & 1.62 & $1.5-1.8$ & 99.0 & $>96^{c}$ & 2.91 & $1.8-3.8$ & 18 & $25-30$ & 164 & $140-200$ \\
\hline \multicolumn{11}{|c|}{ Ralex $^{\circledast}$ (Heterogeneous) } \\
\hline CMH-PES & 2.34 & 2.2 & 94.7 & $>92$ & 11.33 & $<10$ & 31 & $<55$ & 764 & $<700$ \\
\hline \multicolumn{11}{|l|}{ Selemion $^{\circledR}$} \\
\hline $\mathrm{CMV}$ & 2.01 & $\mathrm{~N} / \mathrm{A}$ & 98.8 & $>92$ & 2.29 & $3.0^{\mathrm{d}}$ & 20 & N/A & 101 & 130.0 \\
\hline \multicolumn{11}{|c|}{ Anion Exchange Membranes } \\
\hline \multicolumn{11}{|l|}{ Fumasep $^{\circledR}$} \\
\hline FAD & 0.13 & $>1.5$ & 86.0 & $>91$ & 0.89 & $<0.8$ & 34 & 25 & 74 & $80-100$ \\
\hline \multicolumn{11}{|l|}{ Neosepta ${ }^{\circledR}$} \\
\hline AM-1 & 1.77 & $1.8-2.2$ & 91.8 & $>96^{c}$ & 1.84 & $1.3-2.0$ & 19 & $25-35$ & 126 & $130-160$ \\
\hline AFN & 3.02 & $2.0-3.5$ & 88.9 & $>96^{c}$ & 0.70 & $0.4-1.5$ & 43 & $40-55$ & 163 & $150-200$ \\
\hline AMX & 1.25 & $1.4-1.7$ & 90.7 & $>96^{c}$ & 2.35 & $2.5-3.5$ & 16 & $25-30$ & 134 & $160-180$ \\
\hline \multicolumn{11}{|c|}{ Ralex $^{\circledR}$ (Heterogeneous) } \\
\hline AMH-PES & 1.97 & 1.8 & 89.3 & $>90$ & 7.66 & $<8$ & 56 & $<65$ & 714 & $<850$ \\
\hline \multicolumn{11}{|l|}{ Selemion $^{\circledR}$} \\
\hline DSV & 1.89 & $\mathrm{~N} / \mathrm{A}$ & 89.9 & $\mathrm{~N} / \mathrm{A}$ & 1.03 & $1.0^{\mathrm{d}}$ & 28 & N/A & 121 & 100.0 \\
\hline APS & 0.29 & N/A & 88.4 & N/A & 0.68 & $0.5^{\mathrm{d}}$ & 147 & N/A & 138 & 150.0 \\
\hline
\end{tabular}

a Membrane potential measured across the membrane between $0.5 \mathrm{M}$ and $0.1 \mathrm{M}$ solutions.

b Measured in $0.5 \mathrm{M} \mathrm{NaCl}$ solution at $25^{\circ} \mathrm{C}$.

c Measured by electrophoresis, $2 \mathrm{~mA} / \mathrm{cm}^{2}$.

d Determined by $1 \mathrm{kHz}$ AC measurement in the $0.5 \mathrm{~N} \mathrm{NaCl}$ solution at $25^{\circ} \mathrm{C}$. 
All values were measured three times and the error bars are in all cases less than $5 \%$. However to avoid confusion, these values have been left out of the Table. For comparison also the data of the manufacturers are shown, although they do not always use the same conditions to characterize the membranes [2932]. Tokuyama Co. (Japan) for example determined the transport number (which is directly related to the permselectivity) of Neosepta membranes with electrophoresis $\left(2 \mathrm{~mA} / \mathrm{cm}^{2}\right)$, while other membrane manufacturers use membrane potential measurements to determine the permselectivity of the membrane. Asahi Glass Co., LTD. (Japan) determined the electrical resistance of Selemion membranes by using an alternating current method, which results in lower resistances compared to direct current measurements [33]. Also the solution concentration and composition used by producers to determine the permselectivity is not always the same [29-32].

It is obvious that the values for the measured parameters differ considerably from one membrane to another, as could be expected due to the differences in molecular structure and composition of the membranes.

In general, data provided by the manufacturers are in reasonable good agreement with the experimentally determined values, although there are exceptions.

The ion exchange capacity (IEC) listed in Table 1 quantifies the number of strong acidic $\left.\left(-\mathrm{SO}_{3}\right)^{-}\right)$groups in cation exchange membranes and strong basic $\left(-\mathrm{NR}_{3}{ }^{+}\right)$groups in the anion exchange membranes. In general, the experimentally determined IEC is in good agreement with the data supplied by the manufacturers. There are two exceptions: The anion exchange membranes APS Selemion and FAD Fumasep consist of a mixture of weak and strong ion exchange groups. The determination method for the ion exchange capacity allows only to measure strong basic groups, which result in significantly lower experimental values for the IEC, compared to the manufacturer's data. The membrane permselectivity and resistance data listed in Table 1 and are in good agreement with the data supplied by the manufacturers. In general, swelling 
degree (SD) values are similar to the data of the manufacturers. However, the swelling degree of the Selemion APS membrane is very high compared to other ion exchange membranes. This is probably caused by the rough membrane surface of the APS membrane which affects the wiping of water from the membrane surface before measuring the weight. The thickness of the membrane strongly depends on the type of the membrane: Homogenous membranes are thinner than heterogeneous membranes, which is due to the structure of the membrane and its preparation method [16-20,34].

\subsection{Membrane properties}

\subsubsection{Permselectivity and resistance as a function of charge density}

The charge density of the membrane determines its ion permselectivity and its electrical resistance $[13,35]$. In general, membranes with a lower fixed charge density have a lower selectivity as well. In that case the co-ion exclusion is less effective (e.g. anions in the case of cation exchange membrane and cations in the case of anion exchange membranes). Figure 4 presents the membrane permselectivity and the membrane resistance of the investigated membranes as a function of the fixed charge density of the membrane. Fumasep FAD and Selemion APS membranes are not presented in this Figure because the experimental determination of the concentration of fixed weak ion exchange groups inside the ion exchange membranes was not possible. Although the charge density has a strong influence on the permselectivity and the membrane resistance, there does not exist a straight forward relationship between these properties (Figure $4 \mathrm{a}$ and $4 \mathrm{~b}$ ). 
a)

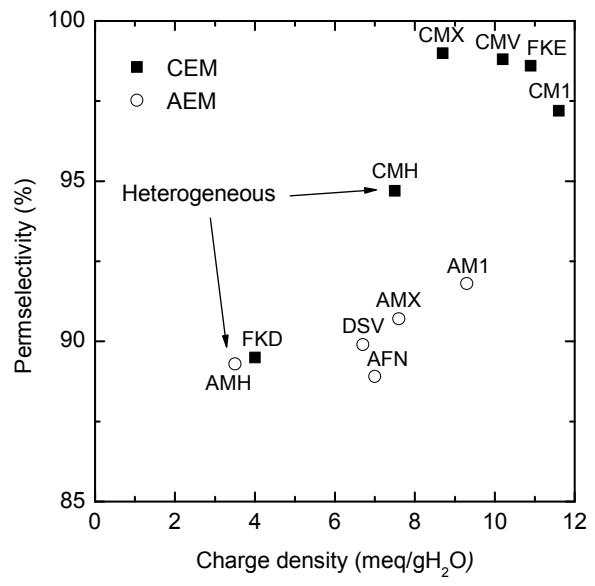

b)

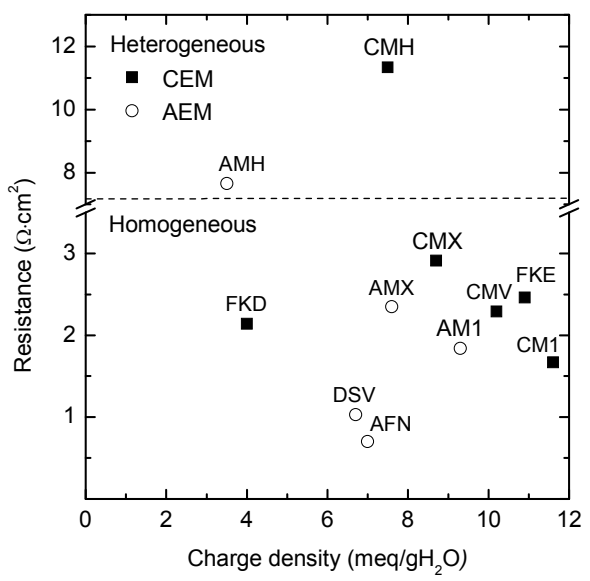

Figure 4: a) Membrane permselectivity b) and membrane resistance as a function of the charge density; CEM is a cation exchange membrane ( $\mathbf{\bullet})$, and AEM is an anion exchange membrane ( $\square$ ).

In general, cation exchange membranes have a higher charge density and a corresponding higher permselectivity than anion exchange membranes. Only the Fumasep FKD membrane has a lower permselectivity than the anion exchange membrane. Figure $4 \mathrm{~b}$ shows that, although the cation exchange membranes in general have a higher charge density, they also seem to have a 
higher membrane resistance. This phenomenon is caused by a high degree of crosslinking which improves mechanical strength of the membrane but also increases its electrical resistance. In general, a high concentration of fixed ionic charges in the membrane matrix leads to a low electric resistance, but causes a high degree of swelling combined with poor mechanical stability [23]. Heterogeneous ion exchange membranes have a relatively low charge density compared to homogeneous membranes and much higher resistance due to the membrane structure and the separation of charged domains in an uncharged polymer matrix [23].

\subsubsection{Relationship between permselectivity and resistance}

The relationship between the membrane permselectivity and the membrane resistance is presented in Figure 5. The values for both homogeneous and heterogeneous membranes are shown.

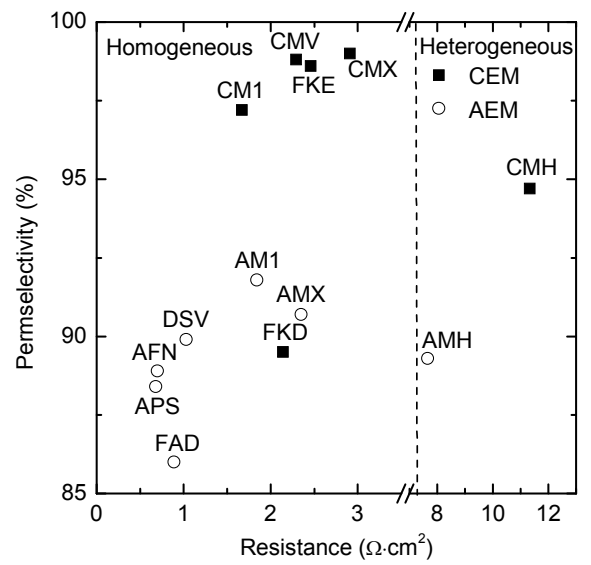

Figure 5: Membrane permselectivity as a function of the membrane resistance (at $25^{\circ} \mathrm{C}$ ). CEM is a cation exchange membrane ( $\mathbf{-})$ and AEM is an anion exchange membrane ( $\square$ ).

In general, heterogeneous ion exchange membranes have a higher resistance than the homogenous types. This phenomenon is due to the membrane 
structure: heterogeneous ion exchange membranes have distinct macroscopic domains of ion exchange resins in an uncharged polymer matrix and as a result these membranes have a higher membrane resistance [20,34]. In general, less selective membranes have a lower membrane resistance [36], whereas high selective membranes have a higher membrane resistance. Figure 4 shows that this is not always true and also depends on the type of membrane, but a general trend is clearly visible. Low resistance membranes (around $1 \Omega \cdot \mathrm{cm}^{2}$ ) have a permselectivity of approximately $90 \%$ and most of them are anion exchange membranes. In general, the cation exchange membranes have a higher permselectivity than the anion exchange membranes. This phenomenon is due to the higher membrane swelling degree for anion exchange membranes, which reduces the effective charge density and thus reduces the permselectivity (a higher density of ion exchange groups results in a higher membrane permselectivity and vice versa).

\subsection{Model results}

The model presented earlier is used to evaluate the relative importance of the membrane resistance and the permselectivity on the maximum power density in a RED stack [8]. As such it provides a tool to compare the different anion and cation exchange membranes with respect to their performance in a RED stack.

\subsubsection{Power density as a function of membrane resistance and permselectivity}

Figure 6 presents a 3D figure showing the relationship between the membrane resistance, the membrane permselectivity, the power density and two different spacer thicknesses (a) $600 \mu \mathrm{m}$ and b) $150 \mu \mathrm{m}$ ). 

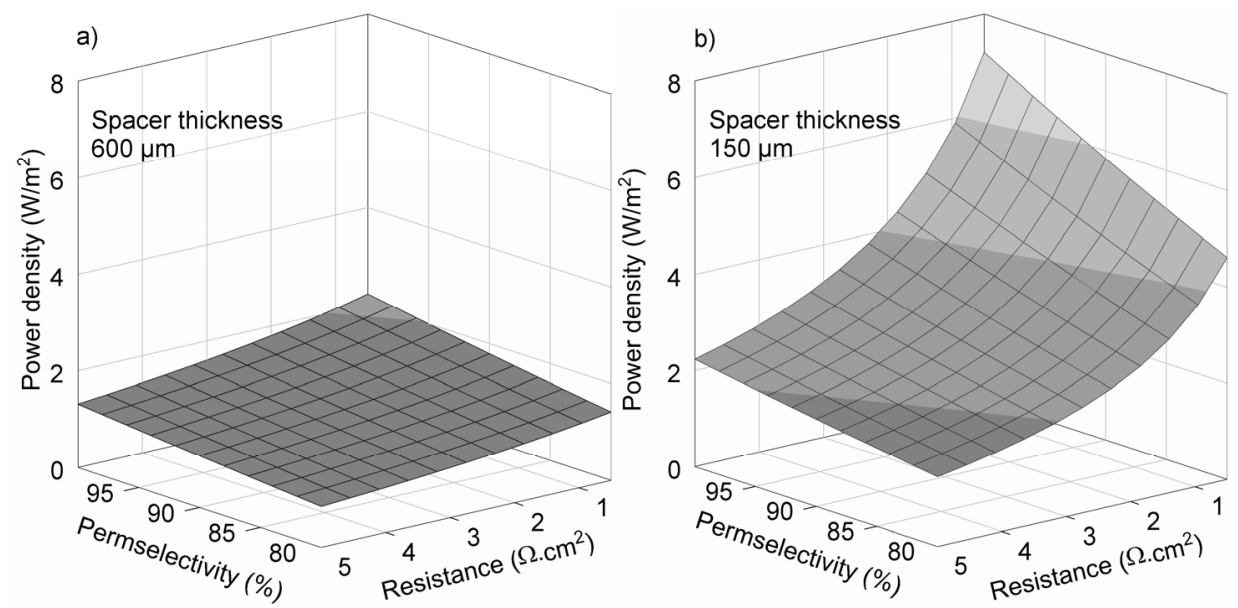

Figure 6: Relationship between the power density, the membrane permselectivity and the membrane cell pair resistance for membrane pair with a) $600 \mu \mathrm{m}$ and b) $150 \mu \mathrm{m}$ thick spacers. Model calculations are based on seawater $(0.5 \mathrm{M} \mathrm{NaCl})$ as concentrated salt solution and river water $(0.05 \mathrm{M} \mathrm{NaCl})$ as diluted stream $\left(\mathrm{T}=25^{\circ} \mathrm{C}\right)$.

Figure 6 clearly shows that the membrane resistance and permselectivity are of minor importance when thicker spacers are used. The power density is almost completely determined by the resistance of the dilute compartment with the spacer, and independent of the membrane properties. In this case the maximum obtainable theoretical power density is approximately $2 \mathrm{~W} / \mathrm{m}^{2}$. With thinner spacers however, the membrane properties do play a role and a large increase in power density (up to values of 6-7 W/m²) can be obtained at low membrane resistance and high permselectivities. Figure $6 \mathrm{~b}$ shows that with a low spacer thickness $(150 \mu \mathrm{m})$ between cation exchange and the anion exchange membrane, especially the membrane cell pair resistance becomes the dominant factor to generate energy. However, when the spacer thickness becomes too small, the pumping energy consumption will significantly increase due to the high pressure drop over the membranes and becomes the limiting factor in a RED process. According to this membrane model, which takes into account both the spacer thickness and the membrane properties, power densities even higher 
than $6 \mathrm{~W} / \mathrm{m}^{2}$ can be obtained by using thin spacers and tailor made membranes with low membrane resistance and high permselectivity especially designed for reverse electrodialysis.

\subsubsection{Calculated power density using experimental data}

Finally the theoretical membrane model for reverse electrodialysis is used to predict the theoretical power density with certain membrane type (anion or cation exchange membrane) obtainable using experimental membrane characterization data. To predict membrane stack power density it needs to be taken average value from both membrane power density predictions. The experimental data presented in Table 1 are used as input values in the theoretical reverse electrodialysis membrane model (Equation 6). It is assumed that sea water has a $\mathrm{NaCl}$ concentration of $0.5 \mathrm{M}\left(\gamma_{ \pm}=0.686\right.$ and $\left.\kappa_{c}=4.648 \mathrm{~S} \cdot \mathrm{m}^{-1}\right)$ and river water has a concentration of $0.05 \mathrm{M} \mathrm{NaCl}\left(\gamma_{ \pm}=0.820\right.$ and $\left.\kappa_{c}=0.551 \mathrm{~S} \cdot \mathrm{m}^{-1}\right)$. The temperature is assumed to be $25{ }^{\circ} \mathrm{C}$. Figure 7 shows the relationship between the power density and the membrane spacer thickness for various types of membranes (a) anion exchange membranes and b) cation exchange membranes). When thick spacers (> $600 \mu \mathrm{m})$ are used in the system, there are only minor differences between the power densities obtainable for various types of membranes. But when the distance between the membranes is decreased, the effect of the membrane properties and thus the difference in power density of the different membranes becomes more pronounced. The heterogeneous membranes have a too high membrane resistance to be useful in reverse electrodialysis. Even in a perfectly designed RED stack (thin spacer design) it is not possible to obtain power densities higher than $1.5 \mathrm{~W} / \mathrm{m}^{2}$. Homogeneous membranes are more suitable for reverse electrodialysis. 

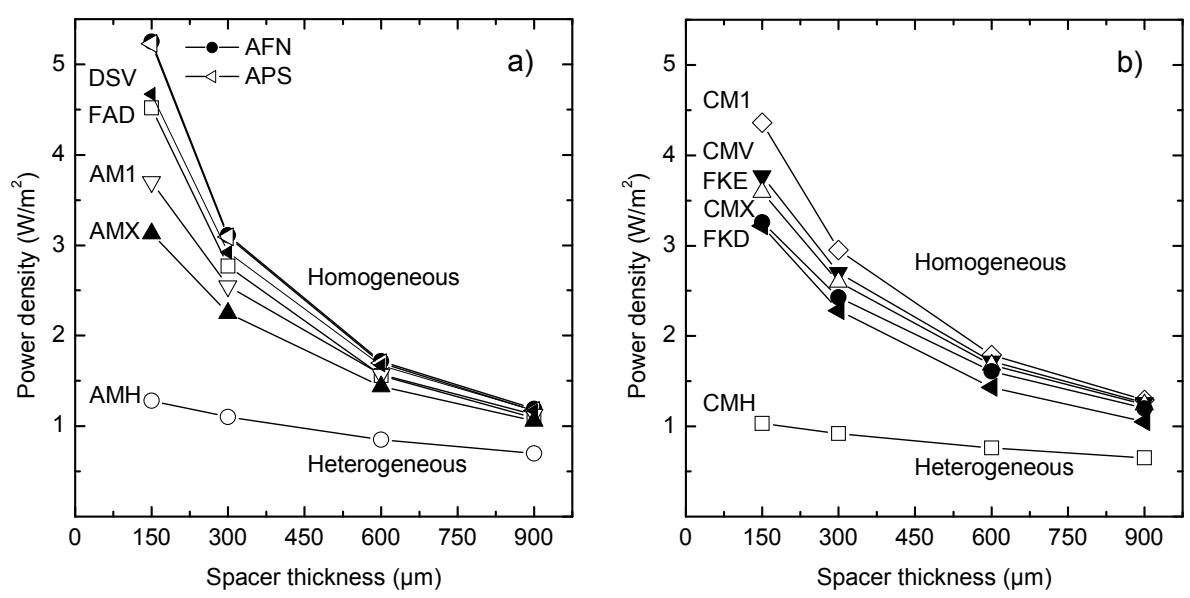

Figure 7: Prediction of the maximum obtainable power density based on experimental membrane characterization for a) anion exchange membranes and b) shows cation exchange membranes.

Based on these results the best benchmarked anion exchange membranes are Neosepta AFN from Tokuyama Co., (Japan) and Selemion APS from Asahi Glass Co., LTD, (Japan) with a predicted power density of more than $5 \mathrm{~W} / \mathrm{m}^{2}$ (at a spacer thickness of $150 \mu \mathrm{m})$. The Neosepta CM-1 cation exchange membrane from Tokuyama Co., (Japan) shows the best performance as cation exchange membrane for reverse electrodialysis and reaches a theoretical power density of more than $4 \mathrm{~W} / \mathrm{m}^{2}$. In practical application of RED other phenomena might limit the power output. For example: current leakage, concentration polarization and process temperature $[5,6,37,38]$. These phenomena depend on the RED membrane stack design (solution flow rate, thickness of spacers and shape of spacers) and region of application (temperature variation). The presented power output gives a maximal theoretical limit and is a good measure for the comparison of the various membrane types. 


\section{Conclusion}

This paper evaluates the potential of commercially available anion and cation exchange membranes for application in RED. Different membrane properties and characterization methods are discussed and a theoretical membrane model for RED was used to allow fair comparison of the characterization results for application in RED. The experimental membrane characterization experiments clearly show that the charge density has a strong influence on the permselectivity and the membrane resistance, but that there does not exist a straight forward relationship between these properties. In general cation exchange membranes have a higher charge density and a corresponding higher permselectivity than anion exchange membranes. Heterogeneous ion exchange membranes have a relatively low charge density compared to homogeneous membranes and a much higher resistance due to the membrane structure and the separation of charged domains in an uncharged polymer matrix.

The experimentally determined membranes characteristics are used as input value for the model calculations and the results suggest that the membrane resistance should be as low as possible, while the membrane selectivity is of minor importance. Based on the results, the best benchmarked anion exchange membranes are Neosepta AFN from Tokuyama Co., (Japan) and Selemion APS from Asahi Glass Co., LTD, (Japan) with a predicted power density of more than $5 \mathrm{~W} / \mathrm{m}^{2}$ (at a spacer thickness of $150 \mu \mathrm{m}$ ). The Neosepta CM-1 cation exchange membrane from Tokuyama Co., (Japan) shows the best performance as cation exchange membrane for reverse electrodialysis and reaches a theoretical power density of more than $4 \mathrm{~W} / \mathrm{m}^{2}$. According to the membrane model calculations, which take into account both the spacer thickness and the membrane properties, power densities higher than $6 \mathrm{~W} / \mathrm{m}^{2}$ can be obtained by using thin spacers and tailor made membranes with low membrane resistance and high permselectivity especially designed for reverse 
electrodialysis. This makes RED a potentially attractive alternative for energy production.

\section{Acknowledgements}

This work was performed at Wetsus, Centre for Sustainable Water Technology. Wetsus is funded by the city of Leeuwarden, the Province of Fryslan, the European Union European Regional Development Fund and by the EZ-KOMPAS Program of the "Samenwerkingsverband Noord/Nederland". The industrial participants of Wetsus research theme Energy (Nuon B.V., MAGNETO special anodes B.V., Triqua B.V., Landustrie SNEEK B.V., Frisia Zout B.V., Waterleidingmaatschappij Drenthe, Waterbedrijf Groningen and Waterlaboratorium Noord) are highly acknowledged for their financial support. 


\section{List of symbols}

\begin{tabular}{|c|c|}
\hline$\alpha$ & Permselectivity (\%) \\
\hline A & Membrane area $\left(\mathrm{m}^{2}\right)$ \\
\hline ac & Concentrated solution activity (-) \\
\hline ad & Diluted solution activity (-) \\
\hline Cfix & Fixed charge (mol/l) \\
\hline $\mathrm{F}$ & Faraday constant (96485 C/mol) \\
\hline $\mathrm{i}$ & Current density $\left(\mathrm{A} / \mathrm{m}^{2}\right)$ \\
\hline I & Current (A) \\
\hline $\mathrm{N}$ & Number of membranes (-) \\
\hline $\mathrm{R}$ & Gas constant $(8.314 \mathrm{~J} /(\mathrm{mol} \cdot \mathrm{K}))$ \\
\hline Raem & Anion exchange membrane resistance $\left(\Omega \cdot \mathrm{cm}^{2}\right)$ \\
\hline Rcem & Cation exchange membrane resistance $\left(\Omega \cdot \mathrm{cm}^{2}\right)$ \\
\hline$R_{c}$ & Concentrated solution resistance $(\Omega)$ \\
\hline $\mathrm{R}_{\mathrm{d}}$ & Diluted solution resistance $(\Omega)$ \\
\hline Rel & Electrode resistance $(\Omega)$ \\
\hline Rload & Load resistance $(\Omega)$ \\
\hline $\mathrm{R}_{\text {stack }}$ & Resistances of the stack $(\Omega)$ \\
\hline $\mathrm{T}$ & Absolute temperature $(\mathrm{K})$ \\
\hline $\mathrm{V}^{0}$ & Stack open circuit potential (V) \\
\hline$\Delta \mathrm{V}_{\text {theo }}$ & Theoretical membrane potential (V) \\
\hline$\Delta \mathrm{V}_{\text {meas }}$ & Measured membrane potential (V) \\
\hline $\mathrm{w}$ & Power density $\left(\mathrm{W} / \mathrm{m}^{2}\right)$ \\
\hline$W_{\max }$ & Maximum power output (W) \\
\hline
\end{tabular}


Current status of ion exchange membranes for reverse electrodialysis

\section{Nomenclature}

$\begin{array}{ll}\text { AEM } & \text { Anion exchange membrane } \\ \text { CEM } & \text { Cation exchange membrane } \\ \text { RED } & \text { Reverse Electrodialysis } \\ \text { PRO } & \text { Pressure retarded osmosis } \\ \text { SD } & \text { Swelling degree (gH2O/gdry }) \\ \text { IEC } & \text { Ion exchange capacity (meq/g) }\end{array}$

\section{References}

1. IPCC, Climate Change 2007: The Physical Science Basis, Summary for Policymakers. 2007.

2. S. Loeb, Production of energy from concentrated brines by pressure retarded osmosis. I. Preliminary technical and economic correlations, Journal of Membrane Science 1 (1976) 49.

3. K. L. Lee, R. W. Baker, H. K. Lonsdale, Membranes for power generation by pressure-retarded osmosis, Journal of Membrane Science 8 (1981) 141-171.

4. R. E. Pattle, Production of Electric Power by mixing Fresh and Salt Water in the Hydroelectric Pile, Nature 174 (1954) 660.

5. J. W. Post, J. Veerman, H. V. M. Hamelers, G. J. W. Euverink, S. J. Metz, K. Nymeijer, C. J. N. Buisman, Salinity-gradient power: Evaluation of pressure-retarded osmosis and reverse electrodialysis, Journal of Membrane Science 288 (2007) 218-230.

6. G. Lagger, H. Jensen, J. Josserand, H. H. Girault, Hydro-voltaic cells: Part I. Concentration cells, Journal of Electroanalytical Chemistry 545 (2003) 1.

7. R. Audinos, Electric power produced from two solutions of unequal salinity by reverse electrodialysis, Indian Journal of Chemistry 31A (1992) 348-354.

8. J. N. Weinstein, F. B. J. W. Leitz, Electric power from differences in salinity: the dialytic battery, Science 191 (1976) 557-559. 
9. R.E. Lacey, Energy by Reverse Electrodialysis, Ocean Engng. 7 (1980) 147.

10. R. K. J. Jagur-Grodzinski, Novel Process for Direct Conversion of Free Energy of Mixing into Electric Power Ind. Eng. Chem. Process Des. Dev. (1986) 443-449.

11. M. Turek, B. Bandura, Renewable energy by reverse electrodialysis, Desalination 205 (2007) 67.

12. F. Suda, T. Matsuo, D. Ushioda, Transient changes in the power output from the concentration difference cell (dialytic battery) between seawater and river water, Energy 32 (2007) 165-173.

13. S. Koter, Influence of the layer fixed charge distribution on the performance of an ion-exchange membrane, Journal of Membrane Science 108 (1995) 177.

14. F. Helfferich, Ion Exchange, Edition, McGraw Hill, New York, 1962.

15. K. Urano, Y. Masaki, M. Kawabata, Electric resistances of ion-exchange membranes in dilute solutions, Desalination 58 (1986) 171.

16. X. Tongwen, Y. Weihua, Fundamental studies of a new series of anion exchange membranes: membrane preparation and characterization, Journal of Membrane Science 190 (2001) 159.

17. F. G. Wilhelm, I. G. M. Punt, N. F. A. van der Vegt, H. Strathmann, M. Wessling, Cation permeable membranes from blends of sulfonated poly(ether ether ketone) and poly(ether sulfone), Journal of Membrane Science 199 (2002) 167.

18. P. Xing, G. P. Robertson, M. D. Guiver, S. D. Mikhailenko, K. Wang, S. Kaliaguine, Synthesis and characterization of sulfonated poly(ether ether ketone) for proton exchange membranes, Journal of Membrane Science 229 (2004) 95.

19. R. K. Nagarale, G. S. Gohil, V. K. Shahi, R. Rangarajan, Preparation and electrochemical characterizations of cation-exchange membranes with different functional groups, Colloids and Surfaces A: Physicochemical and Engineering Aspects 251 (2004) 133.

20. Y. Mizutani, Structure of ion exchange membranes, Journal of Membrane Science 49 (1990) 121. 
21. J. Schauer, L. Brozova, Z. Pientka, K. Bouzek, Heterogeneous ionexchange polyethylene-based membranes with sulfonated poly(1,4phenylene sulfide) particles, Desalination 200 (2006) 632.

22. G. E. Molau, Heterogeneous ion-exchange membranes, Journal of Membrane Science 8 (1981) 309-330.

23. H. Strathmann, Membrane Science and Technology Ion-Exchange Membrane Separation Processes, 9, 1 ${ }^{\text {st }}$ Edition, Elsevier, 2004.

24. T. Sata, Ion Exchange Membranes, Edition, The Royal Society of Chemistry Cambrige, 2004.

25. T. Xu, K. Hu, A simple determination of counter-ionic permselectivity in an ion exchange membrane from bi-ionic membrane potential measurements: permselectivity of anionic species in a novel anion exchange membrane, 40 (2004) 231.

26. J. Balster, O. Krupenko, I. Punt, D. F. Stamatialis, M. Wessling, Preparation and characterisation of monovalent ion selective cation exchange membranes based on sulphonated poly(ether ether ketone), Journal of Membrane Science 263 (2005) 137.

27. F. G. Wilhelm, N. F. A. van der Vegt, M. Wessling, H. Strathmann, Chronopotentiometry for the advanced current-voltage characterisation of bipolar membranes, Journal of Electroanalytical Chemistry 502 (2001) 152-166.

28. J. J. Krol, M. Wessling, H. Strathmann, Concentration polarization with monopolar ion exchange membranes: current-voltage curves and water dissociation, Journal of Membrane Science 162 (1999) 145-154.

29. Selemion, Ion exchange membranes Product Brochure Asahi Glass Co., Ltd., Japan.

30. Ralex, Ion exchanges membranes, Product Brochure Mega a.s., Czech Rep.

31. Neosepta, Ion exchange membranes Product Brochure Tokuyama Co., Japan.

32. Fumasep, Ion exchange membranes, Product Brochure FuMA-Tech $\mathrm{GmbH}$, Germany. 
33. V. I. Zabolotsky, V. V. Nikonenko, Effect of structural membrane inhomogeneity on transport properties, Journal of Membrane Science 79 (1993) 181.

34. P. V. Vyas, B. G. Shah, G. S. Trivedi, P. Ray, S. K. Adhikary, R. Rangarajan, Characterization of heterogeneous anion-exchange membrane, Journal of Membrane Science 187 (2001) 39.

35. T.-J. Chou, A. Tanioka, Ionic behavior across charged membranes in methanol-water solutions. I: Membrane potential, Journal of Membrane Science 144 (1998) 275.

36. F. G. Wilhelm, I. G. M. Punt, N. F. A. van der Vegt, H. Strathmann, M. Wessling, Cation permeable membranes from blends of sulfonated poly(ether ether ketone) and poly(ether sulfone), Journal of Membrane Science 199 (2002) 167-176.

37. I. Rubinstein, J. Pretz, E. Staude, Open circuit voltage in a reverse electrodialysis cell, Physical Chemistry Chemical Physics 3 (2001) 1666.

38. R. Ibanez, D. F. Stamatialis, M. Wessling, Role of membrane surface in concentration polarization at cation exchange membranes, Journal of Membrane Science 239 (2004) 119-128. 
Current status of ion exchange membranes for reverse electrodialysis 


\title{
Chapter 3
}

\section{Transport limitations in ion exchange membranes at low salt concentrations}

\begin{abstract}
In this work we show that the resistance of ion exchange membranes strongly depends on the solution concentration: especially at low solution concentrations $(<0.1 \mathrm{M} \mathrm{NaCl})$ we observe a very strong increase in electrical resistance of the membrane with decreasing concentration. To understand and clarify this behavior we systematically investigate the influence of the solution concentration on ion transport phenomena in two anion exchange membranes (Neosepta AMX and Fumasep FAD) and two cation exchange membranes (Neosepta CMX and Fumasep FKD) in the concentration range from 0.017 M to $0.5 \mathrm{M} \mathrm{NaCl}$ and for different hydrodynamic conditions. The results are highly valuable for processes that operate in the low concentration range $(<0.5 \mathrm{M})$ such as reverse electrodialysis, electrodialysis, microbial fuel cells and capacitive deionization, where the standard membrane characterization values as usually determined in $0.5 \mathrm{M} \mathrm{NaCl}$ solutions do not represent the practical application.
\end{abstract}

Scientific publication:

P. Dlugolecki, A. Benoit, S. J. Metz, K. Nijmeijer, M Wessling, Transport limitations in ion exchange membranes at low salt concentrations, accepted for publication in Journal of Membrane Science 2009. 


\section{Introduction}

Ion exchange membranes are widely used in processes such as electrodialysis, diffusion dialysis, capacitive deionization and Donnan dialysis. Recently also the application of ion exchange membranes for energy generation from e.g. the mixing of fresh and salt water in a process called reverse electrodialysis or from wastewater in microbial fuel cells gained attention [1-8]. Reverse electrodialysis (RED) is a non-polluting, sustainable method for energy generation by controlled mixing of fresh and salt water. RED converts the free energy of mixing of a concentrated and a diluted salt solution into electrical power through an alternating series of anion and cation exchange membranes. RED can be applied wherever two solutions of different salinity are mixed, e.g. where river water flows into the sea $[1-4,8]$.

Membrane properties and especially the electrical resistance of the membrane, or membrane resistance in short, can have significant impact on the overall RED stack performance $[9,10]$. In most literature, it is assumed that the membrane resistance is independent of the concentration and corresponds to the value determined in a standard characterization solution $(0.5 \mathrm{M} \mathrm{NaCl})[2,8$ 12]. Veerman et al. performed a study on the shortcut current losses in the RED process, assuming that the membrane resistance is independent of the salt concentration [10]. The measured cell resistances were about a factor two higher than the calculated values, which made the authors to hypothesize that especially at low concentrations, membrane resistance can not be considered independent of the concentration. The effect of strongly increasing resistance at lower concentrations was also observed in biological fuel cells, where ion exchange membranes are applied as separators, between the anode and cathode compartment [13].

The concentration dependence of the membrane resistance, especially at lower salt concentrations $(<0.5 \mathrm{M} \mathrm{NaCl})$ is hardly studied in literature and only few papers exist that address this topic [14-16], although it can 
significantly affect the performance of ion exchange membrane processes that use solutions in the low salt concentration range $[9,15]$.

This work investigates the influence of the solution concentration on ion transport phenomena in ion exchange membranes. The relationship between the membrane resistance, the limiting current density and the counter ion transport number of commercially available membranes in the concentration range of $0.017 \mathrm{M}-0.5 \mathrm{M} \mathrm{NaCl}$ and at various hydrodynamic conditions is investigated. The results are highly valuable for electromembrane processes operating at low salt concentrations, such as reverse electrodialysis, microbiological fuel cells, electrodialysis and capacitive deionization.

\section{Theoretical background}

Ion exchange membranes are membranes with fixed anionic or cationic exchange groups that are able to transport either cations or anions. The distribution and concentration of these charged groups determines specific membrane properties such as membrane resistance and permselectivity. Current-voltage curves and chronopotentiometry are effective tools to investigate membrane properties and to study the transport of ions through ion exchange membranes [17-24].

\subsection{Current-voltage curves}

A current-voltage curve reflects the relationship between the current through a membrane and the corresponding voltage drop over that membrane and the adjacent boundary layers, thus providing information about the resistance of the system against ion transport, the influence of the nature of the membrane on the limiting current density, and the thickness of the boundary layer $[18,25,26]$. It can be used to determine the membrane resistance, the limiting current density and the boundary layer thickness of a system containing an ion exchange membrane. 
Figure 1 shows a typical example of an experimentally determined I-V curve [21].

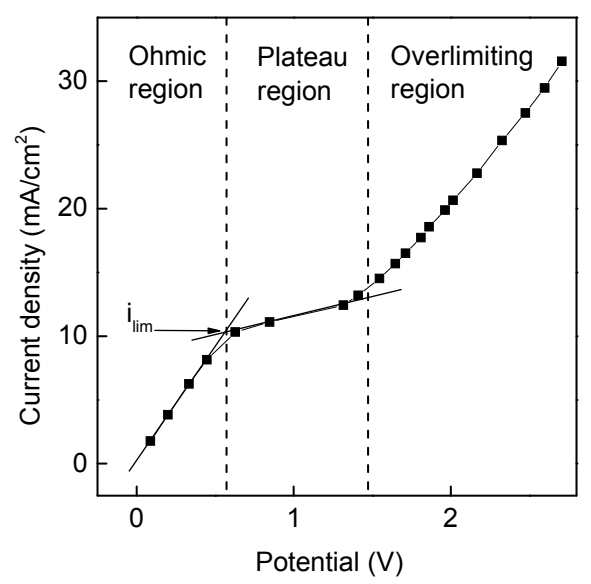

Figure 1: Typical example of a current-voltage curve, reflecting the relationship between the current through a membrane and the corresponding voltage drop over that membrane and its boundary layers.

Three regions can be distinguished in the current-voltage curve. In the first region, at low current densities, a linear relationship exists between the current and the voltage drop over the membrane. This region is generally called the ohmic region and allows the extraction of the ohmic (membrane) resistance. When the so-called limiting current density is reached, the current density reaches a plateau value, after which the current density increases again. The latter part of the current voltage curve is called the overlimiting region; it is the region where electroconvection occurs [18, 27-30].

The limiting current density $\mathrm{i}_{\mathrm{lim}}\left(\mathrm{A} / \mathrm{m}^{2}\right)$ is dependent on the bulk solution concentration $\mathrm{C}^{\mathrm{b}}(\mathrm{mol} / \mathrm{l})$, the salt diffusion coefficient $\mathrm{D}\left(\mathrm{m}^{2} / \mathrm{s}\right)$, the boundary layer thickness $\delta(\mathrm{m})$, the counter ion transport number in the solution $\mathrm{t}^{\mathrm{s}} \mathrm{cou}(-)$, the counter ion transport number in the membrane $\left(\mathrm{t}^{\mathrm{m}}\right.$ cou $\left.(-)\right)$ and the Faraday constant $\mathrm{F}(\mathrm{A} \cdot \mathrm{s} / \mathrm{mol})$ : 
$i_{\lim }=\frac{F \cdot C^{b} \cdot D}{\delta\left(t_{c o u}^{m}-t_{c o u}^{s}\right)}$

The ion transport number of a certain ion is defined as the current carried by that specific ion relative to the total current. In case of a $100 \%$ permselective membrane, all current in the membrane is carried by the counter ions, which thus has a membrane transport number of 1 . Consequently, the co-ions in the membrane have a transport number of 0 .

\subsection{Chronopotentiometry}

Chronopotentiometry is an electrochemical technique that is frequently used to investigate kinetic effects, adsorption, and transport phenomena near electrode surfaces [17, 19, 31, 32]. Apart from their permselectivity, ion exchange membranes behave analogously to electrodes, so the method can also be used to study membrane properties [17, 19, 22, 31-33].

When an electrical current is imposed to a system with an ion exchange membrane, ion transport and consequently concentration polarization near the membrane occurs until a steady state is reached. When a constant current density is imposed to the system, this process can be visualized as a change in voltage drop over the membrane in time. Differences in electrical potential indicate differences in ion transport behavior. Chronopotentiometry therefore yields insight in ion transport processes in the membrane and in the adjacent solutions [19, 33]. Figure 2 shows a typical example of a chronopotentiometry measurement for an ion exchange membrane in a $0.1 \mathrm{M} \mathrm{NaCl}$ solution [19]. The initial sharp increase in the voltage, indicated as Part 1 , is due to the initial ohmic resistance of the solution and membrane between the tips of the voltagemeasuring capillaries. 


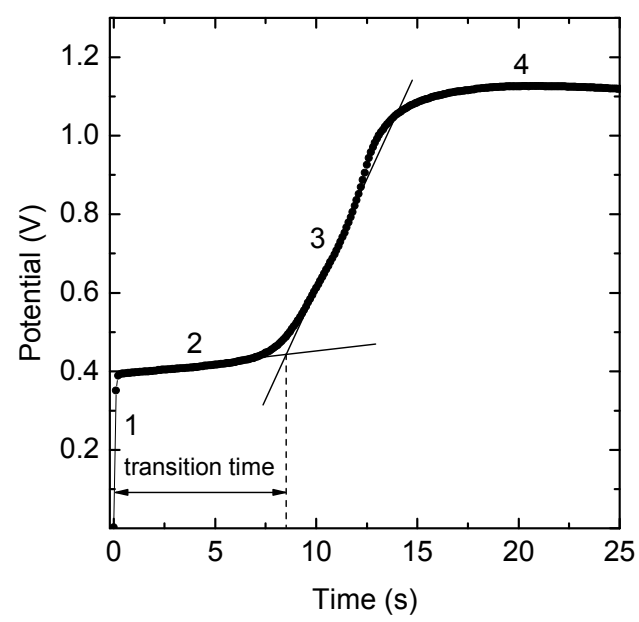

Figure 2: Example of a chronopotentiometric curve measured at $0.1 \mathrm{M} \mathrm{NaCl}$.

After this initial sharp increase, a very slow increase in voltage caused by the ohmic resistance is observed (Part 2). After a specific period of time, the socalled transition time as will be explained below, this is followed by a strong increase in voltage (Part 3) caused by the boundary layer resistance (concentration polarization in the solution, at the ion exchange membrane). The point at which this increase starts is at the end of the transition time, and can be determined from the intersection of the tangents of parts 2 and 3 of the curve. The last (4) part of the curve is reached when the voltage levels off.

During chronopotentiometry measurements, the concentration in the solution at the membrane surface decreases in time and after a certain amount of time (known as the transition time $\tau(\mathrm{s})$ ), it reaches zero. The transition time, as a function of applied current density, can be obtained from Equation 2, which is equivalent to Sand's equation [19]:

$\tau=\frac{\pi \mathrm{D}}{4}\left(\frac{\mathrm{C}_{\mathrm{o}} \mathrm{zF}}{t_{c o u}^{m}-t_{c o u}^{s}}\right)^{2} \frac{1}{\mathrm{i}^{2}}$ 
Where $\mathrm{C}_{0}$ is the concentration at time zero $(\mathrm{mol} / \mathrm{l}), \mathrm{z}$ the electrochemical valence $(-)$, F the Faraday constant $(\mathrm{A} \cdot \mathrm{s} / \mathrm{mol}), \mathrm{t}_{\mathrm{cou}}^{\mathrm{s}}(-)$ the counter ion transport number in the solution and $\mathrm{t}^{\mathrm{m}_{\mathrm{cou}}}(-)$ the ion transport number in the membrane, $\mathrm{D}$ the diffusion coefficient $\left(\mathrm{m}^{2} / \mathrm{s}\right)$, and $\mathrm{i}$ the current density $\left(\mathrm{A} / \mathrm{m}^{2}\right)$. The Equation shows that the transition time increases with decreasing membrane transport number, i.e. a less permselective membrane has a longer transition time. Because the transition time at each specific current density can be extracted from the chronopotentiometry plot, this Equation can be used to calculate the ion transport number in the membrane.

\subsection{Ion transport model}

Although the counter ion transport number in the ion exchange membrane can be determined experimentally from chronopotentiometry measurements, model calculations are a useful tool to predict transport numbers and to understand complex ion transport phenomena. These calculations can be done on the basis of the Donnan equilibrium theory, according to which cations pass through the cation exchange membrane as counter ions whereas anions (co-ions) are rejected [34,35] (exactly the opposite occurs for anion exchange membranes). The Donnan equilibrium equation [34] equals:

$\ln \left[\left(\frac{a_{a}}{\bar{a}_{a}}\right)^{v_{a}} \cdot\left(\frac{a_{c}}{\bar{a}_{c}}\right)^{v_{c}}\right]=\frac{V_{a c}}{V_{w}} \ln \left(\frac{a_{w}}{\bar{a}_{w}}\right)$

Where the symbol a is the activity in the solution and $\bar{a}$ is the activity in the membrane, $v_{a}$ is the number of moles of anions, $v_{c}$ is the number of moles of cations and $\mathrm{V}$ is the partial molar volume of either the electrolyte (subscript ac) or water (subscript $\mathrm{w}$ ). The subscript a refers to anion, c to cation, ac to the electrolyte and $\mathrm{w}$ to water. 
When $\mathrm{V}_{\mathrm{ac}} / \mathrm{V}_{\mathrm{w}}$ equals the activity coefficient $\gamma$, Equation 3 changes into the Donnan membrane equilibrium equation:

$$
\frac{\bar{a}_{a}^{v_{a}} \cdot \bar{a}_{c}^{v_{c}}}{\bar{a}_{w}^{\gamma}}=\frac{a_{a}^{v_{a}} \cdot a_{c}^{v_{c}}}{a_{w}^{\gamma}}
$$

When $\bar{a}_{w} \approx \mathrm{a}_{w}$ and the activity coefficient is assumed to be equal to 1 (which is a reasonable assumption in the case of diluted salt solutions), the distribution of $\mathrm{Na}^{+}$and $\mathrm{Cl}$-ions between the membrane and the solution for a cation exchange membrane equilibrated with an aqueous sodium chloride solution, can be expressed as [34]:

$$
C_{N a}^{m} \cdot C_{C l}^{m}=C_{N a} \cdot C_{C l}
$$

Where $\mathrm{C}^{\mathrm{m}} \mathrm{Na}$ is the concentration of sodium ions in the membrane $(\mathrm{mol} / \mathrm{l}), \mathrm{C}^{\mathrm{m}} \mathrm{Cl}$ is the concentration of chloride ions in the membrane $(\mathrm{mol} / \mathrm{l}), \mathrm{C}_{\mathrm{Na}}$ is the concentration of sodium ions in the solution (mol/l) and $\mathrm{Ccl}$ is the concentration of chloride ions in the solution ( $\mathrm{mol} / \mathrm{l})$

For a system consisting of a membrane and solution, electroneutrality requires that:

$$
C_{N a}^{m}=C_{f i x}+C_{C l}^{m}
$$

Here, $\mathrm{C}^{\mathrm{m}} \mathrm{Na}$ is the concentration of sodium ions in the membrane $(\mathrm{mol} / \mathrm{l}), \mathrm{C}^{\mathrm{m}} \mathrm{Cl}$ is the concentration of chloride ions in the membrane $(\mathrm{mol} / \mathrm{l})$ and $\mathrm{C}_{\mathrm{fix}}$ is the concentration of fixed (negative) charges in the membrane, attached to polymer backbone (eq./l).

Combination of Equation 5 and 6 subsequently allows the calculation of the two unknowns in these equations, i.e. $\mathrm{C}^{\mathrm{m}_{\mathrm{Na}}}$ and $\mathrm{C}^{\mathrm{m}} \mathrm{Cl}$ [34]: 


$$
\begin{aligned}
& C_{N a}^{m}=\frac{1}{2}\left(\sqrt{C_{f i x}+4 C_{N a} C_{C l}}+C_{f i x}\right) \\
& C_{C l}^{m}=\frac{1}{2}\left(\sqrt{C_{f i x}+4 C_{N a} C_{C l}}-C_{f i x}\right)
\end{aligned}
$$

The ion concentrations in the membrane calculated from Equations 7 and 8 can be finally used to calculate the required ion transport numbers of sodium and chloride in the membrane using Equation 9 and 10 [34]:

$t_{N a}^{m}=\frac{u_{N a}^{m} C_{N a}^{m}}{u_{N a}^{m} C_{N a}^{m}+u_{C l}^{m} C_{C l}^{m}}$

$t_{C l}^{m}=\frac{u_{C l}^{m} C_{C l}^{m}}{u_{C l}^{m} C_{C l}^{m}+u_{N a}^{m} C_{N a}^{m}}$

Here, $\mathrm{t}^{\mathrm{m}} \mathrm{Na}$ is the sodium ion transport number in the membrane phase $(-), \mathrm{t}^{\mathrm{m}} \mathrm{Cl}$ is the chloride ion transport number in the membrane phase $(-), \mathrm{u}^{\mathrm{m}_{\mathrm{Na}}}$ is the mobility of sodium in the membrane phase $\left(\mathrm{m}^{2} /(\mathrm{V} \cdot \mathrm{s})\right)$ and $\mathrm{u}^{\mathrm{m}} \mathrm{Cl}$ is the mobility of chloride in the membrane phase $\left(\mathrm{m}^{2} /(\mathrm{V} \cdot \mathrm{s})\right)$ and $\mathrm{C}_{\mathrm{fix}}$ is the concentration of the fixed ion exchange groups in the membrane (eq./l).

\section{Experimental part}

\subsection{Membranes}

Two cation exchange membranes (Neosepta CMX and Fumasep FKD) and two anion exchange membranes (Neosepta AMX and Fumasep FAD) were used for the experiments. The Neosepta membranes (AMX and CMX) were supplied by Tokuyama Soda Inc. (Japan) and Fumasep membranes (FAD and FKD) were acquired from Fuma-Tech GmbH (Germany). All membranes are homogenous membranes. Homogenous membranes have good electrochemical 
properties in terms of low membrane resistance and relatively high selectivity compared to heterogeneous ion exchange membranes [9].

The Neosepta membranes are widely studied ion exchange membranes. They are mostly used in electrodialysis processes and are especially designed to have high mechanical strength [36]. The Fumasep membranes are especially manufactured for dialysis processes [37]. Table 1 summarizes the main characteristics as determined in our previous work [9]. Detailed membrane characteristics can be found elsewhere $[9,36,38]$. Because the FAD membranes not only consists of strong ion exchange groups, but also contain weak acidic groups, the measured ion exchange capacity differs from the manufacturer's value [9].

Table 1: Experimentally determined membrane characteristics [9, 36, 38].

\begin{tabular}{|c|c|c|c|c|c|c|}
\hline Membrane & $\begin{array}{c}\text { IEC } \\
\text { (meq/g dry) }\end{array}$ & $\begin{array}{c}\text { Permselectivity } \\
(\%)\end{array}$ & $\begin{array}{l}\text { Resistance }^{\mathrm{b}} \\
\quad\left(\Omega \cdot \mathrm{cm}^{2}\right)\end{array}$ & $\begin{array}{l}\text { SD } \\
(\%)\end{array}$ & $\begin{array}{l}\text { Thickness } \\
(\mu \mathrm{m})\end{array}$ & Properties \\
\hline \multicolumn{7}{|l|}{ Fumasep ${ }^{\circledR}$} \\
\hline $\begin{array}{l}\text { FAD } \\
\text { anion } \\
\text { exchange }\end{array}$ & 0.13 & 86.0 & 0.89 & 34 & 74 & $\begin{array}{l}\text { Diffusion } \\
\text { dialysis for } \\
\text { acid }\end{array}$ \\
\hline $\begin{array}{l}\text { FKD } \\
\text { cation } \\
\text { exchange }\end{array}$ & 1.14 & 89.5 & 2.14 & 29 & 113 & $\begin{array}{l}\text { Diffusion } \\
\text { dialysis for } \\
\mathrm{NaOH}\end{array}$ \\
\hline \multicolumn{7}{|l|}{ Neosepta $^{\circledR}$} \\
\hline $\begin{array}{l}\text { AMX } \\
\text { anion } \\
\text { exchange }\end{array}$ & 1.25 & 90.7 & 2.35 & 16 & 134 & $\begin{array}{l}\text { High } \\
\text { mechanical } \\
\text { strength }\end{array}$ \\
\hline $\begin{array}{l}\text { CMX } \\
\text { cation } \\
\text { exchange }\end{array}$ & 1.62 & 99.0 & 2.91 & 18 & 164 & $\begin{array}{l}\text { High } \\
\text { mechanical } \\
\text { strength }\end{array}$ \\
\hline
\end{tabular}

a) Membrane potential measured over the membrane between a $0.5 \mathrm{M}$ and a $0.1 \mathrm{M}$ solution.

b) Measured in $0.5 \mathrm{M} \mathrm{NaCl}$ solution at $25^{\circ} \mathrm{C}$. 


\subsection{Experimental setup}

Current-voltage curves and chronopotentiometry data were obtained with the setup presented in Figure 3 [9].

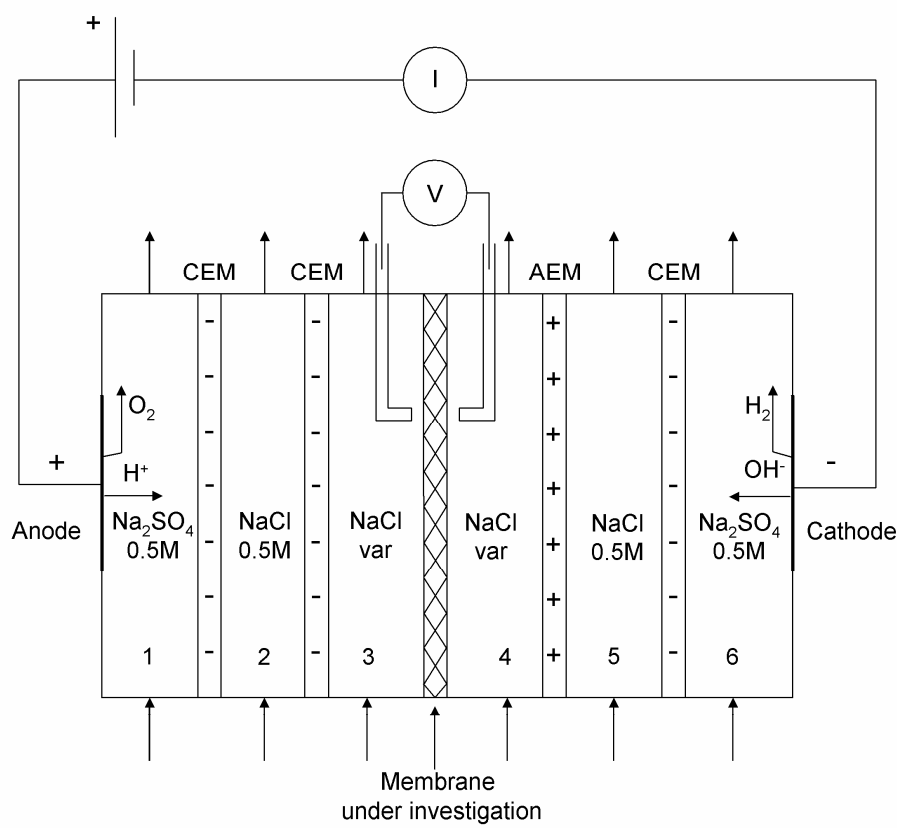

Figure 3: Schematic diagram of the six-compartment cell used to perform current-voltage and chronopotentiometry measurements; CEM is a cation exchange membrane, AEM is an anion exchange membrane, $\mathrm{V}$ is the potential difference over the Haber-Luggin capillaries (V) and I is the electrical current (A) [9].

This setup was made of PMMA poly(methyl 2-methylpropenoate) and consisted of six separate compartments with a total solution volume of $2 \mathrm{dm}^{3}$ per compartment [9]. The membrane under investigation had an effective area of $2.835 \mathrm{~cm}^{2}$ and was equilibrated with the measuring solution for at least 24 hours. Using a smaller membrane area prevents the membrane bulging out and reduces the current density applied on the planar auxiliary electrodes. The other four membranes were auxiliary ion exchange membranes produced by Mega a.s. (Czech Republic). The area of the auxiliary membranes in the cell was 
$23.8 \mathrm{~cm}^{2}$. The experimental set-up is described in more detail in our previous research [9].

Measurements with various sodium chloride concentrations were carried out with a potentiostat/galvanostat apparatus (Iviumstat, The Netherlands), which applied a fixed current density and simultaneously measured the voltage drop over the membrane under investigation. In both compartments adjacent to the central membrane (compartments 3 and 4), a solution with a concentration in a range of $0.017 \mathrm{M}$ to $0.5 \mathrm{M} \mathrm{NaCl}$ (analytical grade, Boom B.V., The Netherlands) was used. For comparison, the standard concentrations we use to represent sea and river water are respectively $0.5 \mathrm{M}$ $\mathrm{NaCl}$ (sea water) and $0.017 \mathrm{M} \mathrm{NaCl}$ (river water).

\subsection{Determination of ion transport numbers}

Chronopotentiometry was used to determine ion transport numbers in the membrane as a function of the salt concentration and the hydrodynamic conditions. A fixed current density was applied through the six-compartment cell (Figure 3) for 40 seconds and the voltage drop over the membrane under investigation was measured as a function of time (10 measurements per second). The conductivity of the solutions adjacent to the membrane under investigation was monitored continuously. The temperature of the system was controlled by a thermostat bath and set at $25 \pm 0.1^{\circ} \mathrm{C}$.

\subsection{Determination of resistance and limiting current density}

Current-voltage measurements were conducted to determine the ohmic resistance and the limiting current density. To determine the limiting current density the six compartment cell with a galvanostatic linear sweep characterization method was used. The current scan rate at low concentrations $(0.017 \mathrm{M}, 0.05 \mathrm{M}$ and $0.1 \mathrm{M} \mathrm{NaCl})$ was $1 \mathrm{~mA} / \mathrm{s}$ with $0.05 \mathrm{~mA}$ current steps. At 
higher solution concentrations $(0.3 \mathrm{M}$ and $0.5 \mathrm{M} \mathrm{NaCl})$, the scan rate was 2 $\mathrm{mA} / \mathrm{s}$ and $5 \mathrm{~mA} / \mathrm{s}$, respectively. All experiments were performed at $25 \pm 0.1^{\circ} \mathrm{C}$.

The membrane resistance was determined in the same six compartment cell and current-voltage curves of three membrane samples of each membrane were recorded for eight current steps below the limiting current density. To measure at steady state conditions each current step was measured for 60 seconds. For the lowest concentration $(0.017 \mathrm{M} \mathrm{NaCl})$, the current steps were $0.35,0.53,0.71,0.88,1.06,1.23,1.41,1.59$ and $1.76 \mathrm{~mA} / \mathrm{cm}^{2}$. The limiting current density at this concentration was in the range of 2 to $6 \mathrm{~mA} / \mathrm{cm}^{2}$, depending on the membrane type and solution flow rate. At higher $\mathrm{NaCl}$ concentrations $(0.1 \mathrm{M}$ to $0.5 \mathrm{M} \mathrm{NaCl})$, the current steps were from $1 \mathrm{~mA} / \mathrm{cm}^{2}$ to $10 \mathrm{~mA} / \mathrm{cm}^{2}$. The conductivity of the solutions was monitored simultaneously during all experiments. All experiments were performed at $25 \pm 0.1^{\circ} \mathrm{C}$.

\subsection{Swelling degree}

The swelling degree of the cation and anion exchange membranes was measured by immersing the membrane in demineralized water and in various $\mathrm{NaCl}$ solutions $(0-1 \mathrm{M} \mathrm{NaCl})$ at room temperature for at least 24 hours. The samples were then removed from the solution, the surface water was removed with blotting paper, and the weight and wet thickness of the membrane samples were determined. Subsequently, the membranes were dried in an oven at $50{ }^{\circ} \mathrm{C}$ for a period of 48 hours, after which the dry weight, mdry, was obtained. The swelling degree SD (\%) is given as the ratio of the amount of absorbed water $m_{\text {wet- }} \mathrm{m}_{\mathrm{dry}}(\mathrm{g})$ and the dry weight of the membrane (g) (Equation 11) [39]:

$$
\mathrm{SD}=\frac{\mathrm{m}_{\text {wet }}-\mathrm{m}_{\text {dry }}}{\mathrm{m}_{\text {dry }}} \cdot 100 \%
$$




\section{Results and discussion}

\subsection{Membrane resistance}

An important property of membranes used for ion exchange processes is their membrane resistance. The membranes used in this research are selected because of their relatively low membrane resistance and relatively high selectivity. Usually membrane resistances are determined at standard conditions i.e. in $0.5 \mathrm{M} \mathrm{NaCl}$ solutions [9]. For many applications this is sufficient, but for processes like reverse electrodialysis, microbial fuel cells, electrodialysis (for brackish water and sea water desalination) and capacitive deionization which use solutions with concentrations typically below $0.5 \mathrm{M}$, determination of the membrane resistance under standard conditions does not represent the practical application. Figure 4 shows the experimentally determined membrane resistance as a function of the $\mathrm{NaCl}$ solution concentration. Values are obtained from measurements under direct current conditions.
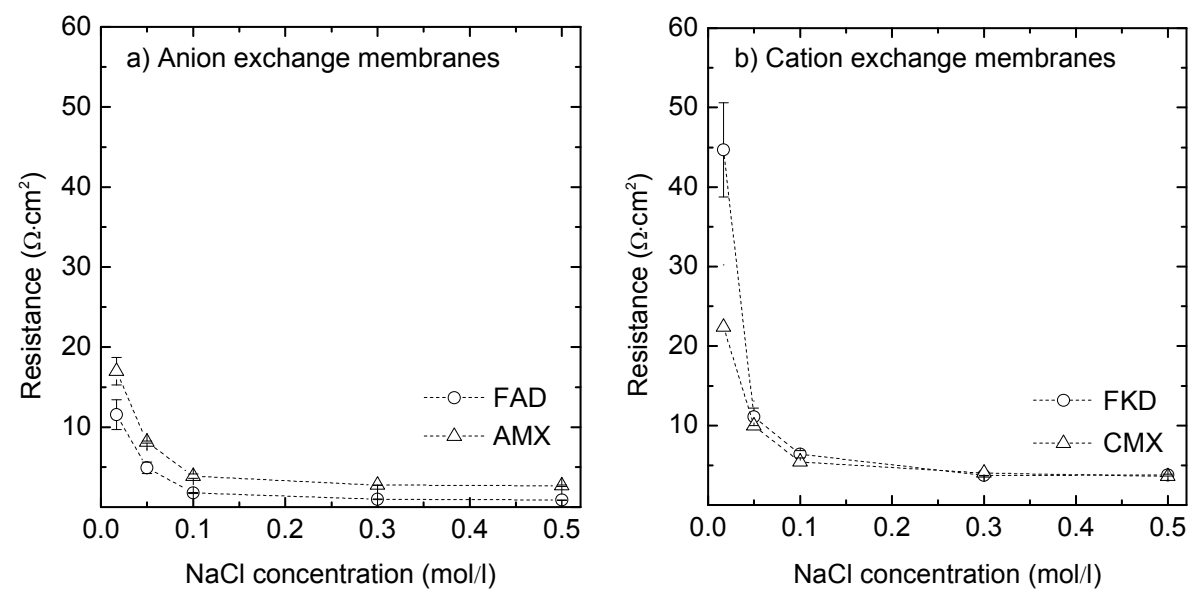

Figure 4: Membrane resistance as a function of $\mathrm{NaCl}$ solution concentration for a) anion exchange membranes and b) cation exchange membranes. Values are obtained from measurements under direct current conditions. 
At solution concentrations between $0.1 \mathrm{M}$ and $0.5 \mathrm{M}$, the resistance is virtually independent of the concentration. Below a concentration of $0.1 \mathrm{M}$, the membrane resistance strongly increases with decreasing concentration, independent of the membrane type. This increase in resistance is more pronounced for the cation exchange membranes than for the anion exchange membranes, which is due to the difference in ion mobility between anions $(\mathrm{Cl})$ and cations $\left(\mathrm{Na}^{+}\right)\left(\mathrm{uc}_{\mathrm{c}} / \mathrm{uNa}_{\mathrm{Na}} \approx 1.5\right)[19,34]$. These results suggest that the solution properties (in this case, the difference in ion mobility between $\mathrm{Cl}^{-}$and $\mathrm{Na}^{+}$ions) do influence the measured resistance and that this effect is included in the resistance determined under direct current conditions. This was also discussed by Strathmann who mentioned that direct current measurements not only determine the membrane resistance but also includes the resistance at the membrane-solution interface (diffusion boundary layer resistance) [35]. The significant increase in membrane resistance at lower $\mathrm{NaCl}$ concentrations therefore seems not to be the result of an increase of the real membrane resistance, but to be caused by the diffusion boundary layer resistance, which is more pronounced at lower solution concentrations [40].

Choi et al. determined the diffusion boundary layer thickness experimentally and found that it has a thickness of $300-350 \mu \mathrm{m}$, which is in a range that can be affected by the hydrodynamic conditions (e.g. solution mixing (flow rate)) [25]. Although the value of the diffusion boundary layer thickness to some extend also depends on the experimental set-up and operating conditions applied, it is assumed that the boundary layer thickness in our system is approximately at the same order of magnitude.

These assumptions are supported by Figure 5, which shows a significant decrease in measured resistance with increasing solution flow rate at low salt concentration $(0.017 \mathrm{M} \mathrm{NaCl})$. 


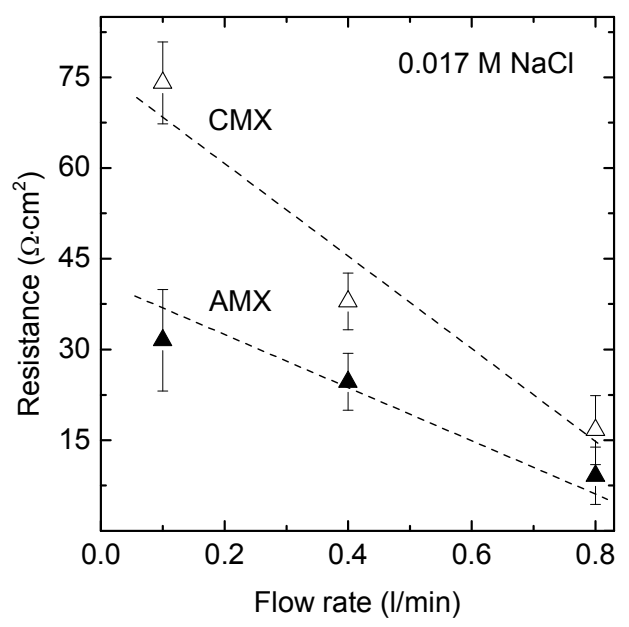

Figure 5: Membrane resistance as a function of the solution flow rate for a solution concentration of $0.017 \mathrm{M} \mathrm{NaCl}$ ( $\mathrm{AMX}$ is an anion exchange membrane, $\mathrm{CMX}$ is a cation exchange membrane).

By increasing the liquid flow rate, the boundary layer thickness and thus the boundary layer resistance decreases. This has a direct effect on the resistance as measured under direct current conditions, as shown in Figure 5. These results indicate that especially at low solution concentration, the diffusion boundary layer resistance (caused by concentration polarization effects) is the dominant factor that determines the measured resistance, whereas the contribution of the real membrane resistance to the measured resistance is of minor importance. At higher solution concentrations, this effect is less pronounced as the relative contribution of the boundary layer resistance to the measured resistance is only limited and the real membrane resistance dominates the measured value.

The remainder of this chapter is dedicated to the understanding and clarification of this behavior and its influence on other membrane properties, such as limiting current density, transition time and ion transport number. 


\subsection{Swelling degree}

The fixed charge density of a membrane, which is calculated as the number of fixed charges at the polymer backbone per unit volume of the swollen membrane, to a large extend determines the membrane properties and is directly related to the membrane resistance and the ion transport number [9, $34,35]$. To exclude a possible effect of the fixed charge density on the resistance, the swelling behavior of the different membranes as a function of the equilibrium salt solution concentration was investigated and the results are shown in Figure 6.

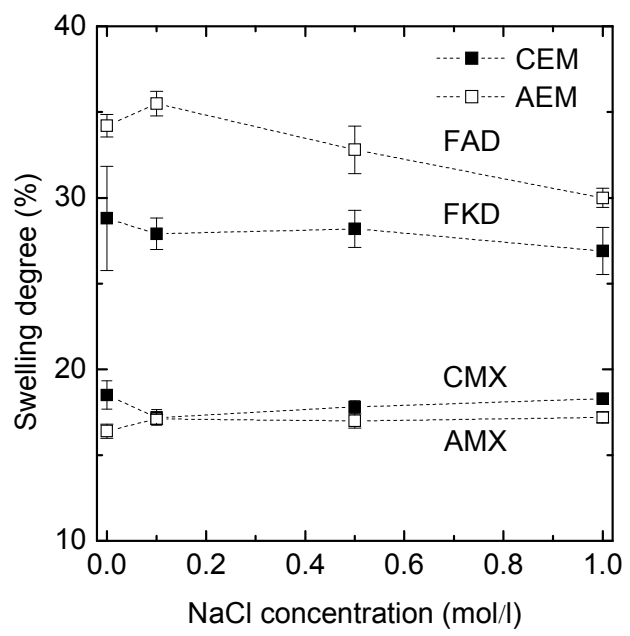

Figure 6: Membrane swelling as a function of the equilibrium solution concentration (at $25^{\circ} \mathrm{C}$ ); AEM ( $\square)$ are anion exchange membranes and CEM ( $\square)$ are cation exchange membranes.

A decrease of the water content with increasing $\mathrm{NaCl}$ concentration could maybe be expected, due to the higher osmotic pressure difference between the external salt solution and the interstitial phase (spaces inside membrane matrix filled with electroneutral solution) at the higher concentrations [41]. This behavior is indeed slightly observed for the two Fumasep membranes, FAD and FKD. Nevertheless, the range of concentrations investigated is small, and 
this effect is not very pronounced, as observed in Figure 6. The swelling degree of the Neosepta membranes AMX and CMX is independent of the concentration, due to the high crosslinking degree and reinforcement in these membranes to produce membranes with high mechanical stability [36]. Although the swelling degree of the FAD and FKD membranes is more sensitive to changes in salt concentration than the AMX and CMX membranes, the water uptake still does not change more than $5 \%$ and swelling phenomena can not be a reason for the strong increase in measured resistance at low salt concentrations.

\subsection{Limiting current density}

Determination of the limiting current density provides information about ion transport limitations in ion exchange membrane systems. Figure 7 shows the experimentally determined values of limiting current density as a function of solution concentration and the flow rate for the different membranes investigated.

a) Anion exchange membranes

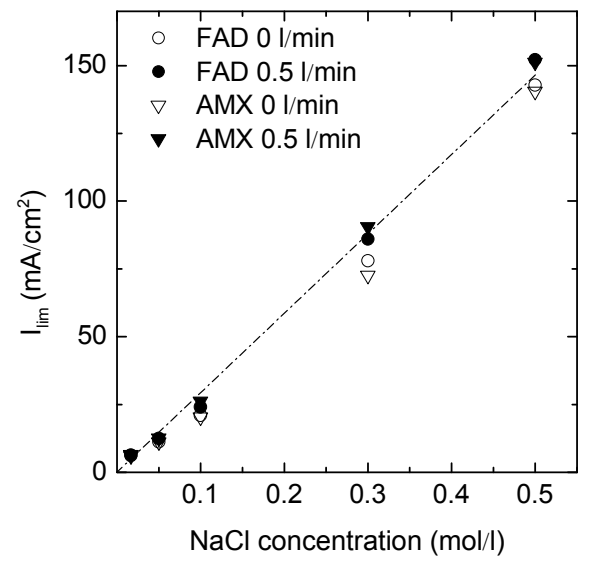

b) Cation exchange membranes

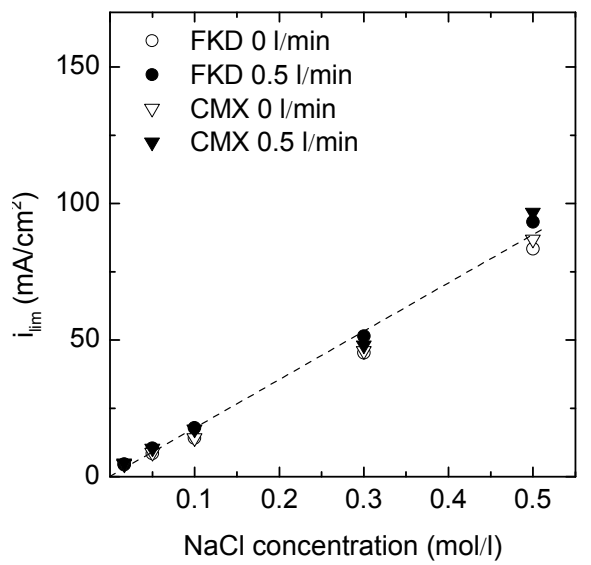

Figure 7: Limiting current density as a function of $\mathrm{NaCl}$ solution concentration and the flow rate for a) anion exchange membranes and b) cation exchange membranes. 
Both graphs in Fig. 7 do indicate a linear relationship between the limiting current density and the sodium chloride concentration for all membranes with and without solution mixing. The ratio of the limiting current densities of the anion exchange membranes to those of the cation exchange membranes as determined from the slope of the current-voltage plot is approximately 1.5, which is in good agreement with the calculated ratio based on Equation 1 [18]. These results show that the ion mobility difference between the anion and the cation (ucl-/unat $\approx 1.5$ ) has a significant influence on the value of the limiting current density $[19,34]$. In this case, the limiting factor with respect to ion transport would thus be the cation exchange membrane.

Figure 7 shows that the effect of the liquid flow rate on the limiting current density at higher salt concentrations is very limited, which is expected because the relative contribution of the boundary layer thickness is only limited at these higher concentrations. At low solution concentrations on the other hand, change of the hydrodynamic conditions by mixing (increase in flow rate) does have an effect on the limiting current density, as presented in Figure 8.

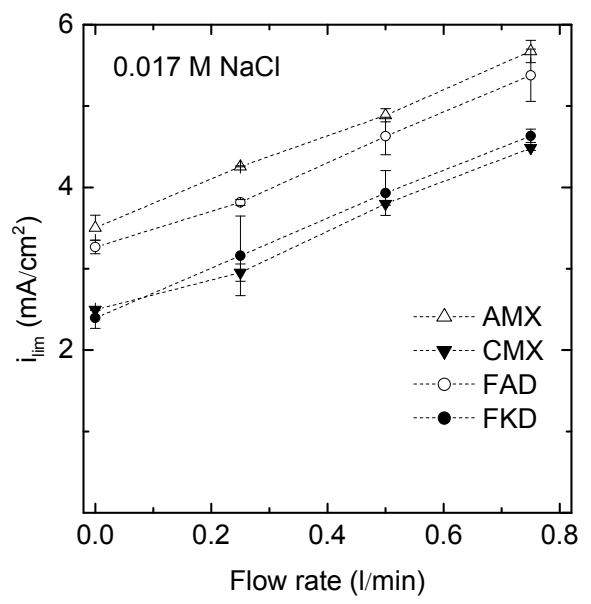

Figure 8: Limiting current density as a function of the solution flow rate at low $\mathrm{NaCl}$ concentration $(0.017 \mathrm{M}) ; \mathrm{AMX}$ and FAD are the anion exchange membranes and CMX and FKD are the cation exchange membranes. 
Figure 8 shows that the limiting current density for all investigated membranes increases with increasing solution flow rate in the measuring cell. At lower salt concentrations the relative importance of the diffusion boundary layer is more pronounced than it is at higher concentrations [40]. Higher solution flow rates reduce the diffusion boundary layer thickness at the membrane surface, and this results directly in an increased limiting current density and thus enhanced process performance at lower salt concentrations. This effect is especially important for processes that operate in the low concentration range such as reverse electrodialysis (river water compartment), capacitive deionization and biological fuel cells $[6,9,10,42]$. The slopes of the lines in Figure 8 are very similar for all four membranes, which indicates that an increase in flow rate induces an equal decrease in diffusion boundary layer thickness and consequently limiting current density for all membranes, independent of their nature (anion or cation exchange membrane), as predicted by Equation 1 .

\subsection{Ion transport number}

\subsubsection{Transition time}

Another factor that could influence the resistance is the ion transport number, i.e. which part of the charge is carried by the counter ion. Equation 2 shows that if there exists a linear relationship between the transition time and the inverse square current density, the ion transport number is constant and independent of the applied current density at a given concentration. This relationship between the transition time and the inverse square current density as measured by chronopotentiometry is shown in Figure 9 as a function of the solution concentration and the flow rate (Sand's plot). For the sake of clarity, only the results for the AMX and CMX membranes at low concentrations (0.017 M - $0.1 \mathrm{M})$ are shown, but similar plots can be made for the other membranes. Figure 9 shows a linear relationship between the transition time 
and the inverse square current density, which means that the ion transport number is independent of the applied current density at a given concentration.
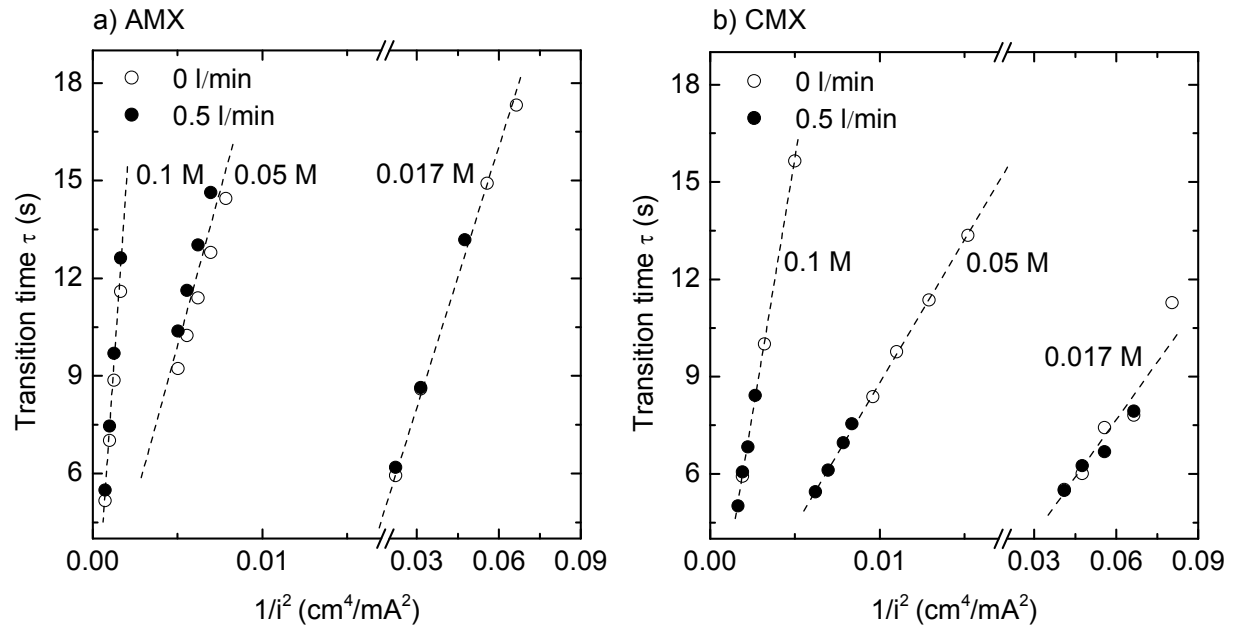

Figure 9: Transition time as a function of the inverse square current density (Sand's plot) as a function of the solution concentration and the flow rate; AMX is the anion exchange membrane and CMX is the cation exchange membrane.

In this case, the difference in the angle of the slope with the $\mathrm{x}$-axis between an anion exchange membrane (Figure 9a) and a cation exchange membrane (Figure $9 \mathrm{~b}$ ) is due to the difference in the ion mobility between anions and cations respectively. The difference in angle between the lower $(0.017 \mathrm{M})$ and the higher $(0.5 \mathrm{M}) \mathrm{NaCl}$ concentrations is caused by the fact that at higher salt concentrations higher current densities are required to carry the charge and to transport the ions through the membrane.

These results suggest that the counter ion transport number, which is directly related to the transition time according to Equation 2, is not dependent on the applied current density, but it can differ with salt concentration. To elucidate the effect of the salt concentration on the ion transport number, the counter ion transport number can be estimated theoretically using model calculations and it can be calculated from the transition time measurements. 


\subsubsection{Ion transport number}

Although the counter ion transport number in the ion exchange membrane can be calculated from experimentally determined transition times using chronopotentiometry measurements, model calculations are a useful tool to predict transport numbers and to understand complex ion transport phenomena. Figure 10 presents the calculated, theoretical ion transport numbers for the different membranes investigated. Calculations are done using the Equations described in the previous chapter, and the experimentally determined values, which are summarized in Table 1, are used as input parameters for the model calculations [9].

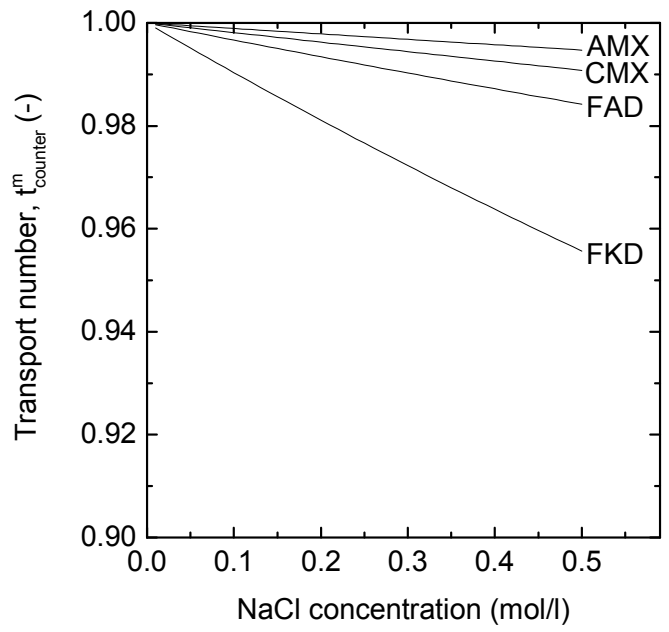

Figure 10: Model calculations of the counter ion transport number as a function of the $\mathrm{NaCl}$ concentration. AMX and FAD are the anion exchange membranes and CMX and FKD are the cation exchange membranes. Experimental data (Table 1) were used as input for the model calculations.

Figure 10 shows that the counter ion transport number decreases when the $\mathrm{NaCl}$ concentration in the solution increases, which is in accordance with the Donnan equilibrium theory $[34,35]$. This means that at lower salt concentration, 
a larger part of the charge is transported by the counter ions, whereas the transport of co-ions becomes restricted.

The transport number of the counter ions in the FAD and FKD membranes decreases more rapidly with increasing sodium chloride concentration than the corresponding values of the AMX and CMX membranes. This is predominantly caused by the lower membrane charge densities (measured experimentally and calculated from the membrane water uptake and ion exchange capacity values) of the FAD and FKD membranes [36, 37]. The charge densities of the FAD and FKD membranes are $4.41 \mathrm{~mol} / \mathrm{l}$ and $3.93 \mathrm{~mol} / \mathrm{l}$ respectively, whereas the charge densities of the AMX and CMX membranes are $7.81 \mathrm{~mol} / \mathrm{l}$ and $9.00 \mathrm{~mol} / 1$ [9, 34, 35]. Figure 10 shows that as expected, the ion transport number decreases more rapidly when the charge density is lower, because according to the Donnan theory the transport number is directly related to the concentration of counter ions in the membrane. The model based on Donnan equilibrium theory does not take into account membrane shrinkage and concentration polarization layer effects, which may affect also the ion transport number. However, because membrane shrinkage in the investigated concentration range $(0.017 \mathrm{M}-0.5 \mathrm{M})$ is less than $5 \%$ (Figure 6) we do not expect that membrane shrinkage has a significant effect on the counter ion transport number. Concentration polarization phenomena on the other hand, especially at low salt concentrations, may well affect ion transport phenomena in the membrane.

The model calculations suggest that the counter ion transport number continuously increases with decreasing salt concentration. Figure 11 shows the counter ion transport numbers calculated from Equation 2 using the experimentally determined values of the transition time as a function of the solution concentration for two different flow rates. The experimental error was less than $3 \%$. 
a) Anion exchange membranes

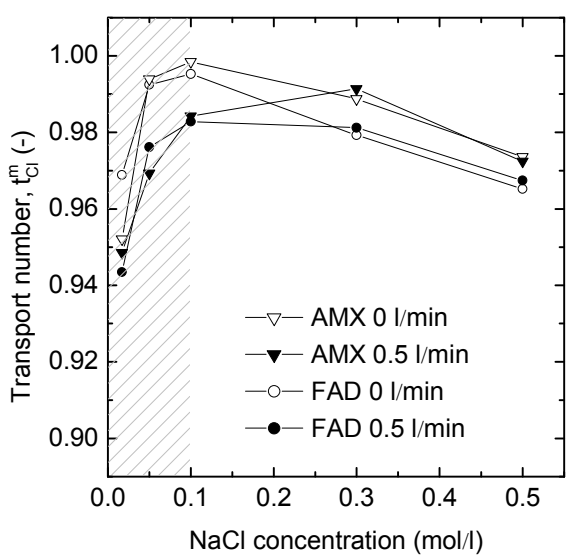

b) Cation exchange membranes

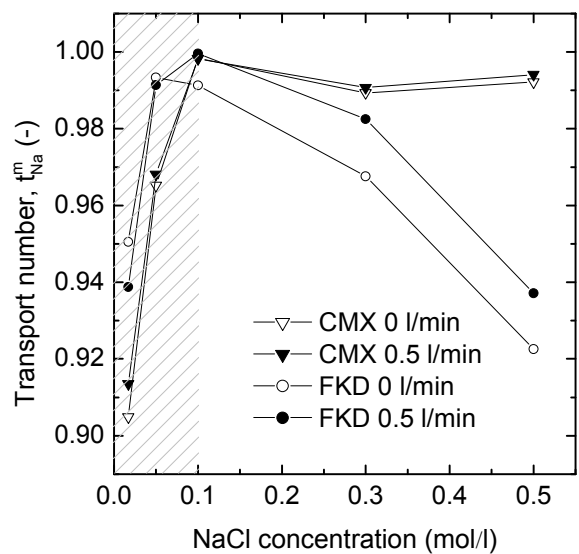

Figure 11: Counter ion transport number for the membranes investigated and calculated from the experimentally determined transition time as a function of the $\mathrm{NaCl}$ concentration; a) anion exchange membranes (AMX and FAD), and b) cation exchange membranes (CMX and FKD).

Comparison of the ion transport numbers from the model calculations and the values obtained from the experimentally determined transition times (Figure 10 and 11) shows that in the higher concentration range of 0.1 to $0.5 \mathrm{M} \mathrm{NaCl}$, the counter ion transport numbers obtained from the experimentally determined transition times are in very good agreement with the theoretical ion transport numbers as calculated from the model equations. However, at lower concentrations, below $0.1 \mathrm{M} \mathrm{NaCl}$, the values obtained from the experimentally determined transition times significantly deviate from the theoretical values. In contrast to what the Donnan theory predicts, we observe in our counter ion transport numbers obtained from the experimentally determined transition times a significant decrease in counter ion transport number at low solution concentrations. The drop in counter ion transport number at low concentrations $(0.1 \mathrm{M}<)$ is more pronounced for cation exchange than for the anion exchange membranes and it is most likely related to ion mobility (ucl-/u $\mathrm{u}_{\mathrm{Na}+} \approx 1.5$ ).

There can be several reasons for this discrepancy between the values obtained from model calculations and the values extracted from the experimental results, between which at the moment we are not able to distinguish. A possible 
explanation for the decrease in counter ion transport number as determined from the experimental values could be that the Sand equation (Equation 2) is not applicable in the low concentration range. It assumes diffusion in an infinite stagnant layer, while in fact we have a flow in the system, either forced or natural, which most likely influences the diffusion boundary layer as well. Experiments to determine the resistance show that this diffusion boundary layer is concentration dependent and its importance increases at lower salt concentrations.

Assuming that the Sand Equation is applicable, another explanation for the discrepancy between the model calculations and the values obtained from experimental results may stem from hydrodynamic instabilities in the diffusion boundary layer. At high current densities (higher than the limiting current density, in the overlimiting regime), hydrodynamic (electro-osmotic) instabilities in ion conduction are present in the diffusion boundary layer, as proven mathematically and experimentally for CMX membranes [43]. Also heterogeneities at the membrane surface can cause hydrodynamic instability in the diffusion boundary layer [29]. These hydrodynamic instabilities (electroconvection) provide additional mixing in the diffusion boundary layer. This results in higher experimental values for the transition time and consequently lower ion transport numbers, especially at lower salt concentrations $(<0.1 \mathrm{M})$ where this effect has a larger relative contribution, while this effect is not included in the model calculations. As mentioned, the relative importance of the diffusion boundary layer is higher at low salt concentration and for this reason the effect of hydrodynamic instabilities (electro-convection) becomes significant in the low concentration range only. In our next paper we will further elucidate the influence of the salt concentration on ion transport phenomena in the membrane and solution boundary layer using electrochemical impedance spectroscopy (EIS). 


\section{Conclusions}

In the present work we investigate the influence of the solution concentration on ion transport phenomena in two anion exchange membranes (Neosepta AMX and Fumasep FAD) and two cation exchange membranes (Neosepta CMX and Fumasep FKD) in the concentration range from 0.017 M to $0.5 \mathrm{M} \mathrm{NaCl}$ and for different hydrodynamic conditions. The results presented in this paper are important for processes that operate in the low concentration range $(<0.5 \mathrm{M})$, such as reverse electrodialysis, electrodialysis, microbial fuel cells and capacitive deionization.

The results prove that the resistance of ion exchange membranes strongly depends on the solution concentration: especially at low solution concentrations $(<0.1 \mathrm{M} \mathrm{NaCl})$ we observe a very strong increase in membrane resistance with decreasing concentration. This increase is solution flow rate dependent and more pronounced for cation exchange membranes than for anion exchange membranes due to the difference in ion mobility, which suggests that the solution properties and the conditions in the diffusion boundary layer do influence the measured resistance and are to some extend included in the resistances determined under direct current conditions. At high concentrations, the limiting current density is hardly influenced by the liquid flow rate, whereas at low concentrations the limiting current density increases with increasing solution flow rate. Higher solution flow rates reduce the diffusion boundary layer thickness at the membrane surface, and this results directly in an increased limiting current density. Model calculations reveal that the ion transport number linearly increases with decreasing solution concentration. Values for the ion transport number extracted from the experimentally determined transition time, however, show that at low concentrations, the ion transport number significantly drops with decreasing concentration, a discrepancy which can have multiple reason, between which 
we are unable to distinguish yet. The next chapter will further address this topic using electrochemical impedance spectroscopy (EIS).

\section{Acknowledgements}

This work was performed at Wetsus, centre of excellence for sustainable water technology. Wetsus is funded by the city of Leeuwarden, the Province of Fryslan, the European Union European Regional Development Fund and by the EZ-KOMPAS Program of the "Samenwerkingsverband Noord/Nederland". The industrial participants of the Wetsus research theme Energy (Nuon B.V., Fuji B.V., MAGNETO special anodes B.V., Triqua B.V., Landustrie SNEEK B.V., Frisia Zout B.V., Waterleidingmaatschappij Drenthe, Waterbedrijf Groningen and Waterlaboratorium Noord) are kindly acknowledged for their financial support.

\section{References}

1. R. K. J. Jagur-Grodzinski, Novel Process for Direct Conversion of Free Energy of Mixing into Electric Power Ind. Eng. Chem. Process Des. Dev. (1986) 443-449.

2. J. W. Post, J. Veerman, H. V. M. Hamelers, G. J. W. Euverink, S. J. Metz, K. Nymeijer, C. J. N. Buisman, Salinity-gradient power: Evaluation of pressure-retarded osmosis and reverse electrodialysis, Journal of Membrane Science 288 (2007) 218-230.

3. R. Audinos, Electric power produced from two solutions of unequal salinity by reverse electrodialysis, Indian Journal of Chemistry 31A (1992) 348-354.

4. $\quad$ R.E. Lacey, Energy by Reverse Electrodialysis, Ocean Engng. 7 (1980) 147.

5. R. E. Pattle, Production of Electric Power by mixing Fresh and Salt Water in the Hydroelectric Pile, Nature 174 (1954) 660. 
6. R. A. Rozendal, H. V. M. Hamelers, C. J. N. Buisman, Effects of Membrane Cation Transport on $\mathrm{pH}$ and Microbial Fuel Cell Performance, Environ. Sci. Technol. 40 (2006) 5206-5211.

7. B. E. Logan, B. Hamelers, R. Rozendal, U. Schroder, J. Keller, S. Freguia, P. Aelterman, W. Verstraete, K. Rabaey, Microbial Fuel Cells: Methodology and Technology, Environ. Sci. Technol. 40 (2006) 51815192.

8. F. Suda, T. Matsuo, D. Ushioda, Transient changes in the power output from the concentration difference cell (dialytic battery) between seawater and river water, Energy 32 (2007) 165-173.

9. P. Dlugolecki, K. Nymeijer, S. Metz, M. Wessling, Current status of ion exchange membranes for power generation from salinity gradients, Journal of Membrane Science 319 (2008) 214-222.

10. J. Veerman, J. W. Post, M. Saakes, S. J. Metz, G. J. Harmsen, Reducing power losses caused by ionic shortcut currents in reverse electrodialysis stacks by a validated model, Journal of Membrane Science 310 (2008) 418-430.

11. M. Turek, B. Bandura, P. Dydo, Power production from coal-mine brine utilizing reversed electrodialysis, Desalination 221 (2008) 462-466.

12. J. N. Weinstein, F. B. J. W. Leitz, Electric power from differences in salinity: the dialytic battery, Science 191 (1976) 557-559.

13. F. Harnisch, U. Schroder, F. Scholz, The suitability of monopolar and bipolar ion exchange membranes as separators for biological fuel cells, Environmental Science and Technology 42 (2008) 1740-1746.

14. L. V. Karpenko, O. A. Demina, G. A. Dvorkina, S. B. Parshikov, C. Larchet, B. Auclair, N. P. Berezina, Comparative study of methods used for the determination of electroconductivity of ion-exchange membranes, Russian Journal of Electrochemistry 37 (2000) 287-293.

15. V. I. Zabolotsky, V. V. Nikonenko, Effect of structural membrane inhomogeneity on transport properties, Journal of Membrane Science 79 (1993) 181-198.

16. K. Urano, Y. Masaki, M. Kawabata, Electric resistances of ion-exchange membranes in dilute solutions, Desalination 58 (1986) 171. 
17. F. G. Wilhelm, N. F. A. van der Vegt, M. Wessling, H. Strathmann, Chronopotentiometry for the advanced current-voltage characterisation of bipolar membranes, Journal of Electroanalytical Chemistry 502 (2001) 152-166.

18. J. J. Krol, M. Wessling, H. Strathmann, Concentration polarization with monopolar ion exchange membranes: current-voltage curves and water dissociation, Journal of Membrane Science 162 (1999) 145-154.

19. J. J. Krol, M. Wessling, H. Strathmann, Chronopotentiometry and overlimiting ion transport through monopolar ion exchange membranes, Journal of Membrane Science 162 (1999) 155-164.

20. A. Yamauchi, A. M. E. L. Sayed, K. Mizuguchi, M. Kodama, Y. Sugito, Ion transport behavior in diffusion layer of new designed ion exchangemosaic composite polymer membrane, Journal of Membrane Science 283 (2006) 301-309.

21. R. Ibanez, D. F. Stamatialis, M. Wessling, Role of membrane surface in concentration polarization at cation exchange membranes, Journal of Membrane Science 239 (2004) 119-128.

22. R. Audinos, G. Pichelin, Characterization of electrodialysis membranes by chronopotentiometry, Desalination 68 (1988) 251-263.

23. J. Balster, I. Punt, D. F. Stamatialis, M. Wessling, Multi-layer spacer geometries with improved mass transport, Journal of Membrane Science 282 (2006) 351-361.

24. J. Balster, O. Krupenko, I. Punt, D. F. Stamatialis, M. Wessling, Preparation and characterisation of monovalent ion selective cation exchange membranes based on sulphonated poly(ether ether ketone), Journal of Membrane Science 263 (2005) 137-145.

25. J.-H. Choi, J.-S. Park, S.-H. Moon, Direct Measurement of Concentration Distribution within the Boundary Layer of an Ion-Exchange Membrane, Journal of Colloid and Interface Science 251 (2002) 311.

26. J.-S. Park, J.-H. Choi, K.-H. Yeon, S.-H. Moon, An approach to fouling characterization of an ion-exchange membrane using current-voltage relation and electrical impedance spectroscopy, Journal of Colloid and Interface Science 294 (2006) 129-138. 
27. I. Rubinstein, E. Staude, O. Kedem, Role of the membrane surface in concentration polarization at ion-exchange membrane, Desalination 69 (1988) 101-114.

28. O. Kedem, I. Rubinstein, Polarization effects at charged membranes, Desalination 46 (1983) 185-189.

29. J. Balster, M. H. Yildirim, D. F. Stamatialis, R. Ibanez, R. G. H. Lammertink, V. Jordan, M. Wessling, Morphology and microtopology of cation-exchange polymers and the origin of the overlimiting current, Journal of Physical Chemistry B 111 (2007) 2152-2165.

30. J. Balster, I. Punt, D. F. Stamatialis, M. Wessling, Multi-layer spacer geometries with improved mass transport, Journal of Membrane Science 282 (2006) 351-361.

31. M. Taky, G. Pourcelly, C. Gavach, A. Elmidaoui, Chronopotentiometric response of a cation exchange membrane in contact with chromium(III) solutions, Desalination 105 (1996) 219-228.

32. P. Sistat, G. Pourcelly, Chronopotentiometric response of an ionexchange membrane in the underlimiting current-range. Transport phenomena within the diffusion layers, Journal of Membrane Science 123 (1997) 121-131.

33. H. W. Rosler, F. Maletzki, E. Staude, Ion transfer across electrodialysis membranes in the overlimiting current range: chronopotentiometric studies, Journal of Membrane Science 72 (1992) 171-179.

34. T. Sata, Ion Exchange Membranes, Edition, The Royal Society of Chemistry Cambrige, 2004.

35. H. Strathmann, Membrane Science and Technology Ion-Exchange Membrane Separation Processes, 9, 1 ${ }^{\text {st }}$ Edition, Elsevier, 2004.

36. Neosepta, Ion exchange membranes Product Brochure Tokuyama Co., Japan.

37. Fumasep, Ion exchange membranes, Product Brochure FuMA-Tech $\mathrm{GmbH}$, Germany.

38. L. X. Tuan, M. Verbanck, C. Buess-Herman, H. D. Hurwitz, Properties of CMV cation exchange membranes in sulfuric acid media, Journal of Membrane Science 284 (2006) 67-78. 
39. F. G. Wilhelm, I. G. M. Punt, N. F. A. van der Vegt, H. Strathmann, M. Wessling, Cation permeable membranes from blends of sulfonated poly(ether ether ketone) and poly(ether sulfone), Journal of Membrane Science 199 (2002) 167-176.

40. J.-S. Park, J.-H. Choi, J.-J. Woo, S.-H. Moon, An electrical impedance spectroscopic (EIS) study on transport characteristics of ion-exchange membrane systems, Journal of Colloid and Interface Science 300 (2006) 655-662.

41. L. X. Tuan, C. Buess-Herman, Study of water content and microheterogeneity of CMS cation exchange membrane, Chemical Physics Letters 434 (2007) 49-55.

42. A. ter Heijne, H. V. M. Hamelers, M. Saakes, C. J. N. Buisman, Performance of non-porous graphite and titanium-based anodes in microbial fuel cells, Electrochimica Acta 53 (2008) 5697-5703.

43. S. M. Rubinstein, G. Manukyan, A. Staicu, I. Rubinstein, B. Zaltzman, R. G. H. Lammertink, F. Mugele, M. Wessling, Direct observation of a nonequilibrium electro-osmotic instability, Physical Review Letters 101 (2008) 


\title{
Chapter 4
}

\section{On the resistances of membrane, diffusion boundary layer and double layer in ion exchange membrane transport}

\begin{abstract}
Membrane resistances are often measured under direct current conditions using a standard $0.5 \mathrm{M} \mathrm{NaCl}$ characterization solution, although several electro-membrane processes (e.g. reverse electrodialysis, electrodialysis, fuel cells, microbial fuel cells and membrane capacitive deionization) operate in a much lower concentration range $(<0.1 \mathrm{M} \mathrm{NaCl})$. Our work reveals that at lower concentrations, the membrane resistance as measured under direct current conditions becomes strongly concentration dependent and strongly increases with decreasing concentration. The overall resistance measured under direct current conditions however, does not only include the pure membrane resistance but also takes the interfacial ionic charge transfer through the double layer and diffusion boundary layer effects into account. Because direct current methods do not allow discriminating between these individual resistances, we applied electrochemical impedance spectroscopy (EIS), which uses an alternating current, to analyze resistance phenomena in ion exchange membranes under different hydrodynamic conditions and at different temperatures.
\end{abstract}

The results clearly show that the increase in membrane resistance with decreasing concentration as measured in direct current experiments is the consequence of the strong increase in resistance of the diffusion boundary layer 
with decreasing concentration. This also explains the strong effect of the flow rate on the resistance. At higher concentrations, the pure membrane resistance starts to dominate the resistance as measured by direct current measurements, although also the diffusion boundary layer resistance still plays a considerable role.

\section{Scientific publication:}

P. Dlugolecki, P. Ogonowski, S. J. Metz, M. Saakes, K. Nijmeijer, M Wessling, On the resistances of membrane, diffusion boundary layer and double layer in ion exchange membrane transport, submitted for publication to Journal of Membrane Science 2009. 


\section{Introduction}

Ion exchange membranes are widely used in various applications such as electrodialysis, fuel cells, diffusion dialysis, Donnan dialysis and membrane capacitive deionization. Two emerging applications for ion exchange membranes can be found in the field of sustainable energy generation and more specifically in a process called reverse electrodialysis (RED) and in microbial fuel cells [1-7]. Ion exchange membranes are membranes with fixed anionic or cationic exchange groups that are able to transport cations or anions. The specific properties of ion exchange membranes are all related to the presence of these charged groups. Membrane properties and especially membrane resistance, have a large influence on the power output obtainable in the RED and microbial fuel cells $[8,9]$.

When a current passes through the ion exchange membrane, charge is carried through the membrane by counter-ions (ions with an opposite charge relative to the fixed charge in the membrane) as a result of Donnan exclusion. In the bulk solution, current is carried by both positive and negative ions. The difference in ion transport number between the solution phase and the membrane leads to the building up of diffusion boundary layers at the membrane surface [10-14]. Also the resistance of these layers may, especially at low salt concentrations, form a significant contribution to the total system resistance thus reducing the power output obtainable.

Dlugolecki et al. used a direct current method to determine the membrane resistance of ion exchange membranes as a function of the solution concentration and they observed a significant increase in membrane resistance at concentrations below $0.1 \mathrm{M} \mathrm{NaCl}$ [15]. The same was also observed in reverse electrodialysis and biological fuel cells $[9,16]$.

In general, membrane or cell resistances are measured via the direct current method. In this case, a current is applied and the resulting potential drop over the cell is measured. Using Ohm's law, the resistance of the system 
(membrane + solution) and the membrane, can be determined. However, direct current measurements are not able to distinguish between the individual membrane resistance and the additional resistances of the interfacial ionic charge transfer through the double layer and the diffusion boundary layer. Therefore, direct current methods not only measure the pure membrane resistance, but also include diffusion boundary layer and double layer effects. In their work, Dlugolecki et al. were not able to attribute the increase in resistance to one of these effects, because they used a direct current method [15]. Electrochemical impedance spectroscopy (EIS), which in contrast to the direct current method, uses an alternating current, allows to distinguish between the individual contributions of the different phenomena occurring at the membrane surface [11, 17-25]. Park et al. performed an electrochemical impedance study on an ion exchange membrane system that contained only an anion exchange membrane (Neosepta AMX) [10, 11]. In this study, the authors observed that heterogeneous transport, which we believe is the transport of ionic charge from the solution phase through the double layer to the membrane matrix, strongly depends on solution mixing and that the diffusion boundary layer can be totally eliminated by solution stirring. Although we believe that the resistance of this interfacial ionic charge transfer on the membrane surface can not be influenced by solution mixing, because ions are transferred through the double layer which thickness is in the order of a few nanometers only (the Debye length) [19, 26-28] and that the resistance of the diffusion boundary layer cannot be totally eliminated, but only minimized by increased solution flow rate, because this layer is in the micrometer range, the work clearly shows the strong potential of EIS for ion exchange membrane characterization.

In this paper we use EIS to characterize four different ion exchange membranes, i.e. two anion and two cation exchange membranes. By doing so we are able to distinguish between the pure membrane resistance and the resistance of ionic transfer through the adjacent layers, i.e. the electrical double 
layer and the diffusion boundary layer. The effect of salt concentration, liquid flow rate and temperature is investigated.

To the best of our knowledge, there are no other scientific publications that investigate the effect of these parameters on the different resistances in a systematic way. The results of our experiments are of major importance for various electro-membrane processes, such as reverse electrodialysis, electrodialysis, fuel cells, microbial fuel cells and membrane capacitive deionization that operate at low salt concentrations and in the temperature range from 10 to $30^{\circ} \mathrm{C}$.

\section{Theoretical background}

\subsection{Electrochemical impedance spectroscopy}

Electrochemical impedance spectroscopy (EIS) is a powerful technique for studying electrical properties of materials and is often used to characterize a wide variety of electrochemical phenomena in porous materials, solid state, liquid electrolytes, synthetic, and biological membranes [10, 11, 17, 22, 25, 29]. In general, this method can be used to provide more information on the functional and structural characteristics of membrane systems $[10,11,17,18,25$, 30]. One of the key principles of EIS is the translation of the electrochemical system under study (e.g. ion exchange membrane) to an equivalent electrical circuit consisting of e.g. capacitors and resistors.

In EIS an alternating sinusoidal current $\mathrm{I}(\mathrm{t})$ or voltage (depending on the system) of a given frequency and amplitude is applied to the system and the response of the system is monitored. The resulting voltage drop over the system is measured as a function of time $\mathrm{U}(\mathrm{t})$, and the phase shift $\phi$ relative to the input signal is determined. This procedure is repeated at different frequencies, and the impedance $\mathrm{Z}$ can then in accordance with Ohm's law be calculated as:

$Z=\frac{U(t)}{I(t)}$ 
Here, $U(t)$ is the voltage as a function of time $t(V)$, and $I(t)$ is the current as a function of time $t(A)$.

The voltage and current vary with time and are defined as:

$$
U(t)=U_{0} \sin \omega t=U_{0} e^{j \omega t}
$$

and

$$
I(t)=I_{0} \sin (\omega t+\varphi)=I_{0} e^{j(\omega t+\varphi)}
$$

Here, $\mathrm{U}(\mathrm{t})$ is the voltage at a certain time $(\mathrm{V}), \mathrm{U}_{0}$ is the voltage in phase (without phase shift) $(\mathrm{V}), \mathrm{I}(\mathrm{t})$ is the alternating current at a certain time $t(A), I_{0}$ is the alternating current in phase (A), $\phi$ is the phase shift $\left(^{\circ}\right)$ and $j$ is the imaginary unity $(j=\sqrt{-1})$. The symbol $\omega$ is the circular velocity $(1 \mathrm{rad} / \mathrm{s})$ which is also referred to as circular frequency of the alternating current. It is a function of the frequency $f$, and is given by:

$\omega=2 \pi f$

By using Euler's formula:

$$
e^{j \varphi}=\cos \varphi+j \sin \varphi
$$

The impedance can subsequently be defined as:

$$
Z(\omega)=\frac{U_{0} e^{j \omega t}}{I_{0} e^{j(\omega t+\varphi)}}=|Z| e^{-i \varphi}=|Z| \cos \varphi-j|Z| \sin \varphi
$$

The impedance thus consists of a real part and an imaginary part (Equation 6), where the real part is:

$$
\operatorname{Re}(Z) \equiv Z^{\prime}=|Z| \cos \varphi
$$

and the imaginary part is:

$$
\operatorname{Im}(Z) \equiv Z^{\prime \prime}=|Z| \sin \varphi
$$

The impedance of an electrical resistance or a capacitance differ. When the current and the voltage are in phase, the imaginary part of the impedance is zero. The real part of this impedance is independent of frequency and in accordance with Ohm's law the impedance of an electrical resistance equals: 
$Z=\frac{U_{0}}{I_{0}}=R$

A capacitor on the other hand is characterized by a phase shift with a phase angle of $\pi / 2$ between current and voltage. Therefore, the impedance of a capacitance is imaginary and frequency-dependent and is given by:

$Z=\frac{1}{j \omega C}$

Here, $\mathrm{C}$ is the capacitance $(\mathrm{F})$.

In reality, ion exchange membrane systems are not completely homogeneous and some dispersion may occur. In that case the capacitor can by represented by the constant phase element $Q$ to obtain better data fitting [11]. The constant phase element $Q$ is a non-intuitive circuit element that was introduced while looking at the response of real systems and it can be represented by [27, 29]:

$$
Z=\frac{1}{(j \omega)^{n} Q}
$$

$\mathrm{Q}$ is the constant phase element with the units $S \cdot \mathrm{s}^{\mathrm{n}}$, where $\mathrm{S}$ represents siemens $(1 / \Omega)$ and s represent seconds. The constant phase element $Q$ is often used to represent complex electrochemical systems to express different relaxation times, which reflect a non-uniform current distribution. When $\mathrm{n}$ is equal to unity, $\mathrm{Q}$ represents a pure capacitor and when $0<\mathrm{n}<1, \mathrm{Q}$ represent a non-ideal capacitor and inhomogeneities appear in the system [27, 29]. The phase angle of this "capacitance" is not $90^{\circ}$, but is given by $\left(n \cdot 90^{\circ}\right)$.

Often, the process under study can be translated into an equivalent electrical circuit consisting of several resistors and capacitors both in series and parallel. When impedances are placed in series, they are additive:

$$
Z_{\text {total }}=Z_{1}+Z_{2}+\ldots Z_{n}
$$

Here, $Z_{\text {total }}$ is the total impedance and $Z_{1}, Z_{2}, \ldots Z_{n}$ are the different impedances in series.

The total impedance for a resistance and a capacitance in series is: 


$$
Z_{\text {total }}(\omega)=R+\frac{1}{j \omega C}
$$

However, when impedances are connected in parallel, the total impedance can be calculated from the following equation:

$$
\frac{1}{Z_{\text {total }}}=\frac{1}{Z_{1}}+\frac{1}{Z_{2}}+\ldots \frac{1}{Z_{n}}
$$

Here, $Z_{\text {total }}(\omega)$ is the total impedance $(\Omega)$ and the superscript $n$ identifies the conductance and the capacitance of each layer.

Consequently, when a resistance and capacitance are placed in parallel, the total impedance is given by $[27,29]$ :

$$
Z_{\text {total }}(\omega)=\frac{R}{1+\omega^{2} R^{2} C^{2}}-j \frac{\omega R^{2} C}{1+\omega^{2} R^{2} C^{2}}
$$

Here, $Z_{\text {total }}(\omega)$ is the total impedance $(\Omega), R$ is the electrical resistance (when the current and the voltage are in phase) $(\Omega)$ and $\omega$ is the circular velocity $(1 \mathrm{rad} / \mathrm{s})$ When placed in a salt solution, in addition to the pure membrane resistance (Figure 1a), several other resistances in the layer adjacent to the membrane will appear (Figure $1 \mathrm{~b}+\mathrm{c}$ ). The ion exchange membrane contains a high concentration of fixed charged groups attached to the polymer back bone (negative charges in the case of Figure 1a). These fixed charged groups attract ions with an opposite charge (counter ions, positive ions in the case of Figure 1) from the salt solution, which are distributed over the membrane surface and form the electrical double layer (Figure 1b) [18, 19]. The interfacial ionic charge transfer from the solution phase through the electrical double layer to the membrane we refer to as the electrical double layer resistance. The thickness of this layer is typically in the order of nanometers (Debye length) [19, 26, 27]. 


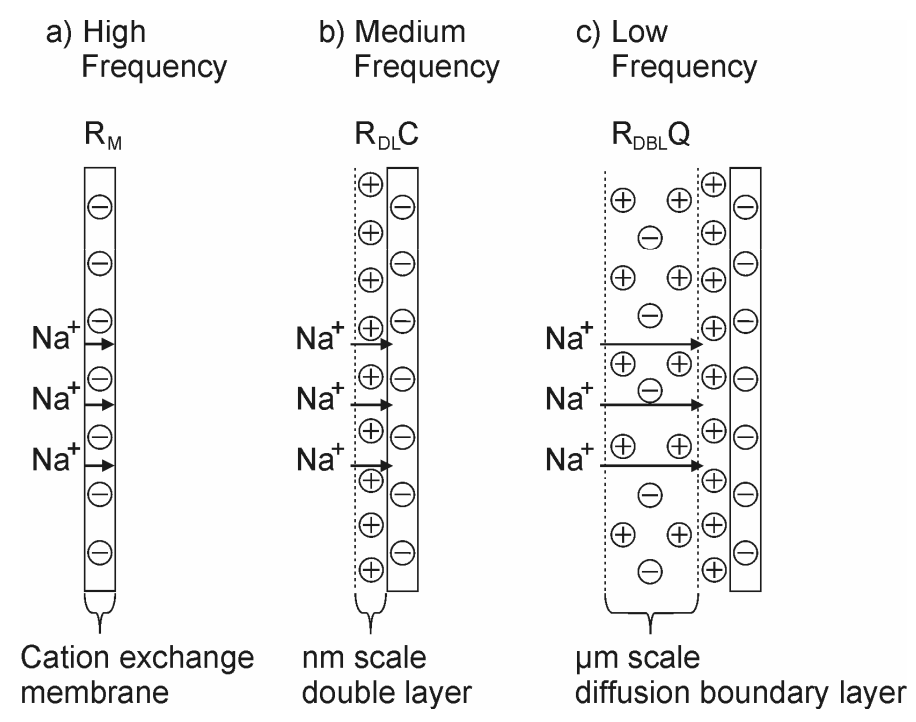

Figure 1: Phenomena occurring in the cation exchange membrane and in the layer adjacent to the membrane. The transition of the different phenomena into equivalent electrical elements is also shown. $R_{M}$ is the membrane resistance, $R_{D L}$ is the resistance of the interfacial ionic transfer from the solution through the double layer into the membrane, $\mathrm{C}$ is the capacitance of the interfacial ionic charge at the membrane surface (double layer), R $\mathrm{DBL}$ is the diffusion boundary layer resistance, and $\mathrm{Q}$ is the constant phase element representing a non-ideal capacitor of the diffusion boundary layer.

When a current passes through an ion exchange membrane, charge is transported through the membrane by counter ions as a result of the Donnan exclusion. In the bulk solution, current is carried by both positive and negative ions. The difference in ion transport number between the bulk solution and the membrane results in the building up of diffusion boundary layers at the membrane surface (Figure 1c) [10-12, 14, 28]. These layers typically have thicknesses in the micrometers range (e.g. $300 \mu \mathrm{m})[10-12,14,28]$. The concentration decreases at one side of the membrane and increases at the other side of the membrane; this phenomenon is called concentration polarization and occurs within the diffusion boundary layer [12].

EIS allows distinguishing between these different layers because the different layers respond differently to the applied signal (current) at different frequencies. At the high frequency range when there is no phase shift between 
voltage and current and the Ohmic relation holds, the response of the single membrane can be extracted from the EIS measurements [11, 18]. In the equivalent electrical circuit the single ion exchange membrane can be easily represented by a simple resistor. The applied current produces a voltage drop over the membrane under investigation, which can be translated into a membrane resistance (this is comparable to the resistance of the resistor in the electrical circuit). In principle, this resistance represents the resistance of the membrane containing also the solution resistance $\left(\mathrm{R}_{\mathrm{M}+\mathrm{S}}\right)$, but the pure membrane resistance $\left(R_{M}\right)$ can be easily extracted by subtracting the solution resistance (Rs) as determined from a blank measurements without a membrane.

When the frequency is decreased the contribution of the interfacial ionic charge transfer from the solution phase through the electric double layer to the membrane can be extracted. Ions start to migrate through the interfacial double layers and a phase shift is observed. The resistance (RDL) and capacitance (C) of ionic transport through these double layers become visible. This surface charging is similar to what is observed for a capacitor and the interfacial ionic charge transfer through the double layer is represented in the equivalent circuit model as a resistor and capacitor in parallel.

When a very low frequency signal (current) is applied, in addition to the membrane and the ionic transfer through the electrical double layer, also concentration gradients in the diffusion boundary layers adjacent to the membrane become visible. At these low frequencies ions are transported through the membrane, the double layer and the diffusion boundary layer (Figure 1) and the system responds with a certain delay to the applied signal. This delay is reflected in a phase shift with at each frequency a specific phase angle $[18,22]$. The phase shift and phase angle at each specific frequency visualize the overall response of the different phenomena in the system sensitive to that specific frequency. Complex systems often give rise to nonideal responses. In these cases a constant phase element $Q$, which represents a non-ideal capacitor can be considered to obtain a better fit [29]. The diffusion 
boundary layer can be represented by a resistor and a constant phase element $\mathrm{Q}$ connected in parallel, where the constant phase element represents the nonideal capacitive behavior of the diffusion boundary layer.

To summarize the previous description, the different contributions of the ion exchange membrane and the solution to the resistance can be electrically represented by the equivalent circuit model presented in Figure $2[10,11,17,18$, 22].

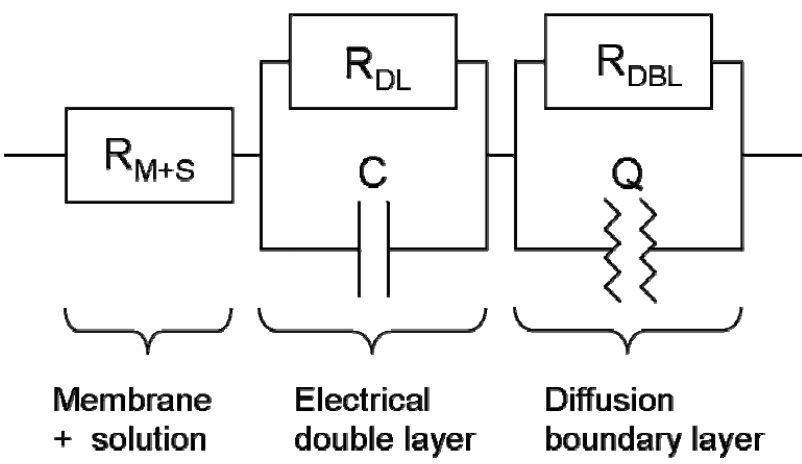

Figure 2: Equivalent circuit for the ion exchange membrane with solution used in this study. The membrane and solution resistance $\left(\mathrm{R}_{\mathrm{M}}+\mathrm{S}\right)$ is represented by a resistor. The ionic transfer resistance through the electrical double layer $\mathrm{RDL}_{\mathrm{D}}$ and capacitance $\mathrm{C}$ can be represented by a resistor and a capacitor connected in parallel. The diffusion boundary layer resistance RDBL and capacitance $Q$ can be represented by a resistor and constant phase element connected in parallel. The constant phase element $\mathrm{Q}$ represents the non-ideal capacitive behavior of the diffusion boundary layer.

\section{Materials and methods}

\subsection{Membranes}

Two cation exchange membranes (Neosepta CMX and KESD) and two anion exchange membranes (Neosepta AMX and AESD) were selected. The Neosepta CMX and AMX membranes, manufactured by Tokuyama Soda Co. (Japan), are reinforced standard-grade homogenous ion exchange membranes based on polyvinyl chloride. Neosepta CMX is a cation exchange membrane that contains sulfonic acid groups as fixed charges and Neosepta AMX is an anion exchange membrane that contains quaternary ammonium groups as fixed 
charges. These membranes are widely used in desalination and electromembrane applications. The other two membranes, KESD and AESD, are membranes from the Institute of Organic and Polymer Technology, Wroclaw University of Technology (Poland). These membranes were obtained by chemical modification of an interpenetrating polymer network (IPN), such as the polyethylene/polystyrene-co-divinyl benzene system where divinyl benzene is used as cross-linking agent [31,32]. KESD is a cation exchange membrane that contains sulphonic acid groups as fixed charges. AESD is an anion exchange membrane that contains tertiary ammonium groups as fixed charges. Table 1 shows some experimentally determined properties of these membranes.

Table 1: Experimentally determined ion exchange membrane properties.

\begin{tabular}{cccccc}
\hline Membrane & $\begin{array}{c}\text { IEC } \\
\text { (meq/g dry } \\
\text { membrane })\end{array}$ & $\begin{array}{c}\text { Permselectivity } \\
(\%)\end{array}$ & $\begin{array}{c}\text { Resistance }^{\mathrm{b}} \\
\left(\Omega \cdot \mathrm{cm}^{2}\right)\end{array}$ & $\begin{array}{c}\text { Swelling } \\
\text { degree }^{\mathrm{c}} \\
(\%)\end{array}$ & $\begin{array}{c}\text { Thickness }^{\mathrm{c}} \\
\text { wet } \\
(\mu \mathrm{m})\end{array}$ \\
\hline AMX & $1.30 \pm 0.02$ & $91.0 \pm 0.4$ & $2.65 \pm 0.04$ & $16.4 \pm 0.5$ & $138 \pm 2$ \\
AESD & $1.34 \pm 0.02$ & $92.6 \pm 0.5$ & $4.22 \pm 0.30$ & $20.3 \pm 0.6$ & $82 \pm 13$ \\
\hline CMX & $1.64 \pm 0.01$ & $92.5 \pm 0.6$ & $3.43 \pm 0.16$ & $21.5 \pm 0.2$ & $181 \pm 2$ \\
KESD & $1.95 \pm 0.03$ & $88.3 \pm 2.3$ & $0.95 \pm 0.04$ & $38.1 \pm 0.9$ & $87 \pm 18$ \\
\hline
\end{tabular}

a) Membrane potential measured over the membrane between $0.5 \mathrm{M}$ and $0.1 \mathrm{M}$ solutions at $25^{\circ} \mathrm{C}$.

b) Measured in $0.5 \mathrm{M} \mathrm{NaCl}$ solution at $25^{\circ} \mathrm{C}$.

c) Membrane equilibrated in Milli-Q water for $24 \mathrm{~h}$.

\subsection{Experimental setup}

Direct current characterization and EIS measurements were performed in the setup shown in Figure 3. 


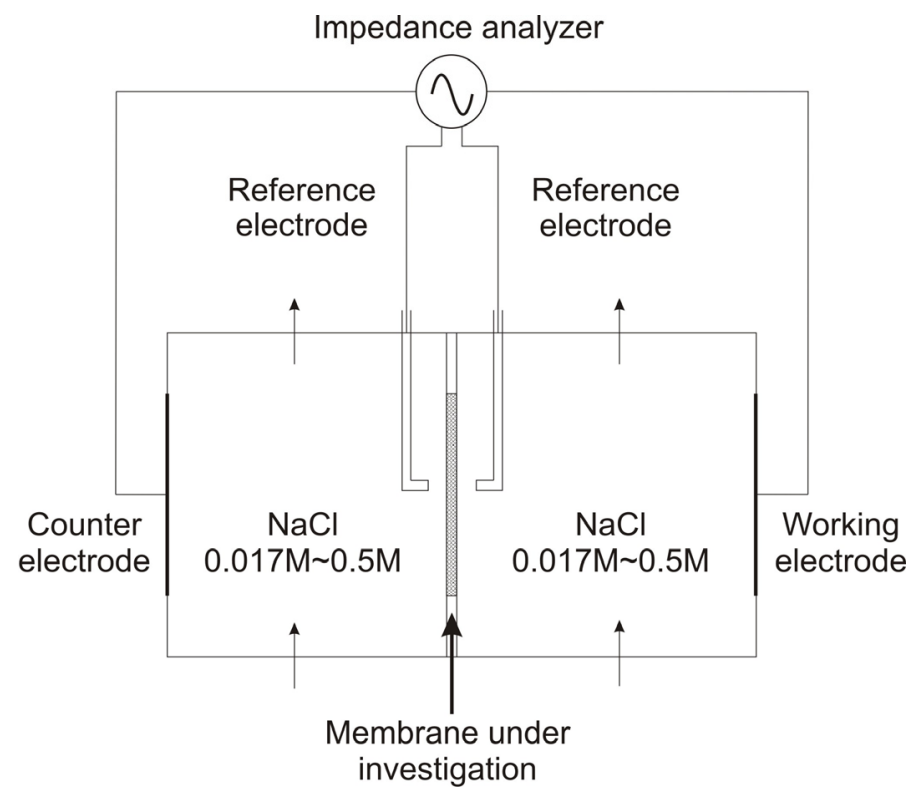

Figure 3: Schematic representation of the experimental set-up used for both electrochemical impedance spectroscopy and direct current characterization of ion exchange membranes.

The cell was made of PMMA (poly(methyl 2-methylpropenoate)) and consisted of two separate compartments with a total flowing solution volume of $2 \mathrm{dm}^{3}$. The membrane under investigation with an effective area of $2.835 \mathrm{~cm}^{2}$ was equilibrated with the measuring solution for at least 24 hours. Using a relatively small membrane area prevents membrane bulging and reduces the current density applied on the planar auxiliary electrodes. The planar auxiliary electrodes were made of $\mathrm{Ag}$ covered with an $\mathrm{AgCl}$ layer. These electrodes were selected to minimize water dissociation at the electrodes because proton/hydroxyl ions may affect the composition of the electrolyte in the compartments. In both compartments adjacent to the central membrane, we used a $\mathrm{NaCl}$ solution of either $0.017 \mathrm{M}$ or $0.5 \mathrm{M}$ (analytical grade, Boom B.V., The Netherlands) prepared from Milli-Q water $(18.2 \mathrm{M} \Omega \cdot \mathrm{cm})$. A solution of $0.017 \mathrm{M} \mathrm{NaCl}$ represents river water, whereas $0.5 \mathrm{M} \mathrm{NaCl}$ represents sea water. The solutions were pumped through the compartments by gear pumps (ColeParmer Instrument Co., Digital Gear Pump, USA) and the flow rate of each 
stream was adjusted to $100 \mathrm{ml} / \mathrm{min}, 400 \mathrm{ml} / \mathrm{min}$ or $800 \mathrm{ml} / \mathrm{min}$. The solutions were placed in a thermostatic bath to keep the temperature constant at $25 \pm 0.2$ ${ }^{\circ} \mathrm{C}$. The concentration of the solutions was monitored with a conductivity meter (Metrohm AG, 712 Conductivity meter, Switzerland).

Direct current and alternating current measurements were carried out with a potentiostat/galvanostat (Iviumstat, The Netherlands) with a frequency response analyzer. The potential difference and impedance over the membrane under investigation was measured by $\mathrm{Ag} / \mathrm{AgCl}$ reference electrodes. These reference electrodes were situated in small reservoirs filled with a $3 \mathrm{M} \mathrm{KCl}$ solution and connected to the cell with Haber-Luggin capillaries. To avoid any influence of external electrical fields, the experimental setup was placed in a Faraday cage.

\subsection{Direct current measurements}

Two membrane samples of each membrane were investigated in nine or ten current steps below the limiting current density. The limiting current density at a concentration of $0.017 \mathrm{M}$ was in the range of 2 to $6 \mathrm{~mA}$, depending on membrane type. For this solution, the current steps were: 1, 1.5, 2, 2.5, 3, 3.5, 4, 4.5, $5 \mathrm{~mA}$. For the $0.5 \mathrm{M} \mathrm{NaCl}$ concentration, the current steps were from 10 $\mathrm{mA}$ to $100 \mathrm{~mA}$ (10 mA steps). Each current step was measured for 60 seconds to reach steady state. The measured resistance was given by the slope of the current density versus voltage drop curve $(\mathrm{U}=\mathrm{f}(\mathrm{I}))$. This resistance measured using the direct current method represents the combined solution and membrane resistance $\mathrm{R}_{\mathrm{m}+\mathrm{s}}$ (Eq. 16) [8]:

$$
R_{m+s}=\frac{U}{i}
$$

Here, $R_{m+s}$ is the combined membrane and solution resistance $\left(\Omega \cdot m^{2}\right), U$ is the voltage drop measured between the Haber-Luggin capillaries (V) and i is the current density $\left(\mathrm{A} / \mathrm{m}^{2}\right)$. To obtain the membrane resistance, the measured 
resistance needs to be corrected for the resistance of the solution, which could be determined from a blank experiment without a membrane. However, this membrane resistance as measured in direct current experiments also includes the phenomena occurring at the membrane surface and in the adjacent layers (diffusion boundary layer and double layer) and does not represent the pure membrane resistance as mentioned before [11, 12, 18-21].

\subsection{Impedance measurements}

Electrical impedance spectroscopy can be used to discriminate between the individual pure membrane resistance and the resistances of the diffusion boundary layer and the double layer. In the EIS measurements, a sinusoidal current was applied by a potentiostat/galvanostat with impedance analyzer. The voltage response to the imposed current was measured by $\mathrm{Ag} / \mathrm{AgCl}$ reference electrodes. The frequency range of the impedance experiments was $10^{3} \mathrm{~Hz}$ to $10^{-3} \mathrm{~Hz}$ and the current amplitude was $3 \mathrm{~mA}$. The resistance measured at high frequency by the alternating current method represents the combined solution and membrane resistance $\mathrm{R}_{\mathrm{M}+\mathrm{s}}$. To obtain the pure membrane resistance $\mathrm{R}_{\mathrm{M}}$, this combined resistance had to be corrected for the resistance of the solution Rs, which could be determined from a blank experiment without a membrane over the whole frequency range.

\section{Results and discussion}

\subsection{Resistance determined from direct current measurements}

Figure 4 shows the experimentally determined membrane resistance as a function of the $\mathrm{NaCl}$ concentration as determined from direct current measurements. 


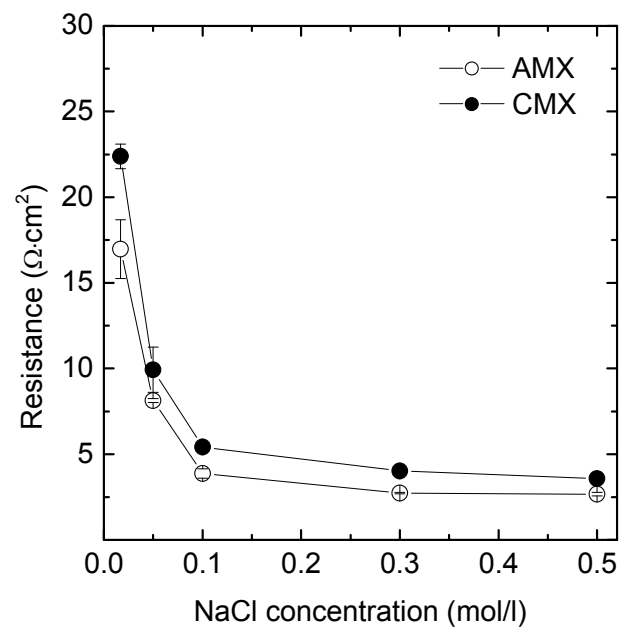

Figure 4: Membrane resistance as a function of $\mathrm{NaCl}$ solution concentration for an anion exchange membrane (Neosepta AMX) and a cation exchange membrane (Neosepta CMX); values were obtained from measurements under direct current conditions and at a solution flow rate of $0.5 \mathrm{l} / \mathrm{min}$.

At solution concentrations above $0.1 \mathrm{M}$, the resistance appears to be independent of the solution concentration. Below a concentration of $0.1 \mathrm{M}$, the membrane resistance strongly increases with decreasing concentration, independent of membrane type. This is an extremely important observation for processes that operate in the low concentration range, as the increase in resistance immediately also reduces the process performance and efficiency. To investigate this further, we chose a $0.017 \mathrm{M}(1 \mathrm{~g} / \mathrm{l}) \mathrm{NaCl}$ solution and measured the resistance as a function of the solution flow rate (Figure 5).

Figure 5 shows the measured resistance as a function of solution flow rate at low salt concentration $(0.017 \mathrm{M})$. At this low salt concentration, the measured resistance is a factor 10 higher than the resistance measured in a standard $(0.5 \mathrm{M}$ $\mathrm{NaCl})$ characterization concentration, especially at low solution flow rate (0.1 $1 / \min )[8]$. 
a) anion exchange membranes

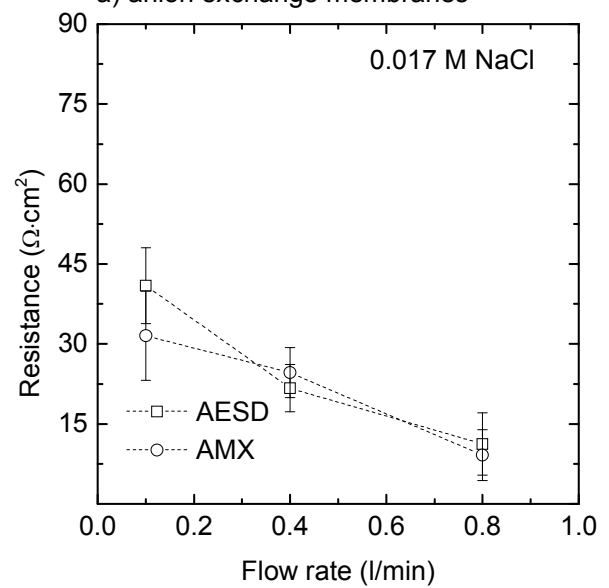

b) cation exchange membranes

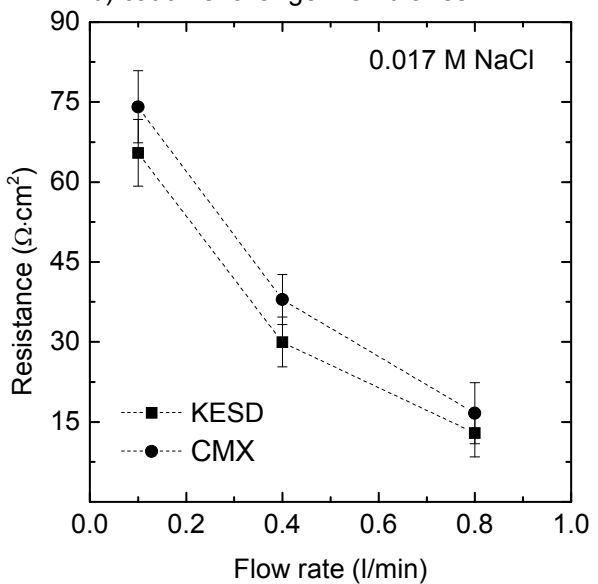

Figure 5: Measured resistance as a function of the solution flow rate for a $0.017 \mathrm{M} \mathrm{NaCl}$ solution; a) anion exchange membranes and b) cation exchange membranes. Measurements performed under direct current conditions.

These results clearly indicate that the solution flow rate at low salt concentrations has a significant effect on the measured resistance. With increasing flow rate, the resistance strongly decreases. From these experiments, we hypothesize that this visualizes the contribution of the resistance of the diffusion boundary layer resistance, which can be minimized by enhanced mixing of the salt solution. Unfortunately the direct current method does not allow extraction of the individual resistances from the measured overall resistance data.

The left panel of Figure 5 shows a comparison between the Neosepta AMX and AESD anion exchange membranes. Both anion exchange membranes show similar resistance values and trends at low salt concentrations. The measured resistance remained below $45 \Omega \cdot \mathrm{cm}^{2}$. The right panel of Figure 5 shows a comparison between the Neosepta CMX and KESD cation exchange membranes. These two cation exchange membranes show a similar relationship between measured resistance and solution flow rate. The Neosepta CMX membrane has a slightly higher resistance compared with the KESD membrane. The difference 
in resistance between the anion and cation exchange membranes is evident; this effect appears to be based on the ion mobility ratio in the bulk solution, which for $\mathrm{uc}_{\mathrm{c}} / \mathrm{u}_{\mathrm{Na}}=1.5[19,33]$. These results suggest that at low salt concentrations not the membrane but the solution performance plays a major role in the measured overall resistance.

Figure 6 shows the same measurements at a higher salt concentration $(0.5 \mathrm{M}$ $\mathrm{NaCl}$ ) for the two anion and two cation exchange membranes.

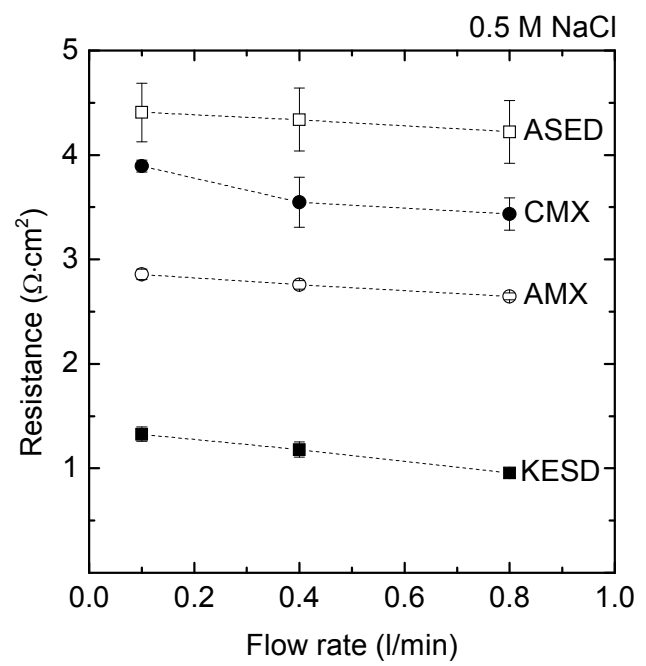

Figure 6: Measured resistance as a function of solution flow rate for the different anion and cation exchange membranes at a solution concentration of $0.5 \mathrm{M} \mathrm{NaCl}$.

From Figure 6 it is very clear that at the higher solution concentration the solution flow rate does not influence the membrane resistance significantly. This supports our hypothesis that at low solution concentrations the diffusion boundary layer resistance is the dominant factor, whereas at higher concentrations the pure membrane resistance dominates. At this higher concentration of $0.5 \mathrm{M} \mathrm{NaCl}$, the differences between the measured resistances of the membranes become more evident. The cation exchange membrane KESD has a more than 3 times lower resistance than the Neosepta CMX membrane. 
This low resistance of the KESD membrane can stem from two phenomena. Due to low membrane permselectivity ( $88 \%)$, which can be the result of the lower fixed charge density of the KESD membrane compared to the CMX membrane (KESD: cfix $^{2} 5.11 \mathrm{~mol} / 1$ and CMX: $\mathrm{Cfix}=7.63 \mathrm{~mol} / \mathrm{l}$ ), ions can freely migrate through the membrane and experience less interaction with the fixed charge groups in the membrane [8]. Another important reason for the low resistance is the low membrane thickness of KESD membrane $(80 \mu \mathrm{m})[8,34]$. Neosepta CMX membrane was designed to have extra mechanical strength, which is obtained from a higher cross-linking degree and greater membrane thickness. Unfortunately, this higher mechanical and dimensional stability of the CMX membrane also results in higher resistance values when compared to the other cation exchange membrane [19].

The anion exchange membrane AESD has a higher resistance than Neosepta AMX. Both membranes have a comparable membrane permselectivity, very similar values of ion exchange capacity (IEC) and also a similar swelling degree (Table 1). However, the greatest difference between these two membranes is that the AESD membrane has tertiary amines as fixed groups and the Neosepta AMX contains quaternary ammonium groups as fixed charges [31, 32, 35]. These weak ion exchange groups in the AESD membrane also have an impact on the membrane properties, e.g. membrane resistance and permselectivity.

\subsection{Electrochemical impedance spectrometry (EIS)}

The previous part clearly showed that direct current measurements can not be used to distinguish between the individual resistances of the pure membrane, the interfacial ionic charge transfer through the electrical double layer and the diffusion boundary layer. EIS, which uses an alternating current, is able to do so and was applied to investigate the influence of the pure membrane resistance, the ionic transfer resistance through the electrical double layer and the diffusion boundary layer resistance on the total measured 
resistance. We analyzed these impedance data in terms of the equivalent electrical circuit model presented in Figure 2. The model fit was carried out by the Ivium software of the Iviumstat impedance analyzer. From these experiments, we could derive the contributions of the consecutive resistances for a $0.017 \mathrm{M} \mathrm{NaCl}$ and a $0.5 \mathrm{M} \mathrm{NaCl}$ solution.

\subsubsection{Impedance data fitting}

To show our approach to analyze the data we chose the results for the low salt concentration $(0.017 \mathrm{M} \mathrm{NaCl})$ for the two ion exchange membranes Neosepta AMX and CMX as an example. Impedance data are typically depicted in Nyquist and Bode plots. Figure 7 shows such a Nyquist plot, which shows the real part $\operatorname{Re}(Z)$ and the imaginary part $-\operatorname{Im}(Z)$ of the impedance $Z$. Figure 8 shows the corresponding Bode plot which shows the relation between the impedance and the frequency.

a) Equivalent circuit fitting (AMX)

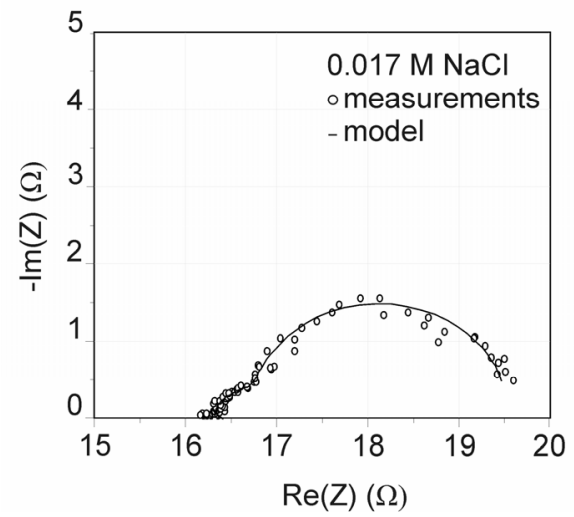

b) Equivalent circuit fitting (CMX)

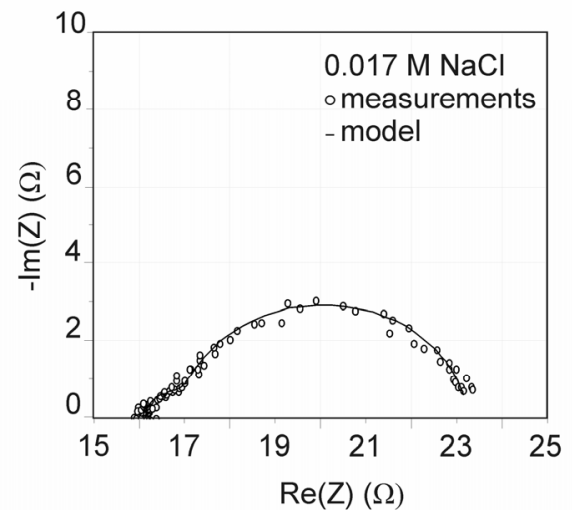

Figure 7: Typical example of a Nyquist plot obtained from EIS measurements. $\operatorname{Re}(Z)$ is the real part and $-\operatorname{Im}(Z)$ is the imaginary part of the impedance Z. Experimental data $(\circ)$ are fitted according to the equivalent electrical circuit model shown in Figure 2 (the model fit is represented by the line): a) anion exchange membrane AMX and b) cation exchange membrane CMX. The values were obtained from measurements in a $0.017 \mathrm{M} \mathrm{NaCl}$ solution at a solution flow rate of $400 \mathrm{ml} / \mathrm{min}$. 
a) Equivalent circuit fitting (AMX)

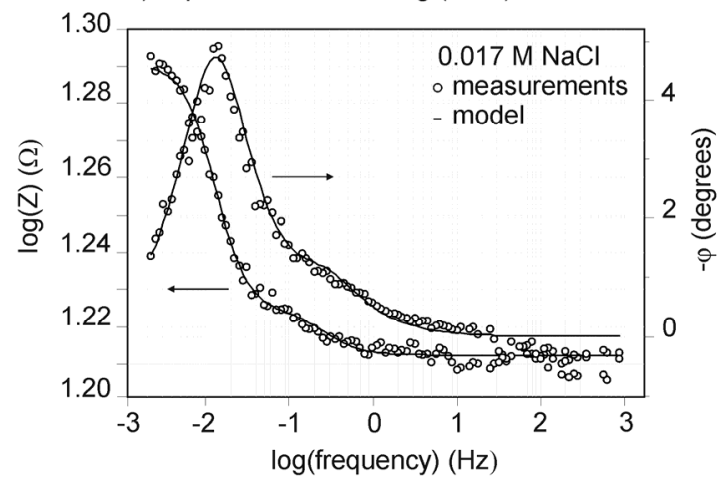

b) Equivalent circuit fitting (CMX)

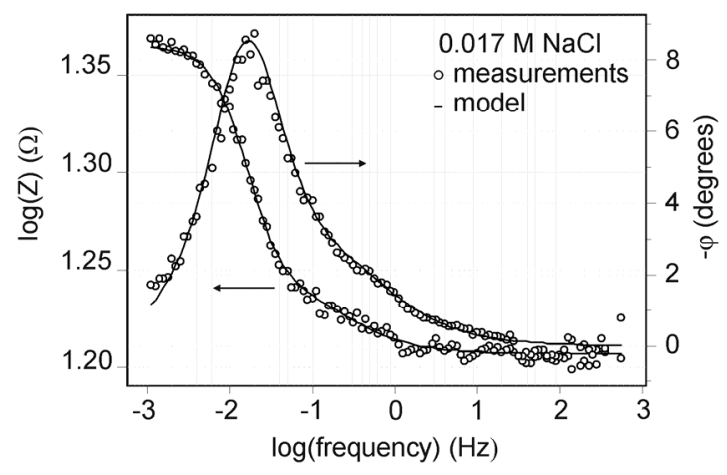

Figure 8: Typical example of a Bode plot obtained from EIS measurements. $\mathrm{Z}$ represents the impedance and $\phi$ represents the phase shift. Experimental data (०) are fitted according to the equivalent electrical circuit model shown in Figure 2 (model fit is represented by the line): a) anion exchange membrane AMX and b) cation exchange membrane CMX. The values were obtained from measurements in a $0.017 \mathrm{M} \mathrm{NaCl}$ solution at a solution flow rate of $400 \mathrm{ml} / \mathrm{min}$.

Both in the Nyquist and the Bode plot the experimentally obtained data are fitted according to the equivalent electrical circuit representing the system of membrane and solution (Figure 2). As an example, Table 2 shows the fitting parameters obtained from the experimental data presented in Figure 7 and 8. These parameters represent the equivalent circuit model presented in Figure 2, from which membrane and solution resistance $\left(\mathrm{R}_{\mathrm{M}+\mathrm{S}}\right)$, the interfacial ionic 
charge transfer resistance through the double layer $\left(R_{D L}\right)$, diffusion boundary layer resistance $\left(\mathrm{R}_{\mathrm{DBL}}\right)$, the interfacial ionic charge capacitance $\left(\mathrm{C}_{\mathrm{DL}}\right)$ and diffusion boundary layer capacitance (QDBL) can be extracted. Pure membrane resistance $\left(R_{\mathrm{M}}\right)$ can be calculated by subtracting the solution resistance $\left(\mathrm{R}_{\mathrm{s}}\right)$ (measured without the membrane, $\mathrm{Rs}=42.41 \Omega \cdot \mathrm{cm}^{2}$ ) from the membrane and solution resistance $\left(\mathrm{R}_{\mathrm{M}+\mathrm{S}}\right)$.

Table 2: Fitting parameters for AMX and CMX membranes in a $0.017 \mathrm{M} \mathrm{NaCl}$ solution at a liquid flow rate of $400 \mathrm{ml} / \mathrm{min}$.

\begin{tabular}{ccccccc}
\hline Membrane & $\begin{array}{c}\mathrm{RM}_{\mathrm{M}+\mathrm{S}} \\
\left(\Omega \cdot \mathrm{cm}^{2}\right)\end{array}$ & $\begin{array}{c}\mathrm{RDL} \\
\left(\Omega \cdot \mathrm{cm}^{2}\right)\end{array}$ & $\begin{array}{c}\mathrm{CDL} \\
\left(\mathrm{F} / \mathrm{cm}^{2}\right)\end{array}$ & $\begin{array}{c}\text { RDBL } \\
\left(\Omega \cdot \mathrm{cm}^{2}\right)\end{array}$ & $\begin{array}{c}\text { QDBL } \\
\left(\mathrm{S} \cdot \mathrm{s}^{\mathrm{n}} / \mathrm{cm}^{2}\right)\end{array}$ & $\begin{array}{c}\mathrm{n} \\
(-)\end{array}$ \\
\hline AMX & $46.3 \pm 0.4$ & $1.3 \pm 0.1$ & $0.47 \pm 0.01$ & $6.9 \pm 1.0$ & $1.8 \pm 0.1$ & $0.96 \pm 0.02$ \\
\hline $\mathrm{CMX}$ & $45.8 \pm 0.3$ & $2.5 \pm 0.1$ & $0.12 \pm 0.01$ & $18.6 \pm 0.9$ & $0.6 \pm 0.1$ & $0.97 \pm 0.04$ \\
\hline
\end{tabular}

$\mathrm{R}_{\mathrm{M}+\mathrm{S}}$ is the membrane and solution resistance ( $\left.\mathrm{Rs}_{s}=42.4 \Omega \cdot \mathrm{cm}^{2}\right)$, $R_{D L}$ is the resistance of the interfacial ionic charge transfer through the double layer, RDBL is the resistance of the diffusion boundary layer, $\mathrm{CDL}$ is the capacitance of the interfacial ionic charge at the membrane surface (double layer), QDBL is the capacitance of the diffusion boundary layer (constant phase element - non-ideal capacitor), $\mathrm{n}$ is the parameter for the constant phase element $(\mathrm{Q})$. If $\mathrm{n}=1$, the constant phase element represent a capacitor [28, 29].

\subsubsection{Resistance at low concentration $(0.017 \mathrm{M} \mathrm{NaCl})$}

By applying the equivalent circuit model to the impedance measurements, we were able to distinguish between the membrane resistance, electrical double layer resistance and diffusion boundary layer resistance as a function of the solution flow rate. The relationships between these resistances and the identification of the dominant resistance are especially important for improving, designing and optimizing electro-membrane processes, such as 
reverse electrodialysis, electrodialysis, fuel cells, microbial fuel cells and membrane capacitive deionization, which operate at low salt concentrations. Figure 9 shows the different resistances for the four membranes investigated under different hydrodynamic conditions.

a) $\mathrm{AMX}$

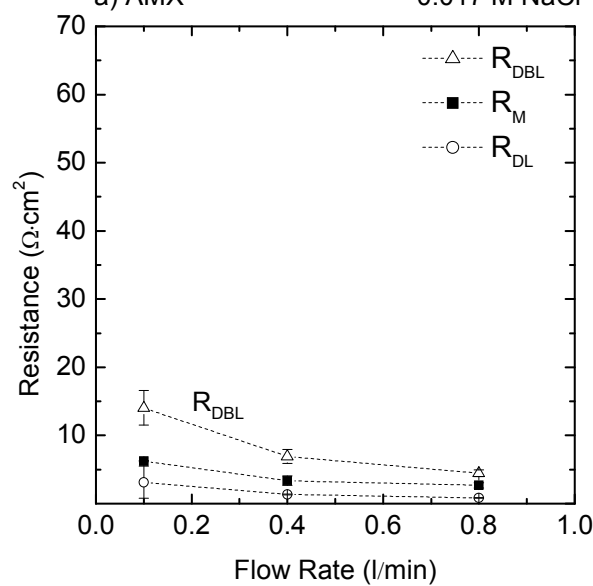

c) AESD

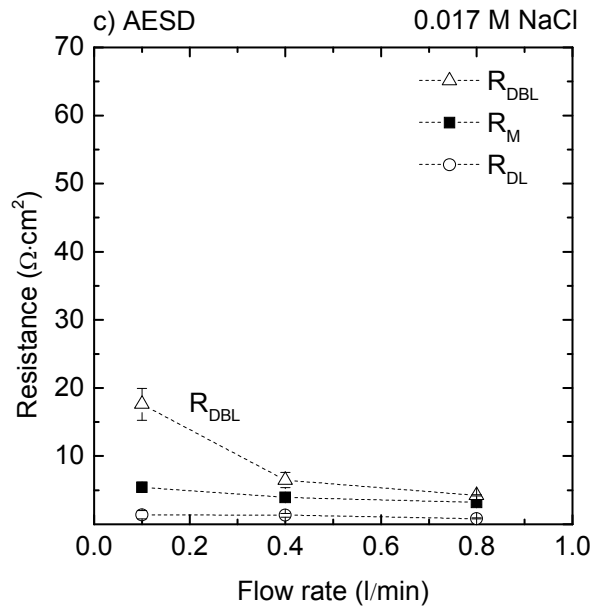

b) $\mathrm{CMX}$

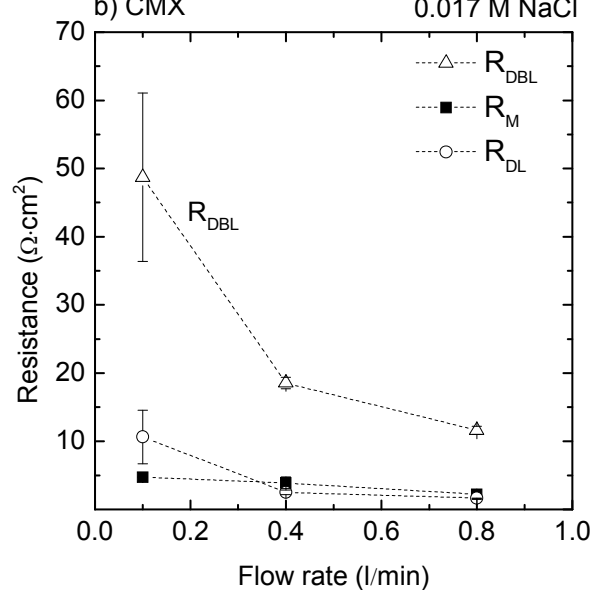

d) KESD

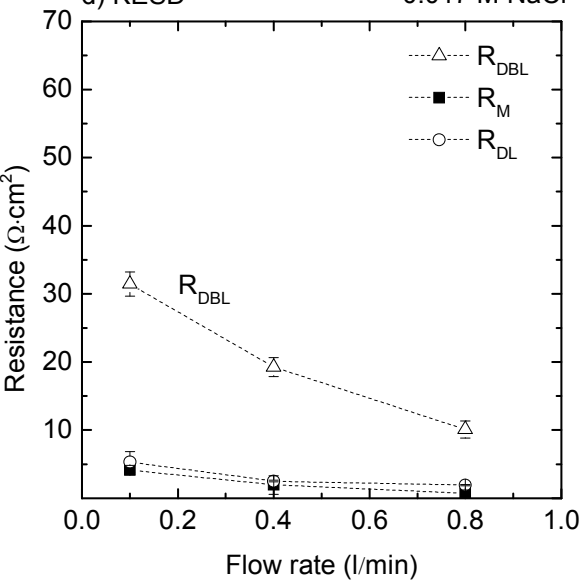

Figure 9: Membrane resistance $\left(\mathrm{RM}_{\mathrm{M}}\right)$, the resistance of the interfacial ionic charge transfer through the double layer $\left(\mathrm{RDL}_{\mathrm{L}}\right)$ and diffusion boundary layer resistance ( $\left.\mathrm{R}_{\mathrm{DBL}}\right)$ as a function of solution flow rate for a $0.017 \mathrm{M} \mathrm{NaCl}$ solution; a) anion exchange membrane AMX; b) cation exchange membrane CMX; c) anion exchange membrane AESD and d) cation exchange membrane KESD. 
From the impedance results, it is obvious that at a low salt concentration $(0.017 \mathrm{M} \mathrm{NaCl})$, for all membranes and at all solution flow rates, the diffusion boundary layer resistance $\mathrm{R}_{\mathrm{DBL}}$ is the dominant resistance that determines the overall resistance as determined from direct current methods, while the membrane resistance and the resistance of the electrical double layer are relatively small and have only a very minor contribution to the overall resistance. The diffusion boundary layer resistance decreases significantly with increasing solution flow rate. This effect was expected as the diffusion boundary layer typically has a thickness of a few hundred micrometers and can be affected by solution mixing [36].

Both the membrane resistance and the resistance of the interfacial ionic charge transfer through the double layer should be independent of the solution flow rate. The double layer thickness is on the nanometer scale (Debye length) and therefore ionic transport through that layer should not be affected by solution mixing. Nevertheless, a very small influence of the flow rate on these resistances ( $\mathrm{R}_{\mathrm{M}}$ and $\mathrm{RDL}$ ) at the lowest flow rate was observed, but this is most likely related to the non-uniform electric field distribution over the measuring setup at low solution flow rates and relatively high pure solution resistance (Rs $=42.41 \Omega \cdot \mathrm{cm}^{2}$ ) compared with the membrane and "double layer" resistance at a $0.017 \mathrm{M} \mathrm{NaCl}$ solution, which results in a greater experimental error.

The resistances of the diffusion boundary layer RDBL and the interfacial ionic charge transfer through the double layer $\mathrm{R}_{\mathrm{DL}}$ for anion exchange membranes are lower than for cation exchange membranes. This is due to the difference in ion mobility between $\mathrm{Cl}^{-}$ions and $\mathrm{Na}^{+}$ions (ratio ucl/una $\approx 1.5$ ) [33, 37].

From these results, it is clear that the diffusion boundary layer is the dominant resistance for all membranes at $0.017 \mathrm{M} \mathrm{NaCl}$ and that it can be minimized by an increased solution flow rate and improved hydrodynamics. The membrane resistance and the resistance of the interfacial ionic charge transfer through the electrical double layer play a minor role. 


\subsubsection{Resistance at high concentration $(0.5 \mathrm{M} \mathrm{NaCl})$}

Figure 10 shows the membrane resistance $(\mathrm{RM})$, the resistance of the interfacial ionic charge transfer through the double layer $\left(\mathrm{R}_{\mathrm{DL}}\right)$ and the diffusion boundary layer resistance (RDBL) as a function of the solution flow rate at a concentration of $0.5 \mathrm{M} \mathrm{NaCl}$ as determined from EIS measurements.

a) $A M X$

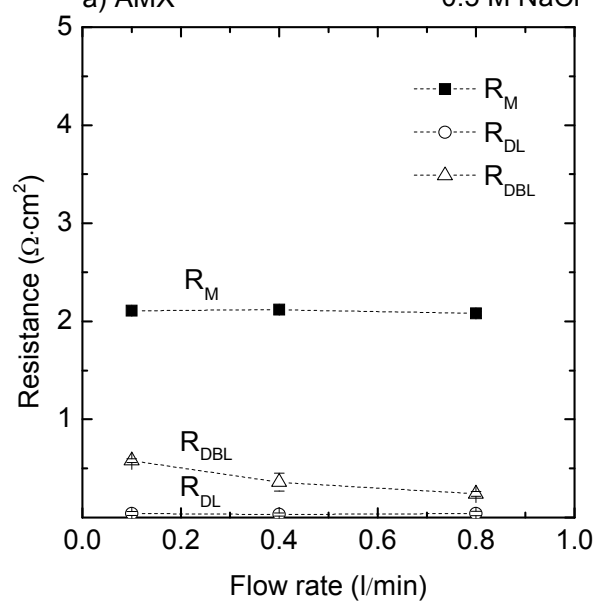

c) AESD

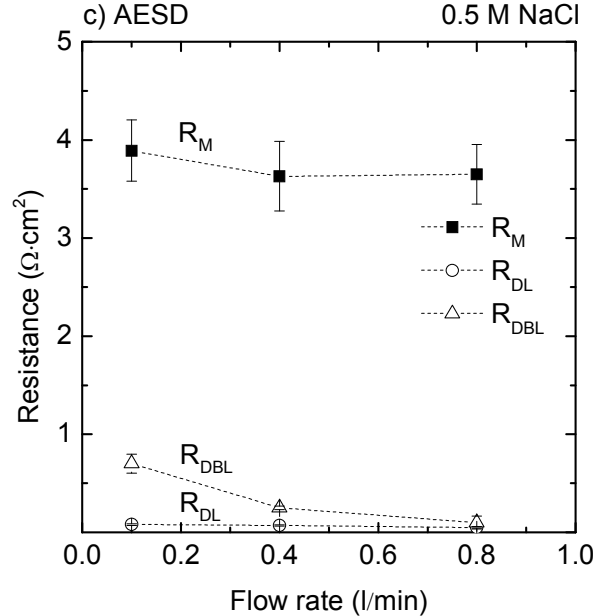

b) $\mathrm{CMX}$

$0.5 \mathrm{M} \mathrm{NaCl}$

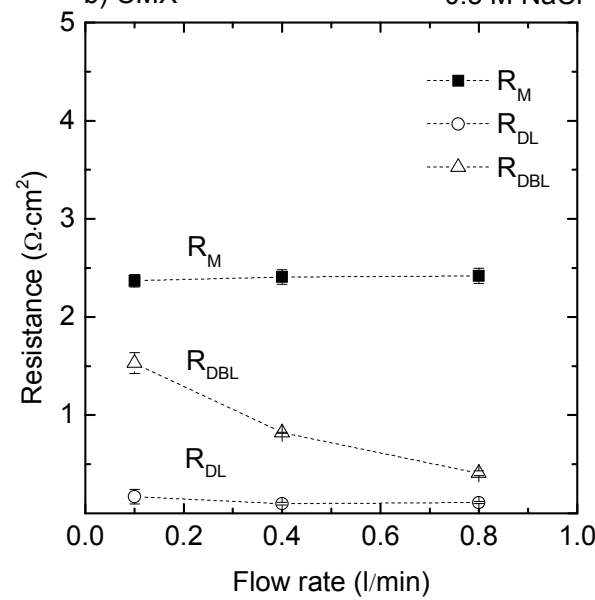

d) KESD

$0.5 \mathrm{M} \mathrm{NaCl}$

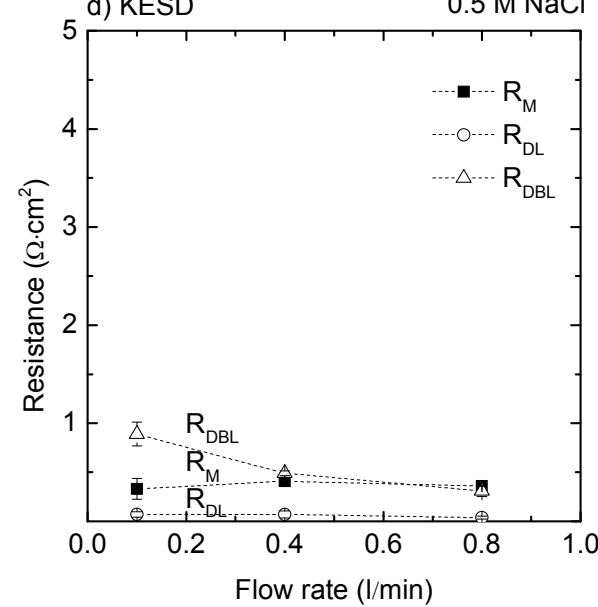

Figure 10: Membrane resistance (RM), the resistance of the interfacial ionic charge transfer through the double layer $\left(R_{D L}\right)$ and diffusion boundary layer resistance $\left(R_{D B L}\right)$ as a function of the solution flow rate for a $0.5 \mathrm{M} \mathrm{NaCl}$ solution; a) anion exchange membrane AMX; b) cation exchange membrane CMX; c) anion exchange membrane AESD and d) cation exchange membrane KESD. 
At higher concentrations $(0.5 \mathrm{M} \mathrm{NaCl})$ the membrane resistance is the dominant resistance (relative to the resistance of the ionic charge transfer through the double layer and the diffusion boundary layer resistance). It is significantly higher than two other resistances and it is independent of the solution flow rate. Only for the KESD membrane, which is a low resistance cation exchange membrane, the diffusion boundary layer resistance is somewhat higher than the pure membrane resistance and both resistances are of equal importance. The resistance of the diffusion still plays a considerable role, even at higher concentrations and contributes to the overall resistance in contrast to what Park described [11]. Even at a concentration of $0.5 \mathrm{M} \mathrm{NaCl}$, the diffusion boundary layer resistance decreases with increasing solution flow rate, The resistance of the interfacial ionic charge transfer through the double layer for all measured membranes is independent of the solution flow rate, because its thickness is on the nanometer scale and therefore it cannot be influenced by solution mixing $[26,27]$.

These results reveal that the diffusion boundary layer resistance is the dominant resistance for a $0.017 \mathrm{M}$ solution. It can be minimized by a factor 3 to 4 by increasing the flow rate from $100 \mathrm{ml} / \mathrm{min}$ to $800 \mathrm{ml} / \mathrm{min}$. The membrane resistance is the dominant resistance for a $0.5 \mathrm{M}$ solution and cannot be minimized by increasing the solution flow rate. However, even for a $0.5 \mathrm{M}$ solution, which is a standard characterization solution, the diffusion boundary layer resistance still plays a considerable role in the overall measured resistance $\left(R_{M}+R_{D L}++R_{D B L}\right)$.

\subsubsection{Influence of temperature}

Resistance in general strongly depends on the temperature and for many ion exchange processes it is important to investigate the temperature effect on the various resistances. This can be done via EIS measurements as well $[4,38]$. Figure 11 shows the membrane resistance (RM), the resistance of 
interfacial ionic charge transfer through the double layer $\left(\mathrm{RDL}_{\mathrm{DL}}\right)$ and the diffusion boundary layer resistance ( $\mathrm{R}_{\mathrm{DBL}}$ ) as a function of the temperature for a $0.5 \mathrm{M}$ $\mathrm{NaCl}$ solution. Neosepta AMX and CMX membranes were used and the solution flow rate was set to $400 \mathrm{ml} / \mathrm{min}$.
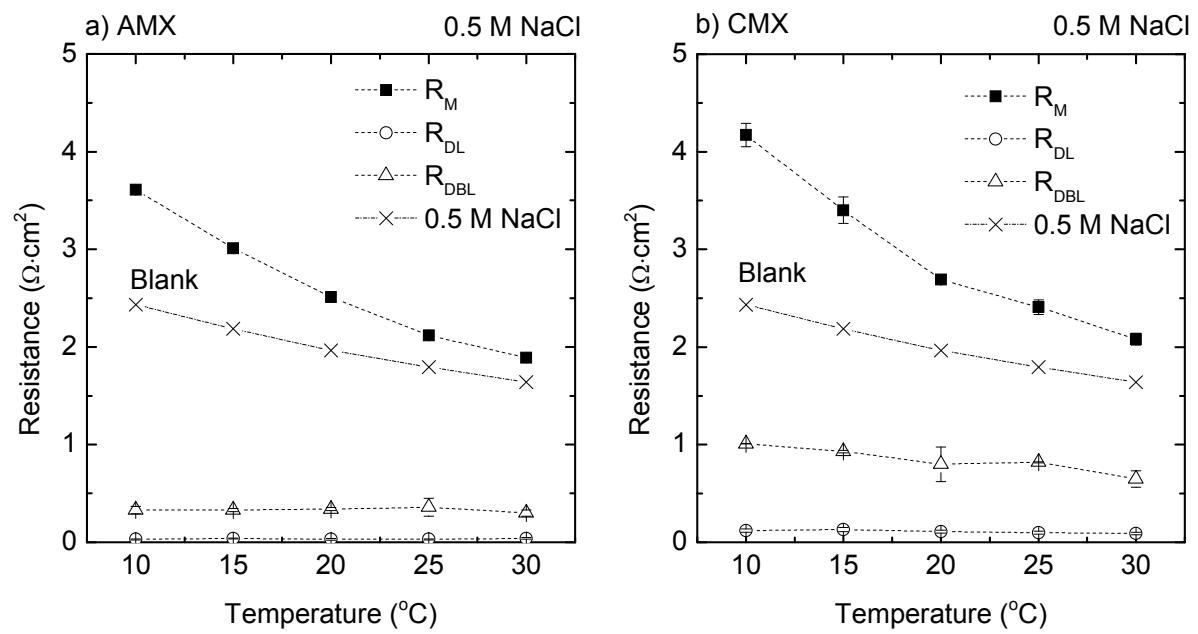

Figure 11: The membrane resistance $(\mathrm{RM})$, the resistance of interfacial ionic charge transfer through the double layer $\left(R_{D L}\right)$ and diffusion boundary resistance ( $R_{D B L}$ ) as a function of the solution temperature for a) the anion exchange membrane Neosepta AMX and b) the cation exchange membrane Neosepta CMX in a $0.5 \mathrm{M} \mathrm{NaCl}$ solution.

It is well known that the solution and membrane resistances decrease with increasing temperature $[4,38,39]$. This is what we also observe in Figure 11. Our results show that the effect is the most significant for the membrane resistance which strongly decreases with increasing temperature, whereas the solution resistance only slowly changes with temperature. This provides highly relevant information for processes operating at lower temperatures; it means that in order to have a sufficiently high process efficiency also at lower temperatures, especially the membrane resistance should be minimized (by using low-resistance membranes) [33]. The effect of the temperature on the membrane resistance is stronger for the CMX cation exchange membrane than 
for the AMX anion exchange membrane. This effect appears attributable to the difference in ion mobility of the anions and cations in the bulk solution ( $\mathrm{ucl}_{\mathrm{c}} / \mathrm{u}_{\mathrm{Na}}=1.5$ ), but also the concentration of the fixed ion exchange groups inside the ion exchange membrane plays a role $[19,33]$. Because the CMX membrane has a higher fixed charge concentration than the AMX membrane (CMX: 7.63 mol/l; AMX: $6.40 \mathrm{~mol} / \mathrm{l})$, ion transport in the CMX membrane is relatively more sensitive to changes in the temperature. Also the higher value of the resistance of the interfacial ionic charge transfer $(\mathrm{RDL})$ for the $\mathrm{CMX}$ membrane might be caused by the higher fixed-charge concentration of this membrane relative to that of the AMX membrane and the difference in ion mobility of the anions and cations ( $\mathrm{ucl}_{\mathrm{Cl}} / \mathrm{una}_{\mathrm{a}}=1.5$ ). The diffusion boundary layer resistance for the CMX membrane decreases with increasing temperature. This effect can be related to ion mobility as well, which increases with increasing temperature [38]. We expected the same effect for the anion exchange membrane AMX, but it is not evident from our results and most probably this effect is within the experimental error. Nevertheless, the effect for the AMX membrane should be smaller, however, due to the difference in ion mobility between $\mathrm{Cl}^{-}$and $\mathrm{Na}^{+}$ions $[33,37]$.

\subsubsection{Comparison of the direct current and alternating current resistance}

In contrast to direct current measurements where we measure an overall resistance, electrical impedance spectroscopy, which uses an alternating current allowed us to discriminate between the individual resistances of the pure membrane, the electrical double layer and the diffusion boundary layer. As a consequence, the total of the individual resistances as measured by EIS should be equal to the 'overall' resistance determined from the direct current experiments. Table 3 shows this comparison between the resistance determined 
with direct current method and the total resistance $\left(R_{M}+R_{D L}+R_{D B L}\right)$ as measured by EIS.

Table 3: Comparison between the resistance as measured by direct current (DC) and alternating current (AC).

\begin{tabular}{|c|c|c|c|c|c|}
\hline \multirow[b]{2}{*}{ Membrane } & \multirow[b]{2}{*}{$\begin{array}{l}\text { Flow rate } \\
(\mathrm{ml} / \mathrm{min})\end{array}$} & \multicolumn{2}{|c|}{$0.017 \mathrm{M} \mathrm{NaCl}$} & \multicolumn{2}{|c|}{$0.5 \mathrm{M} \mathrm{NaCl}$} \\
\hline & & $\begin{array}{c}\mathrm{RDC} \\
\left(\Omega \cdot \mathrm{cm}^{2}\right)\end{array}$ & $\begin{array}{c}\mathrm{R}_{\mathrm{AC}} \\
\left(\mathrm{R}_{\mathrm{M}}+\mathrm{R}_{\mathrm{DL}}+\mathrm{R}_{\mathrm{DBL}}\right) \\
\left(\Omega \cdot \mathrm{cm}^{2}\right)\end{array}$ & $\begin{array}{c}\mathrm{RDC} \\
\left(\Omega \cdot \mathrm{cm}^{2}\right)\end{array}$ & $\begin{array}{c}\mathrm{R}_{\mathrm{AC}} \\
\left(\mathrm{R}_{\mathrm{M}}+\mathrm{R}_{\mathrm{DL}}+\mathrm{R}_{\mathrm{DBL}}\right) \\
\left(\Omega \cdot \mathrm{cm}^{2}\right)\end{array}$ \\
\hline \multirow[t]{3}{*}{ CMX } & 100 & 54.2 & 64.1 & 3.9 & 4.1 \\
\hline & 400 & 37.6 & 25.0 & 3.6 & 3.3 \\
\hline & 800 & 16.3 & 15.5 & 3.4 & 2.9 \\
\hline \multirow[t]{3}{*}{ AMX } & 100 & 34.0 & 23.4 & 2.9 & 2.7 \\
\hline & 400 & 27.1 & 11.6 & 2.8 & 2.5 \\
\hline & 800 & 11.6 & 7.9 & 2.6 & 2.6 \\
\hline \multirow[t]{3}{*}{ KESD } & 100 & 66.8 & 40.9 & 1.3 & 1.3 \\
\hline & 400 & 31.4 & 23.8 & 1.1 & 1.0 \\
\hline & 800 & 14.2 & 12.8 & 0.9 & 0.7 \\
\hline \multirow[t]{3}{*}{ AESD } & 100 & 43.4 & 23.6 & 4.4 & 4.7 \\
\hline & 400 & 24.1 & 11.7 & 4.3 & 4.0 \\
\hline & 800 & 13.7 & 8.3 & 4.2 & 3.8 \\
\hline
\end{tabular}

The results show that for all membranes, the resistance measured by the direct current method is indeed comparable to the total resistance $\left(R_{M}+R_{D L}+R_{D B L}\right)$ as determined by the alternating current method (EIS). The results presented in this article clearly show that the increase in membrane resistance with decreasing concentration as measured in direct current experiments does not stem from an increase in membrane resistance, but is the consequence of the strong increase in the resistance of the diffusion boundary layer with decreasing concentration. This also explains the strong effect of the flow rate on the resistance as measured by direct current experiments. At higher concentrations, the pure membrane resistance starts to dominate the resistance as measured by direct current measurements, although also the diffusion boundary layer resistance still plays a considerable role. 


\section{Conclusions}

The results presented in this work show a strong increase (more than 5 times) in membrane resistance at low solution concentrations $(<0.1 \mathrm{M} \mathrm{NaCl})$ as measured under direct current conditions. In addition, a strong dependency of this resistance on the solution flow rate was observed. Analysis of experimental data from electrochemical impedance spectroscopy revealed that at very low salt concentrations $(0.017 \mathrm{M} \mathrm{NaCl})$, the dominant resistance is the diffusion boundary layer resistance, whereas the pure membrane resistance is of minor importance. At higher salt concentration $0.5 \mathrm{M} \mathrm{NaCl}$ the pure membrane resistance is the dominant resistance, but even at this concentration the diffusion boundary layer plays a considerable role in overall measured resistance. For both concentrations the membrane resistance and the resistance of the interfacial ionic charge transfer through the double layer were independent of the solution flow rate, but the resistance of the diffusion boundary layer could be minimized by approximately a factor 3 to 4 by increasing the solution flow rate from 100 to $800 \mathrm{ml} / \mathrm{min}$. The membrane resistance decreases significantly with increasing temperature, whereas the solution resistance is only slightly influenced by the temperature. We found that for all membranes the sum of the individual resistances as measured by EIS equals the overall resistance as measured under direct current conditions.

These results are of major importance for various electro-membrane processes, such as reverse electrodialysis, electrodialysis, fuel cells, microbial fuel cells and membrane capacitive deionization that operate at low salt concentrations and in the temperature range. 


\section{Acknowledgements}

A special word of thanks goes to Bart van Limpt for the fruitful discussions on electrochemical impedance spectroscopy and to Professor Marek Bryjak from the Wroclaw University of Technology for providing the KESD and AESD membranes. This work was performed at TTIW Wetsus, Centre of Excellence for Sustainable Water Technology. Wetsus is funded by the city of Leeuwarden, the Province of Fryslan, the European Union European Regional Development Fund and by the EZ-KOMPAS Program of the "Samenwerkingsverband Noord/Nederland". The industrial participants of the Wetsus research theme Energy (DOW, FujiFilm B.V., Nuon B.V., MAGNETO special anodes B.V., Triqua B.V., Landustrie SNEEK B.V., Frisia Zout B.V., Waterleidingmaatschappij Drenthe, Waterbedrijf Groningen and Waterlaboratorium Noord) are kindly acknowledged for their financial support.

\section{References}

1. R. K. J. Jagur-Grodzinski, Novel Process for Direct Conversion of Free Energy of Mixing into Electric Power Ind. Eng. Chem. Process Des. Dev. (1986) 443-449.

2. J. W. Post, J. Veerman, H. V. M. Hamelers, G. J. W. Euverink, S. J. Metz, K. Nymeijer, C. J. N. Buisman, Salinity-gradient power: Evaluation of pressure-retarded osmosis and reverse electrodialysis, Journal of Membrane Science 288 (2007) 218-230.

3. R. Audinos, Electric power produced from two solutions of unequal salinity by reverse electrodialysis, Indian Journal of Chemistry 31A (1992) 348-354.

4. $\quad$ R.E. Lacey, Energy by Reverse Electrodialysis, Ocean Engng. 7 (1980) 147.

5. R. E. Pattle, Production of Electric Power by mixing Fresh and Salt Water in the Hydroelectric Pile, Nature 174 (1954) 660. 
6. R. A. Rozendal, H. V. M. Hamelers, C. J. N. Buisman, Effects of Membrane Cation Transport on $\mathrm{pH}$ and Microbial Fuel Cell Performance, Environ. Sci. Technol. 40 (2006) 5206-5211.

7. B. E. Logan, B. Hamelers, R. Rozendal, U. Schroder, J. Keller, S. Freguia, P. Aelterman, W. Verstraete, K. Rabaey, Microbial Fuel Cells: Methodology and Technology, Environ. Sci. Technol. 40 (2006) 51815192.

8. P. Dlugolecki, K. Nymeijer, S. Metz, M. Wessling, Current status of ion exchange membranes for power generation from salinity gradients, Journal of Membrane Science 319 (2008) 214-222.

9. F. Harnisch, U. Schroder, F. Scholz, The suitability of monopolar and bipolar ion exchange membranes as separators for biological fuel cells, Environmental Science and Technology 42 (2008) 1740-1746.

10. J. S. Park, T. C. Chilcott, H. G. L. Coster, S. H. Moon, Characterization of BSA-fouling of ion-exchange membrane systems using a subtraction technique for lumped data, Journal of Membrane Science 246 (2005) 137.

11. J.-S. Park, J.-H. Choi, J.-J. Woo, S.-H. Moon, An electrical impedance spectroscopic (EIS) study on transport characteristics of ion-exchange membrane systems, Journal of Colloid and Interface Science 300 (2006) 655-662.

12. J.-H. Choi, J.-S. Park, S.-H. Moon, Direct Measurement of Concentration Distribution within the Boundary Layer of an Ion-Exchange Membrane, Journal of Colloid and Interface Science 251 (2002) 311-317.

13. P. Sistat, G. Pourcelly, Chronopotentiometric response of an ionexchange membrane in the underlimiting current-range. Transport phenomena within the diffusion layers, Journal of Membrane Science 123 (1997) 121-131.

14. J. J. Krol, M. Wessling, H. Strathmann, Concentration polarization with monopolar ion exchange membranes: current-voltage curves and water dissociation, Journal of Membrane Science 162 (1999) 145-154.

15. P. Dlugolecki, A. Benoit, S. J. Metz, K. Nijmeijer, M. Wessling, Transport limitations in ion exchange membranes at low salt concentrations, accepted for publication to J. Membr. Sci. (2009) 
16. J. Veerman, J. W. Post, M. Saakes, S. J. Metz, G. J. Harmsen, Reducing power losses caused by ionic shortcut currents in reverse electrodialysis stacks by a validated model, Journal of Membrane Science 310 (2008) 418-430.

17. J.-S. Park, J.-H. Choi, K.-H. Yeon, S.-H. Moon, An approach to fouling characterization of an ion-exchange membrane using current-voltage relation and electrical impedance spectroscopy, Journal of Colloid and Interface Science 294 (2006) 129-138.

18. H. G. L. Coster, T. C. Chilcott, A. C. F. Coster, Impedance spectroscopy of interfaces, membranes and ultrastructures, Bioelectrochemistry and Bioenergetics 40 (1996) 79-98.

19. H. Strathmann, Membrane Science and Technology Ion-Exchange Membrane Separation Processes, 9, 1 ${ }^{\text {st }}$ Edition, Elsevier, 2004.

20. J. Benavente, A. Canas, M. J. Ariza, A. E. Lozano, J. de Abajo, Electrochemical parameters of sulfonated poly(ether ether sulfone) membranes in $\mathrm{HCl}$ solutions determined by impedance spectroscopy and membrane potential measurements, Solid State Ionics 145 (2001) 53.

21. T. C. Chilcott, M. Chan, L. Gaedt, T. Nantawisarakul, A. G. Fane, H. G. L. Coster, Electrical impedance spectroscopy characterisation of conducting membranes: I. Theory, Journal of Membrane Science 195 (2002) 153-167.

22. T. C. Chilcott, H. G. L. Coster, E. P. George, A novel method for the characterisation of the double fixed charge (bipolar) membrane using impedance spectroscopy, Journal of Membrane Science 108 (1995) 185197.

23. A. Narebska, A. Warszawski, S. Koter, L. Tran Ti, Irreversible thermodynamics of transport across charged membranes. Part V. Isothermal transport through anion-exchange membranes and macroscopic resistance coefficients, Journal of Membrane Science 106 (1995) 25-38.

24. A. Narebska, S. Koter, A. Warszawski, L. Tran Ti, Irreversible thermodynamics of transport across charged membranes. Part VI. Frictional interactions and coupling effects in transport of acid through 
anion exchange membranes, Journal of Membrane Science 106 (1995) 39-48.

25. L. V. Karpenko, O. A. Demina, G. A. Dvorkina, S. B. Parshikov, C. Larchet, B. Auclair, N. P. Berezina, Comparative study of methods used for the determination of electroconductivity of ion-exchange membranes, Russian Journal of Electrochemistry 37 (2001) 287-293.

26. I. Rubinstein, SIAM, Electro-Diffusion of Ions, Edition, Philadelphia, 1990.

27. A. J. Bard, L. R. Faulkner, Electrochemical Methods, Edition, Wiley, New York, 1980.

28. P. Sistat, A. Kozmai, N. Pismenskaya, C. Larchet, G. Pourcelly, V. Nikonenko, Low-frequency impedance of an ion-exchange membrane system, Electrochimica Acta 53 (2008) 6380-6390.

29. J. R. Macdonald, Impedance Spectroscopy, Emphasizing Solid Materials and Systems, Edition, John Wiley \& Sons Ltd, New York, 1987.

30. A. Alcaraz, H. Holdik, T. Ruffing, P. Ramirez, S. Mafe, AC impedance spectra of bipolar membranes: an experimental study, Journal of Membrane Science 150 (1998) 43.

31. M. Grzebyk, G. Pozniak, Microbial fuel cells (MFCs) with interpolymer cation exchange membranes, Separation and Purification Technology 41 (2005) 321-328.

32. G. Pozniak, W. Trochimczuk, Tubular interpolymer ion-exchange membranes. Donnan dialysis through strong-base membranes, Journal of Membrane Science 49 (1990) 55-68.

33. T. Sata, Ion Exchange Membranes, Edition, The Royal Society of Chemistry Cambrige, 2004.

34. F. G. Wilhelm, I. G. M. Punt, N. F. A. van der Vegt, H. Strathmann, M. Wessling, Cation permeable membranes from blends of sulfonated poly(ether ether ketone) and poly(ether sulfone), Journal of Membrane Science 199 (2002) 167-176.

35. Y. Mizutani, Structure of ion exchange membranes, Journal of Membrane Science 49 (1990) 121-144. 
36. J.-H. Choi, J.-S. Park, S.-H. Moon, Direct Measurement of Concentration Distribution within the Boundary Layer of an Ion-Exchange Membrane, Journal of Colloid and Interface Science 251 (2002) 311.

37. J. J. Krol, M. Wessling, H. Strathmann, Chronopotentiometry and overlimiting ion transport through monopolar ion exchange membranes, Journal of Membrane Science 162 (1999) 155-164.

38. G. R. Langereis, W. Olthuis, P. Bergveld, A demonstration of acquiring specific concentration data by variations in the operating conditions of a non-specific sensor, Chemometrics and Intelligent Laboratory Systems 50 (2000) 211-223.

39. D. S. Kim, M. D. Guiver, S. Y. Nam, T. I. Yun, M. Y. Seo, S. J. Kim, H. S. Hwang, J. W. Rhim, Preparation of ion exchange membranes for fuel cell based on crosslinked poly(vinyl alcohol) with poly(styrene sulfonic acid-co-maleic acid), Journal of Membrane Science 281 (2006) 156-162. 


\title{
Chapter 5
}

\section{The practical potential of reverse electrodialysis as process for sustainable energy generation}

\begin{abstract}
Reverse electrodialysis (RED) is a non-polluting sustainable technology that converts the free energy of mixing of two solutions with different salinity directly into electrical energy. Although the theoretical potential is high, the practical power output obtained is limited yet due to concentration polarization phenomena and spacer shadow effects. In this work we combine theoretical calculations with direct current and alternating current experimental stack characterization methods to quantify the contribution of concentration polarization phenomena, spacer shadow effects and stack resistance in RED under different hydrodynamic conditions in a temperature range from 10 to 40 ${ }^{\circ} \mathrm{C}$ to show the practical potential of RED. Concentration polarization phenomena play an important role and their influence can be minimized by optimal stack hydrodynamics. Improved spacer designs and new spacer concepts offer extensive room to reduce the spacer shadow effect and to further increase the practical power output. Improvement of hydrodynamics and reduction of the spacer shadow effect directly result in a significant increase in power output of the RED process and values almost double the values currently obtained can be realized, which brings RED close to economical viability.
\end{abstract}

\section{Scientific publication:}

P. Dlugolecki, A. Gambier, K. Nijmeijer, M. Wessling, The practical potential of reverse electrodialysis as process for sustainable energy generation, Environmental Science and Technology 43 (2009) 6888-6894. 


\section{Introduction}

Salinity gradient energy has a global potential of 2.6 TW as renewable energy source [1]. Salinity gradient energy converts the free energy of mixing of two solutions with different salinity into electrical energy and can be applied wherever two solutions of different salinity are mixed, e.g. where river flows into the sea. Reverse electrodialysis (RED) can convert the majority of this free energy (up to $80 \%$ ) directly into electrical power [2-4]. In RED, a concentrated salt solution and a less concentrated salt solution are brought into contact through an alternating series of anion exchange membranes (AEM) and cation exchange membranes (CEM). The principle of reverse electrodialysis is well described in the literature $[2,5]$.

Especially the resistance of the river water compartment (which is directly related to the thickness of this compartment and the ionic conductivity of the solution present in this compartment) and the performance of the ion exchange membranes have a large impact on the process performance and efficiency [2]. Due to the relatively low concentration of ions in river water, the resistance of the diluted compartment becomes especially important when river water is used as the diluted solution. A way to increase the ionic conductivity is the use of a more concentrated salt solution (e.g. sea water) in the diluted compartment $[6,7]$. This would automatically imply the use of an even more concentrated solution (e.g. industrial brines) in the concentrated compartment. This directly results in a decrease of the resistance of the solution compartments and an increase in power output [6-8]. Other effective ways to reduce the resistance of the diluted compartment are the decrease of the thickness of the diluted compartment or the premixing of the diluted salt solution and the concentrated solution to reach an optimal salt concentration in the diluted chamber [5].

Dlugolecki et al. studied the performance of commercially available ion exchange membranes in RED and presented a theoretical model to predict the 
maximum obtainable power density [2]. This model assumes that the stack resistance equals the sum of the resistances of the individual stack components i.e. the resistance of the anion and cation exchange membrane, the resistance of the diluted and concentrated solution compartments and the resistance of the electrodes (Equation 1).

$$
\mathrm{R}_{\text {stack }}=\frac{\mathrm{N}}{\mathrm{A}} \cdot\left(\mathrm{R}_{\mathrm{aem}}+\mathrm{R}_{\text {cem }}+\frac{\mathrm{d}_{\mathrm{c}}}{\kappa_{\mathrm{c}}}+\frac{\mathrm{d}_{\mathrm{d}}}{\kappa_{\mathrm{d}}}\right)+\mathrm{R}_{\mathrm{el}}
$$

Where $\mathrm{N}$ is the number of cell pairs (one anion and one cation exchange membrane), $\mathrm{A}$ is the effective membrane area $\left(\mathrm{m}^{2}\right)$, Raem is the anion exchange membrane resistance $\left(\Omega \cdot \mathrm{m}^{2}\right)$, R $\mathrm{R}_{\mathrm{cem}}$ is the cation exchange membrane resistance $\left(\Omega \cdot m^{2}\right), d_{c}$ is the thickness of the concentrated solution compartment $(m), d_{d}$ is the thickness of the diluted solution compartment $(\mathrm{m}), \kappa_{\mathrm{c}}$ is the concentrated compartment conductivity $\left(\mathrm{S} \cdot \mathrm{m}^{-1}\right), \kappa_{\mathrm{d}}$ is the diluted compartment conductivity $\left(\mathrm{S} \cdot \mathrm{m}^{-1}\right)$ and Rel is the electrode resistance $(\Omega)$. The resistance of the electrodes is assumed to be negligible, because a full size stack will contain at least multiple hundreds of membranes reducing the contribution of the electrode resistance to less than $2 \%$. The resistance of the diluted compartment and the membrane resistance are the dominant resistances [2].

Even though concentration polarization can have a significant effect in the real application, the theoretical model does not take it into account and spacer shadow effects are omitted as well [9]. Concentration polarization phenomena occur at the membrane-solution interface due to differences in ion transport number between the solution phase and the membrane resulting in the build up of concentrations gradients in the diffusion boundary layer adjacent to the membrane surface. The spacer shadow effect occurs because spacers applied are non-conductive and block the ionic transport [9]. Veerman et al. investigated the performance of a RED stack operating on artificial sea and river water and showed that the total cell resistance was one and a half times higher than expected based on the contribution of the individual components 
[10]. Post et al. studied the internal energetic losses in a RED stack for two different spacer thicknesses $(0.2$ and $0.5 \mathrm{~mm})$ and concluded that decreasing the inter-membrane distance (spacer thickness) could be beneficial for power generation, although not to the expected extent [4]. These results suggest that concentration polarization phenomena and spacer shadow effects play an important role in the overall stack performance. To the best of our knowledge there are no scientific papers that report the influence of concentration polarization phenomena and spacer shadow effects on the reverse electrodialysis process performance and efficiency.

Often, resistances are measured using direct current methods [10-15]. However, the overall RED stack resistance as measured under direct current conditions does not only include the pure resistances of the individual components in the stack (i.e. membrane resistance, sea and river water compartment resistance) but also includes concentration polarization phenomena and spacer shadow effects occurring at the membrane-solution interface [16].

Electrochemical impedance spectroscopy (EIS) is a powerful technique to study electrical properties of materials and is often used to characterize a wide variety of electrochemical phenomena in porous materials, solid state, liquid electrolytes, synthetic, and biological membranes [17-21]. It allows discriminating between the pure stack resistance, which is the resistance of the individual components in the stack, and concentration polarization phenomena in the RED stack. Combined with direct current measurements and the theoretical model calculations as presented previously, EIS is a powerful tool to analyze and quantify concentration polarization phenomena and spacer shadow effects in a RED stack.

The aim of this work is to quantify the individual contributions of concentration polarization phenomena, spacer shadow effects and single stack resistance in RED for a given configuration under different hydrodynamic conditions in a temperature range from 10 to $40{ }^{\circ} \mathrm{C}$. In particular we identify a 
potential gain in power density by as much as what will bring RED close to economical viability. This set of experiments provides valuable knowledge for an optimal reverse electrodialysis process design and allows us to reflect on the potential and operating window of RED as a source for sustainable energy generation.

\section{Experimental section}

\subsection{Reverse electrodialysis stack}

The experimental stack used for RED experiments is well described in literature [4, 15]. We slightly modified this stack by adding two extra compartments with Haber-Luggin capillaries in order to exclude the influence of the red-ox reactions occurring at the electrodes in our experiments. The schematic representation of the experimental reverse electrodialysis stack used in this study is shown in Figure 1.

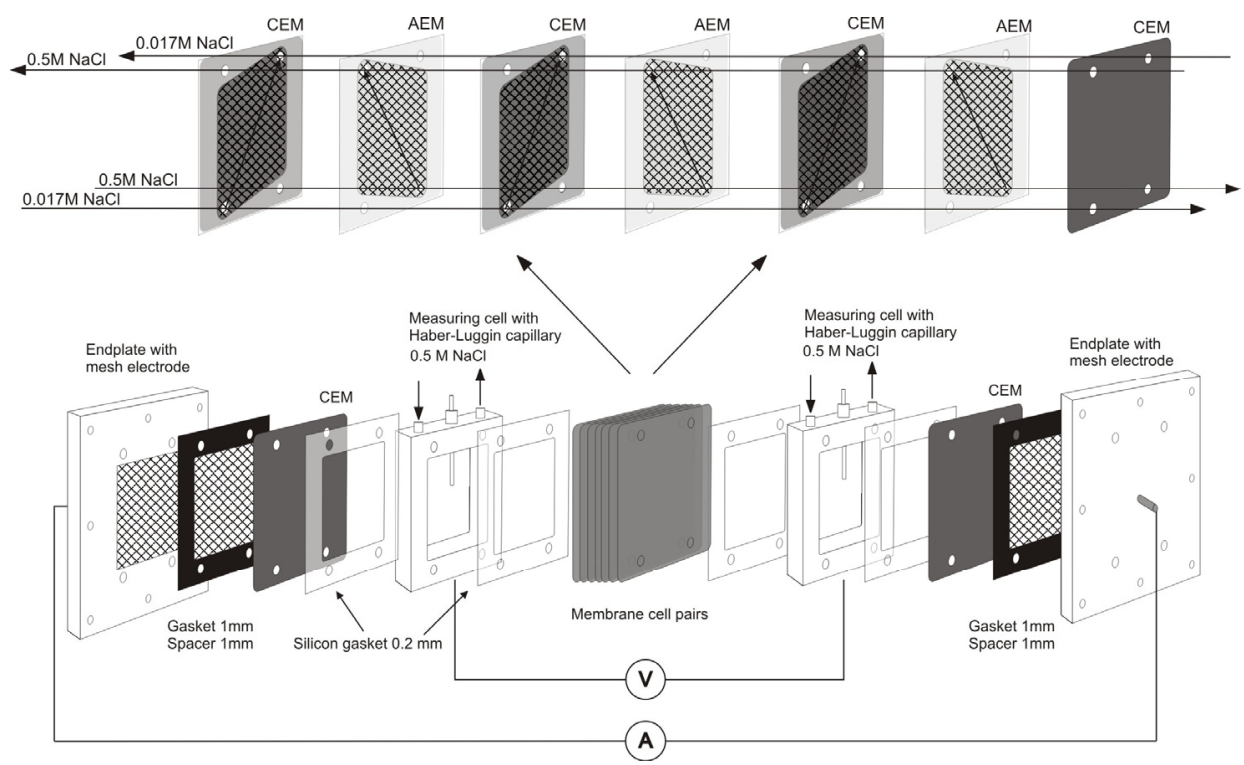

Figure 1: Scheme of reverse electrodialysis stack used in this study. CEM is a cation exchange membrane, AEM is an anion exchange membrane, $\mathrm{V}$ is the potential difference over the HaberLuggin capillaries $(\mathrm{V})$ and $\mathrm{A}$ is the electrical current flowing in the system (A). Current and voltage are controlled by a potentiostat/galvanostat. 
The experimental set-up was placed in a Faraday cage to avoid any influence of the external electric fields during alternating current measurements.

\subsection{Electrode system}

Endplates were made of PMMA (poly(methyl 2-methylpropenoate) (STT Products B.V., The Netherlands)). An electrode made of titanium mesh coated with Ru-Ir mixed metal oxides with dimensions of $10 \mathrm{~cm} \times 10 \mathrm{~cm}$ (Magneto Special Anodes B.V., The Netherlands) was placed inside each endplate. This type of electrode can be used as anode and cathode, which allowed us to perform alternating current measurements. The electrode compartments contained a $0.5 \mathrm{M} \mathrm{NaCl}$ solution as electrolyte. The electrolyte was pumped through the anode and cathode compartment at a rate of 450 $\mathrm{ml} / \mathrm{min}$. All chemicals used were analytical grade (Boom B.V., The Netherlands). The different stack components were kept together by nine stainless steel bolts.

\subsection{Measuring cells with Haber-Luggin capillaries}

The measuring cells were located adjacent to the electrode compartment, separated from them by a cation exchange membrane (Neosepta CMX). These cells were also made of PMMA. A $0.5 \mathrm{M} \mathrm{NaCl}$ solution was pumped through these compartments at a flow rate of $900 \mathrm{ml} / \mathrm{min}$ using gear pumps (Cole-Parmer Instrument Co., Digital Gear Pump, USA). Each measuring cell contained a Haber-Luggin capillary filled with $3 \mathrm{M} \mathrm{KCl}$, connected to small reservoirs with calomel reference electrodes, which measured the potential difference and impedance over the stack using a potentionstat/galvanostat (Iviumstat, The Netherlands). 


\subsection{Membranes}

Anion exchange membranes Neosepta AMX and cation exchange membranes Neosepta CMX were used. These membranes are reinforced standard grade homogenous ion-exchange membranes based on poly(vinyl chloride) and manufactured by Tokuyama Soda Co. (Japan). Neosepta AMX contains quaternary ammonium groups as fixed charges and Neosepta CMX contains sulfonic acid groups as fixed charges. The effective membrane area of each membrane was $100 \mathrm{~cm}^{2}$. Three membrane pairs (3 cation and 3 anion exchange membranes) were used in the stack. An extra cation exchange membrane was added to separate the last membrane from the measuring compartment. Each membrane was separated from the next membrane by a spacer. Experimentally determined membrane properties are shown in Table 1.

Table 1: Membrane properties of the anion exchange (AMX) and cation exchange (CMX) membranes used.

\begin{tabular}{cccccc}
\hline Membrane & $\begin{array}{c}\text { IEC } \\
(\text { meq/g dry } \\
\text { membrane })\end{array}$ & $\begin{array}{c}\text { Permselectivitya } \\
(\%)\end{array}$ & $\begin{array}{c}\text { Resistance } \\
\left(\Omega \cdot \mathrm{cm}^{2}\right)\end{array}$ & $\begin{array}{c}\text { Swelling } \\
\text { degree }(\%)\end{array}$ & $\begin{array}{c}\text { Thickness } \\
(\mu \mathrm{m})\end{array}$ \\
\hline AMX & $1.30 \pm 0.02$ & $91.0 \pm 0.4$ & $2.12 \pm 0.04$ & $16.4 \pm 0.5$ & $138 \pm 2$ \\
\hline CMX & $1.64 \pm 0.01$ & $92.5 \pm 0.6$ & $2.41 \pm 0.05$ & $21.5 \pm 0.2$ & $181 \pm 2$ \\
\hline
\end{tabular}

a) Membrane potential measured over the membrane between $0.5 \mathrm{M}$ and $0.1 \mathrm{M} \mathrm{NaCl}$ solutions at $25^{\circ} \mathrm{C}$.

b) Measured by impedance spectroscopy at $1 \mathrm{kHz}$ in $0.5 \mathrm{M} \mathrm{NaCl}$ solution at $25^{\circ} \mathrm{C}$.

\subsection{Spacers and gaskets}

The distance between the membranes (i.e. spacer thickness) is a crucial parameter with respect to power output in RED [2]. Large distances introduce a high resistance whereas smaller distances lead to increased pressure drop over the compartments, thus reducing the net power output. The optimum distance between the membranes is expected to be in the range of $0.15-0.5 \mathrm{~mm}$ [2]. Therefore, we used two different spacer thicknesses, one with a thickness of 
$0.2 \mathrm{~mm}$ (Sefar, 03-300/51) and one with a thickness of $0.485 \mathrm{~mm}$ (Sefar, 06700/53). These spacers have similar open area and porosity. The main characteristics of the spacers are summarized in Table 2.

Table 2: Spacer properties.

\begin{tabular}{lccc}
\hline & Unit & $03-300 / 51$ & $06-700 / 53$ \\
\hline Thickness fabric & $(\mathrm{mm})$ & 0.200 & 0.485 \\
Spacer material & $(-)$ & PA 6.6 & PA 6 \\
Porosity & $(\%)$ & 67 & 75 \\
Open area & $(\%)$ & 51 & 53 \\
\hline
\end{tabular}

\subsection{Artificial sea and river water}

Analytical grade sodium chloride (Boom B.V., The Netherlands) was used to prepare artificial sea water $(0.5 \mathrm{M} \mathrm{NaCl})$ and river water $(0.017 \mathrm{M} \mathrm{NaCl})$. The solutions were pumped in a single pass through the stack by a peristaltic pump (Masterflex L/S, Cole Parmer Instrument Company, USA) and the linear flow rate was varied from 0.06 to $1.1 \mathrm{~cm} / \mathrm{s}$. The conductivity of the solutions was monitored using a conductivity meter (Metrohm AG, 712 conductivity meter, Switzerland). During the experiments the temperature was controlled and varied from 10 to $40 \pm 0.5^{\circ} \mathrm{C}$.

\subsection{Electrochemical characterization measurements}

Electrochemical measurements were performed to determine the stack performance using a potentiostat/galvanostat (Iviumstat, The Netherlands). Both direct and alternating current measurements were performed. Direct current measurements were performed for a period of 300 seconds to ensure steady state. The overall stack resistance was calculated using Ohm's law. Alternating current measurements (EIS) allow to measure the pure stack resistance including the spacer shadow effect, but excluding the contribution of 
concentration polarization phenomena at the membrane-solution interface. Because the difference between the resistance obtained under direct current and alternating current conditions directly gives the contribution of concentration polarization phenomena to the total resistance, EIS measurements were performed in the high frequency range only ( $1 \mathrm{kHz}$ to $0.1 \mathrm{kHz})$ to ensure that only the pure stack resistance is measured [16].

Both the direct and the alternating current method measure the stack resistance including the solution resistance $\left(\mathrm{R}_{\mathrm{m}+\mathrm{s}}\right)$, but excluding the electrodes and the electrolyte resistance of the electrode compartments by using additional measuring cells with Haber-Luggin capillaries over the three membrane pairs under investigation (Figure 1). To extract the pure stack resistance of the 3 cell pairs, the values need to be corrected for the resistance of the $0.5 \mathrm{M} \mathrm{NaCl}$ measuring solution and the resistance of one additional cation exchange membrane used to separate the measuring solution from the feed solution (sea water). This resistance was calculated from the distance between the HaberLuggin capillary and the first membrane in the stack $(0.9 \Omega)$.

\section{Results and discussion}

\subsection{Stack resistance characterization}

Figure 2 shows the stack resistance for both spacer thicknesses as a function of the linear solution flow rate. The theoretical resistance was calculated from Equation 1, the overall stack resistance including concentration polarization phenomena and the spacer shadow effect was determined from direct current measurements and the pure stack resistance only including the spacer shadow effect but excluding concentration polarization phenomena was obtained from EIS measurements. Figure 2 clearly shows the difference between the three resistance values. 

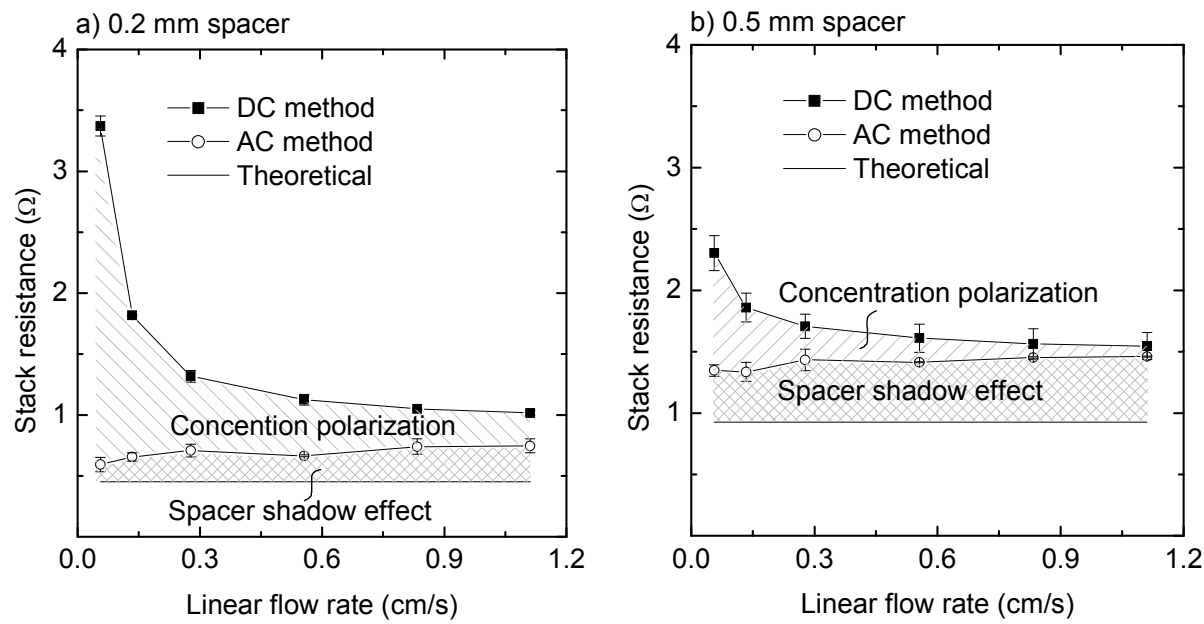

Figure 2: Stack resistance as a function of linear solution flow rate for a spacer thickness of a) 0.2 $\mathrm{mm}$ and b) $0.5 \mathrm{~mm}$. All measurements performed at $25^{\circ} \mathrm{C}$.

The theoretical resistance represents the absolute lower limit of the stack resistance for a specific type of membrane, based on pure solution and membrane properties, not including any other effects. The calculated value of the stack resistance for the $0.2 \mathrm{~mm}$ spacer $(0.45 \Omega)$ is approximately half of the value for the $0.5 \mathrm{~mm}$ spacer $(0.93 \Omega)$, which is mainly due to the higher resistance of the diluted compartment due to the thicker spacer $[2,6,7]$. The diluted compartment resistance for the $0.2 \mathrm{~mm}$ spacer is $67 \%(0.30 \Omega)$ of the total stack resistance while that value for the $0.5 \mathrm{~mm}$ spacer is $82 \%(0.76 \Omega)$. These results show that one of the key issues to a better RED stack power output performance is the reduction of the resistance of the diluted solution compartment [6, 7].

The resistance determined via direct current measurements gives the highest value and represents the upper limit of the resistance. It is an overall stack resistance and it includes all effects occurring in the stack and contributing to the resistance, i.e. concentration polarization phenomena and the influence of the reduced membrane area due to the presence of the spacer 
(spacer shadow effect). These additional effects can be minimized by proper stack design.

The use of the alternating current method allows excluding the effect of concentration polarization phenomena. It thus represents the resistance of the stack under excellent hydrodynamic conditions, where concentration phenomena can be fully eliminated [16]. It characterizes the room available for resistance decrease and power output increase by optimizing the hydrodynamic conditions in the stack. The difference between the theoretical resistance and the resistance determined by alternating current finally represents the spacer shadow effect [9]. The spacer shadow effect of the $0.2 \mathrm{~mm}$ spacer increases the theoretical stack resistance with approximately $67 \%(0.3 \Omega)$, whereas the increase for the $0.5 \mathrm{~mm}$ spacer is approximately $54 \%(0.5 \Omega)$. This effect cannot be minimized by increasing the linear solution flow rate, but improved spacer design to reduce this effect would directly result in a decrease in stack resistance and increase in net power output.

From these results it is clear that at low linear solution flow rates concentration polarization phenomena are the dominant resistance, which can be minimized significantly by increasing the solution flow rate. This is especially important for the stack with the $0.2 \mathrm{~mm}$ spacers. The concentration polarization layers at the membrane-solution interface can reach thicknesses of $300 \mu \mathrm{m}$ and when thin spacers are used, the relative contribution of these layers is greater than when thicker spacers are used [7, 22].

\subsection{Stack open circuit voltage (OCV)}

The OCV is an important parameter for power generation in reverse electrodialysis systems as it gives the maximum voltage obtainable from the system. The theoretical value of the stack OCV can be calculated from the Nernst equation $[2,5]$. 


$$
\mathrm{V}_{\text {theo }}^{\circ}=\mathrm{N} \frac{\alpha \mathrm{RT}}{\mathrm{zF}} \ln \left(\frac{\mathrm{a}_{\mathrm{c}}}{\mathrm{a}_{\mathrm{d}}}\right)
$$

Where $\mathrm{V}^{\circ}$ theo is the theoretical open circuit voltage $(\mathrm{V}), \mathrm{N}$ is the number of membranes, $\alpha$ is the average membrane permselectivity of an anion and a cation exchange membrane, $\mathrm{R}$ is the universal gas constant $\left(8.314 \mathrm{~J} \cdot \mathrm{mol}^{-1} \cdot \mathrm{K}^{-1}\right), \mathrm{T}$ is the absolute temperature $(\mathrm{K}), \mathrm{z}$ is the electrochemical valence, $\mathrm{F}$ is the Faraday constant $\left(96485 \mathrm{C} \cdot \mathrm{mol}^{-1}\right)$, ac is the activity of the concentrated solution $\left(\mathrm{mol} \cdot \mathrm{l}^{-1}\right)$ and ad is the activity of the diluted solution $\left(\mathrm{mol} \cdot \mathrm{l}^{-1}\right)$. For fresh $(0.017 \mathrm{M}$ $\mathrm{NaCl})$ and sea water $(0.5 \mathrm{M} \mathrm{NaCl})$ the theoretical voltage difference over each membrane for $100 \%$ selective membranes is $0.080 \mathrm{~V}$. The overall OCV of the system is the sum of the potential differences over each membrane and for six $100 \%$ selective membranes (three cell pairs) the theoretical value is $0.482 \mathrm{~V}$.

Figure 3 shows the OCV of the stack for the $0.2 \mathrm{~mm}$ and the $0.5 \mathrm{~mm}$ spacer as a function of the solution flow rate. The average stack permselectivity calculated as the ratio of the experimentally determined $\mathrm{OCV}$ and the theoretical OCV, multiplied by $100 \%$ is show as well (second y-axis).

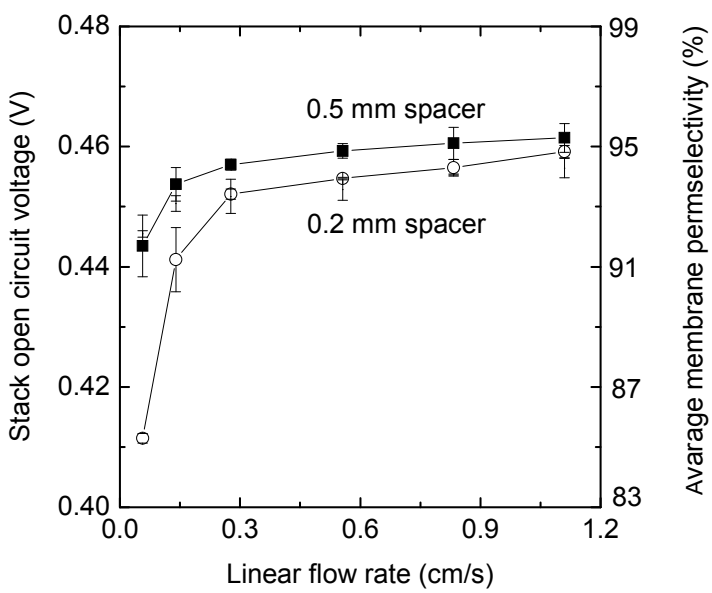

Figure 3: Open circuit potential of the reverse electrodialysis stack as a function of the solution flow rate for two different spacer thicknesses. All measurements performed at $25^{\circ} \mathrm{C}$. 
Figure 3 shows that the solution flow rate has a significant effect, not only on the stack resistance, but also on its OCV. The OCV decreases significantly for both spacers below a linear solution flow rate of $0.3 \mathrm{~cm} / \mathrm{s}$. This decrease is the consequence of the occurrence of concentration polarization phenomena, which can be reduced at higher solution flow rates [3]. The OCV values for the $0.2 \mathrm{~mm}$ spacers are slightly lower than the values for the $0.5 \mathrm{~mm}$ spacers. This is due to the relatively greater effect of concentration polarization phenomena in the thinner salt compartments in the stack. From Figure 3 is clear that the average stack selectivity depends strongly on the hydrodynamic performance of the stack and the average membrane selectivity can be enhanced or reduced by the liquid flow rate. Due to the occurrence of more severe concentration polarization phenomena at the membrane-solution interface at lower linear solution velocities, the actual concentration gradient for transport is lower at lower linear velocities than expected based on the bulk solution concentrations,

resulting in a lower experimental OCV. Consequently also the permselectivity which is calculated based on the actual OCV and the theoretical OCV decreases with decreasing linear solution velocity.

\subsection{Number of cells pair}

Figure 4 shows the effect of the number of cell pairs (one anion and one cation exchange membrane) on the stack $\mathrm{OCV}$ and resistance as determined from direct current measurements. Figure $4 \mathrm{a}$ and $\mathrm{b}$ show a linear relationship between the open circuit voltage and the stack resistance as a function of the number of cell pairs for 2 to 6 cell pairs. These results can be used to predict the stack performance of larger RED stacks. 
a)

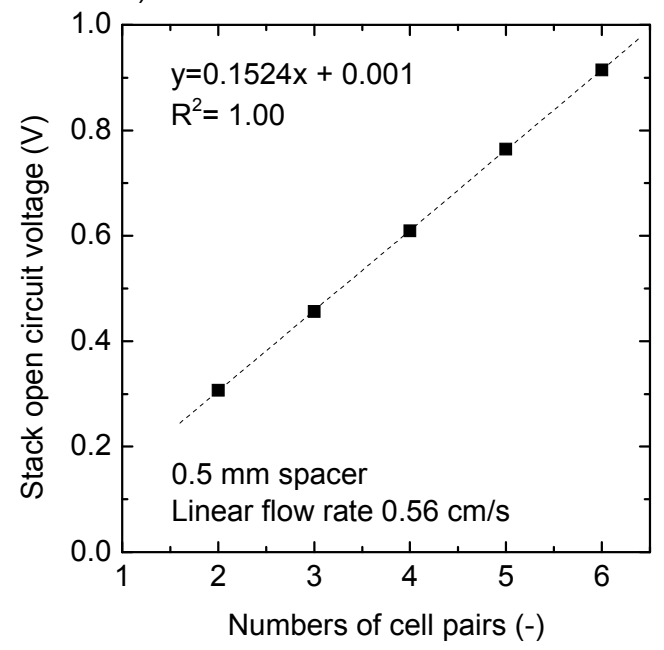

b)

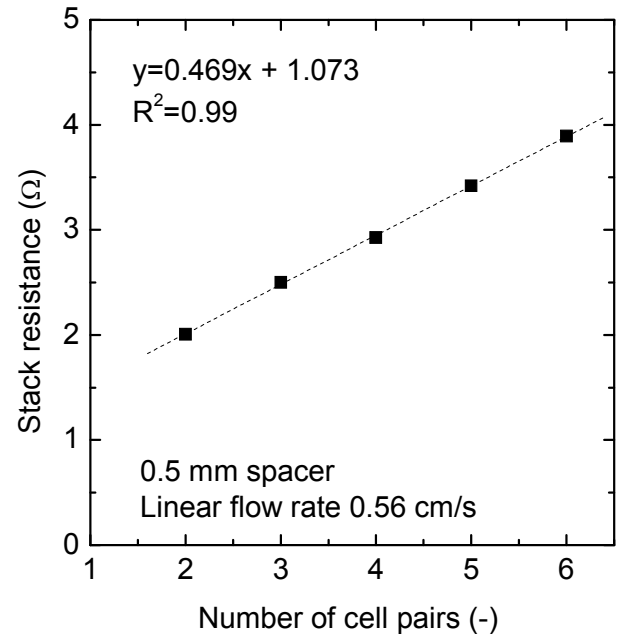

Figure 4: Stack open circuit voltage and stack resistance as a function of the number of cell pairs as measured by direct current from a stack with $0.5 \mathrm{~mm}$ spacers at a linear solution flow rate of 0.56 $\mathrm{cm} / \mathrm{s}$.

The open circuit voltage for one cell pair can be extracted from the intercept of the line in Figure 4a with the Y-axis and has a value of $0.152 \mathrm{~V}$. When the 
experimentally determined OCV $(0.152 \mathrm{~V})$ is divided by the theoretical OCV $(0.161 \mathrm{~V})$, the average permselectivity of the ion exchange membranes in the reverse electrodialysis stack can be calculated, which gives a value of $94.4 \%$. The point where the stack resistance crosses the $y$-axis $(1.073 \Omega$ in this particular case) represents the resistance of one measuring cell with Haber-Luggin capillaries filled with $0.5 \mathrm{M} \mathrm{NaCl}$ (Figure 1). In the real application this approach can be applied to extract the resistance of the electrodes and electrolyte solution in the stack.

\subsection{Stack power density}

The maximum power density in reverse electrodialysis is obtained when the resistance of the external load equals the resistance of the stack [5]. The power density ( $\mathrm{P}_{\max }$ in $\mathrm{W} / \mathrm{m}^{2}$ of membrane) is determined from the stack $\mathrm{OCV}$ and the stack resistance [5]:

$$
\mathrm{P}_{\max }=\frac{\left(\mathrm{V}^{0}\right)^{2}}{4 \mathrm{AR}_{\text {stack }}}
$$

Where $\mathrm{P}_{\max }$ is the maximum power density $\left(\mathrm{W} / \mathrm{m}^{2}\right), \mathrm{V}^{0}$ is the stack open circuit voltage $(\mathrm{V})$, A is the membrane area $\left(\mathrm{m}^{2}\right)$ and Rstack is the stack resistance $(\Omega)$.

Figure 5 shows the maximum theoretical value of the stack power density as calculated from the theoretical OCV for 95\% selective membranes and the calculated stack resistance based on the conductivity of the solution and the experimentally measured resistance of AMX and CMX membrane (Table 1) [16] We used a value of $95 \%$ for the selectivity to represent a realistic value, obtainable in practice (Figure 4). The power density as experimentally determined from the direct current and the alternating current (EIS) measurements as a function of the linear solution flow rate for both spacer thicknesses is also shown in Figure 5. 

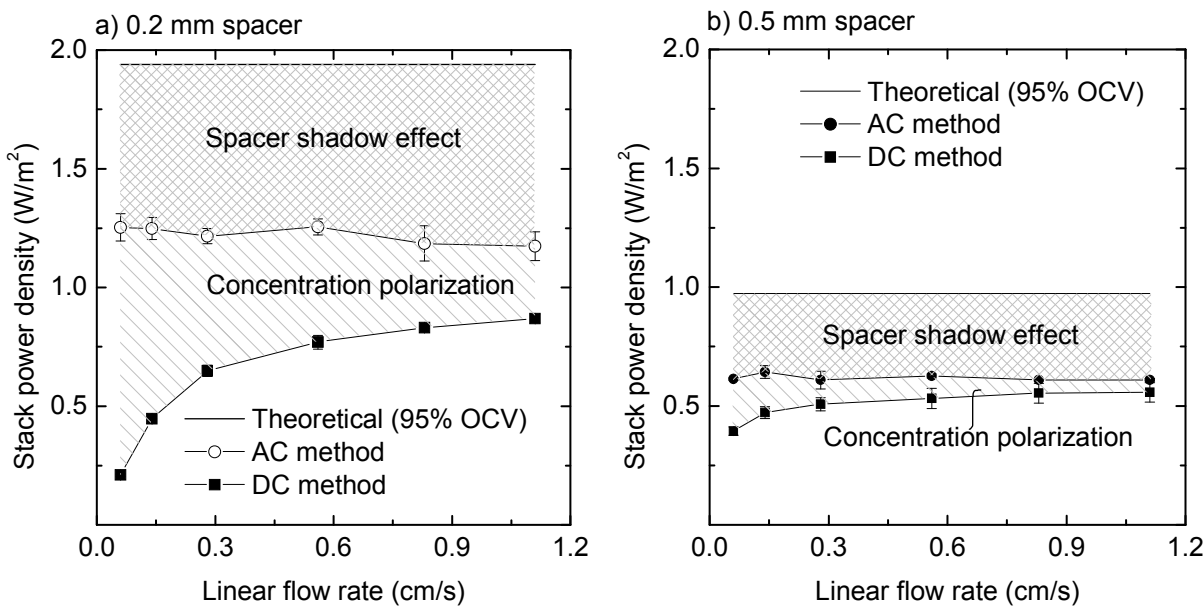

Figure 5: Stack power density as a function of the linear solution flow rate for a) $0.2 \mathrm{~mm}$ spacers and b) $0.5 \mathrm{~mm}$ spacers. All measurements performed at $25^{\circ} \mathrm{C}$.

As in Figure 2 the theoretical, calculated stack power density shows the maximum obtainable power density for the specific stack design. Values as high as almost $2 \mathrm{~W} / \mathrm{m}^{2}$ for this specific stack with the $0.2 \mathrm{~mm}$ thick spacers can be obtained, whereas the stack with the $0.5 \mathrm{~mm}$ spacer thickness can produce a maximum power density of almost $1 \mathrm{~W} / \mathrm{m}^{2}$. The spacer shadow effect and concentration polarization phenomena have a significant effect and reduce this maximum power density, especially at lower liquid flow rates and thinner spacers, as extracted from the (EIS) alternating current measurements and direct current measurements respectively.

The maximum power density measured by the direct current method was $0.87 \mathrm{~W} / \mathrm{m}^{2}$ for the $0.2 \mathrm{~mm}$ spacer and only $0.56 \mathrm{~W} / \mathrm{m}^{2}$ for $0.5 \mathrm{~mm}$ spacer. Maximum obtainable power density obtained from the alternating current measurements was $1.25 \mathrm{~W} / \mathrm{m}^{2}$ for the stack with the $0.2 \mathrm{~mm}$ spacers and 0.62 $\mathrm{W} / \mathrm{m}^{2}$ for the $0.5 \mathrm{~mm}$ spacers. Improvement of hydrodynamics and reduction of the spacer shadow effect directly result in a strong increase in power output of the RED process and values almost double the values currently obtained can be realized. 
The presence of the spacers significantly reduces the power output obtainable from RED, as the use of non conductive spacers blocks part of the membrane making it inaccessible for ion transport, thus reducing the effective membrane area (spacer shadow effect). This spacer shadow effect (SSE) can be quantified as:

$\mathrm{SSE}=\left(1-\frac{\mathrm{P}_{\mathrm{AC}}}{\mathrm{P}_{\text {theo }}}\right) \cdot 100 \%$

Where SSE is the spacer shadow effect (\%), $\mathrm{P}_{\mathrm{AC}}$ is the power density measured by alternating current $\left(\mathrm{W} / \mathrm{m}^{2}\right)$ and $\mathrm{P}_{\text {theo }}$ is the theoretical power density $\left(\mathrm{W} / \mathrm{m}^{2}\right)$. A value of $0 \%$ means no spacer shadow effect, whereas a value of $100 \%$ indicates that the membrane area is completely blocked by the spacer.

The spacer shadow effect for the stack with the $0.2 \mathrm{~mm}$ spacers is $37 \%$ and for the $0.5 \mathrm{~mm}$ spacers a value of $36 \%$ is obtained. The theoretical maximum spacer shadow effect can be roughly estimated from the spacer open area as (1-open area) $\cdot 100 \%$. For the stack with the $0.2 \mathrm{~mm}$ spacers this value is $49 \%$ and the stack with the $0.5 \mathrm{~mm}$ spacers gives a value of $47 \%$. The theoretical value is higher because it assumes maximum spacer coverage based on the spacer fiber diameter. In the real situation the spacer fibers do not contact the membrane over their full fiber diameter, but are in contact with the membrane at their bottom side only, making the effective contact area smaller than expected based on the fiber diameter of the spacer and thus resulting in lower experimental values for the spacer shadow effect than expected based on the open area of the spacer.

\subsection{Temperature effect}

In the practical application when real sea and river water are used, the temperature of the water may significantly vary, which can affect the RED performance $[3,7]$. Figure 6 shows the effect of the temperature on the stack power density for the stack with a) $0.2 \mathrm{~mm}$ and b) $0.5 \mathrm{~mm}$ spacers. 

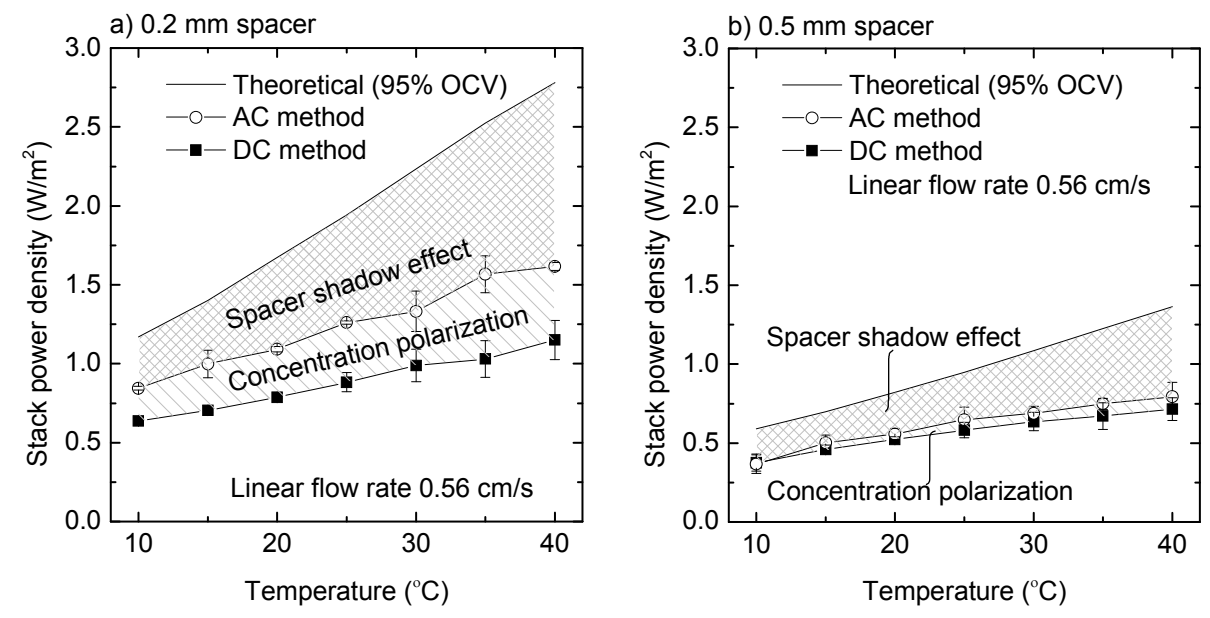

Figure 6: Stack power density as a function of the temperature for the stack with a) $0.2 \mathrm{~mm}$ spacers and b) $0.5 \mathrm{~mm}$ spacers. Linear solution flow rate was set at $0.56 \mathrm{~cm} / \mathrm{s}$.

Figure 6 clearly shows that an increase in temperature from 10 to $40{ }^{\circ} \mathrm{C}$ results in a strong increase in stack power density. Although the relative effect of the concentration polarization layer and the spacer shadow effect remains almost the same, the higher power densities obtainable at higher temperatures, result in a higher absolute counterproductive influence of the concentration polarization layer and spacer shadow effect. The absolute effect of concentration polarization phenomena only slightly increases with increasing temperature for both spacers, but especially the spacer shadow effect for both spacers strongly increases with increasing temperature. An explanation for this behavior is that the non-conductive spacer covers approximately $30 \%$ of the solution volume blocking the ionic transport. 


\section{Future perspective and outlook}

This study identifies and quantifies the potential and operating window of RED as sustainable source for power generation. There exists a large potential to increase the power density in the RED process. Concentration polarization phenomena play an important role and significantly reduce the practical power output currently obtainable in RED. Their influence can be minimized by optimal stack hydrodynamics. The spacer shadow effect cannot be minimized by improved hydrodynamics, but requires new spacer concepts. The use of alternative, conductive spacer materials offer extensive room to further increase the power output of RED. Improvement of hydrodynamics and reduction of the spacer shadow effect directly result in a strong increase in power output of the RED process and values almost double the values currently obtained can be realized.

\section{Acknowledgement}

A special word of thanks goes to Michel Saakes, Sybrand Metz, Jan Post and Joost Veerman from the energy team at Wetsus for the fruitful discussions on the practical potential of RED. This work was performed at Wetsus, centre of excellence for sustainable water technology. Wetsus is funded by the city of Leeuwarden, the Province of Fryslan, the European Union European Regional Development Fund and by the EZ-KOMPAS Program of the "Samenwerkingsverband Noord/Nederland". The industrial participants of the Wetsus research theme Energy (DOW, FujiFilm B.V., Nuon B.V., MAGNETO special anodes B.V., Triqua B.V., Landustrie SNEEK B.V., Frisia Zout B.V.,

Waterleidingmaatschappij Drenthe, Waterbedrijf Groningen and Waterlaboratorium Noord) are kindly acknowledged for their financial support. 


\section{References}

1. G. L. Wick, Power from salinity gradients, Energy 3 (1978) 95-100.

2. P. Dlugolecki, K. Nymeijer, S. Metz, M. Wessling, Current status of ion exchange membranes for power generation from salinity gradients, Journal of Membrane Science 319 (2008) 214-222.

3. R. E. Lacey, Energy by reverse electrodialysis, Ocean Engineering 7 (1980) 1-47.

4. J. W. Post, H. V. M. Hamelers, C. J. N. Buisman, Energy recovery from controlled mixing salt and fresh water with a reverse electrodialysis system, Environmental Science and Technology 42 (2008) 5785-5790.

5. J. N. Weinstein, F. B. J. W. Leitz, Electric power from differences in salinity: the dialytic battery, Science 191 (1976) 557-559.

6. E. Brauns, Towards a worldwide sustainable and simultaneous largescale production of renewable energy and potable water through salinity gradient power by combining reversed electrodialysis and solar power?, Desalination 219 (2008) 312-323.

7. E. Brauns, Salinity gradient power by reverse electrodialysis: effect of model parameters on electrical power output, Desalination 237 (2009) 378-391.

8. J. W. Post, J. Veerman, H. V. M. Hamelers, G. J. W. Euverink, S. J. Metz, K. Nymeijer, C. J. N. Buisman, Salinity-gradient power: Evaluation of pressure-retarded osmosis and reverse electrodialysis, Journal of Membrane Science 288 (2007) 218-230.

9. H. Strathmann, Membrane Science and Technology Ion-Exchange Membrane Separation Processes, 9, 1st Edition, Elsevier, 2004.

10. J. Veerman, J. W. Post, M. Saakes, S. J. Metz, G. J. Harmsen, Reducing power losses caused by ionic shortcut currents in reverse electrodialysis stacks by a validated model, Journal of Membrane Science 310 (2008) 418-430.

11. J. Balster, I. Punt, D. F. Stamatialis, H. Lammers, A. B. Verver, M. Wessling, Electrochemical acidification of milk by whey desalination, Journal of Membrane Science 303 (2007) 213-220. 
12. J. Balster, I. Punt, D. F. Stamatialis, M. Wessling, Multi-layer spacer geometries with improved mass transport, Journal of Membrane Science 282 (2006) 351-361.

13. F. Harnisch, U. Schroder, F. Scholz, The suitability of monopolar and bipolar ion exchange membranes as separators for biological fuel cells, Environmental Science and Technology 42 (2008) 1740-1746.

14. M. Turek, B. Bandura, Renewable energy by reverse electrodialysis, Desalination 205 (2007) 67.

15. J. Veerman, M. Saakes, S. J. Metz, G. J. Harmsen, Reverse electrodialysis: Performance of a stack with 50 cells on the mixing of sea and river water, Journal of Membrane Science 327 (2009) 136-144.

16. P. Dlugolecki, P. Ogonowski, S. J. Metz, M. Saakes, K. Nijmeijer, M. Wessling, On the resistances of membrane, diffusion boundary layer and double layer in ion exchange membrane transport submitted for publication to J. Membr. Sci. (2009)

17. J. R. Macdonald, Impedance Spectroscopy, Emphasizing Solid Materials and Systems, Edition, John Wiley \& Sons Ltd, New York, 1987.

18. J. S. Park, T. C. Chilcott, H. G. L. Coster, S. H. Moon, Characterization of BSA-fouling of ion-exchange membrane systems using a subtraction technique for lumped data, Journal of Membrane Science 246 (2005) 137.

19. J.-S. Park, J.-H. Choi, J.-J. Woo, S.-H. Moon, An electrical impedance spectroscopic (EIS) study on transport characteristics of ion-exchange membrane systems, Journal of Colloid and Interface Science 300 (2006) 655-662.

20. J.-S. Park, J.-H. Choi, K.-H. Yeon, S.-H. Moon, An approach to fouling characterization of an ion-exchange membrane using current-voltage relation and electrical impedance spectroscopy, Journal of Colloid and Interface Science 294 (2006) 129-138.

21. T. C. Chilcott, H. G. L. Coster, E. P. George, A novel method for the characterisation of the double fixed charge (bipolar) membrane using impedance spectroscopy, Journal of Membrane Science 108 (1995) 185197. 
22. J.-H. Choi, J.-S. Park, S.-H. Moon, Direct Measurement of Concentration Distribution within the Boundary Layer of an Ion-Exchange Membrane, Journal of Colloid and Interface Science 251 (2002) 311-317. 


\title{
Chapter 6
}

\section{Ion conductive spacers for increased power generation in reverse electrodialysis process}

\begin{abstract}
Reverse electrodialysis (RED) is a sustainable energy source that converts the free energy of mixing of two solutions with different salinity directly into electrical energy. High power outputs are predicted theoretically, but the practical power output and the efficiency of the process are still relatively low. Next to concentration polarization phenomena, especially the spacer shadow effect, which occurs due to the use of non-conductive spacers, has a high impact on the net power output. Non-conductive spacers block the ionic transport in the stack thus reducing the area effectively available for ionic transport. In this work we developed and applied ion conductive spacers for RED, which eliminates the spacer shadow effect and obviously improves the overall process performance. We combined theoretical calculations with direct current and alternating current experimental stack characterization methods to quantify this effect on stack resistance and power output in RED process under different hydrodynamic conditions. The use of ion conductive spacers led to a decrease in stack resistance and an increase in power density of a factor 3 compared to the use of non-conductive spacers made of PVC with the same open area and shape. This result increases the impact of RED as renewable energy source and brings it closer to economical viability and practical implementation.
\end{abstract}

Scientific publication:

P. Dlugolecki, J. Dabrowska, K. Nijmeijer, M. Wessling, Ion conductive spacers for increased power generation in reverse electrodialysis process, accepted for publication in Journal of Membrane Science 2009. 


\section{Introduction}

Reverse electrodialysis (RED) is a sustainable energy source with a large global potential [1]. RED uses the free energy of mixing sea and river water and can harvest this so called salinity gradient energy with efficiencies as high as $>80 \%$ [2]. In RED, the two salt solutions are separated by ion exchange membranes that control the transport of the cations $\left(\mathrm{Na}^{+}\right)$and anions $\left(\mathrm{Cl}^{-}\right)$and generate a potential difference over each membrane. The membrane properties and inter-membrane distance have a significant impact on the overall process performance [3]. The distance between the membranes is determined by the spacers, which are located between each anion and cation exchange membrane to keep the inter-membrane distance constant and to enhance mass transfer by promoting turbulence. In general, spacers are made of non-conductive material. In our previous paper we used electrochemical characterization methods and showed that the use of non-conductive spacers and concentration polarization phenomena result in a large decrease in efficiency (up to 60\%) of the process leading to significantly lower power outputs than expected based on calculations [4]. Concentration polarization occurs at the membrane-solution interface due to a difference in ion mobility in the membrane phase and in the solution phase. It can be minimized by optimal stack hydrodynamics. The blocking of ionic transport from the solution phase to the membrane due to the use of non-conductive spacers (spacer shadow effect) on the other hand can not be minimized by improved stack hydrodynamics [4, 5]. Dlugolecki et al. studied the significance of the spacer shadow effect on reverse electrodialysis stack performance and showed that $30-40 \%$ of the available energy is lost due to the spacer shadow effect when commercially available, non-conductive spacers are used.

The majority of the research on the RED process focuses on ion exchange membranes, spacer thickness, stack characterization and fuel efficiency [2, 3, 68]. To the best of our knowledge there are no scientific papers that report 
methods to minimize the spacer shadow effect as a tool to increase the power output in RED, although reduction of this effect is an important issue with respect to process economics and efficiency.

Aim of this study. Here we investigate the potential of the application of ion conductive spacers in RED as a tool to overcome the spacer shadow effect, which is observed in RED when non-conductive spacers are used and significantly reduces the net power output obtainable in RED. The conductive spacers used in this study are prepared of two parts: an anion exchange part and a cation exchange part. We systematically study the effect of the implementation and configuration of two of such conductive spacer parts on the stack resistance, stack open circuit voltage and stack power density under different hydrodynamic conditions. Theoretical calculations are combined with direct current and alternating current experimental stack characterization methods to quantify the effect. The results are compared to the values obtained when non-conductive spacers made of PVC with the same open area and shape are used. This study is a valuable contribution towards the knowledge and discussion on spacers and hydrodynamics in general and in RED more specifically.

\section{Experimental section}

\subsection{Reverse electrodialysis stack}

The experimental RED stack used in our experiments is well described in our previous work [4].

\subsection{Membranes and spacers}

Anion exchange membranes Neosepta AMX and cation exchange membranes Neosepta CMX were used (Tokuyama Soda Co., Japan). These membranes are reinforced, standard grade, homogenous ion-exchange membranes based on poly(vinyl chloride). Neosepta AMX contains quaternary 
ammonium groups as fixed charges and Neosepta CMX contains sulfonic acid groups as fixed charges. The effective membrane area of each membrane was $100 \mathrm{~cm}^{2}$. Three membrane pairs (4 cation and 3 anion exchange membranes) were used in the stack. One extra cation exchange membrane was added to separate the sea or river water compartment from the measuring compartment. Experimentally determined membrane properties can be found in our previous work $[3,4]$.

In the experimental set up, each membrane is separated from the next membrane by a spacer. In our previous study [4] we used standard, nonconductive, net spacers and we showed that these spacers significantly reduce the net power output due to the blocking of ionic transport from the membrane to the solution and vice versa (spacer shadow effect). Therefore, in the present work, we investigate the use of ion conductive spacers between the membranes, as a method to reduce this spacer shadow effect (Figure 1).

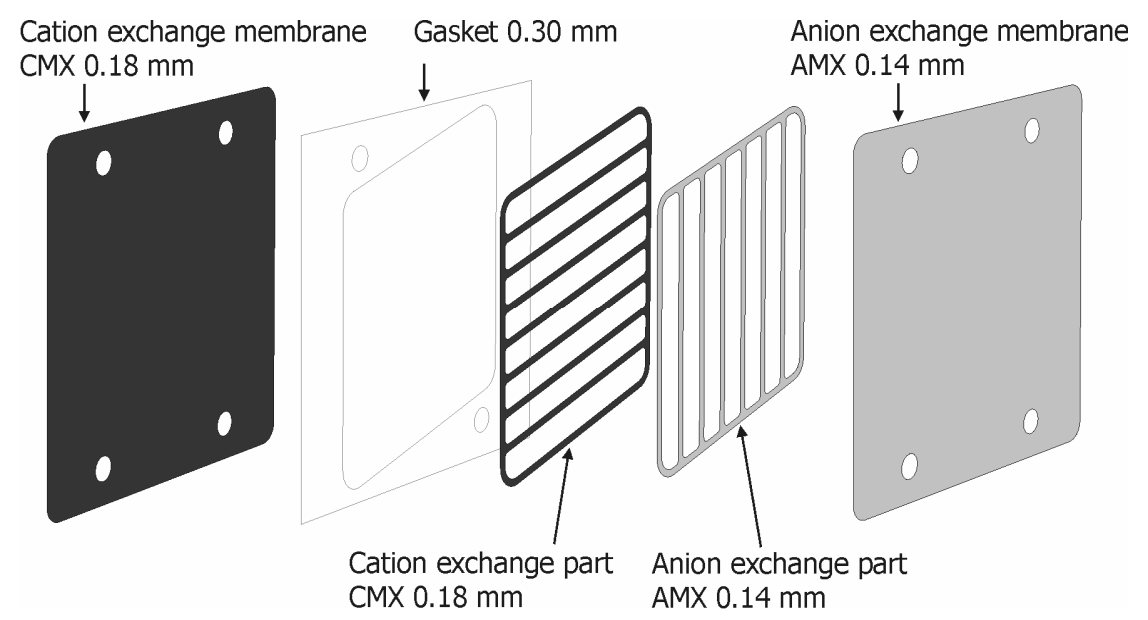

Figure 1: Schematic representation of the position of the ion conductive spacer made of a cation and an anion exchange part located in the stack between a cation and an anion exchange membrane.

The cation exchange membrane material (Neosepta CMX) and the anion exchange membrane material (Neosepta AMX) were also used as materials for the preparation of the cation and the anion conductive spacers respectively. 
Spacers were cut from the CMX and AMX membrane using a press and a mould with the desired spacer geometry. Two different spacer configurations were investigated and compared to the situation where we used nonconductive spacers (reference case): 1) the cation-conducting part of the spacer placed on the cation exchange membrane and the anion-conducting part of the spacer placed on the anion exchange membrane. This configuration is referred to as the normal configuration; 2) the cation-conducting spacer part located on the anion exchange membrane and the anion-conducting spacer part located on the cation exchange membrane. This configuration is referred to as the reverse configuration. For comparison, also the non-conductive spacer (reference case) was made of two parts with exactly the same shape and thickness as the two ion conductive spacer parts. As non-conductive spacer material we used PVC foil (VINK Kunststoffen B.V., The Netherlands). Table 1 shows the main characteristics of the different spacers with the different configurations.

Table 1: Specifications of spacers used in the experiments.

\begin{tabular}{l|c|c|c}
\hline & Unit & Non-conductive & Ion conductive \\
\hline Material & - & PVC & AMX - CMX \\
\hline Thickness & $\mathrm{mm}$ & 0.32 & 0.32 \\
\hline Open area & $\%$ & 54 & 54 \\
\hline Porosity & $\%$ & 73 & 73 \\
\hline
\end{tabular}

\subsection{Artificial sea and river water}

Analytical grade sodium chloride (Boom B.V., The Netherlands) was used to prepare artificial sea water $(0.5 \mathrm{M} \mathrm{NaCl})$ and river water $(0.017 \mathrm{M} \mathrm{NaCl})$. The solutions were pumped through the stack in a single pass by a peristaltic pump (Masterflex L/S, Cole Parmer Instrument Company, USA) and the linear flow rate was varied from 0.06 to $0.83 \mathrm{~cm} / \mathrm{s}$. The conductivity of the solutions was monitored using a conductivity meter (Metrohm AG, 712 conductivity 
meter, Switzerland). During the experiments the temperature was controlled and set to $25 \pm 0.5^{\circ} \mathrm{C}$.

\subsection{Electrochemical characterization measurements}

Electrochemical characterization measurements were performed using a potentiostat/galvanostat (Iviumstat, The Netherlands) to determine the stack resistance and power output. Both direct and alternating current measurements were performed. Using direct current measurements allows determining the overall stack resistance and performance including concentration polarization and spacer shadow effects occurring in the stack $[4,9,10]$. These measurements were performed for a period of 300 seconds to ensure steady state and the overall stack resistance was calculated using Ohm's law. Electrochemical impedance spectroscopy (EIS) uses an alternating current and can be used to identify the contribution of the pure stack resistance including the spacer shadow effect, but excluding the contribution of concentration polarization phenomena at the membrane-solution interface and at the ion conductive spacer-solution interface. As a consequence [10], the difference between the resistance obtained under direct current and alternating current conditions directly gives the contribution of concentration polarization phenomena to the total resistance [4]. As the pure stack resistance is determined in the high frequency range, only EIS measurements in the $1 \mathrm{kHz}$ to $0.1 \mathrm{kHz}$ frequency range are required to extract the pure stack resistance [10]. More information on EIS as a tool for ion transport and stack characterization can be found in our previous work $[4,10]$.

As mentioned [10], the resistance of the $0.5 \mathrm{M} \mathrm{NaCl}$ measuring solution is included in these experimentally determined resistances (both for direct and indirect current experiments) and needs to be extracted form the measured values. This solution resistance was calculated from the ionic conductivity of 
the $0.5 \mathrm{M} \mathrm{NaCl}$ solution and the distance between the Haber-Luggin capillaries and the first membrane in the stack $(0.9 \Omega)$.

\section{Results and discussion}

\subsection{Stack resistance characterization}

Figure 2 shows the stack resistance as a function of the linear solution flow rate for the stack with the non-conductive spacers (reference case) and the one that uses ion conductive spacers in the normal configuration (anion exchange part of the spacer positioned on the anion exchange membrane and cation ion exchange part of the spacer located on the cation exchange membrane).

a) non-conductive spacer $0.32 \mathrm{~mm}$

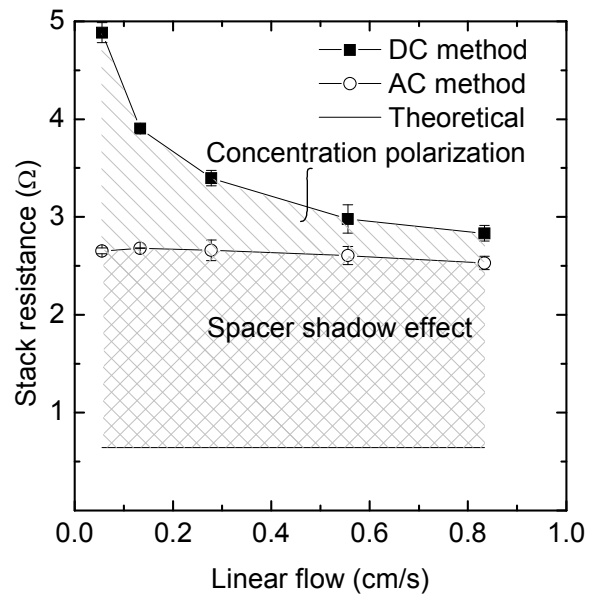

b) ion conductive spacer $0.32 \mathrm{~mm}$

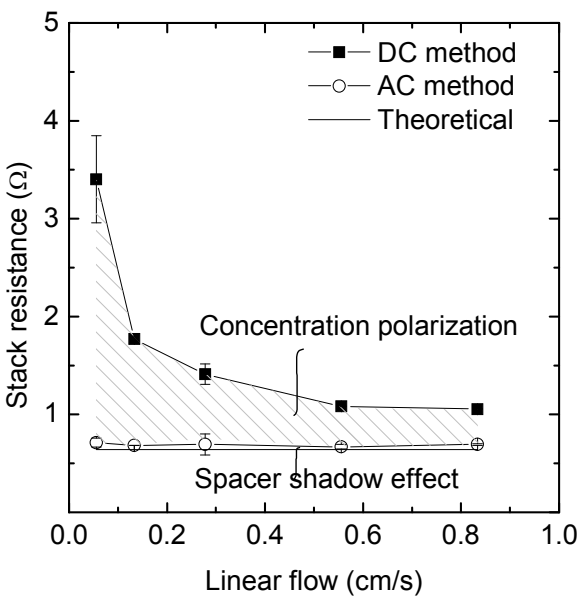

Figure 2: Stack resistance as a function of the linear solution flow rate for a) the non-conductive 0.32 $\mathrm{mm}$ spacer, b) the ion conductive $0.32 \mathrm{~mm}$ spacer with the anion exchange part of the spacer positioned on the anion exchange membrane and the cation ion exchange part of the spacer located on the cation exchange membrane (normal configuration). DC represents direct current measurements and AC represents alternating current measurements. All measurements performed at $25^{\circ} \mathrm{C}$. 
The theoretical stack resistance is equal to the sum of the resistances of the individual components in the stack: the resistance of the anion and cation exchange membrane, the resistance of the diluted and concentrated solution compartments where the spacers are located and the resistance of the electrodes $[3,4]$. The resistance of the diluted compartment and the membrane resistance are the dominant resistances [3]. This theoretical stack resistance represents the pure stack resistance and is the lowest possible value obtainable for the resistance in the stack for a specific configuration. This resistance does not include concentration polarization phenomena or spacer shadow effects [4].

The resistance experimentally determined from direct current measurements refers to the highest resistance and represents the resistance under real process conditions. It is the upper limit of the resistance for a specific stack configuration. It is an overall stack resistance including concentration polarization phenomena and the spacer shadow effect, effects which can be minimized by proper stack design and improved hydrodynamics [4].

Electrical impedance spectroscopy (EIS) uses an alternating current and makes it possible to exclude the effect of concentration polarization phenomena. In this case, the use of alternating current (AC) allows determining the resistance of the stack where concentration phenomena can be fully eliminated [3]. It also allows identifying the room available for further increase in power output in the practical application by decreasing the resistance through optimizing the hydrodynamic conditions in the stack [4].

As a consequence of the above mentioned consideration, the difference between the resistance values from the theoretical calculations and the resistances determined experimentally using alternating current, represents the spacer shadow effect $[4,5]$.

As presented in Figure 2, the calculated, theoretical minimum value of the stack resistance for the $0.32 \mathrm{~mm}$ spacer is $0.64 \Omega$. This value is independent of the type of spacer used, because the mathematical equation used only includes the 
effect of the spacer thickness (being equal to the thickness of the sea or river water compartment), while the effect of the type of spacers is neglected.

In our previous work [4] we described that the significant contribution of the spacer shadow effect on the total resistance is due to the blockage of ionic transport when non-conductive spacers are used. The use of non-conductive spacers simply reduces the area available for ion transport. This effect is clearly visualized when the contribution of the spacer shadow effect to the total resistance for both the non-conductive and the conductive spacers (Figure 2a and b) are compared. When non-conductive spacers are used, the contribution of the spacer shadow effect is clearly visible as measured by both AC and DC, where DC measures the 'real' resistance in the practical application. The use of non-conductive spacers increases the stack resistance as experimentally determined using direct or alternating current with approximately a factor 4 - 5, because it reduces the area available for the transport of ions from the solution to the membrane (blockage of ion transport). The use of ion conductive spacers on the other hand, almost completely eliminates this spacer shadow effect, which is visible in a significant decrease in resistance as determined by both the $A C$ and DC method (Figure $2 b$ ). The values as determined by the AC method are almost equal to the calculated, theoretical values of the stack resistance, showing that the spacer shadow effect can be almost completely removed when ion conductive spacers are used. This results in a large reduction in stack resistance and consequently a tremendous increase in stack power output. In contrast to non-conductive spacers, ion conductive spacers allow, the transport of ions through the spacer material itself as well as through the open spacer area, thus hardly limiting the transport of ions (Figure $2 b$ ).

Figure 3 shows the effect on the resistance of the different spacer configurations of the ion conductive spacers in the stack. The normal configuration represents the situation where the anion exchange part of the spacer is placed at the anion exchange membrane and the cation exchange part of the spacer at the cation exchange membrane. The reverse configuration 
represents the opposite situation where the anion exchange part of the spacer contacts the cation exchange membrane and the cation exchange part of the spacer contacts the anion exchange membrane.

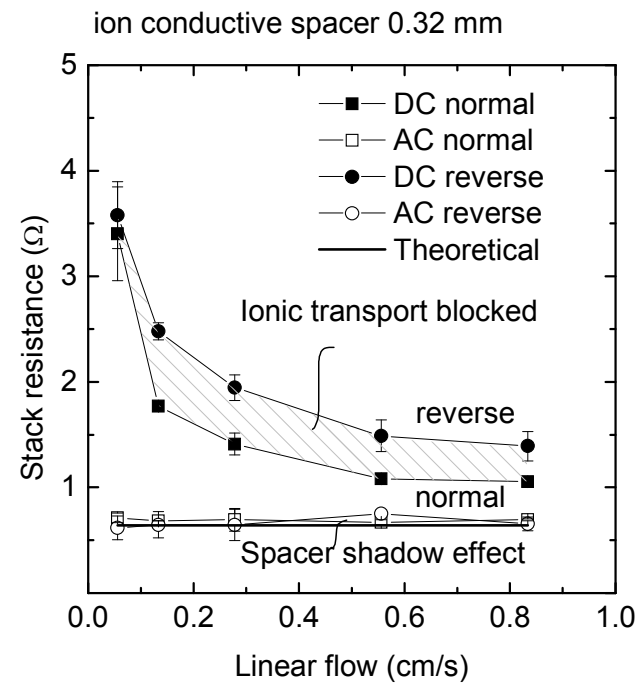

Figure 3: Stack resistance as a function of linear solution flow rate for two different spacer configurations; normal and reverse. DC represents direct current measurements and AC represents alternating current measurements. All measurements performed at $25^{\circ} \mathrm{C}$.

Figure 3 shows a large decrease in stack resistance in RED when ion conductive spacers are used in both configurations (the normal and the reverse) compared to non-conductive spacer. Consequently large improvements in net power output in RED can be expected when ion conductive spacers are used.

In RED, ions from the sea water compartment are transported through the spacers into and through the membrane and after the membrane through the spacer at the fresh water side into the fresh water compartment. The use of ion conductive spacers in the normal configuration where the anion exchange spacer part is located at the anion exchange membrane and the cation exchange spacer part is located at the cation exchange membrane, allows the smooth transport of cations from the sea water compartment through the spacer and the 
spacer material itself, directly to and in the membrane. Of course the same is valid for the anions, which can be easily transported from the sea water compartment through the anion conductive spacer part and the anion exchange membrane. When the reverse configuration is used and the anion exchange spacer part faces the cation exchange membrane, the transport of anions from the sea water compartment through the anion exchange spacer part is at least partly blocked at the spacer-membrane interface where the anions face the cation exchange membrane. Of course the same accounts for the cations at the other side. Consequently one would expect to see a distinct difference in resistance in RED between the two different spacer configurations, giving a higher resistance for the reverse configuration and a lower value for the normal configuration. This is indeed visible in the DC measurements, which represent the real application under practical conditions. DC measurements do show a difference between both configurations and show a stronger reduction in stack resistance when the normal spacer configuration (anion exchange part of the spacer facing the anion exchange membrane and cation exchange part of the spacer facing the cation exchange membrane) is used. Although the DC measurements also show a large decrease in stack resistance for the reverse spacer configuration, this decrease is less strong than for the normal configuration.

A different response of the system is visible when AC measurements are performed. Figure 3 shows that for all ion conductive spacer configurations, AC measurements reveal that the spacer shadow effect is almost completely eliminated. No distinct difference in resistance is visible between the normal and the reverse configuration. The reason that this is not visible in the $\mathrm{AC}$ measurements resulting in an apparent inconsistency between $\mathrm{AC}$ and $\mathrm{DC}$ measurements lays in the fact that $\mathrm{AC}$ methods do not include the effect of ionic transport. Because of the high frequency of the alternating current used, AC measurements thus only identify the resistances of the pure stack components, neglecting the resistance of ionic transport between the different components 
[10]. DC measurements on the other hand do take ionic transport resistance into account and represent the actual practical situation. Therefore, DC measurements indeed show the expected difference in resistance between the normal and the reverse spacer configuration with the reverse spacer configuration showing stack resistances that are approximately $0.5 \Omega$ higher compared to the values obtained with the normal configuration.

As mentioned an explanation for the difference in resistance between the normal and the reverse configuration is that the transport of the counter ions (ions with opposite charge compared to the charge of the membrane) through the spacer parts does occur, but that the transport of the counter ions at the membrane-spacer interface is blocked due to the opposite charge of the spacing material compared to the charge of the ion exchange membrane. This phenomenon can be visualized as an increase in concentration polarization effects when the reversed configuration is used, as is visible in Figure 3.

These results clearly show the benefit of the use of ion conductive spacers in the reverse electrodialysis process. A strong decrease in experimental stack resistance can be obtained resulting in increased performance. The positioning of the different spacer parts does play a role as well and is especially important for process performance and efficiency considerations.

\subsection{Stack open circuit voltage (OCV)}

The stack OCV gives the maximum voltage obtainable from the system. It is determined as the voltage available with an open circuit, in the situation without current flow. It is an important parameter often used to characterize the maximum power output obtainable in processes such as RED or fuel cells.

Figure 4 shows the OCV of the stack for the different configurations of the ion conductive spacer as a function of the solution flow rate. The Nernst equation is used to calculate the theoretical value of the stack OCV and for fresh $(0.017 \mathrm{M}$ $\mathrm{NaCl})$ and sea water $(0.5 \mathrm{M} \mathrm{NaCl})$, this theoretical voltage difference over each 
membrane for $100 \%$ selective membranes is $0.080 \mathrm{~V}[3,4,11]$. Using the experimentally determined and the calculated, theoretical stack $\mathrm{OCV}$, the average membrane permselectivity can be calculated as the ratio of these two values multiplied by $100 \%$. This membrane permselectivity is shown as well in Figure 4 (second y-axis).

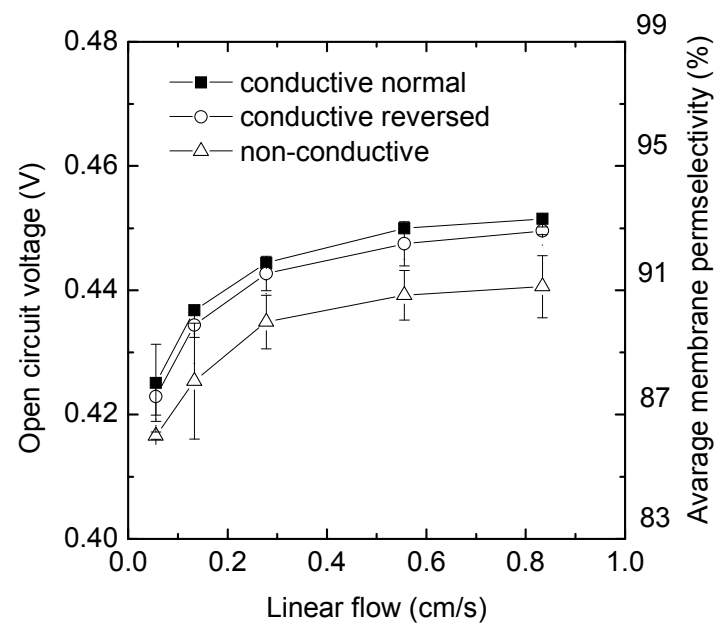

Figure 4: Open circuit potential of the reverse electrodialysis stack as a function of the solution flow rate for different spacer configurations in the stack. The average membrane permselectivity as determined from the ratio of the experimentally determined and the calculated, theoretical stack $\mathrm{OCV}$ is also shown (second y-axis). All measurements performed at $25^{\circ} \mathrm{C}$.

Figure 4a shows that the stack OCV values for the ion conductive spacers are slightly higher than the values obtained for the non-conductive spacer. One possible reason for this is blockage of ionic transport due to the spacer shadow effect and addition to that phenomenon also concentration polarization phenomena may play bigger role when ion conductive spacers are used. This behavior is caused by the occurrence of concentration polarization not only at the membrane-solution interface, but also on the spacer-solution interface. The configuration of the conductive spacer has almost no effect on the stack OCV, because the $\mathrm{OCV}$ is determined as the maximum voltage obtainable when there 
is no current flow (comparable to the conditions under alternating current measurements). Figure 4 shows that the solution flow rate has a large impact on both the stack resistance and its OCV. The OCV decreases significantly for all spacer configurations below a linear solution flow rate of $0.3 \mathrm{~cm} / \mathrm{s}$ due to the occurrence of concentration polarization phenomena, which can be reduced at higher solution flow rates $[4,10,12]$. The average membrane permselectivity depends strongly on the hydrodynamic conditions in the stack. Due to the occurrence of more severe concentration polarization phenomena at the membrane-solution and spacer-solution interface at lower linear solution velocities, the actual concentration gradient for transport is lower at lower linear velocities than expected based on the bulk solution concentrations, resulting in a lower experimental OCV and therefore lower average membrane permselectivity.

\subsection{Stack power density}

The maximum power density in reverse electrodialysis can be reached when the resistance of the external load is equal to the resistance of the stack. The maximum power density can be calculated theoretically from the theoretical stack OCV and the theoretical stack resistance or it can be determined experimentally using measured OCV values and the resistance measured by DC or AC methods [11].

Figure 5 shows the experimentally determined power density obtained with non-conductive spacers and ion conductive spacers in the normal configuration (the anion exchange part of the spacer oriented towards the anion exchange membrane and the cation exchange part of the spacer facing the cation exchange membrane). Both values obtained from direct current and alternating current (EIS) measurements as a function of the linear solution flow rate for non-conductive spacers and ion conductive spacers with different configurations are shown. Also the maximum theoretical value of the stack 
power density is presented in Figure 5. This value is calculated from the theoretical OCV for 95\% selective membranes and the calculated stack resistance based on the conductivity of the solution and the experimentally measured resistance of AMX and CMX membrane [4, 10]. A selectivity value of 95\% is considered to be a realistic value, obtainable in practice (Figure 4) [4].

a) non-conductive spacer $0.32 \mathrm{~mm}$

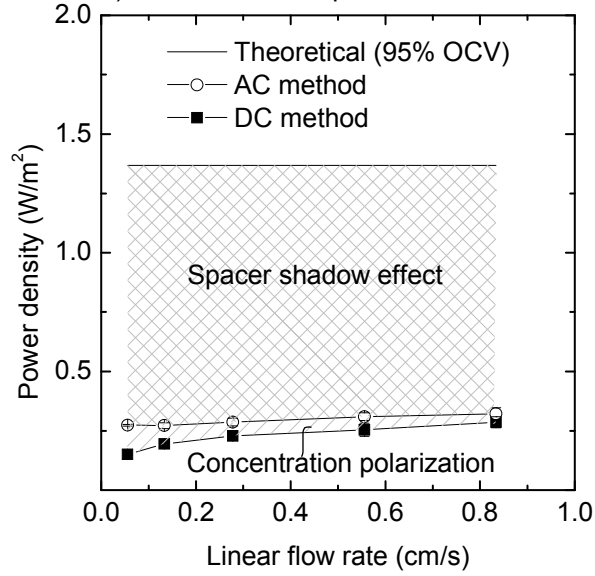

b) ion conductive spacer $0.32 \mathrm{~mm}$

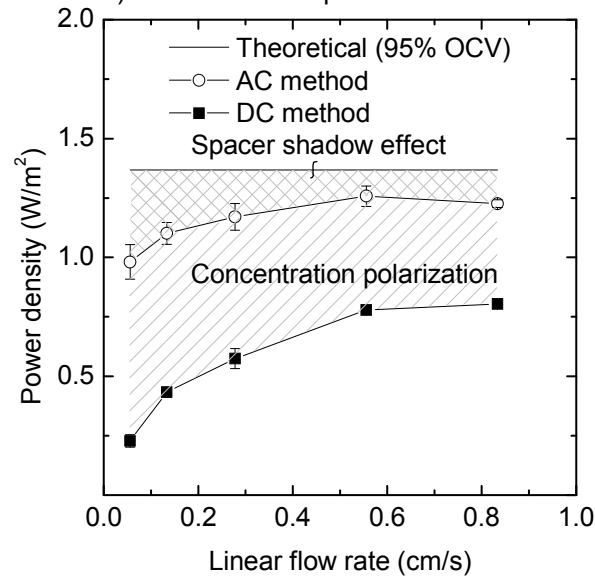

Figure 5: Stack power density as a function of linear solution flow rate for a) non-conductive 0.32 $\mathrm{mm}$ spacer and b) ion conductive $0.32 \mathrm{~mm}$ spacer. All measurements performed at $25^{\circ} \mathrm{C}$.

Comparison of the experimental power outputs obtained by DC measurements in Figure $5 \mathrm{a}$ and $\mathrm{b}$ immediately shows the strong advantage of the use of ion conductive spacers in RED. Large improvements in practical power output can be obtained when ion conductive spacers are used and the spacer shadow effect is significantly reduced. The power density obtained under real process conditions (direct current) is improved by a factor 3 - 4 at higher linear solution flow rates. Figure 5 also reveals that at the same time concentration polarization phenomena play a bigger role when ion conductive spacers are used. The origin of this effect lays in occurrence of concentration polarization phenomena not only at the membrane-spacer interface, but also at the spacer-solution interface when ion conductive spacers are used. In addition, also the extent to which concentration polarization occurs, could have changed upon the introduction of 
the conductive spacers compared to the non-conductive spacers. The complex nature of these concentration polarization phenomena nevertheless does not allow us distinguishing between these effects or quantifying them at this stage.

Figure 6 compares the practical power output as determined from DC measurements obtainable for the two different ion conductive spacer configurations. The values for the non-conductive spacers are also added for comparison.

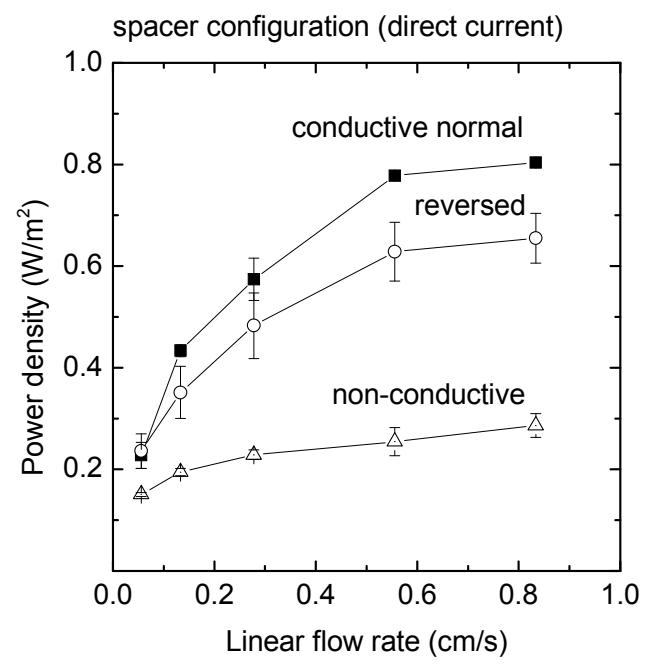

Figure 6: Practically obtainable stack power density determined by DC measurements as a function of linear solution flow rate for the non-conductive $0.32 \mathrm{~mm}$ spacer, the ion conductive $0.32 \mathrm{~mm}$ spacer in the normal configuration and the ion conductive $0.32 \mathrm{~mm}$ spacer in the reverse configuration. All measurements performed at $25^{\circ} \mathrm{C}$.

Figure 6 shows the power density obtainable in RED in the real application under practical conditions. The beneficial effect of the use of ion conductive spacers is clearly visible and a strong increase in power density can be observed. Power densities obtained are almost 3 times higher when ion conductive spacers are used compared to the use of non-conductive spacers.

The order of the different spacer parts (spacer configuration) has an effect on the practically obtainable power output. When the spacers are positioned in 
reverse order (the anion exchange spacer part facing the cation exchange membrane and the cation exchange spacer part oriented towards the anion exchange membrane) the obtained power density is still considerable higher compared to the situation with non-conductive spacers, but a $15-20 \%$ reduction in power density is visible compared to the use of ion conductive spacers in the reversed configuration, as explained earlier.

\section{Future perspective and outlook}

This study clearly shows that the use of ion conductive spacers in RED leads to a tremendous increase in power density of a factor 3 - 4 and decrease of stack resistance by a factor 2 compared to the use of non-conductive spacers with the same open area and shape. This significantly increases the practical potential and operating window of RED as source for sustainable energy production. Because concentration polarization phenomena still play an important role, especially when ion conductive spacers are used, there still exists room to further increase the power density in the RED process by optimizing the hydrodynamics and spacer and stack design of the process and thus reducing the effect of concentration polarization phenomena. Another important aspect to further increase the power output in RED is the development of low resistance membranes and linked to that low resistance, thin ion conductive spacers. Based on theoretical calculations, power densities higher than $4 \mathrm{~W} / \mathrm{m}^{2}$ can be easily obtained with low resistance membranes and spacers with thicknesses of only $0.15 \mathrm{~mm}$ [3]. 


\section{Acknowledgement}

A special word of thanks goes to Sybrand Metz, Michel Saakes, Jan Post and Joost Veerman from the Energy team at Wetsus are especially acknowledged for the fruitful discussions on the practical potential of RED. This work was performed at TTIW Wetsus, Centre of Excellence for Sustainable Water Technology. Wetsus is funded by the city of Leeuwarden, the Province of Fryslan, the European Union European Regional Development Fund and by the EZ-KOMPAS Program of the "Samenwerkingsverband Noord/Nederland". The industrial participants of the Wetsus research theme Energy (DOW, FujiFilm B.V., Nuon B.V., MAGNETO special anodes B.V., Triqua B.V., Landustrie SNEEK B.V., Frisia Zout B.V., Waterleidingmaatschappij Drenthe, Waterbedrijf Groningen and Waterlaboratorium Noord) are kindly acknowledged for their financial support.

\section{References}

1. G. L. Wick, Power from salinity gradients, Energy 3 (1978) 95-100.

2. J. W. Post, H. V. M. Hamelers, C. J. N. Buisman, Energy recovery from controlled mixing salt and fresh water with a reverse electrodialysis system, Environmental Science and Technology 42 (2008) 5785-5790.

3. P. Dlugolecki, K. Nymeijer, S. Metz, M. Wessling, Current status of ion exchange membranes for power generation from salinity gradients, Journal of Membrane Science 319 (2008) 214-222.

4. P. Dlugolecki, A. Gambier, K. Nijmeijer, M. Wessling, The practical potential of reverse electrodialysis as process for sustainable energy generation, Environmental Science and Technology 43 (2009) 6888-6894.

5. H. Strathmann, Membrane Science and Technology Ion-Exchange Membrane Separation Processes, 9, 1 ${ }^{\text {st }}$ Edition, Elsevier, 2004.

6. J. W. Post, J. Veerman, H. V. M. Hamelers, G. J. W. Euverink, S. J. Metz, K. Nymeijer, C. J. N. Buisman, Salinity-gradient power: Evaluation of pressure-retarded osmosis and reverse electrodialysis, Journal of Membrane Science 288 (2007) 218-230. 
7. J. Veerman, J. W. Post, M. Saakes, S. J. Metz, G. J. Harmsen, Reducing power losses caused by ionic shortcut currents in reverse electrodialysis stacks by a validated model, Journal of Membrane Science 310 (2008) 418-430.

8. J. Veerman, M. Saakes, S. J. Metz, G. J. Harmsen, Reverse electrodialysis: Performance of a stack with 50 cells on the mixing of sea and river water, Journal of Membrane Science 327 (2009) 136-144.

9. P. Dlugolecki, A. Benoit, S. J. Metz, K. Nijmeijer, M. Wessling, Transport limitations in ion exchange membranes at low salt concentrations, accepted for publication in Journal of Membrane Science (2009)

10. P. Dlugolecki, P. Ogonowski, S. J. Metz, M. Saakes, K. Nijmeijer, M. Wessling, On the resistances of membrane, diffusion boundary layer and double layer in ion exchange membrane transport, submitted for publication to Journal of Membrane Science (2009).

11. J. N. Weinstein, F. B. J. W. Leitz, Electric power from differences in salinity: the dialytic battery, Science 191 (1976) 557-559.

12. R. E. Lacey, Energy by reverse electrodialysis, Ocean Engineering 7 (1980) 1-47. 
Chapter 6 


\title{
Chapter 7
}

\section{General conclusions and future outlook}

\begin{abstract}
This final Chapter summarizes the main conclusions of the research on reverse electrodialysis as source for sustainable energy generation as presented in this thesis. Furthermore, it discusses some technological and economical considerations and challenges for future development and scale-up of the RED process that need to be addressed before reverse electrodialysis can be referred to as a full scale and mature technology for sustainable energy generation from salinity gradients.
\end{abstract}




\section{General conclusions}

This PhD thesis investigates the design, optimization and potential of the reverse electrodialysis process, with a special focus on membrane properties, mass transfer of the ionic species and concentration polarization phenomena.

The membranes are one of the key components in the reverse electrodialysis process and their performance has a direct influence on the power output. The membrane resistance should be as low as possible, while the membrane selectivity is of minor importance. The best benchmarked commercially available ion exchange membranes reach a power density of more than $4 \mathrm{~W} / \mathrm{m}^{2}$. According to the membrane model calculations power densities higher than $6 \mathrm{~W} / \mathrm{m}^{2}$ could be obtained by using thin spacers and tailor made membranes with low membrane resistance and high permselectivity especially designed for reverse electrodialysis.

At the low salt concentrations applicable in RED $(<0.1 \mathrm{M} \mathrm{NaCl})$ the membrane resistance strongly depends on the salt solution concentration and a strong increase in membrane resistance with decreasing concentration was observed when the resistance was measured as a function of the concentration using a direct current characterization method. The use of electrochemical characterization techniques based on alternating current revealed that this increase in membrane resistance is the consequence of the strong increase in resistance of the diffusion boundary layer with decreasing concentration. This also explains the strong effect of the flow rate on the resistance. At higher concentrations, the pure membrane resistance starts to dominate the resistance as measured by direct current measurements, although also the diffusion boundary layer resistance still plays a considerable role.

Concentration polarization phenomena in the stack play an important role and directly influence the practical power output obtainable in RED. Their influence can be minimized by optimal stack hydrodynamics. Improved spacer designs and new spacer concepts offer extensive room to reduce the spacer 
shadow effect and to further increase the practical power output. Optimized hydrodynamics and reduction of the spacer shadow effect (blockage of the ionic transport from solution to membrane due to the physical presence of a nonconductive spacer) directly result in a significant increase in power output of the RED process and values almost double the values currently obtained can be realized, which brings RED close to economical viability. Increase in temperature from 10 to $40{ }^{\circ} \mathrm{C}$ results in a strong increase in stack power density as well.

When non-conductive spacers are used, the spacer shadow effect plays an important role and significantly reduces the practical power output in RED. The use of ion conductive spacers offers a method to reduce this effect and to increase the power output leading to a decrease in stack resistance by a factor 2 and an increase in power density of a factor 3 compared to the use of nonconductive spacers made of PVC with the same open area and shape.

The work presented in this thesis shows the strong practical potential of RED as source for sustainable energy generation and brings the scale up of RED towards larger scale application closer to practical and economical viability.

\section{Future outlook}

The future perspective for renewable energy sources is bright and promising and as presented in the introduction still significant efforts are required to meet the numbers set by the different countries regarding the future share of renewable energy sources to the total energy mix of the world [1, 2]. In line with the ambitions of the European Union directives $20 \%$ of the final energy consumption in 2020 needs be obtained from renewable energy sources, while in 2006 the effective share of renewable energy to the total energy mix was only $7 \%[1]$.

This $\mathrm{PhD}$ thesis identifies and quantifies the potential and operating window of RED as sustainable energy source and it shows that there still exists 
a large potential to further improve the RED process performance and increase the power density of the stack before RED can be considered as a full scale and mature technology for sustainable energy generation from salinity gradients.

Most of the research on reverse electrodialysis published in literature focuses on power density, which is a direct measure of the overall system performance [35]. Power densities increased tremendously over the last few years (Table 1).

Table 1: Power density (in $\mathrm{W} / \mathrm{m}^{2}$ of membrane) measured at certain spacer thickness over the years [5].

\begin{tabular}{lccc}
\hline Author & Year & $\begin{array}{c}\text { Spacer thickness } \\
(\mathbf{m m})\end{array}$ & $\begin{array}{c}\text { Power } \\
\text { density } \\
\left(\mathbf{W} / \mathbf{m}^{2} \text { membrane }\right)\end{array}$ \\
\hline Pattle & 1954 & 0.7 & 0.05 \\
\hline Weinstein and Leitz & 1976 & 1.0 & 0.17 \\
\hline Jagur-Grodzinski and Kramer & 1986 & 0.55 & 0.41 \\
\hline Turek & 2007 & 0.19 & 0.46 \\
\hline Suda & 2007 & 1.0 & 0.26 \\
\hline Veerman et al. & 2008 & 0.2 & 0.95 \\
\hline Dlugolecki et al. & 2009 & 0.2 & 0.87 \\
\hline Veerman et al. & 2009 & 0.2 & 1.18
\end{tabular}

In addition, Table 1 also shows the regained interest of researchers in this technology: after the pioneering work of Pattle, Weinstein and Leitz, and JagurGrodzinski and Kramer from the 50s till the 80s in the previous century, RED as potential source of sustainable energy lost the attention. Only since a few years it has regained large attention again with renewed efforts on the further development and scale up of the process and technology. This Chapter discusses the main technological challenges and addresses several directions for future research on RED not only regarding stack power density and overall process performance, but also issue to address for fundamental understanding 
of RED, all required to bring the process further towards larger scale applications.

\subsection{Membrane development}

The highest published RED power densities measured up to date were reported by Veerman et al. [5, 6] and Dlugolecki et al. [5, 6]. Power density values indicated by both researchers were measured in a similar experimental set-up and under similar experimental conditions (Table 1). The difference in power density values between these measurements as reported in Table 1 is the consequence of the use of different types of membranes for both measurements $[5,7]$. According to model calculations it is envisaged that power densities of approximately $4 \mathrm{~W} / \mathrm{m}^{2}$ can be obtained with commercially available membranes (e.g. Tokuyama, FumaTech or Asahi Glass) using a spacer with a thickness of $0.15 \mathrm{~mm}$ [6]. In this case, when thin spacers are used, the distance between the different membranes is small $(0.15 \mathrm{~mm})$ reducing the relative contribution of the resistance of the solution compartments to the overall resistance significantly. In this case the membrane resistance becomes the dominant resistance, and the properties of the membranes, and especially the membrane resistance, become of importance for power generation [6].

Therefore, development of low resistance membranes $\left(<0.8 \Omega \cdot \mathrm{cm}^{2}\right)$ with membrane permselectivity values of approximately $95 \%$ is an important issue for further development of the technology [6]. In addition to that also the durability of the membranes is an aspect that requires attention. Up till now durability of the ion exchange membranes for RED has not been tested and the lifetime of the membranes is not known. Mechanical and chemical stability must be investigated in long term experiments. For economical viability of RED, the membrane lifetime should be at least 5 years. The stability of membrane properties over longer time periods (2, 4, 6 years) is still not known and needs investigation. Moreover, membranes situated next to the electrodes require 
special chemical strength to prevent them from damage due to the attack of radicals released from the red-ox reactions at the electrodes. Oxidation, UV and high temperature resistance of the membranes should be tested as well.

One of the biggest bottlenecks do not seem to be the membrane properties, but the membrane price, which is at the moment too high (50-70 euro $/ \mathrm{m}^{2}$ of membrane) for profitable large scale application of RED [4]. Calculations show that the membrane price should drop down at least 10 times to values of $<5 \mathrm{euro} / \mathrm{m}^{2}$ of membrane to make the application attractive.

In addition, at longer time scales, the issue of large scale, fast, industrial ion exchange membrane production capacity becomes a topic to address.

\subsection{Hydrodynamics and stack optimization}

Concentration polarization phenomena and hydrodynamic limitations in the stack reduce the practical power output in RED to a large extent. Proper stack design, improved hydrodynamics and new spacer concepts provide interesting routes to improved power outputs (Figure 1).

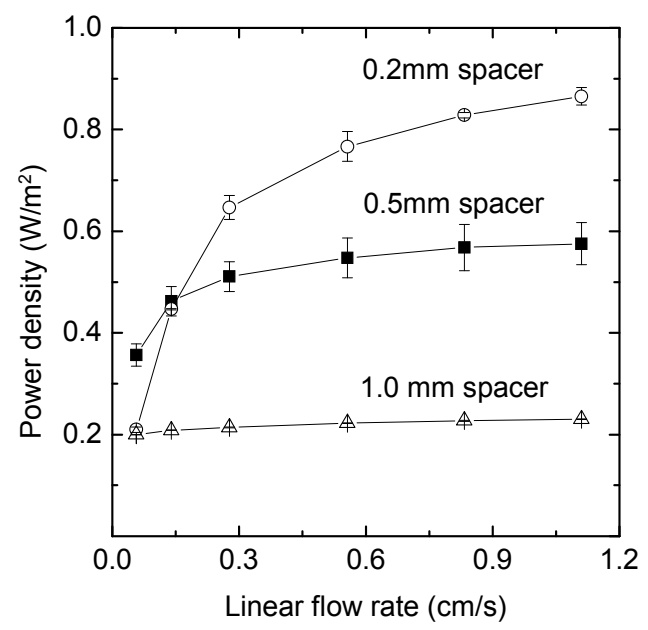

Figure 1: Practically obtainable stack power density determined by DC measurements as a function of the linear solution flow rate for non-conductive commercially available spacers with a thickness of $0.2,0.5$ and $1.0 \mathrm{~mm}$. 
Figure 1 shows the stack power density as a function of the solution flow rate for three different spacer thicknesses. An increase in solution flow rate leads to power density increase and this effect is especially visible when thinner spacers are applied $(0.2 \mathrm{~mm})$, showing the importance and potential of well developed hydrodynamic conditions in the stack. Improved hydrodynamics reduce the effect of concentration polarization layers at the membrane-solution interface.

Not only improvement of hydrodynamics provide a route to improved process performance, but also the application of new spacer concepts offers room for improvement. Especially, the spacer shadow effect can be strongly reduced by the implementation of ion conductive spacers. This result in a strong increase in power output of the RED process and values more than three times higher than the values currently obtained can be realized (Figure 2).

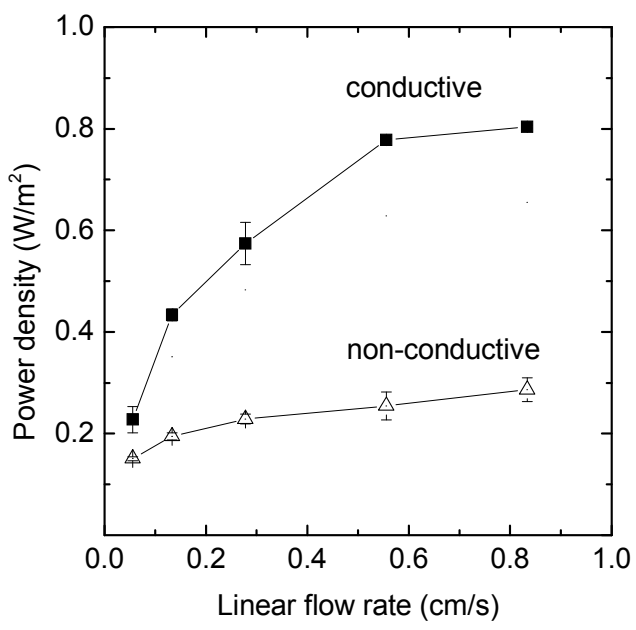

Figure 2: Practically obtainable stack power density determined by DC measurements as a function of linear solution flow rate for the non-conductive $0.32 \mathrm{~mm}$ spacer and the ion conductive $0.32 \mathrm{~mm}$ spacer. All measurements performed at $25^{\circ} \mathrm{C}$. 
Based on these preliminary results it is obvious that the concept of highly conductive ion exchange spacers for RED deserves further exploration and development.

Another important task to investigate is the energy loss associated with solution pumping through the RED stack. This very important issue was described by Jagur-Grodzinski in 1986 and it seems that since than this topic was not considered anymore [3]. Pumping losses might be a crucial parameter with respect to full-scale application and must be elucidated before further scale up is addressed.

\subsection{Pretreatment and stack fouling}

Although hardly investigated so far, pretreatment of the feed water before use in the stack and fouling phenomena in the stack do have an impact on the stack performance. Different methods for pretreatment of the feed water before use should be extensively investigated and evaluated, not only in terms of water quality which might be crucial for stack fouling as well, but also with respect to energy consumption and costs. The energy consumed for solution pumping through the stack and the pretreatment unit should not exceed 10$15 \%$ of the overall RED stack energy production [3]. Because at higher power densities the fuel efficiency of the process decreases significantly [8], evaluation of the process should not only be done based on maximum power output, but should also include parameters such as fuel efficiency, power density and hydrodynamic losses.

The type and extent of feed water pretreatment also at least partially influences the occurrence of fouling and clogging in the stack and both pretreatment and fouling cannot be considered independently. In relation to this also cleaning methods need to be addressed and evaluated. Not only chemical methods should be taken into account, but also mechanical and even electrochemical methods to prevent and remove fouling and scaling in RED. 
Recently, it was shown that fouling layers can be reduced by the use of inverse electrical pulses combined with alternating or fluctuating current [9]. Moreover, also electrochemical layers such as the electrical double layer and the diffusion boundary layer at the membrane surface can be diminished resulting in a lower stack resistance and higher power output. The length, amplitude and frequency of inverse e-pulse and alternating or fluctuating current should be studied carefully to obtain maximum benefits from the cleaning.

\section{References}

1. European Commision's Second Strategic Energy Review, 2008.

2. IPCC, Climate Change 2007: The Physical Science Basis, Summary for Policymakers. 2007.

3. J. Jagur-Grodzinski, R. Kramer, Novel process for direct conversion of free energy of mixing into electric power, Industrial \& Engineering Chemistry Process Design and Development 25 (1986) 443-449.

4. M. Turek, B. Bandura, Renewable energy by reverse electrodialysis, Desalination 205 (2007) 67.

5. J. Veerman, M. Saakes, S. J. Metz, G. J. Harmsen, Reverse electrodialysis: Performance of a stack with 50 cells on the mixing of sea and river water, Journal of Membrane Science 327 (2009) 136-144.

6. P. Dlugolecki, K. Nymeijer, S. Metz, M. Wessling, Current status of ion exchange membranes for power generation from salinity gradients, Journal of Membrane Science 319 (2008) 214-222.

7. P. Dlugolecki, A. Gambier, K. Nijmeijer, M. Wessling, The practical potential of reverse electrodialysis as process for sustainable energy generation Environmental Science and Technology 43 (2009) 6888-6894.

8. J. W. Post, H. V. M. Hamelers, C. J. N. Buisman, Energy recovery from controlled mixing salt and fresh water with a reverse electrodialysis system, Environmental Science and Technology 42 (2008) 5785-5790.

9. P. Dlugolecki, K. Nijmeijer, S.J. Metz, M. Wessling, Method and device for membrane cleaning in electro-membrane processes, (NL 2002984) 2009. 


\section{Summary}

Reverse electrodialysis (RED) is a promising and potentially attractive technology for the generation of sustainable energy from the mixing of salt and fresh water. It uses the free energy of mixing two solutions of different salinity (e.g. river and sea water) to generate power. In RED, a concentrated salt solution and a less concentrated salt solution are brought into contact through an alternating series of anion exchange membranes (AEM) and cation exchange membranes (CEM). Anion exchange membranes contain fixed positive charges which allow anions to permeate through the AEM towards the anode and cation exchange membranes contain fixed negative charges which allow cations to be transported through the CEM towards the cathode. At the electrodes a redox couple is used to mitigate the transfer of electrons. The ion exchange membranes are one of the key elements in the RED process as they, together with ion transport phenomena and concentration polarization effects occurring at the membrane-solution interface determine to a large extent the net power output of the system. This PhD thesis investigates the design, optimization and potential of the reverse electrodialysis process, with a special focus on membrane properties, mass transfer of the ionic species and concentration polarization phenomena.

Chapter 2 evaluates the potential of commercially available anion and cation exchange membranes for application in RED. Different membrane properties and characterization methods are discussed and a theoretical membrane model for RED was used to allow fair comparison of the characterization results for application in RED. The results suggest that the membrane resistance should be as low as possible, while the membrane selectivity is of minor importance. Based on the results, the best-benchmarked commercially available ion exchange membranes reach a power density of more 
than $4 \mathrm{~W} / \mathrm{m}^{2}$. According to the membrane model calculations power densities higher than $6 \mathrm{~W} / \mathrm{m}^{2}$ could be obtained by using thin spacers and tailor made membranes with low membrane resistance and high permselectivity especially designed for reverse electrodialysis. This makes RED a potentially attractive sustainable energy source.

In most literature, it is assumed that the membrane resistance is independent of the concentration and corresponds to the value determined in a standard characterization solution $(0.5 \mathrm{M} \mathrm{NaCl})$. The concentration dependence of the membrane resistance, especially at the low salt concentrations used in RED $(<0.5 \mathrm{M} \mathrm{NaCl})$ is hardly studied in literature. To clarify this, Chapter 3 systematically investigates the influence of the solution concentration on ion transport phenomena in two anion exchange membranes and two cation exchange membranes in the concentration range from $0.017 \mathrm{M}$ to $0.5 \mathrm{M} \mathrm{NaCl}$ and for different hydrodynamic conditions. The results show that at low solution concentrations $(<0.1 \mathrm{M} \mathrm{NaCl})$ the resistance of ion exchange membranes strongly depends on the salt solution concentration and a strong increase in membrane resistance with decreasing concentration was observed. However, this measured resistance does not only include the pure membrane resistance but also includes the resistance of the ionic transfer through the electrical double layer and the diffusion boundary layer. By using direct current characterization methods, we are unable to discriminate between these effects and to address the increase in resistance to one of them. The results are of high importance for processes that operate in the low concentration range $(<0.5 \mathrm{M})$ such as reverse electrodialysis, electrodialysis, microbial fuel cells and capacitive deionization, where the standard membrane characterization values as usually determined in $0.5 \mathrm{M} \mathrm{NaCl}$ solutions do not represent the practical application.

In Chapter 4 the underlying reason for the increase in membrane resistance at lower salt concentrations is further investigated using direct and alternating current characterization methods. As the direct current 
characterization method is unable to distinguish between the membrane resistance an the contributions of the electrical double layer and concentration polarization phenomena at the membrane-solution interface, we used electrochemical impedance spectroscopy (EIS), which uses an alternating current, to analyze resistance phenomena in ion exchange membranes under different hydrodynamic conditions and at different temperatures. The results clearly show that the increase in membrane resistance with decreasing concentration as measured in direct current experiments is the consequence of the strong increase in resistance of the diffusion boundary layer with decreasing concentration. This also explains the strong effect of the flow rate on the resistance. At higher concentrations, the pure membrane resistance starts to dominate the resistance as measured by direct current measurements, although also the diffusion boundary layer resistance still plays a considerable role.

Chapter 5 discusses the practical potential of reverse electrodialysis. Theoretically, salinity gradient energy has a global potential of 2.6 TW as renewable energy source. Although the theoretical potential is high, the practical power output obtained is limited yet due to concentration polarization phenomena and spacer shadow effects. In this Chapter theoretical calculations are combined with direct current and alternating current experimental stack characterization methods to quantify the contribution of concentration polarization phenomena, spacer shadow effects and stack resistance in RED under different hydrodynamic conditions in a temperature range from 10 to 40 ${ }^{\circ} \mathrm{C}$. Increase in temperature from 10 to $40^{\circ} \mathrm{C}$ results in a strong increase in stack power density. Concentration polarization phenomena play an important role and their influence can be minimized by optimal stack hydrodynamics. Improved spacer designs and new spacer concepts offer extensive room to reduce the spacer shadow effect and to further increase the practical power output. Optimized hydrodynamics and reduction of the spacer shadow effect directly result in a significant increase in power output of the RED process and 
values almost double the values currently obtained can be realized, which brings RED close to economical viability.

Chapter 6 is dedicated to the spacer shadow effect and methods to overcome this effect. The spacer shadow effect in RED occurs when nonconductive spacers are used that block the ionic transport in the stack thus reducing the area effectively available for ionic transport. This has a high impact on the net power output obtainable in RED. This Chapter shows the potential of the use of ion conductive spacers in RED, which eliminates the spacer shadow effect and obviously improves the overall process performance. Theoretical calculations are combined with direct current and alternating current experimental stack characterization methods to quantify the effect on stack resistance and power output in the RED process under different hydrodynamic conditions. The use of ion conductive spacers led to a decrease in stack resistance by a factor 2 and an increase in power density of a factor 3 compared to the use of non-conductive spacers made of PVC with the same open area and shape. These results increase the impact of RED as renewable energy source and bring it closer to practical implementation.

The last part of this thesis, Chapter 7 discusses the current status and the future potential of reverse electrodialysis as a sustainable energy source. It summarizes the main insights that were gained in this $\mathrm{PhD}$ thesis, evaluates the practical potential of this technology and assesses important research directions for further development and scale-up of the RED process that need to be addressed before reverse electrodialysis can be referred to as a full scale and mature technology for sustainable energy generation from salinity gradients. 


\section{Samenvatting}

Reverse electrodialysis (RED) of wel omgekeerde elektrodialyse is een veelbelovende en in potentie zeer aantrekkelijke technologie voor de opwekking van duurzame energie uit het mengen van zout en zoet water. RED gebruikt de verandering in Gibbs vrij energie die optreedt wanneer twee oplossingen met een verschillende zoutconcentratie (bijvoorbeeld zee- en rivierwater) met elkaar worden gemengd om energie op te wekken. In RED worden een geconcentreerde en een verdunde zoutoplossing met elkaar in contact gebracht door een alternerende serie anion- en kationuitwisselende membranen. Anionuitwisselende membranen zijn positief geladen en transporteren selectief negatief geladen ionen uit de zoutoplossing. Kationuitwisselende membranen zijn negatief geladen en kunnen selectief positief geladen ionen uit de zoutoplossing transporteren. Ionen met dezelfde lading als het membraan worden tegengehouden. Aan de elektrodes wordt gebruik gemaakt van redox reacties waarbij het ladingtransport door middel van ionen in de RED stack direct wordt omgezet in elektrische energie. De ionuitwisselende membranen vormen een cruciaal onderdeel van het RED systeem, aangezien de eigenschappen van deze membranen gecombineerd met effecten gerelateerd aan het transport van ionen en concentratie-polarisatie verschijnselen op het grensvlak van de membranen en de zoutoplossingen tevens direct gerelateerd zijn aan de totale hoeveelheid energie die geproduceerd kan worden in het RED proces.

Dit proefschrift onderzoekt en beschrijft het ontwerp, de optimalisatie en de potentie van RED als duurzame energiebron, met een sterke nadruk op membraaneigenschappen, massatransportverschijnselen en concentratiepolarisatie effecten.

Hoofdstuk 2 onderzoekt en evalueert de mogelijkheden en potentie van commercieel verkrijgbare anion- en kationuitwisselende membranen voor 
gebruik in RED. Relevante membraaneigenschappen en karakteriseringmethoden worden besproken. Om de verkregen resultaten op een objectieve manier met elkaar te kunnen vergelijken, wordt er gebruik gemaakt van een theoretisch model. De uitkomsten van het onderzoek laten zien dat voor een maximale energieopbrengst de membraanweerstand zo laag mogelijk moet zijn, terwijl de selectiviteit van het membraan minder invloed heeft. De in potentie meest geschikte commercieel verkrijgbare ionuitwisselende membranen kunnen een energiedichtheid van meer dan 4 $\mathrm{W} / \mathrm{m}^{2}$ produceren. Modelberekeningen laten zien dat, wanneer membranen met een lage weerstand en een hoge selectiviteit die speciaal geproduceerd zijn voor toepassing in RED, gecombineerd worden met dunnere spacers, energiedichtheden van meer dan $6 \mathrm{~W} / \mathrm{m}^{2}$ mogelijk zijn. Dit maakt RED tot een aantrekkelijk alternatief voor de opwekking van duurzame energie.

Over het algemeen wordt in de literatuur verondersteld dat de membraanweerstand onafhankelijk is van de concentratie van de oplossing waarin deze weerstand bepaald is en overeenkomt met de weerstandswaarde bepaald in een oplossing van $0.5 \mathrm{M} \mathrm{NaCl}$. De concentratieafhankelijkheid van de membraanweerstand, en dan met name in het lage concentratiegebied zoals van toepassing in RED $(<0.5 \mathrm{M} \mathrm{NaCl})$ is echter nauwelijks onderzocht. In Hoofdstuk 3 wordt op systematische wijze de invloed van de concentratie van de zoutoplossing op het transport van ionen in twee verschillende anionuitwisselende en twee kationuitwisselende membranen onderzocht. Hierbij is de concentratie gevarieerd van $0.017 \mathrm{M}$ tot $0.5 \mathrm{M} \mathrm{NaCl}$ en is tevens de invloed van de hydrodynamische condities in beschouwing genomen door het effect van de stroomsnelheid te bekijken. De resultaten tonen aan dat bij lage zoutconcentraties $(<0.1 \mathrm{M} \mathrm{NaCl})$, de membraanweerstand sterk afhankelijk is van deze concentratie: een verlaging van de concentratie leidt tot een sterke toename van de membraanweerstand. Deze membraanweerstand is bepaald met een methode die gebruik maakt van gelijkstroom. Door het gebruik van gelijkstroom is het echter niet mogelijk onderscheid te maken tussen de zuivere 
membraanweerstand en de extra weerstanden tegen ionentransport die veroorzaakt worden door de aanwezigheid van concentratie-polarisatie verschijnselen en de vorming van een elektrische dubbellaag op het grensvlak van membraan en zoutoplossing. De bijdrage van deze additionele weerstanden zit derhalve verdisconteerd in de totale weerstand zoals deze in dit hoofdstuk gemeten is. Het is met deze karakteriseringmethode onmogelijk de herkomst van de toename in weerstand bij lagere zoutconcentraties te adresseren. De resultaten gepresenteerd in dit hoofdstuk zijn van groot belang voor membraanprocessen die opereren bij lage zoutconcentraties $(<0.5 \mathrm{M})$, zoals RED elektrodialyse, maar ook voor biologische brandstofcellen en capacitieve deionisatie, waarbij de weerstandswaardes zoals bepaald onder standaard condities $(0.5 \mathrm{M} \mathrm{NaCl})$ niet overeenkomen met de praktische toepassing.

In Hoofdstuk 4 wordt de onderliggende reden voor de sterke toename in membraanweerstand in het lage concentratiebereik verder onderzocht door middel van electrochemische impedantiesspectroscopie (EIS). EIS maakt gebruik van een wisselstroom voor de karakterisering van het transport van ionen en is daardoor in staat onderscheid te maken tussen de zuivere membraanweerstand en de weerstand tegen ionentransport van de verschillende effecten die optreden in het grensvlak membraan-zoutoplossing (de vorming van een elektrische dubbellaag en concentratie-polarisatie verschijnselen). Met behulp van EIS is de bijdrage van de verschillende weerstanden als functie van de hydrodynamische condities en de temperatuur onderzocht. De resultaten laten duidelijk zien dat de toename in membraanweerstand bij lagere zoutconcentraties zoals die bepaald is met behulp van karakterisering op basis van gelijkstroom (hoofdstuk 3), het gevolg is van een sterke toename in de weerstand van de grenslaag voor diffusie (concentratie-polarisatie) met afnemende zoutconcentratie. Dit verklaart tevens het sterke effect van de langsstroomsnelheid op de totale weerstand. In tegenstelling tot de situatie waargenomen bij lage concentraties, domineert bij 
hogere zoutconcentraties wel degelijk de zuivere membraanweerstand, hoewel ook de weerstand van de grenslaag voor diffusie een belangrijke rol blijft spelen.

In Hoofdstuk 5 wordt de praktische potentie van RED als bron voor duurzame energie opwekking verder onderzocht. Wereldwijd is de theoretisch potentie van deze vorm van energie 2.6 TW. Hoewel de theoretische potentie hoog is, is de praktische energieopbrengst (in $\mathrm{W} / \mathrm{m}^{2}$ membraanoppervlak) nog slechts beperkt door het optreden van concentratie-polarisatie verschijnselen die deze theoretische energieopbrengst aanzienlijk verlagen. Ook de aanwezigheid van spacers zorgt voor een significante verlaging van de energieopbrengst doordat wanneer gebruik gemaakt wordt van niet-geleidende spacermaterialen, het effectieve membraanoppervlak beschikbaar voor het transport van ionen aanmerkelijk gereduceerd wordt door de aanwezigheid van deze spacer (schaduweffect van de spacer). In dit hoofdstuk worden theoretische berekeningen gecombineerd met karakteriseringstechnieken op basis van gelijk- dan wel wisselstroom om de invloed van concentratiepolarisatieverschijnselen en het effect van de aanwezigheid van de spacer op de stack weerstand en de totale energieopbrengst van RED te kwantificeren als functie van de langsstroomsnelheid en de temperatuur. Een stijging van de temperatuur van 10 naar $40{ }^{\circ} \mathrm{C}$ resulteert in een sterke toename van de energieopbrengst van de stack. Concentratie-polarisatieverschijnselen spelen een belangrijke rol en de invloed ervan kan sterk gereduceerd worden door verbetering van de hydrodynamische condities in de stack. Verbeteringen in het spacerontwerp en de toepassing van nieuwe spacerconcepten kunnen het zogenaamde schaduweffect van de spacers aanzienlijk verminderen en zullen tevens leiden tot een significante verhoging van de energieopbrengst. Gecombineerd maakt dit het mogelijk de energieopbrengst in RED vrijwel te verdubbelen, wat RED economisch gezien tot een aantrekkelijk alternatief voor duurzame energie maakt.

Het optreden van het schaduweffect wanneer niet-geleidende spacers worden gebruikt, heeft een sterk negatieve invloed op de uiteindelijke 
energieopbrengst in RED. In Hoofdstuk 6 wordt het effect van het gebruik van spacers gemaakt van een iongeleidend materiaal op de energieopbrengst in RED als functie van de hydrodynamische condities onderzocht. De resultaten laten zien dat het gebruik van dergelijke iongeleidende spacers het schaduweffect van de spacer sterk reduceert en de energieopbrengst van RED navenant verhoogt. Het gebruik van iongeleidende spacers leidt tot een reductie van de stack weerstand met een factor 2 en een toename in energieopbrengst met een factor 3 in vergelijking tot de situatie waarin gebruik gemaakt wordt van niet-geleidende spacers met dezelfde geometrie. Deze resultaten vergroten de potentie van RED als energiebron sterk.

Hoofdstuk 7 tenslotte, bespreekt de huidige status en de kansen en mogelijkheden van RED als duurzame energiebron. De belangrijkste conclusies van dit werk worden samengevat en de potentie van de technologie wordt geëvalueerd. Tenslotte worden de belangrijkste richtingen voor verder onderzoek naar RED en de opschaling van RED geadresseerd met als doel RED verder te ontwikkelen richting de daadwerkelijke toepassing als aantrekkelijke en competitieve technologie voor de opwekking van duurzame energie. 


\section{Acknowledgements}

It is impossible to mention all the people that helped and supported me during past four years. However, I would like to mention several people of people that made my life easier and more colorful.

In first place I would like to express my sincere appreciation to Matthias Wessling, Kitty Nijmeijer, Sybrand Metz and Gert-Jan Euverink for believing in me since my first interview at Wetsus and the University of Twente and for giving me the opportunity to do this PhD research. I would also like to thank the Wetsus scientific director Prof. Dr. Ir. Cees Buisman and the managing director Johannes Boonstra of Wetsus for their support and wise advices during my $\mathrm{PhD}$. It was pleasure for me to observe the rapid growth of Wetsus and to see its progress in becoming an International Center of Excellence for Sustainable Water Technology. Thank you also for showing me, with you as an example, that everything is possible and that I have to think big and one step ahead.

I would like to thank Kitty for all her input, fruitful discussions and for her precise corrections to improve all the scientific papers and this Ph.D. thesis. It was pleasure to learn from you and to chat with you. Matthias, I would like to thank you for believing in me, teaching me a lot and of course for your enthusiasm and fruitful midnight e-mail conversation about ion transport phenomena. Sybrand, I'm grateful for your help on the beginning of my PhD route and for teaching me how to make "tsjak tsjak" papers. Great thanks for the "RED army": Bert, Jan (P.), Joost and Michel, for your very warm welcome in the Blue Energy team and for the great time together. I am grateful to prof. Marek Bryjak from the Wroclaw University of Technology for a nice cooperation and the very knowledgeable discussions. Big thanks for my officemates René, Tom, Urania, Astrid, Joost, Jan and Adriaan for your smile, nice jokes, and many advices during the past 4 years. Thanks to Jörg for 
teaching me the different membrane characterization methods at very beginning of my Ph.D. I would like to thank Antoine, Bart, Bert, Henk, Ingo, Maarten, Michel, and Mateo for the enthusiastic scientific discussions and help with many difficult questions and problems. I also would like to say big thanks to Gert-Jan, Helena, Greet, Trienke and Bob for their help with arranging things.

My gratitude also goes to a few great persons which helped me with setting up and adjusting the experiments: Wim, Harry, Harm and Jan. We had many enthusiastic discussions not only about scientific equipment, but also about cars, motorbikes and life. I would also like to thank Janneke, Jelmer and Naomi for bringing many smiles in the Wetsus laboratory and for their professional sample analysis.

This thesis would not have been possible without the valuable contribution of a number of students: Antoine, Anton, Joanna, Benoit, Piotr (O.). Your input and positive energy were very important for me and for this thesis.

Sincere thanks also to my dear friend Adriaan for his help, great discussions and many great moments not only on the motorbike, parties or holidays (Croissant!). Petra, Jos and Natasja thank you for being here, our friendship grew during many nice moments spent together. Thanks for the great dinners. Big thanks to my friend Maxim for introducing me to the beautiful world of digital photography, for the long discussions about almost everything and for the nice time in France. Thanks René for showing me how to do high quality research and for the many useful advices. Lucia thanks for lots of "glove". Thanks to Paula for her help with the administration and the very nice time at the conference in Greece. Jens, Sander, Hakan and Nilesh thanks for being with me at the famous conference in Greece (Network Young Membranes 9). Hans, Natalia, and Jan (P.) it was a pleasure to be with you on Hawaii. The ICOM conference was great, as was the snorkeling at the Hanauma Bay and the visit to Pearl Harbor. Philipp and Schwan thanks for a nice time in England at the electrochemistry course. Adriaan, Aleid, Natasja, Martijn, Perry, Tom and Ingo, thanks for being my opponent at the squash court. 
Wetsians, Agata, Aleksandra, Andre, Ana, Anna, Albert, Agatha, Artur, Arie, Bruno, Brechje, Carien, Claudia, Christoph, Camiel, Ellen, Elmar, Ernst, Elsemiek, Florian, Floor, Geke, Geo, Guillo, Gerrit, Gerard, Hellen, Heleen, Hester, Hardy, Ivo, Justina, Johannes, Jan (G.), Kamuran, Kerstin, Ludmila, Lucian, Loes, Luewton, Lena, Linda, Libertus, Marthe, Marta, Marcel, Marek, Marco, Nelleke, Nynke, Nadine, Nathalie, Nina, Nienke, Paul, Piet, Ronald, Sonja, Sofia, Simon, Sandra, Tiara, Tim and Walter. I would like to thank you all with all my heart for bringing a lot of nice moments in my life and for your help .

My gratitude also goes to the Membrane Technology Group of the University of Twente.

I'm very grateful to prof. van der Steenhoven, prof. H. Strathmann, prof. Buisman, prof. van der Meer, prof. Melin and dr. Boukamp. It is an honor for me having you as a member of my promotion committee.

I would like to thank all my friends for all their support and the great moments: Natalia, Pawel (B.), pani Janka, Ania (B.), Marek, Marta, Karol, Pawel (L.), Adam, Ania (D.), Sebastian, Dorotka, Pawel (G.), Przemek, Jacek, Rysiek, Szymon, Karolina, Tommy and Bożena.

My gratitude goes to Prof. Marek Biziuk and Prof. Jacek Namieśnik from Gdańsk University of Technology for giving me opportunity to do my master project in Delft (The Netherlands).

I would like to thank Victor and Olga (L.), Jaroslav and Olga for the great moments during my master project and during my $\mathrm{PhD}$ research.

My endless thanks goes to my family for their love and strong support: my father Edward ${ }^{+}(23 / 10 / 1948$ - 19/12/2006), my mother Halina, my sister Kasia (D.), my nephew Łukasz and Kuba, Grzesiek, Ania, Monika, Kaska, Elżbieta, Andrzej, and Basia.

Piotr Długołęcki, Leeuwarden, The Netherlands, 2009 


\section{About the author}

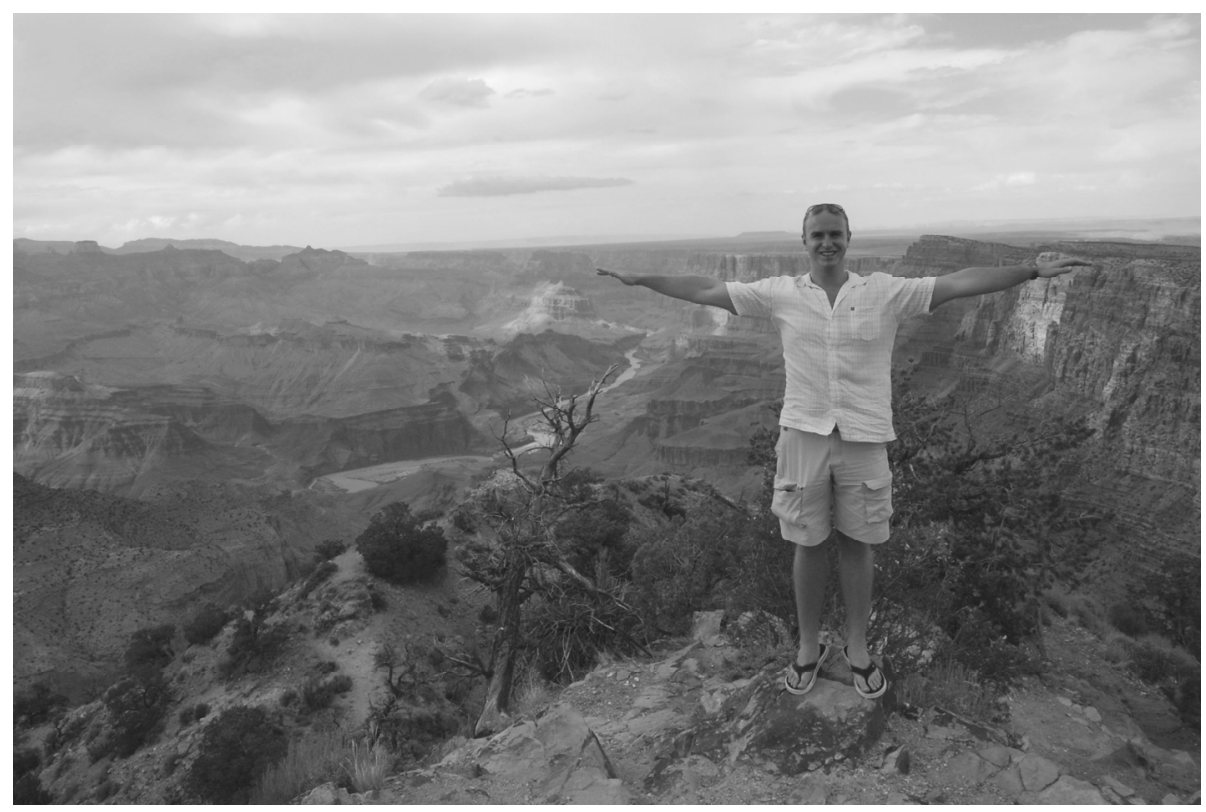

Piotr Długołęcki was born on the 24 $4^{\text {th }}$ of September 1980 in Warsaw, Poland. In September 2004 he obtained his Master degree in Chemical Technology at Gdańsk University of Technology with special focus on Technologies for Environmental Protection. The experimental part of his master thesis he performed at the Interfaculty Reactor Institute (IRI) of the Delft University of Technology, The Netherlands. His master thesis resulted in a scientific publication. In June 2005, Piotr joined the Membrane Technology Group of the University of Twente and Wetsus, Center of Excellence for Sustainable Water Technology as a Ph.D. student. He worked on a project entitles "Mass transport in reverse electrodialysis for sustainable energy generation" under the supervision of Prof. Dr. -Ing. Matthias Wessling and Dr. Ir. Kitty Nijmeijer from the Membrane Technology Group of the University of Twente. During the four years of his Ph.D. he received several awards: Shell Personal Development Award 2008, Poster Award at the Conference of the North American Membrane Society 2009, Professor Marcel Mulder Award 2009 at Wetsus. He completed his thesis in October 2009. From the $1^{\text {st }}$ of November 2009 Piotr is employed as R\&D manager at Voltea B.V., Leiden, The Netherlands. 


\section{List of publications}

E. Raińska, M. Biziuk, P. Bode, P. Długołęcki, K. Astel, An evaluation of endemic exposure of citizens living in near a Gdańsk Phosphatic Fertilizer Plant, Polish Journal of Environmental Studies 16 (2007) 243-250

P. Długołęcki, K. Nijmeijer, S. Metz, M. Wessling, Current status of ion exchange membranes for power generation from salinity gradients, Journal of Membrane Science 319 (2008) 214-222.

P. Długołęcki, A. Gambier, K. Nijmeijer, M. Wessling, The practical potential of reverse electrodialysis as process for sustainable energy generation, Environmental Science and Technology 43 (2009) 6888-6894.

P. Długołęcki, K. Nijmeijer, B. Anet, S.J. Metz, M. Wessling, Ion transport limitations in ion exchange membranes at low salt concentrations, accepted for publication in Journal of Membrane Science (2009).

P. Długołęcki, J. Dąbrowska, K. Nijmeijer, M. Wessling, Ion conductive spacers for increased power generation in reverse electrodialysis, accepted for publication in Journal of Membrane Science (2009).

P. Długołęcki, S.J. Metz, M. Saakes, K. Nijmeijer, M. Wessling, On the resistances of membrane, diffusion boundary layer and double layer in ion exchange membrane transport, submitted for publication to Journal of Membrane Science (2009).

\section{List of patents}

P. Długołęcki, Spacer, cell and device for an ion-exchanging process and method therefore, NL 1036698

P. Długołęcki, M. Wessling, S.J. Metz, K. Nijmeijer, Membrane cleaning with inverse e-pulse, NL 2002984 
